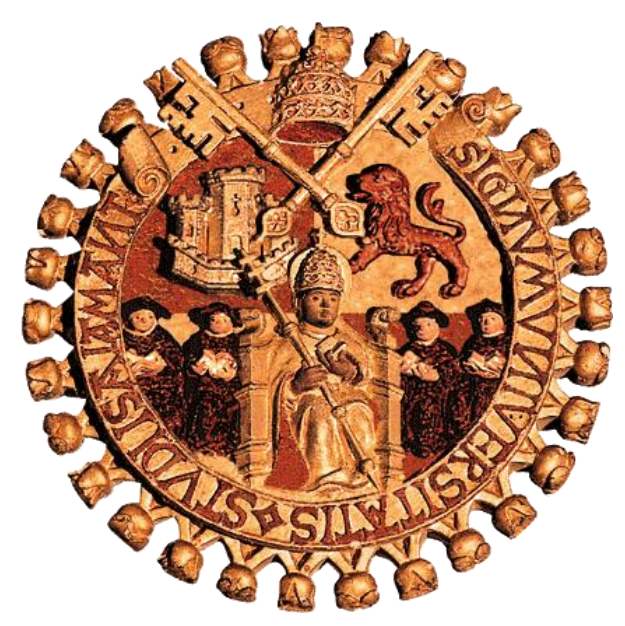

UNIVERSIDAD DE SALAMANCA

Facultad de Medicina

Inteligencia Emocional y Enfermedad Oncológica

TESIS DOCTORAL 
DEPARTAMENTO DE PSIQUIATRÍA Y PSICOLOGIA MÉDICA, MEDICINA LEGAL E HISTÓRIA DE LA CIENCIA

Programa de Doctorado: La enfermedad: su dimensión personal y condicionantes socioculturales

Área de Psicología Médica

\section{Inteligencia Emocional y Enfermedad Oncológica}




\section{VNiVERSİDAD \\ BSALAMANCA}

Facultad de Medicina

\section{LOS DOCTORES GINÉS LLORCA RAMÓN Y GLORIA MARIA BUENO CARRERA}

CERTIFICAN:

Que el presente trabajo titulado Inteligencia Emocional y Enfermedad Oncológica realizado por Dña Andreia Patrícia de Sousa Pereira Teques, licenciada en Psicología, se ha desarrollado bajo nuestra dirección y reúne, a nuestro criterio, méritos suficientes de originalidad y rigor metodológico para que su autora pueda optar con él al Título de Doctora.

En Salamanca a 16 de julio de dos mil catorce

Directores

Dr. Ginés Llorca Ramón Dra. Gloria Mª Bueno Carrera 
DOCTOR JOSÉ LUIS PAIS RIBEIRO

\section{CEERTIFICA}

Que el presente trabajo titulado Inteligencia Emocional y Enfermedad Oncológica realizado por Dña ANDREIA PATRICIA DE SOUSA PEREIRA TEQUES, licenciada en Psicología, se ha desarrollado bajo mi supervisión reúne, según mis criterios, méritos suficientes de originalidad y rigor metodológico para que su autora pueda optar con él al Título de Doctora

Porto a 26 de agosto de dos mil catorce

Tutor<smiles>CCCCCCC(C)C</smiles>

José Luis Pais Ribeiro, PhD

Universidade do Porto 


\section{AGRADECIMIENTOS}

A los luchadores que dieron el privilegio de presenciar sus emociones y episodios significativos de sus historias de vida. Serán siempre una fuente de búsqueda de sentido en mi biografía. Gracias.

A mis directores, Profesor Ginés Llorca y Profesora Gloria, les agradezco el optimismo año tras año. Finalmente hemos construido algo. Gracias. Profesora Gloria fue uno de los elementos más presentes en este proceso emocionalmente exigente pero gratificante, espero que pudiésemos construir mucho más lado a lado. Gracias por todo!

A Profesor Dr. Pais-Ribeiro, Gracias por implicarse en mi proyecto, alguien a quien siempre he admirado y a la que siempre inculcaron que jamás llegaría a conocerle... ante otros Profesores de mi recorrido académico, se ha revelado como una Inminencia en la interrelación y el conocimiento. Siga me orientando y confiando en mi trabajo, es un privilegio trabajar con usted.

A Paco, por todas las orientaciones e ayuda. Gracias.

A Dr. a . Marta Silva por la maestría en el tacto para con nuestros "luchadores de la vida", su simplicidad y empeño revelan la verdadera relación médico-paciente. Gracias por permitirme entrar en su mundo laborar y compartir las luchas de sus enfermos.

A Dirección de los Hospitales de Trofa y Sto. Tirso por haber permitido que mi sueño se volviese realidad. Gracias.

A los familiares y amigos que siempre valoran mis capacidades y desean que termine este proyecto y objetivo de vida. Sí, ahora tendré una mayor disponibilidad para devolver este incentivo, cariño y amistad. Gracias.

A mis hermanos... aunque estén lejos, ante las vicisitudes de la vida son elementos fundamentales en mi historia personal. ¡Deseo que sean más felices y se sientan más realizados que yo misma! 
A mis padres... mis mentores en uno de los más valiosos aprendizajes de la vida: alcanzar la realización a través del esfuerzo continuo, ¡sin bajar jamás los brazos! Gracias por creer en mí y por facilitarme nuevas etapas de mi vida, siempre buscando mi felicidad. ¡Gracias!

A mi compañero para toda la vida... creo que eres la persona que mejor comprende el significado de este momento en mi recorrido, nuestro. Ansío continuar respondiendo a tus expectativas y que juntos podamos saborear el resultado de tanto trabajo, empeño, estrés, tiempo y emociones. Gracias por hacer esta tarea más llevadera, por ser mi norte. Contigo aprendí y aprendo a mantener la esperanza, a pesar de tu pesimismo, me enseñas que todo es posible. Creo que seremos aún más felices y, en gran medida, será gracias a ti, que eres una de las personas, si no la persona más inteligente que he conocido y que contempla mi día a día. ¡Me gusta creer en nosotros, por lo menos cinco ceros!

A la mayor fuente de significado e incluso de vida, en mi vida... jamás imaginé que podría sentirme tan plena, ni aunque viviera más de mil siglos, todo gracias a ti. Lo mejor que hice y que poseo en mi vida. Espero ser un modelo parental que te transmita los valores más nobles en la relación con los demás, con el mundo y por encima de todo, contigo mismo. ¡Lucharemos siempre por tu bienestar, te lo prometo! 


\section{ÍNDICE}

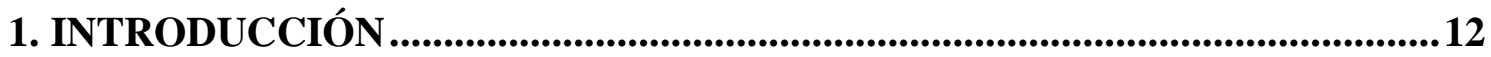

2. INTELIGENCIA EMOCIONAL .........................................................................15

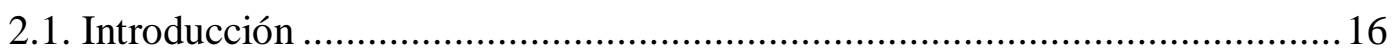

2.2. Evolución conceptual de la inteligencia emocional .................................. 17

2.3. Modelos teóricos de inteligencia emocional ..............................................20

2.4. Evaluación de la inteligencia emocional .....................................................22

2.5. Estado actual del estudio sobre inteligencia emocional ............................26

2.6. Modelo de inteligencia emocional de Mayer y Salovey..............................32

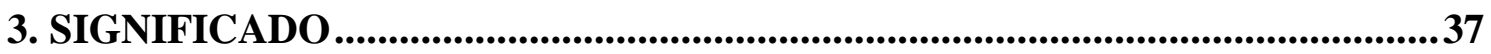

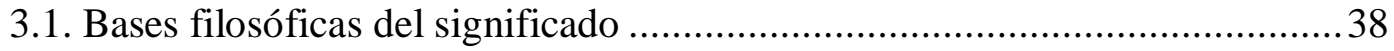

3.2. Conceptualización y constructo del significado..................................... 42

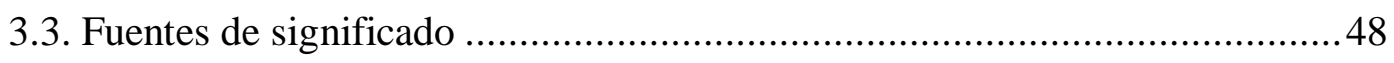

3.4. Modelo del sentido en la vida de Frankl............................................... 49

3.5. Modelo del mantenimiento de significado (MMM) de Heine Proulx, y Vohs52

3.6. Modelo de atribución de significado de Park y Folkman .............................55

3.7. Inteligencia emocional y significado ..............................................5

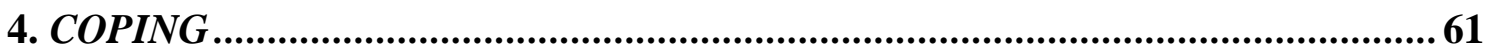

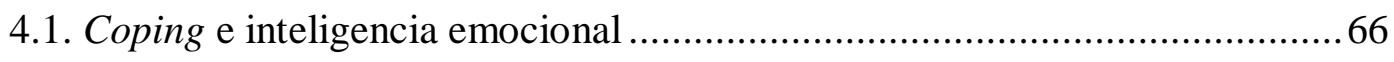

4.1.1. Modelo de la relación entre la auto-percepción de inteligencia emocional y estrés de Gohm, Corser, y Dalsky .....................................73

4.1.2. Modelo dinámico del afecto (DMA) de Zautra, Smith, Affleck, y Tennen .74

4.1.3. Teoría construida y amplia de las emociones positivas de Fredrickson 75

4.1.4. Coping, inteligencia emocional y salud ......................................76 
4.2.1. Coping, inteligencia emocional y significado 86

5. SATISFACCIÓN CON LA VIDA ......................................................................90

5.1. Satisfacción con la vida e inteligencia emocional, significado y coping .......92

6. ENFERMEDAD ONCOLÓGICA ..................................................................101

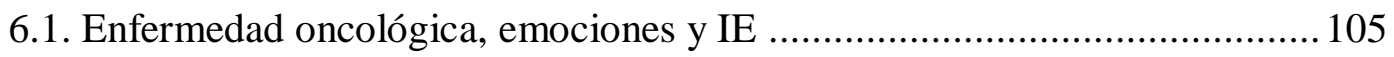

6.1.1. Inteligencia emocional y salud-enfermedad ............................... 113

6.2. Enfermedad oncológica y significado ................................................ 123

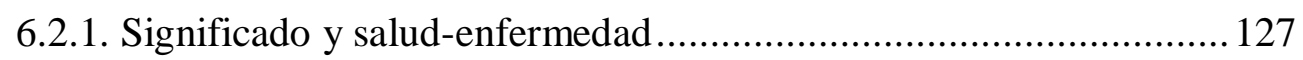

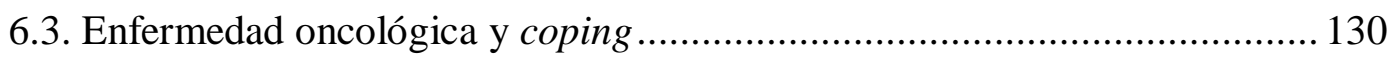

6.4. Enfermedad oncológica, satisfacción con la vida y salud-enfermedad ......... 134

7. OBJETIVOS E HIPÓTESIS..........................................................................139

8. CONSTRUCCIÓN Y VALIDACión DEL CUESTIONARIO DE AUTOPERCEPCIÓN DE INTELIGENCIA EMOCIONAL (CIE-AP)......141

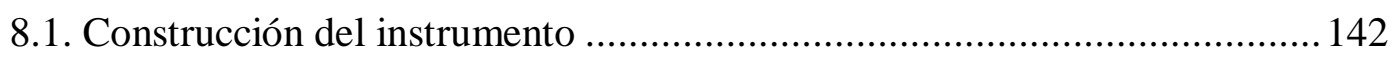

8.1.1. Material y método................................................................. 142

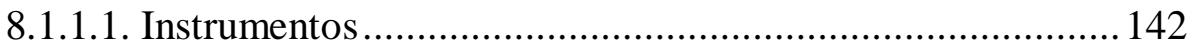

8.1.1.2. Muestra y procedimiento .......................................... 144

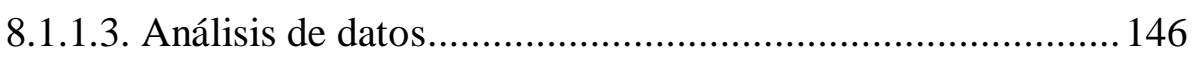

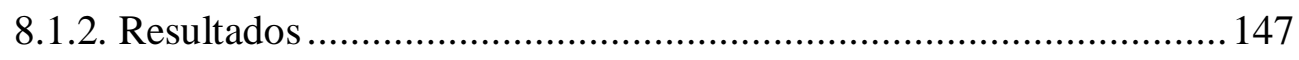

8.2. Validación del instrumento

8.2.1. Material y método................................................................. 149

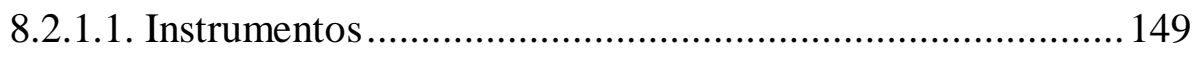

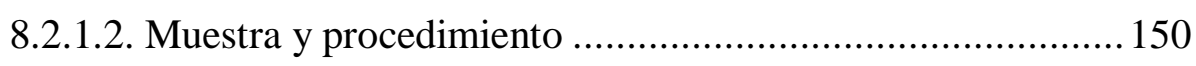

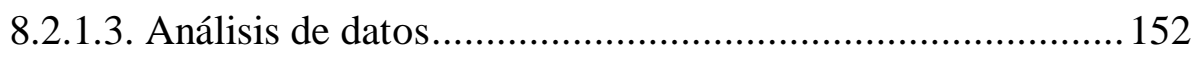


8.3. Discusión de los resultados

9. METODOLOGÍA

9.1. Muestra y procedimento 162

9.2. Batería de instrumentos 165

9.2.1. Cuestionario sociodemográfico y clínico 166

9.2.2. Cuestionario de Autopercepción de Inteligencia Emocional ........... 166

9.2.3. Escala de Satisfacción con la Vida (SWLS) 167

9.2.4. Test de Objetivos de Vida (PIL-R).

9.2.5. Escala Reducida de la Adaptación Mental al Cáncer (Mini-MAC). 169

10. RESULTADOS Y DISCUSIÓN 171

10.1. Primera(s) hipóteses 172

10.2. Segunda Hipótesis 189

11. CONCLUSIONES 201

12. REFERENCIAS BIBLIOGRÁFICAS. 204 ANEXOS

Anexo I - Instrumentos

Anexo II - Autorización de los autores para la utilización de los instrumentos Anexo III - Autorización del hospital para la recogida de la muestra 


\section{ÍNDICE DE FIGURAS}

Figura 1 - Modelo de Inteligencia Emocional de Mayer y Salovey ..............................33

Figura 2 - Modelo de Atribución de Significado de Park y Folkman .........................56

Figura 3 - Modelo original de Estrés y Coping de Lazarus y Folkman......................63

Figura 4 - Modelo de Estrés y Coping de Lazarus y Folkman revisado...................... 83

Figura 5 - Modelo de Coping de Atribución de Significado con Acontecimientos Estresantes de Park

Figura 6 - Algunos factores mediadores en la relación IE - salud........................... 118

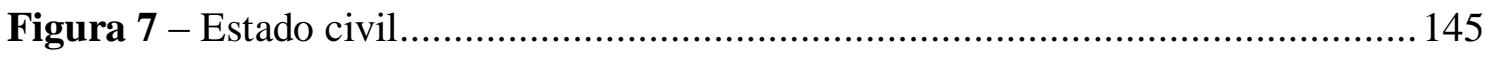

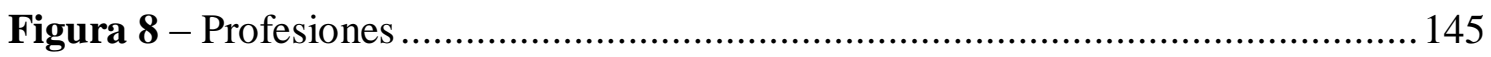

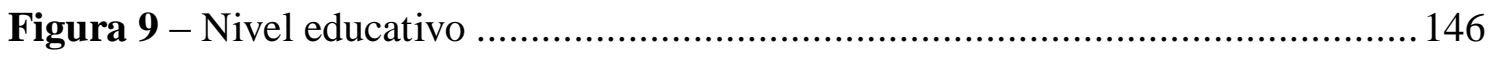

Figura 10 - Scree plot de la extracción de los factores ........................................ 148

Figura 11 - Estado civil........................................................................ 151

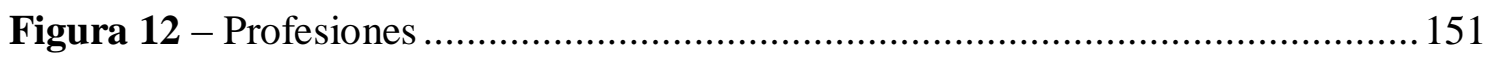

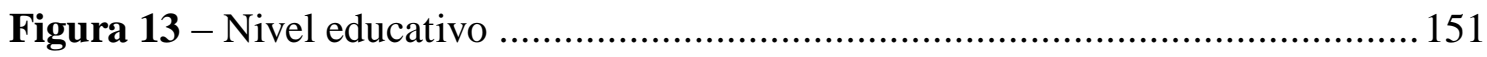

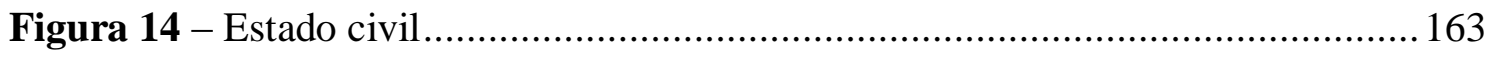

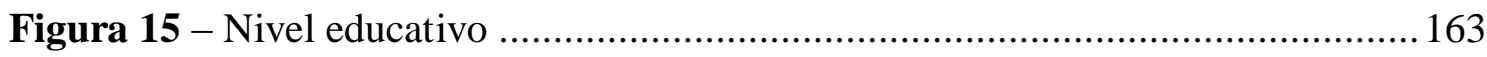

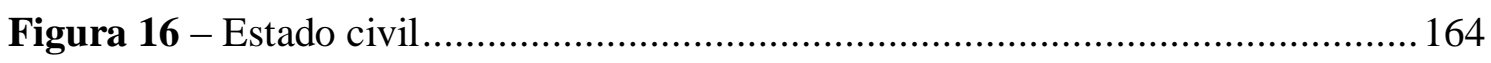

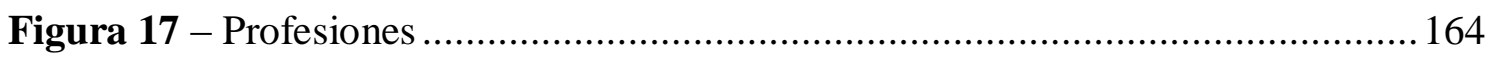

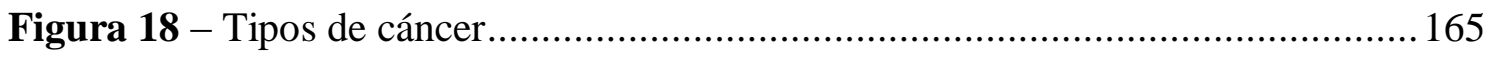

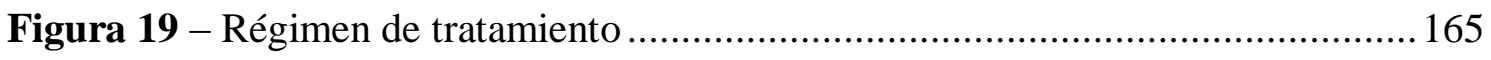

Figura 20 - Modelo propuesto con las relaciones entre la percepción de capacidades de inteligencia emocional, el significado en la vida y la satisfacción con la vida en enfermos oncológicos y en la población saludable 


\section{ÍNDICE DE TABLAS}

Tabla 1 - Evolución conceptual de la IE ............................................................ 19

Tabla 2 - Distinción entre la IE-capacidad y IE-rasgo........................................20

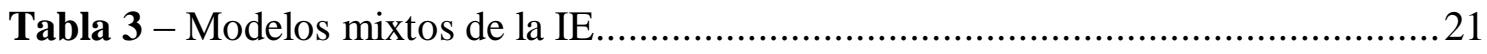

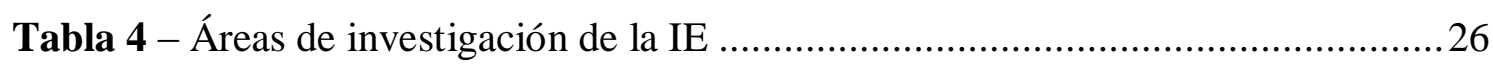

Tabla 5 - Revisión de la conceptualización del significado .......................................42

Tabla 6 - Relación entre emociones/IE y estrés en la adaptación personal ..................71

Tabla 7 - Modelo de la Relación entre la Auto-Percepción de IE y Estrés...................73

Tabla 8 - Medias, desviación típica, comunalidades y los factores del CIE-AP......... 148

Tabla 9 - Pesos factoriales y coeficientes de consistencia interna ........................... 154

Tabla 10 - Correlaciones, medias, desviación típica y variancia extraída media........ 155

Tabla 11 - Resultados de los análisis multigrupo testando la invariancia del modelo 156

Tabla 12 - Pesos factoriales, coeficientes de Cronbach y variancia extraída media ...175

Tabla 13 - Medias (M), desviaciones típicas (DT) y matriz de correlaciones ............ 177

Tabla 14 - Resumen de los resultados del modelo estructural para cada muestra ...... 179

Tabla 15 - Medias, desviación típica y correlaciones entre todas las variables .......... 191

Tabla 16 - Análisis de mediación para evaluar los efectos indirectos de las variables de la IE sobre la SCV a través de las categorías de Coping ........................................ 192 


\section{Introducción}




\section{INTRODUCCIÓN}

En los últimos años se han publicado varios trabajos científicos sobre la Inteligencia emocional, principalmente en el área educacional, organizacional y en la salud mental (Mayer, Salovey, Caruso, \& Sitarenios, 2003). Acompañando este interés por la Inteligencia emocional, se han desarrollado múltiples instrumentos de medida, revelando muchos de ellos una incoherencia teórica o simplemente ausencia de cualquier constructo (Pérez-González, Petrides, \& Furnham, 2007).

En este ámbito, se pone en evidencia la necesidad de investigaciones, con instrumentos válidos, en situaciones negativas y traumáticas de la vida, con la finalidad de entender la selección de estrategias de afrontamiento adaptativas de personas emocionalmente inteligentes (Brackett \& Salovey, 2007), teniendo en cuenta la poca evidencia científica, en el área del estrés, que refuerce la idea de que individuos con problemas de vida graves puedan ser diferenciados en un continuo de Inteligencia emocional (Matthews \& Zeidner, 2000).

El distrés vivido en situaciones negativas, frecuente en un proceso de enfermedad, se considera como el probable impulsor de la búsqueda de significado, o una señal de una reconstrucción de contemplación provisionalmente exitosa (Gillies \& Neimeyer, 2006). No obstante, en este "optimismo trágico" (Frank1, 1986) es donde el sujeto se reconstruye y realiza un crecimiento global, atribuyendo significado a su vida, a la vez que percibe satisfacción con la misma.

La presente investigación enfoca uno de los acontecimientos más estresantes de la vida, el padecer un cáncer (Carapinheiro, 2002). La enfermedad oncológica se ha convertido en Portugal y al nivel mundial en una de las prioridades en la política de la salud, al haberse identificado como una de las principales causas de muerte (Direção 
Geral da Saúde, 2013; Hillner \& Smith, 2009). Se está planteando la posibilidad de considerarla como enfermedad epidémica o incluso pandémica, teniendo en cuenta el aumento de la supervivencia dado el desarrollo de las técnicas diagnósticas y terapéuticas, sin embargo, irónicamente, su incidencia alcanza tasas más elevadas (Barros \& Lunet, 2006; Macedo et al., 2008). Los datos obtenidos por el Instituto Nacional de Estatística de Portugal [INE], señalan que las enfermedades circulatorias $(32 \%)$, los tumores malignos $(23 \%)$ y las enfermedades respiratorias $(11,1 \%)$ son, para ambos sexos, las principales causas de mortalidad (INE, 2012).

En base a la necesidad percibida, debido a la escasa literatura, que facilite el conocimiento sobre la relación de la Inteligencia emocional con el Significado en la vida y su relación con el Coping en la enfermedad oncológica, se ha desarrollado la presente investigación con el objetivo último de comprender la interacción entre las variables en estudio, creando bases para modelos comprensivos en la predicción de Satisfacción con la vida en personas sin enfermedades crónicas, así como en enfermos oncológicos, añadiendo la influencia en la adaptación al proceso de enfermedad.

El reducido número de trabajos de investigación que abordan la aplicación de estos modelos, en personas con o sin enfermedad crónica, nos ha llevado a la selección de una amplia variedad de variables, descritas como relevantes en la literatura, en la percepción de Satisfacción con la vida y en el afrontamiento eficaz de los enfermos. Con este propósito, nos embarcamos en la presente investigación en el campo de la psicología de la salud y de la psicooncología. 


\section{Inteligencia Emocional}




\section{INTELIGENCIA EMOCIONAL}

\subsection{Introducción}

La inteligencia emocional (IE) según Mayer y Salovey (2007) determina el éxito emocional de los seres humanos, sin embargo este aprendizaje emocional está influenciado por múltiples factores, tales como el contexto familiar en el que somos educados, las experiencias emocionales y los acontecimientos de vida pasados. Es en la propia estructura cultural de los individuos donde la IE es susceptible de ser analizada, más que en las representaciones emocionales complejas. En este sentido, es necesario conocer el sujeto de forma general así, como sus contextos para evaluar un patrón o las reacciones emocionales del mismo, siendo posible de esta forma acceder a las diversas inteligencias de los sujetos (Mayer \& Salovey, 1995).

La evolución del concepto se presenta de acuerdo a influencias divergentes. Al inicio se partió de la idea de que la emoción se podría entender como una respuesta organizada y facilitadora de la actividad cognitiva, su punto divergente se dirigió hacia la tradición filosófica occidental, en la cual la emoción se consideraba como una respuesta desorganizada y visceral, que acababa en la ausencia de congruencia cognitiva. Más recientemente, surgieron nuevas concepciones sobre la IE, como por ejemplo las relacionadas con los rasgos de personalidad, y en otra perspectiva, relacionada con las capacidades cognitivas, determinantes en el proceso de información emocional (Salovey \& Mayer, 1995).

Con esta divergencia teórica, en el constructo de la IE se han desarrollado varios instrumentos de medida (Mayer \& Salovey, 2007). Sin embargo, el fundamento conceptual de la IE desde una perspectiva adaptativa ofrece un marco teórico de referencia para una mayor comprensión de la misma, al contrario de la perspectiva 
psicométrica (Mayer, Salovey, Caruso, \& Sitarenios, 2001). Teniendo en cuenta la perspectiva psicométrica, los resultados de la investigación revelan que estamos frente a un concepto dudoso, en la medida en que prevalece una relación débil entre los modelos y los resultados. Se ha llegado a la conclusión, de que los modelos se encuentran disociados de la evidencia empírica y, a su vez, la mayoría de los estudios empíricos se han desarrollado en un vacío de fundamentos teóricos (Pérez-González et al., 2007). Después de 20 años de investigación en el ámbito de la IE, siguen existiendo dudas en su conceptualización y relevancia en contextos de vida diferentes (Martins, Ramalho, \& Morin, 2010). Los pioneros se oponen y defienden que está en contradicho la popularidad del constructo de 1990, con la seria investigación empírica que emergió en esta última década, en el dominio de la IE (Salovey, Detweiler-Bedell, DetweilerBedell, \& Mayer, 2008).

\subsection{Evolución conceptual de la inteligencia emocional}

Para la comprensión del concepto de la IE, es necesario explorar los términos que la componen, tales como la inteligencia y la emoción. En este sentido, desde el siglo XVIII los psicólogos reconocen una división de la mente en tres partes, la cognición o el pensamiento, el afecto que incluye la emoción, y la motivación que realiza la conexión. El nivel cognitivo alcanza funciones como la memoria, el razonamiento, la ponderación y el pensamiento abstracto. Las emociones forman parte del segundo nivel, el cual contempla las emociones en sí mismas, los estados de humor, las evaluaciones y otros sentimientos o estados. La motivación forma el tercer nivel, que se refiere a los impulsos biológicos o a comportamientos dirigidos hacia objetivos. Todos estos niveles indican que todo lo que conecta a la cognición con la emoción es la IE (Mayer \& Salovey, 2007). 
Según Mestre, Comunian, y Comunian (2007) la primera vez que se hace referencia al concepto de IE es en un trabajo de Barbara Leuner de 1966, en el cual todavía no se hace alusión específica al término. Posteriormente, en una disertación no publicada de Wayne Leon Payne en 1986, titulada "Un estudio de la emoción: desarrollando la IE, la auto-integración: relacionado al miedo, dolor y deseo", se hace un uso poco convencional del concepto. De este modo, surgió la necesidad de desarrollar una estructura teórica sobre la IE de tres formas: primero, aumentar la importancia de las cuestiones relacionadas con la emoción, segundo, proporcionar una estructura y lenguaje que permitan examinarla y hablar sobre ésta, y tercero, buscar conceptos, métodos y herramientas para desarrollar la IE. Otro autor que vinculó la inteligencia y la emoción fue Stanley Grenspan en 1989, relacionándola con el área del autismo en el desarrollo de capacidades socio adaptativas, siendo imposible separar el hecho cognitivo del afectivo. Finalmente, el constructo de IE se presentó formalmente definido en 1990 con los trabajos publicados de Mayer, DiPaolo, y Salovey (1990). De acuerdo a lo descrito anteriormente, la IE se desarrolló inicialmente en el área de la Psicología, y actualmente se extiende a otras áreas, tales como, Educación, Recursos Humanos, y Psiquiatría, entre otras. Bar-On (2010) considera la IE como una parte integrante de la psicología positiva, siendo que la aproximación de las dos disciplinas justifica que la IE se torne en un campo/área de la Psicología. En cuanto al área de la Psicología, la evolución de la IE se revela a partir de 1900, conforme se presenta en la Tabla 1. 
Tabla 1: Evolución conceptual de la IE

\begin{tabular}{|c|c|c|}
\hline Autores & Período histórico & Perspectiva \\
\hline \multirow[t]{5}{*}{$\begin{array}{l}\text { Mayer } \\
(2006)\end{array}$} & 1900 a 1969 & $\begin{array}{l}\text { El estudio psicológico de la inteligencia y emociones se encontraba } \\
\text { relativamente separado. }\end{array}$ \\
\hline & 1970 a 1989 & $\begin{array}{l}\text { Los psicólogos enfocaron la influencia de las emociones y pensamientos } \\
\text { en los otros. }\end{array}$ \\
\hline & 1990 a 1994 & La IE surgió como un tópico de estudio. \\
\hline & 1995 a 1996 & El concepto de IE se popularizó. \\
\hline & Actualmente & Clarificación del constructo en la investigación. \\
\hline $\begin{array}{l}\text { Franco } \\
(2007)\end{array}$ & Actualmente & $\begin{array}{l}\text { Momento en el que se realizan estudios que ponen en evidencia que la IE } \\
\text { explica su validez predictiva del día a día de las personas, revelando así } \\
\text { la consolidación del constructo de la IE. }\end{array}$ \\
\hline $\begin{array}{l}\text { Regner } \\
\text { (2008) }\end{array}$ & $\begin{array}{l}\text { De } 1980 \text { a la } \\
\text { actualidad }\end{array}$ & $\begin{array}{l}\text { El constructo de IE adquirió una nueva dirección, en la medida en que se } \\
\text { reformuló la capacidad de predicción de las pruebas de inteligencia más } \\
\text { allá del rendimiento académico, al considerar la importancia de las } \\
\text { emociones para la facilitación del uso de las capacidades puramente } \\
\text { intelectuales. }\end{array}$ \\
\hline $\begin{array}{l}\text { Roberts, } \\
\text { MacCann, } \\
\text { Matthews, y } \\
\text { Zeidner } \\
\text { (2010) }\end{array}$ & Actualmente & $\begin{array}{l}\text { Múltiples correcciones importantes fueran encubiertas en la forma de } \\
\text { conceptualizar y evaluar la IE, incluyendo caracteres para el } \\
\text { reconocimiento emocional, pruebas de evaluación de IE en situaciones } \\
\text { específicas, y el paradigma del sujeto empático. }\end{array}$ \\
\hline
\end{tabular}

En actualidad, Mayer (2000) defiende que existen dos inteligencias emocionales, la IE popular, definida como innata, auto-predictiva y, como lo que mejor predice el éxito en la vida y la IE como concepto científico. En este ámbito, Van der Zee, Thies, y Schakel (2002) señalan que la popularidad del concepto de la IE resultó de la necesidad de las capacidades cognitivas para resolver problemas frecuentes del día a día, como solucionar conflictos, colaborar con otras personas, o adaptarse a nuevos contextos. Joseph y Newman (2010), siguiendo a los autores anteriores, definen la IE como la capacidad de reparar y pensar sobre las emociones, promoviendo la experiencia del afecto positivo. 


\subsection{Modelos teóricos de inteligencia emocional}

De acuerdo con Bedwell (2003), frente a las diferentes teorías sobre IE, surgieron como consecuencia, conceptuaciones e instrumentos de medida diferentes. En esta amplitud teórica, Mayer, Salovey, y Caruso (2000, 2002) destacan la distinción teórica entre los modelos basados en los rasgos de personalidad o descritos como modelos mixtos (e.g., Bar-On, 1997; Goleman, 1995), y los modelos basados en las capacidades cognitivas (e.g., Mayer \& Salovey, 1997). Teniendo como base esta distinción, Petrides y Furnham (2001) crean las terminologías IE-rasgo y IE-capacidad. La respectiva diferenciación teórica se describe en la Tabla 2.

Tabla 2: Distinción entre la IE-capacidad y la IE-rasgo

\begin{tabular}{|c|c|c|}
\hline $\begin{array}{l}\text { Perspectiva } \\
\text { teórica }\end{array}$ & Autores & Visión \\
\hline \multicolumn{3}{|l|}{ IE-capacidad } \\
\hline & Mayer et al. (1990) & $\begin{array}{l}\text { Los modelos basados en la capacidad se fundamentan en la } \\
\text { conceptuación original de la IE de Mayer et al. (1990), que } \\
\text { consideran la IE como un grupo de capacidades, diferentes a las } \\
\text { dimensiones tradicionales de inteligencia. }\end{array}$ \\
\hline & $\begin{array}{l}\text { Petrides y Furnham } \\
(2000,2001)\end{array}$ & $\begin{array}{l}\text { Los modelos basados en el procesamiento de la información de la } \\
\text { IE, muestran una relación mucho más explícita con la capacidad } \\
\text { cognitiva. }\end{array}$ \\
\hline & $\begin{array}{l}\text { Roberts, Zeidner, y } \\
\text { Matthews (2001) }\end{array}$ & $\begin{array}{l}\text { Las pruebas basadas en la evaluación de la capacidad muestran } \\
\text { correlaciones moderadas con las medidas de inteligencia. }\end{array}$ \\
\hline \multicolumn{3}{|l|}{$\begin{array}{l}\text { IE-rasgo o } \\
\text { modelo mixto }\end{array}$} \\
\hline & Bar-On (1997) & $\begin{array}{l}\text { Conceptúa la IE como "un conjunto de competencias y habilidades } \\
\text { personales, emocionales y sociales, que influyen en las } \\
\text { capacidades de las personas para enfrentar de forma eficaz las } \\
\text { exigencias y presiones ambientales" (p.14). }\end{array}$ \\
\hline & $\begin{array}{l}\text { Petrides y Furnham } \\
(2000,2001)\end{array}$ & $\begin{array}{l}\text { Los modelos de rasgo se centran en la consistencia de los patrones } \\
\text { de conducta a través de las situaciones, y la maximización de esta } \\
\text { conducta incluye conceptos tales como, el optimismo y el control } \\
\text { de los impulsos en el desarrollo actitudinal. }\end{array}$ \\
\hline & $\begin{array}{l}\text { Goldenberg, } \\
\text { Matheson, y Mantler } \\
\text { (2006); } \\
\text { Goleman (2003) }\end{array}$ & $\begin{array}{l}\text { Los modelos mixtos de la IE, más conocidos, hacen referencia a } \\
\text { otras capacidades en el proceso y uso de la información emocional, } \\
\text { y se combinan con otros rasgos y características como el } \\
\text { optimismo, la motivación y la capacidad para iniciar relaciones. }\end{array}$ \\
\hline & Roberts et al. (2001) & $\begin{array}{l}\text { Los estudios muestran una baja correlación entre pruebas basadas } \\
\text { en los modelos mixtos y las pruebas de inteligencia. }\end{array}$ \\
\hline
\end{tabular}


A lo largo de la década de 1990 han surgido modelos con visiones diferentes sobre la IE. Entre los modelos mixtos se realza el Modelo de Goleman y el de Bar-On, sintetizados en la Tabla 3.

Tabla 3: Modelos mixtos de la IE

Modelo de Goleman (1995)

Modelo de Bar-On (1997)

Modelo de Petrides y Furnham (2001)
Basado en el modelo teórico de Mayer et al. (1990), agregó otros componentes a su modelo, como cuidado específico, persistencia y habilidades sociales. Conjuga de esta forma, las capacidades cognitivas del modelo de base con rasgos personales. Goldman (1998) agrega componentes a su modelo inicial, tales como, la autoconfianza, la adaptabilidad, la innovación, la comunicación y las habilidades grupales como las principales competencias emocionales.

Describe la IE como un conjunto de capacidades no-cognitivas, como conocimiento y competencias que hacen a la persona capaz de sobrellevar eficazmente variadas situaciones de vida. En su modelo identifica cinco dimensiones, equiparables a las competencias de la IE, como son: el auto-conocimiento (con las sub dimensiones: auto-robustez emocional, auto-confidencia, auto-evaluación, auto-actualización e independencia), las capacidades sociales (empatía, relaciones interpersonales, responsabilidad social), adaptabilidad (resolución de problemas, pruebas de realidad, flexibilidad), gestión del estrés (tolerancia al estrés, control de los impulsos), y estado de humor general (felicidad, optimismo). En 2000 y 2006 presenta una remodelación del modelo, definiéndolo como Modelo de Inteligencia Emocional y Social, y diferencia dos tipos principales de capacidades emocionales en base al modelo inicial, como por ejemplo, las capacidades básicas y las capacidades facilitadoras. Las básicas constituyen aspectos esenciales de la IE y se componen de las sub-escalas de auto-consciencia emocional, auto-conocimiento, asertividad, empatía, relaciones interpersonales, afrontamiento de presiones, control de los impulsos, prueba de la realidad, flexibilidad y resolución de problemas. Las capacidades facilitadoras, presentan las sub-escalas de optimismo, auto-realización, alegría, independencia emocional y de la responsabilidad social.

Agregan componentes como la auto-evaluación adaptativa, la asertividad, la competencia social y la gestión de estrés.

Mikolajczak (2009) presenta un modelo unificador que intenta reconciliar las dos concepciones de la IE, la IE como capacidad y la IE como rasgo. Alude que ambas perspectivas han contribuido al avance del conocimiento científico de las competencias de IE, tanto en procesos como en resultados. En este sentido, sugiere el Modelo de Tres Niveles de IE, enfocado en las diferencias individuales de la emoción, relacionadas con el conocimiento de aptitudes-disposiciones. El conocimiento se refiere a la capacidad que las personas poseen sobre las emociones y como lidian con situaciones emocionalmente intensas. Se puede realizar de un modo semántico, donde la persona 
dice lo que va hacer en la situación, y de modo episódico, considerando su experiencia pasada. Las aptitudes emocionales se asocian a la capacidad de implementación de una determinada estrategia en la situación emocional. En esta dimensión no se expone lo que sabe, pero sí lo que puede hacer. Por último, las disposiciones emocionales se orientan hacia la propensión de comportarse de cierta manera en situaciones emocionales, relacionando los rasgos emocionales, abordando lo que el sujeto hace y no lo que podría hacer.

Regner (2008) señala que la discusión subyacente a esta distinción teórica se debe a la duda de si los modelos divergentes se refieren, igualmente, a constructos diferentes o si forman aspectos distintos del mismo constructo. Los modelos de rasgo o mixtos son criticados, debido, entre otras cosas, a la poca credibilidad de la posibilidad de definir la IE. Otros autores defienden que la IE definida como rasgo o como capacidad, se refiere cualitativamente al mismo constructo, y que la diferencia entre los tipos de IE se relaciona con la operatividad de la variable, o sea, con el instrumento utilizado (Chapman \& Hayslip, 2005). La IE como capacidad revela mayor cientificidad, ya que los resultados obtenidos en sus escalas, son muy semejantes a las pruebas de inteligencia. Las escalas de los modelos mixtos no definen la IE de forma consistente y científica (Mayer, Roberts, \& Barsade, 2008). Sin embargo, las concepciones mixtas tienen algunos aspectos subjetivos, que hacen descripciones interesantes de una persona emocionalmente inteligente (Mayer \& Cobb, 2000).

Para Lyusin (2006), la naturaleza de los modelos no se relaciona tan sólo con la teoría, sino, también con los métodos utilizados para medir el constructo. Por un lado, se recurre a los cuestionarios para evaluar la IE - rasgo de modo que explica la persistencia del comportamiento en situaciones diferentes. Por otro lado, la IE capacidad que forma parte del campo tradicional de la psicología de la inteligencia, se 
evalúa a través de la resolución de problemas/tareas. De acuerdo con Pérez-González et al. (2007), pese a que las pruebas de IE - capacidad existen desde hace más de una década, continúan subsistiendo dudas respecto a la consistencia interna y la estructura factorial. En lo que concierne a las medidas de IE - rasgo, pocas fueron las medidas desarrolladas en un marco teórico claro, y muchas son aquellas que no presentan fundamentos empíricos consistentes.

\subsection{Evaluación de la inteligencia emocional}

Según Mayer (2006), varios instrumentos de medida de la IE fueron construidos de acuerdo con los diferentes tipos de los Modelos citados anteriormente. El constructo de IE desencadenó la construcción desenfrenada de cuestionarios, llevando a los investigadores y teóricos a sobrepasar la diferencia fundamental entre rendimiento típico versus rendimiento máximo (Pérez-González et al., 2007). Por consiguiente, considerando el mismo constructo teórico, algunos investigadores desarrollan y utilizan cuestionarios de auto evaluación (auto percepción del entrevistado) y otros desarrollan pruebas de rendimiento máximo (resolución de tareas), lo que ha dado lugar, a confusiones conceptuales y resultados contradictorios.

Extremera-Pacheco y Fernández-Berrocal (2007), refiriéndose a la medición y evaluación de estas variables, subrayan que el hecho de la existencia de diversos modelos teóricos conduce a una falta de definición consensual sobre el constructo de la IE y sus dimensiones. En la perspectiva de estos autores, si consideramos la IE como una capacidad mental compuesta por procesos emocionales básicos, tal vez sería más adecuado utilizar las propuestas de evaluación enumeradas por Mayer y Salovey (1997), ya sean de auto evaluación o de ejecución. Por otro lado, si pretendemos evaluar competencias más generales, podría ser más adecuado tener en cuenta áreas más amplias de la IE, basadas en las destrezas socio emocionales y de personalidad, dado 
que proporcionan un mapa completo del perfil de la persona, incluyendo las competencias sociales, los constructos emocionales tradicionales y las variables estables de personalidad. Si el investigador tiene por objetivo evaluar habilidades intra personales, las medidas de auto evaluación son una opción bastante adecuada, ya que, al confiar en la introspección permiten evaluar procesos emocionales subyacentes, difícilmente medidos a través de tareas de capacidad. En este sentido, la mejor forma de evaluar el mundo emocional de una persona es preguntándole acerca de sus capacidades y destrezas emocionales (Extremera-Pacheco \& Fernández-Berrocal, 2007). Las medidas de ejecución presentan la ventaja de acceder directamente al nivel de funcionamiento individual en las tareas, área en la cual las pruebas de auto evaluación son más vulnerables a los motivos de deseabilidad social (Ciarrochi, Chan, \& Caputi, 2000; Mayer et al., 2000; Schutte et al., 1998).

En este sentido, se indica que en la conceptuación de la IE como capacidad se recurre al instrumento Mayer-Salovey-Caruso Emotional Intelligence Test (MSCEIT) de Mayer, Salovey, y Caruso (2002) que ha revelado buenas características psicométricas. El modelo de rasgo o mixto recurre a los instrumentos de auto evaluación y observación de testimonios. Las pruebas más utilizadas en este ámbito son, el Emotional Quotient Inventory (EQ-I) de Bar-On (1997) que presenta una relación entre varios constructos, suscitando alguna confusión teórica, y el Self-Report EI Test (SREIT) de Schutte et al. (1998). El MSCEIT es un instrumento de ejecución, y tiene un factor estructural congruente con las cuatro dimensiones del modelo de base. El EQ-I es un test de auto evaluación que se fundamenta en dos cuestiones: ¿porqué algunas personas obtienen más bienestar que otras?, y ¿porqué hay personas más exitosas en la vida?. El SREIT es un test de auto evaluación y fue desarrollado basándose en el modelo de Mayer y Salovey (1997). A pesar de presentar una buena consistencia interna 
y un buen test-retest de fiabilidad, algunos autores critican sus propiedades psicométricas, al no representar el modelo de modo fiable y por no ser unidimensional como defienden sus autores (Brackett \& Mayer, 2003). En el mismo sentido, Teques (2009) ha pretendido adaptar el SREIT a la población portuguesa y los resultados fueron similares, presentando buenos índices de fiabilidad a través del alpha de Cronbach, pero el análisis factorial exploratorio reveló una estructura de 11 factores, contradiciendo el modelo de base de Mayer y Salovey (1997).

En Portugal se han desarrollado y adaptado algunos instrumentos de IE, como la Trait Meta-Mood Scale de Salovey, Mayer, Goldman, Turvey, y Palfay (1995) que fue adaptada por Queirós, Fernández-Berrocal, Extremera, Carral, y Queirós (2005) en una versión modificada, estando igualmente compuesta por sólo tres dimensiones como la escala original, no remetiendo a las cuatro dimensiones del modelo de base. El Emotional Skills and Competence Questionnaire de Taksic, Takalcic, y Brajkovic (2001) adaptado por Lima-Santos y Faria (2005) basado en el Modelo de Mayer y Salovey (1997), presenta sólo tres de las dimensiones que lo componen y no todas presentan una consistencia interna satisfactoria. Y la Multi-factor Emotional Intelligence Scale de Mayer, Salovey, y Caruso (2002) adaptada por Franco (2003) sólo en una población del $1^{\text {er }}$ ciclo, por lo que aún queda mucho para desarrollar instrumentos de ejecución de la IE (Franco, 2007).

En este ámbito, se debe tener en cuenta las recomendaciones de Franco (2007) y Rodrigues, Rebelo, y Coelho (2011), para se adaptar o desarrollar escalas de IE con buenas características psicométricas, ya que las escalas adaptadas a la población portuguesa no revelan consistencia interna satisfactoria, o estas no se ajustan al modelo de base, como lo descrito anteriormente. Por otro lado, se deben respectar íntegramente los modelos teóricos de base, sin acrecentar otros constructos en su composición 
multidimensional o retirar cualquier dimensión que los componen, conforme se ha señalado en otras escalas de autopercepción de IE, lo que lleva a una designación o descripción insuficiente en el dominio de la IE (e.g., TMMS, EQ-I, SREIT) (Pérez, Petrides, \& Furnham, 2005).

\subsection{Estado actual del estudio sobre inteligencia emocional}

El estudio de la IE a nivel psicométrico es reciente, y a pesar de la divergencia teórica existente del constructo, se mantiene el interés en la investigación (Regner, 2008). La autora revela la importancia y la utilidad de un nuevo constructo, que obtenga capacidad predictiva, al contrario de las taxonomías de personalidad o capacidades. En

la tabla 4 se presentan de forma sintetizada las principales áreas de investigación desarrolladas.

Tabla 4: Áreas de investigación de la IE

\begin{tabular}{|c|c|}
\hline Autores & Áreas de investigación \\
\hline $\begin{array}{l}\text { Schutte, Malouff, } \\
\text { Simunek, McKenley, y } \\
\text { Hollander (2002) }\end{array}$ & $\begin{array}{l}\text { Múltiples áreas revisadas: } \\
\text { Relacionan la IE a un estado de humor positivo y alta autoestima, así como a la } \\
\text { capacidad de resistir a situaciones exigentes, como por ejemplo presenciar la muerte } \\
\text { de un enfermo oncológico. }\end{array}$ \\
\hline Veríssimo (2005) & $\begin{array}{l}\text { Ha relacionado la IE con el apoyo social y la afectividad en estudiantes. Los } \\
\text { resultados obtenidos indican que el apoyo social se encuentra significativamente } \\
\text { asociado con la reparación del humor y con más afectos positivos y búsqueda de } \\
\text { sensaciones. }\end{array}$ \\
\hline $\begin{array}{l}\text { Limonero, Tomás- } \\
\text { Sábado, y Fernández- } \\
\text { Castro (2006) }\end{array}$ & $\begin{array}{l}\text { Analizaron la relación entre los niveles de IE sentida y la ansiedad frente a la muerte } \\
\text { en estudiantes universitarios, describiéndola como un buen intermediario. Es también } \\
\text { un buen anticipador de estrategias de afrontamiento, de felicidad, de ajuste } \\
\text { psicológico en los adolescentes, de calidad de vida, y en el afrontamiento de la fatiga } \\
\text { subjetiva y el estrés postraumático. }\end{array}$ \\
\hline Mayer (2006) & $\begin{array}{l}\text { En una revisión de los resultados obtenidos con el MSCEIT, se afirma que un sujeto } \\
\text { con una IE significativa en relación a otras personas, se involucra menos en } \\
\text { comportamientos problemáticos y visiones auto-destructivas, en comportamientos } \\
\text { negativos como fumar, beber, abusar de drogas o en episodios violentos con terceros. } \\
\text { Incluso, la persona emocionalmente inteligente posee más lazos sentimentales en su } \\
\text { casa y más interacciones sociales positivas. Estos sujetos son más persistentes en sus } \\
\text { objetivos, metas y misiones motivadoras. Ya en la década de 1990, Mayer y Salovey } \\
\text { describieron el carácter emocionalmente inteligente como el de una persona bien } \\
\text { adaptada, genuina, tierna, persistente y optimista. }\end{array}$ \\
\hline
\end{tabular}

Goldenberg et al. (2006)
Afirman que, recientemente, la IE se ha presentado como la mejor anticipadora de éxito en la vida en varios dominios relacionados con el funcionamiento emocional. Al revisar resultados oriundos de estudios de IE, destacan su relación con la 
Mayer et al. (2008)

Schutte, Malouff, y Bhullar (2007)

Schutte et al. (2010)

Bhullar, Schutte, $y$ Malouff (2012)

Winters, Clift, y Dutton (2004)

Brackett, Warner, y Bosco (2005); Malouff, Schutte, $y$

Thorsteinsson (2014)

Zeidner, Kloda, y

Matthews (2013)

Tamaren (2010)

Alegre y Benson (2010)

Garaigordobil

Oñederra (2010) satisfacción en la vida y una orientación adaptativa de objetivos, incluso después de controlar rasgos de personalidad. Señalan incluso que la IE es anticipadora de comportamientos adaptativos, al contrario de los sujetos que inician peleas y discusiones, fuman y abusan de substancias.

Señalan la importancia de la IE en el área de las relaciones sociales, en la escuela, en el trabajo y en relación al bienestar. De este modo, la IE predice de forma consistente resultados positivos a nivel social y escolar en la infancia; en el auto percepción de competencia social; en la percepción de los otros en relación a la IE propia; en las relaciones familiares y de intimidad; en el rendimiento académico y laboral y en varias categorías profesionales. A nivel del bienestar, se verifica que influye positivamente en las interrelaciones, y es inversa al estado de humor negativo, a la depresión y a la ansiedad. Con respecto a los comportamientos de salud, la IE se presenta como un anticipador de menos comportamientos aditivos, en el consumo de alcohol y tabaco en adolescentes; y en el uso de Internet.

La IE se relaciona con mejores capacidades sociales y con interacciones de cooperación interpersonal, concretamente, correlacionan la IE a más optimismo, un mejor control de los impulsos, menor depresión, una perspectiva más empática, un mejor autocontrol en situaciones sociales, menos aislamiento e introversión en las relaciones, una mejor relación conyugal, una mejor cooperación entre prisioneros, más persistencia en circunstancias frustrantes, una mejor adaptación al ingreso en la universidad, un mejor funcionamiento de los supervisores de alumnos de Psicología y una mejor reparación del humor después de emociones negativas. En general, llegan a la conclusión de que la IE predice aspectos de la salud mental y del bienestar emocional.

La IE influye en el proceso racional y vivencial del sujeto, que a su vez afecta la percepción de bienestar subjetivo (afectividad y la satisfacción con la vida).

Observan en varios estudios que la IE se relaciona positivamente con la salud mental, física y psicosomática; bienestar subjetivo, buen humor; mayor satisfacción en la vida; altos niveles de bienestar psicológico, señales positivos de salud mental, como menos depresión y ansiedad; menos estrés ocupacional; así como con características positivas como el comportamiento prosocial, la empatía, la afectividad parental, mejores relaciones parentales, buena calidad en la interacción social, en la salud en general, y con muchas variables organizacionales como la satisfacción laboral, el compromiso, la producción y la confianza organizacional.

\section{Área de la interrelación:}

Familiar - A nivel de la violencia doméstica, los agresores revelan un bajo índice de IE comparados con personas no agresoras.

Señalan que la calidad sentida en la relación conyugal y romántica se asocia a mayores índices de IE, y esta se relaciona negativamente con el conflicto en las relaciones conyugales negativas.

El coping media la relación entre la IE y la cualidad marital.

La IE se asocia positivamente con la satisfacción conyugal y sexual.

Padres que revelan mayor IE emiten comportamientos parentales que promueven la adaptación de sus hijos adolescentes, así como disminuyen comportamientos de internalización de los mismos.

y En la escuela - Defienden que al implementar programas de IE en las escuelas se podrá prevenir situaciones de bullying escolar. Teniendo en cuenta que la víctima de varios comportamientos de abuso revela un bajo índice de IE, menos emocionalidad, una menor autoestima, menor tolerancia a la frustración, menor eficacia y poca actividad. 
Welty (2010)

Brackett, Mayer, Warner (2004)

Puglia, Stough, Cárter, y Joseph (2005)

Cha y Nock (2009)

Kun y Dometrovics (2010)

Harris, Reiter-Palmon, y Kaufman (2013)

Mavroveli y SanchezRuiz (2011)

Fernandez,

Salamonson, y Griffiths (2012)

Fisher y Ashkanasy

(2000)

Joseph y Newman

(2010)

Gignac (2010)

Ojedokun (2010)

McQueen

(2004);Gorgens-

Ekermans y Brand

(2012)

Tavabie, Koczwara, y

Patterson (2010)
Sociales - Revelan que personas agresivas evidencian menos IE, perpetuando la violencia.

\section{Comportamientos desviantes/negativos:}

Analizaran las relaciones entre la IE y situaciones cotidianas, presentando resultados que predicen que la IE puede proteger a los sujetos del sexo masculino del desarrollo de comportamientos peligrosos debido al consumo de drogas y al desvío social.

Estudiaron el déficit de funcionamiento emocional en detenidos por abusos sexuales, y los resultados alertan sobre un alto nivel de IE como anticipador de objetivos altruistas, pero también, de objetivos perjudiciales, ya que los abusadores no revelaran déficit en el funcionamiento emocional.

Afirman que la IE es un factor protector de la ideación y tentativas de suicidio.

En una revisión de 51 artículos sobre el consumo de tabaco, alcohol y drogas ilícitas, se ha concluido que el mayor consumo se relaciona con menores índices de IE, comparativamente con sujetos no consumidores.

Sujetos con IE elevada resuelven problemas de forma cooperativa y positiva en vez de recurrir a la creatividad maléfica.

\section{Escolar/académica:}

La IE influye en la realización y en el comportamiento escolar en la enseñanza primaria.

La IE predice el rendimiento académico en estudiantes de enfermería, poseyendo mayores capacidades para la práctica clínica.

\section{Profesional:}

Indican la IE como crucial en la selección y gestión organizacional.

Desarrollaran el Modelo Cascada, que asocia los componentes de los mecanismos de IE al rendimiento profesional y a las diferencias individuales. Realzan, en este sentido, la dimensión de la percepción emocional, comprensión emocional y regulación emocional siguiendo una estructura progresiva y en cual la percepción emocional precede a la comprensión emocional, en esta reside una regulación emocional y un funcionamiento profesional consciente. Especifica igualmente, el papel de los rasgos de personalidad inherentes a la IE, como la actitud consciente, estabilidad emocional e inteligencia cognitiva. Se identifica como un test empírico integrado en la teoría de la Personalidad psicológicamente social en el contexto organizacional.

Ha desarrollado el Modelo de IE de los Siete Factores, que asocia las siete dimensiones a un óptimo rendimiento profesional, es decir, autoconocimiento emocional, expresión emocional, conocimiento emocional de los otros, raciocinio emocional, autogestión emocional, gestión emocional de los otros y autocontrol emocional.

Revelan que una mayor asociación entre IE y equilibrio, entre esfuerzo y recompensa en los colaboradores, influencia que estos emitan menos comportamientos de trabajo antiético.

Realzan la importancia de la IE en las profesiones de cuidados de salud, ya sea en la calidad de la relación con los enfermos, como para evitar el síndrome del Burnout.

En profesionales de salud, como médicos, es beneficioso desarrollar en las facultades programas de promoción de IE. Resultando evaluaciones médicas eficaces de los 
Arora et al.

(2010); Koczwara,

Tavabie, y Patterson

(2011);Taylor, Farver,

y Stoller

(2011); Cherry,

Fletcher, O'Sulivan, y

Shaw (2012)

Azimi, AsgharNejad-

Farid, Kharazi-Fard, y

Khoei (2010)

Akerjordet

Severinsson (2010)

Heffernan, QuinnGriffin, McNulty, Fitzpatrick (2010)

Bailey, Murphy, Porock (2011)

Bennett y Sawatzky (2013);Codier, Freitas, y Muneno (2013)

Hurley (2008)

Kaplowitz, Safran, y Muran (2011);

Rieck y Callahan (2013)

Chaffey, Unsworth, y Fossey (2012)

Chrobot-Mason

Leslie (2012)

López-Curbelo, AcostaPérez, García-García, y Fumero (2006); Freitas y Noronha (2006);

Muniz, Primi, y Miguel (2007)

Perlini y Halverson (2006)

Rutkowska y Gierczuk (2012)

Samar (2001) participantes/pacientes, al promover paralelamente su capacidad de afrontamiento en situaciones emocionalmente intensas.

En la meta análisis realizada en estudios con población médica y/o estudiantes de medicina (casi 500 estudios), los autores afirman que el género femenino revela mayor nivel de IE, que un mayor índice de IE favorece una relación más próxima y eficaz con los enfermos, aumentando la empatía, la capacidad de comunicación, la gestión del estrés, el compromiso laboral y el liderazgo. Concluyen que la IE debería formar parte de la formación de los médicos, ya que se encuentra asociada a múltiples competencias que componen el currículo médico actual.

La satisfacción de los estudiantes de odontología aumenta según el nivel de IE que presentan.

y En la meta análisis de artículos publicados entre 1999 y 2009, surge la IE como un nuevo constructo potencial para aumentar los resultados en la formación y en la profesionalidad de los enfermeros.

Revelan que la autocompasión se relaciona significativamente con la IE, favoreciendo las relaciones positivas entre enfermeros y pacientes.

La IE se relaciona con la pericia para afrontar la muerte y el morir en enfermeros en el servicio de urgencia.

Enfermeros jefes se evidencian mejor equipados y competentes para reparar precozmente comportamientos negativos de bulliyng laboral, así como para fomentar un contexto de trabajo más positivo, cuanto más elevado sea su nivel de IE.

Programas de desarrollo de capacidades de IE llevan a una mayor salud mental en enfermeros, evidenciada en sus narrativas.

El desarrollo de capacidades de IE en los psicólogos es crucial, en el sentido de que influencian menos neurosis en los pacientes y una prestación de servicios de mayor calidad. Obtienen mejores resultados terapéuticos y menos abandonos de los pacientes.

Terapeutas ocupacionales revelan moderadamente una asociación entre la capacidad de intuición y la IE.

y Gestores revelan mayores capacidades interpersonales, de gestión de estrés y mayor competencia multicultural cuanto mayor es su nivel de IE.

La IE se presenta como un buen intermediario en situaciones de estrés, los policías emocionalmente inteligentes afrontan de forma más eficaz las situaciones percibidas como peligrosas y estresantes.

\section{Deporte:}

La IE se relaciona positivamente con un mayor rendimiento en jugadores de hockey y promueve estilos de liderazgo más eficaces.

Defienden la creación/alteración de programas de entrenamiento deportivo, en los que la IE se revela un componente esencial para el proceso en el wrestling.

\section{Salud mental/Física:}

La IE relacionase significativamente con la diabetes tipo1 en las prácticas de autogestión y control glucémico. 
Rego y Fernandes La IE relacionase a la salud física y la satisfacción en la vida.

(2005)

Willard (2006)

Franco (2007)

Fernandéz-Berrocal y Extremera-Pacheco (2007)

Panagiotakos,

Pitsavos, Chrysohoou,

Satefanadis, y Toutovas

(2002); O'Donnell y

Elosua (2008)

Yalcin, Karahan,

Ozcelik, y Igde (2008)

Kravvariti, Maridaki-

Kassotaki

Kravvaritis (2010)

Martins et al. (2010)

Rey, Extremera-

Pacheco, Durán, y

Ortiz-Tallo (2013)

Costa, Petrides, $y$ Tillmann (2014)

Zysberg y Rubanov (2010); Pence (2010)
Enfermos con el Virus de la Inmunodeficiencia Humana (VIH) fueran objeto de estudio y presentaron una puntuación muy baja de IE evaluada con el MSCEIT. No obstante, los autores no han encontrado relación entre la adhesión terapéutica y la IE.

Correlaciona la IE como mediadora de estados de humor depresivos y ansiosos en embarazadas, y con la calidad de vida en mujeres en la menopausia. Con respecto a la salud física, se ha verificado que la IE modera el dolor postoperatorio.

Aluden que la adaptación al estrés depende de la capacidad para prestar atención, discriminar y regular los sentimientos. O sea, los participantes que regulaban sus estados emocionales, en momentos de estrés se quejaban menos de enfermedades, e iban a menos consultas médicas. A pesar de que existen pocos estudios sobre la percepción de IE y el dolor crónico, se evaluaron enfermos de artritis y fibromialgia, llegándose a la conclusión de que el afecto positivo reducía el dolor, y la focalización emocional puede funcionar como una estrategia de afrontamiento frente al dolor crónico. El estudio en mujeres con cáncer mamario, mostró que la percepción de IE influye en el apoyo social y las restricciones sociales en la adaptación psicológica, o sea, las mujeres con restricciones sociales significativas se veían obligadas a ocultar sus emociones sobre la enfermedad, así como, una percepción baja de IE originaba un estado de humor negativo, como ansiedad y depresión. En este sentido, la IE puede funcionar como un protector contra el impacto destructivo del ambiente social negativo, y refuerza la idea de que la IE de las personas desempeña un papel importante en el proceso de adaptación al cáncer mamario.

La IE se relaciona negativamente con la ocurrencia de la enfermedad arteriacoronaria en la población urbana griega, identificando factores de alto riesgo para la enfermedad, nombradamente, la edad, el género, el hábito de fumar, la presencia de hipertensión, obesidad y histórico familiar de la enfermedad.

Confirman efectos positivos de la aplicación de un programa de intervención basado en la IE, en pacientes con diabetes tipo2, resultando en la promoción de su cualidad de vida.

La reducción en la capacidad de usar y regular las emociones, así como la expresión con frecuencia negativa asociase con la incidencia de la enfermedad coronaria.

La IE cuando evaluada como rasgo se asocia más con estados de mayor salud, que cuando evaluada como una capacidad. Esta asociación se direcciona más para la salud mental que la física, los autores refieren ser plausible que IE prediga la salud.

La competencia emocional se asocia significativamente a la satisfacción en la vida y a la felicidad, siendo un factor potencial para la cualidad de vida en personas con incapacidades intelectuales.

Los factores de IE se asocian a más bien-estar y a la sociabilidad en personas saludables comparadas a personas con enfermedades inflamatorias.

La IE relacionase negativamente con perturbaciones del comportamiento alimentar, revelándose un protector en el desenvolvimiento de las mismas perturbaciones. 
Kwako, Szanton, La IE es evaluada como un nuevo componente en la intervención para la prevención Saligan, y Gill (2011) y tratamiento de la depresión mayor.

Lizeretti y Extremera- Los déficits en las capacidades de IE son un factor de vulnerabilidad para el Pacheco (2011) desenvolvimiento del trastorno de ansiedad generalizada.

Saxena, Pandey, Caracterizan enfermos diabéticos con un nivel relativamente superior de IE en Dubey, Pratap, y comparación con pacientes con enfermedad coronaria, pero presentan una pobre Pandey (2012) capacidad para expresar emociones positivas y una fuerte convicción para la no expresión y no compartición de las emociones. Los coronarios presentan un perfil afectivo específico, contrario al de los diabéticos, siendo relativamente pobres en IE pero mejores en la expresión emocional.

Ermer, Kahn, Salovey,

Sujetos con rasgos de psicopatía revelan en algunos aspectos menos IE, aunque no y Kiehl (2012); Copestake, Gray, y Snowden (2013)

Peter et al. (2013)

$\operatorname{Liu}(2010)$

LaMothe (2010)

La personalidad boderline asociase a déficits en la comprensión y regulación emocional.

\section{Religión:}

Asocia una mayor IE a una orientación religiosa más intrínseca.

Sugiere que el sujeto que presenta la necesidad de emociones en el desarrollo cognitivo y social, relacionase con la IE, y cuanto más emocionalmente inteligente es el sujeto, este optará por un tipo de fe, que se refleja en manifestaciones más adaptativas.

\section{Neurociencias:}

Koven, Roth, Correlacionan positivamente la integridad y el volumen de regiones cerebrales Garlinghouse,

Flashman, y Saykin (2011); Takeuchi et al. (2011); Killgore et al. (2012);

Takeuchi et al. (2013) Wojtalik, Eack, y Keshavan (2013)

Toyota (2011, 2013)

Davies, Lane,

Devonport, y Scott (2010); Parker, Keefer, $y$ Wood (2011); Blickle, Momm, Liu, Witzki, y Steinmayr (2011); López-Zafra, PulidoMartos, Martos, y Augusto-Landa (2012); Iliescu, Ilie, Ispas, y Ion (2013)

Franco (2007) (sustancia blanca y gris) con las capacidades de IE.

Estructuras neuro-biológicas están implicadas en el proceso emocional en los sujetos con Esquizofrenia.

El proceso de auto elección intencional en la memoria es influenciado por el nivel de IE. La memoria de episodios agradables o neutros se asocia a la IE.

\section{Psicometría:}

Desarrollo, adaptación a otras lenguas y validación de escalas de IE rasgo y/o de IE capacidad.

En Portugal, la investigación en el área de la IE es aún muy reciente, y lo poco que se encuentra se limita a la construcción y adaptación de instrumentos. 


\subsection{Modelo de inteligencia emocional de Mayer y Salovey (1997)}

Salovey y Mayer (1990) han definido la IE como "la capacidad de regular nuestros sentimientos y emociones y los de las otras personas, discriminándolas, y utilizar esta información para guiar nuestro pensamiento y acción" (p.11). Los autores indican que esta definición sólo se refería al sentir y regular las emociones, y omitía el pensar en las emociones. Mayer y Salovey (1997) reformulan la definición anterior, refiriendo que la "IE implica la capacidad para sentir y evaluar con exactitud la emoción; la capacidad para acceder y/o generar sentimientos cuando estos facilitan el pensamiento; la capacidad para comprender la emoción y el conocimiento emocional; y la capacidad para regular las emociones que incentivan el crecimiento emocional e intelectual." (p.13). Tales capacidades se presentan en el Modelo de Inteligencia Emocional (Mayer \& Salovey, 1997), como puede observarse en la Figura 1. La definición referida, así como el Modelo de base, son los fundamentos para la presente investigación. El modelo está constituido por cuatro dimensiones configuradas desde los procesos psicológicos más básicos a los más elevados. Cada una de las dimensiones tiene cuatro capacidades representativas de las subdimensiones. En cada dimensión, las capacidades situadas en las subdimensiones que se encuentran más a la izquierda son las que surgen más temprano en el desarrollo, las que surgen más tarde se ubican en las subdimensiones de la derecha. Se espera que las personas con una elevada IE progresen más rápidamente a través de las capacidades y las dominen en su mayoría. 
4. Regulación reflexiva de las emociones para promover el crecimiento emocional e intelectual
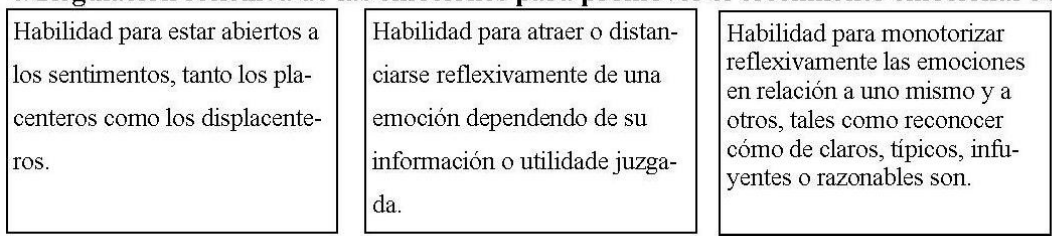

3. Comprensión y análisis de las emociones empleando el conocimiento emocional Habilidad para etiquetar emociones y reconocer las relaciones entre las palabras y las emociones mismas, tales como la relación entre gustar y amar.

Habilidad para interpretar los
significados que las emociones
conllevan respecto a las rela-
ciones, tales como la tristeza a
menudo es predecida de una
pérdida.

Habilidad para compreender sentimentos complejos: sentimentos simultâneos de amor y odio, o mesclados, tales como el temor como una combinación de miedo y sorpresa.

2. Facilitación emocional del pensamiento

\begin{tabular}{|l|l}
$\begin{array}{l}\text { Las emociones preceden el } \\
\text { pensamiento al dirigir la aten- } \\
\text { ción a la información impor- } \\
\text { tante. }\end{array}$ & $\begin{array}{l}\text { Las emociones son tan intensas } \\
\text { y disponibles que pueden ser } \\
\text { generadas como ayuda de la } \\
\text { opinión e de la memória sobre } \\
\text { los sentimientos. }\end{array}$ \\
\hline
\end{tabular}

El humor cambia la perspectiva del individuo desde el optimismo hasta el pesimismo, favoreciendo la consideración de múltiples puntos de vista.

1. Percepción, evaluación y expresión de la emoción La habilidad para identificar la
emoción en los estados fisi-
cos, sentimientos y pensamen-
tos de uno.

La habilidad para identificar
emociones en otros, en boce-
tos, en obras de arte, a través
de la lenguaje, sonido aparen-
cia y conducta.

Habilidad para expressar emociones adecuadamente e y expressar necesidades relacionadas con esos sentimientos.

Habilidad para regular las
emociones en uno mismo y en
otros, mitigando las emociones
negativas y intensificando las
placenteras, sin reprimir o exa-
gerar la información que trans-
miten.

Habilidade para reconocer las transiciones entre emociones, tales como la transición de la ira a la satisfacción, o de la ira a la vergüenza.

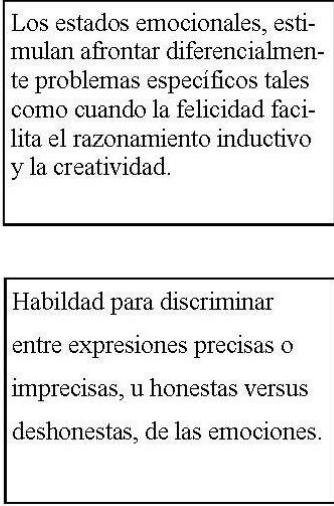

Figura 1: Modelo de Inteligencia Emocional de Mayer y Salovey (1997)

Describiendo los cuatro niveles, se presenta en base la "Percepción, Evaluación y Expresión de la Emoción", en la cual los individuos pueden identificar las emociones y el contenido emocional. Los niños a lo largo de su desarrollo, van progresando en la capacidad de identificar y diferenciar sus propios estados emocionales y los de las otras personas. Distinguen desde muy temprano las expresiones faciales de los padres y les responden; posteriormente, identificarán más correctamente sus sensaciones musculares y corporales, como también las de los que le rodean socialmente (subdimensión 1, dimensión 1). Con la madurez individual se logra controlar mejor los sentimientos internos. Los sentimientos pueden no ser solamente reconocidos en nosotros mismos sino también, en los otros y en los objetos. El niño en desarrollo va desplegando su imaginación en la atribución de sentimientos a objetos animados o inanimados. Este 
pensamiento imaginativo facilita la capacidad de compartir con los otros. En esta progresión, en términos de imaginación les atribuyen emociones a objetos y animales, llevando a un mejor reconocimiento de expresiones emocionales en las personas (subdimensión 2, dimensión 1). En este punto, el sujeto empieza a evaluar las emociones en cualquier contexto que se expresen, incluso a través de medios artísticos. Y, mediante estas emociones evaluadas, la persona expresará igualmente sus propias emociones (subdimensión 3, dimensión 1). Incluida en esta evaluación podrán reconocer la manifestación emocional, como también tener más sensibilidad para detectar si las expresiones son falsas o manipuladas (sub-dimensión 4, dimensión 1).

En sentido ascendente se halla el nivel de la "Facilitación Emocional del Pensamiento" referente a la acción de la emoción sobre la inteligencia. Este describe los eventos emocionales que aparecen en el proceso intelectual. Desde el nacimiento, la emoción se vuelve un sistema de alerta para que sus necesidades sean respondidas. El niño llora cuando quiere comer o recibir cuidados, y se ríe cuando siente placer. En una fase de madurez, las emociones comienzan a moldearse y mejora el pensamiento al dirigir la atención de la persona hacia cambios importantes (subdimensión 1, dimensión 2). La emoción contribuye a que el pensamiento genere emociones para que se entiendan mejor, haciendo posible de inmediato analizar el sentimiento y sus características. Un sujeto se puede integrar en nuevos contextos, al anticipar los sentimientos que le facilitarán la adaptación a esos contextos. La planificación y anticipación mejoran en las personas más maduras las emociones, creando un "escenario emocional en la mente", y clarificando el proceso de toma de decisión, al hacer más complejos y eficientes los pensamientos (subdimensión 2, dimensión 2). En este sentido, la emocionalidad puede ayudar a las personas a considerar múltiples perspectivas, como un estado de humor positivo, remite a pensamientos optimistas y un 
humor negativo a pensamientos pesimistas (subdimensión 3, dimensión 2). La última capacidad de esta segunda dimensión se refiere al reconocimiento de que diferentes tipos de trabajo y formas de razonamiento (deductivo versus inductivo) pueden beneficiar gracias a diferentes estados de humor (subdimensión 4, dimensión 2).

La tercera dimensión se relaciona con la capacidad de "Comprensión y Análisis de las Emociones usando el Conocimiento Emocional”. Los niños empiezan a etiquetar las emociones (como sentir amor u odio) y a relacionarlas, reconociendo las semejanzas y diferencias de las mismas y los significados de éstas en las relaciones (subdimensión 1, dimensión 3). El respectivo conocimiento emocional empieza en la infancia y aumenta a lo largo de toda la vida, con una mayor comprensión de estos significados emocionales. Los padres ayudan en este reconocimiento y diferenciación emocional a través de la vivencia de varias situaciones (subdimensión 2, dimensión 3). Se encuadra en este proceso evolutivo el reconocimiento de la existencia de la complejidad emocional, dado que en la misma situación se puede desencadenar emociones diferentes o mezcladas. El niño aprende que es posible amar y detestar a la misma persona, como también que puede sentir en la misma circunstancia emociones opuestas, como miedo y sorpresa (subdimensión 3, dimensión 3). A través del desarrollo humano se realizan asociaciones y secuencias emocionales llevando a la progresión del razonamiento, siendo ejemplo de este progreso, la evasión de situaciones en las cuales somos indeseados socialmente. Razonar sobre la progresión y/o consecuencias de los sentimientos en las relaciones interpersonales es fundamental para la inteligencia emocional (subdimensión 4, dimensión 3).

En la cumbre del modelo se encuentra la dimensión "Regulación Reflexiva de las Emociones para Estimular el Crecimiento Intelectual y Emocional”, la cual se refiere a la regulación consciente de las emociones que fomenta el crecimiento emocional e 
intelectual. Desde esta perspectiva, las reacciones emocionales cuando ocurren deben ser toleradas independientemente de si son positivas o negativas, porque sólo al prestarle atención se las puede comprender (subdimensión 1, dimensión 4). La regulación se inicia con el aprendizaje de adecuar las emociones a las situaciones y expresarlas de la forma más socialmente deseable, separándose las emociones de los comportamientos, como forma de control emocional y fomentando igualmente el insight emocional (subdimensión 2, dimensión 4). A través del desarrollo o madurez se permite la reflexión de la meta-experiencia de los estados de humor y de las emociones, para hacer conscientes las respuestas emocionales, en vez de desarrollar percepciones simples de los sentimientos. La meta experiencia del humor se puede dividir en dos partes, la meta evaluación y la meta regulación. Las evaluaciones incluyen el grado de atención brindado a los estados de humor de alguien, analizando si este es claro, típico, aceptable y/o influido (subdimensión 3, dimensión 4). Por ello la meta experiencia del humor se relaciona con un fenómeno importante, como por ejemplo, el tiempo que alguien pasa pensando en sus experiencias traumáticas. Los niveles de meta experiencia no están totalmente reconocidos aún, pero se han desarrollado medidas nuevas para acceder a sus cualidades dinámicas y dispositivas. Una de las cualidades señaladas es la cualidad de comprender las emociones sin exagerar o mermar su importancia (subdimensión 4, dimensión 4) (Mayer \& Salovey, 1997). 
Significado 


\section{SIGNIFICADO}

\subsection{Bases filosóficas del significado}

El concepto de significado se presenta como un componente esencial en múltiples movimientos filosóficos, por ejemplo el fenomenológico, el existencialista y el hermenéutico (Langdridge, 2007).

Con respecto a la fenomenología, esta se refiere al estudio de la experiencia humana y al modo en que las cosas son vistas de forma consciente. Este movimiento filosófico se inició con Edmund Husserl y fue desarrollado fundamentalmente por Martin Heidegger. La filosofía fenomenológica direcciona la psicología a las percepciones de las personas del mundo en el que viven y del significado de esta vivencia, o sea, se enfocan en la experiencia de vida de las personas. En esta experiencia se subraya la intencionalidad del sujeto a través de su percepción del mundo en que habita, por un lado se describe lo que el sujeto vive (noema) y por otro lado, la forma como lo vive (noesis). Esta descripción experiencialista se realiza por medio de los relatos de las experiencias de vida contadas en primera persona. Incluso contextualizada en la investigación fenomenológica, Husserl defiende que el investigador debe desarrollar una actitud natural, teniendo en cuenta solamente la experiencia relatada por la otra persona, exenta de cualquier influencia de nuestra propia experiencia (epoché). De esta forma se funda la psicología fenomenológica, al considerarse como objeto de estudio al mundo vivido (lebenswelt), o sea, el mundo de acuerdo a cómo es vivido concretamente, realzándose nuevamente la importancia de la experiencia, pero incluyendo la forma como se crece diariamente a través de la experiencia vivida, en la cual el significado es prioridad (Langdridge, 2007). 
El existencialismo se construye con las bases de la fenomenología, pero presenta un método filosófico diferente. Fue fundado por Kierkegaard, que defendía que la fuerza humana se encuentra en la libertad y en nuestra necesidad de aceptar esta fuerza como una parte esencial de la condición humana. En esta misma línea orientadora surge Nietzche, que enfatiza la libertad y la elección humana, considerando que Dios está muerto, transformando al sujeto como único ser capaz de crear significados en su vida. Incluso teniendo en cuenta la imposibilidad de la separación entre las personas y el mundo en el que habitan, incluyendo la imposibilidad de anular nuestra visión y las formas de identificar el fenómeno, como defendía Husserl (Angerami, 2007). Heidegger añade que, nuestra existencia se encuadra en un contexto histórico y cultural, comprendido a través del lenguaje, el cual debe ser interpretado y no descrito. Al existir nos encontramos inevitablemente en un espacio de lugar (estar-en el-mundo) y de tiempo (temporalidad), y con los otros que nos rodean (estar-con-los-otros), con quien desarrollamos una relación de cuidado. El autor define a los humanos como una máquina de crear significados, y esta creación se basa en el mundo en el que se vive, como se vive y con quien se vive (Heidegger, 2004).

El humor, a su vez, es evaluado por el autor como un medio pre reflexionado de vivir el mundo, en el sentido de que a veces coloreamos nuestro modo de vivir, como el resultado de los sucesos de vida negativos. El momento de la experiencia vivencial, que revela el límite de la existencia, surge cuando el sujeto se encuentra estar-frente-a lamuerte, o sea, la muerte marca el fin de todas nuestras posibilidades. Por este límite surge la responsabilidad del sujeto de crear una vida con significado. La vida no está intrínsecamente cargada de significado, y frente a la responsabilidad humana de crearla, se genera en los sujetos un estado de ansiedad, y este estado es el que nos lleva a la creación de significado, conociendo de esta forma los límites de la existencia. Por el 
contrario, cerrarse a la posibilidad de estar en el mundo con significado y al perder el cuidado de lo que nos rodea, lleva a la falta de autenticidad (Heidegger, 2004).

El estar-con, se encuentra estrictamente relacionado con el estar-en el-mundo, en la medida en que igualmente nos encontramos-en el-mundo-con-los-otros, y en este sentido toda nuestra experiencia se relaciona con las otras personas. Somos inevitablemente seres sociales, en constante relación con el otro y en el sentido de facilitar las interrelaciones se identifica el discurso como el medio de relación. Para Heidegger, el discurso es el medio por el cual el significado del mundo se manifiesta hacia nuestro estar-en el-mundo. Volviéndose alcanzable a través del discurso, el autor refiere, incluso, que el lenguaje es el pilar del ser/estar (Heidegger, 2004). En el movimiento existencial se encuentran los filósofos Jean-Paul Sartre, Simone de Beauvoir y Maurice Merleau-Ponty. Sartre se asemeja a Heidegger al aludir al hecho de que estamos constantemente creando a través de la experiencia vivida, como también al referir que somos libres para elegir qué y cuándo queremos ser, en los límites de las posibilidades de nuestra existencia. Merleau-Ponty defiende que la libertad del Hombre depende de sus acciones y de su posición en el mundo. En este sentido, a través de nuestras acciones nos autoconstruimos como personas, y construimos un mundo en el cual habitamos con significado (Langdridge, 2007).

En el movimiento de la fenomenología hermenéutica, surgen dos filósofos importantes, Hans-Georg Gadamer y Paul Ricoeur. Gadamer (2003) considera que la comprensión no es una producción sin verdades históricas y culturales sobre el mundo, situada en un espacio particular, contingentemente histórico y cultural. Revela el lenguaje como el significado a través del cual conseguimos comprender el mundo que habitamos, añadiendo que es al hablar, y más específicamente a través de la conversación, cuando se crea el arte de la comprensión. Ricoeur (1996) teoriza como 
Gadamer el reconocimiento de los seres humanos en relación con el estar-en el-mundo, el cual preexiste al lenguaje, y una comprensión interpretativa de la naturaleza humana a través del lenguaje. Considerando que esta comprensión interpretativa señala el acto de capturar el ser significado expreso por un texto, la aproximación empática de su autor con quien lo interpreta, creando una fusión de perspectivas, a través de la cual expandimos nuestro autoconocimiento en relación con el otro. El autor defiende como elementos interpretativos preponderantes, la metáfora y la narrativa, que facilitan la creación de significado, algo vital para el proyecto humano, ya que estamos siempre en un proceso creativo en acción (Ricoeur, 1996). Insertada en este proceso creativo se realza la historia, mediante la forma en que es construida creamos el sentido de la experiencia de vida, organizándola. Así, a través de las historias construimos y creamos un sentido de lo que somos y de lo que los otros son, alcanzando nuestras identidades narrativas (Langdridge, 2007). Por otro lado, las historias de vida describen la experiencia humana, al vivirlas mediante historias y no resultados estadísticos de investigación. Nuestra autoría vivencial es continua al reflexionar, interpretar y reinterpretar las historias personales de vida, y al contarlas a los otros y a nosotros mismos. El significado se implica en esas mismas historias, que son activadas a través de nuestras palabras (Gilbert, 2002). En este sentido, las historias y los cuentos de hadas en la Psicología, se consideran componentes integrantes de la forma en que atribuimos el sentido a nuestras vidas (Bruner, 1990; Swatton \& O’Callaghan, 1999). Con Bruner (1990) se llega a la conclusión de que la narrativa personal se apoya en el mantenimiento de la existencia de significado en nuestras historias de vida, y el proceso narrativo elige como medio el discurso, medio por el cual es posible, compartir la riqueza contemplada en cada experiencia de vida. 


\subsection{Conceptualización y constructo del significado}

El concepto de significado o sentido ha sido objeto de múltiples definiciones. En la Tabla 5 se presenta una revisión, realizada por Mascaro y Rosen (2008).

Tabla 5: Revisión del concepto de significado

\begin{tabular}{|c|c|}
\hline Autores & Definición \\
\hline $\begin{array}{l}\text { Yalom } \\
(1980)\end{array}$ & $\begin{array}{l}\text { Utilización de la referencia al sentido de coherencia o conocimiento de nuestra existencia, } \\
\text { como un sentido de objetivo o función. Los dos conceptos de coherencia y objetivo están } \\
\text { asociados a las primeras aproximaciones teóricas del sentido existencial. }\end{array}$ \\
\hline Reker (2000) & $\begin{array}{l}\text { El conocimiento del orden, coherencia y propósito de la existencia personal, el seguir y ligarse } \\
\text { a objetivos dignos, acompañados de un sentido de realización. }\end{array}$ \\
\hline $\begin{array}{l}\text { Battista y } \\
\text { Almond } \\
(1973)\end{array}$ & Poseer una evaluación positiva de la construcción de vida o filosofía de vida unipersonal. \\
\hline $\begin{array}{l}\text { Klinger } \\
(1998)\end{array}$ & Sugiere que la esencia del sentido implica intencionalidad y un propósito/objetivo. \\
\hline $\begin{array}{l}\text { Frankl } \\
(1992)\end{array}$ & Poseer un único objetivo o función de realización. \\
\hline $\begin{array}{l}\text { Mascaro y } \\
\text { Rosen } \\
(2008)\end{array}$ & $\begin{array}{l}\text { Poseer una estructura coherente para percibir la vida con un sentido de propósito o dirección, } \\
\text { que vivido de acuerdo, nos da un sentido de realización. }\end{array}$ \\
\hline
\end{tabular}

Feldman y Snyder (2005), refieren que como en cualquier otro constructo en la Psicología, surgen definiciones y teorías diferentes sobre el significado en la vida. Resaltan que de forma general surgen dos nociones sobre las teorías del significado: como un medio general de acceso a la comprensión de nuestra propia vida, y acreditar que la vida que no tiene sentido/significado se encuentra asociada a altos niveles de emociones negativas (especialmente ansiedad y depresión), o bien como a un mayor riesgo de desarrollar enfermedad mental.

Edwards (2007) define el significado como la composición de una serie de creencias que hacen el mundo comprensible, de objetivos a través de los cuales nos esforzamos y nos percibimos como capaces para alcanzarlos, de un compromiso auto disminuido con otros elementos (por ejemplo, otras personas, animales, naturaleza, o 
con un poder superior), y de un sentido de realización y satisfacción que surgen debido a la presencia de estos componentes.

Según King, Hicks, Krull, y Gaiso (2006) el constructo del significado se considera un componente importante e incuestionable para entender una vida con cualidad, e influye, incluso, en el bienestar psicológico desde la adolescencia hasta la adultez. Los autores, defienden que la vida es concebida como significativa cuando se siente que existe un sentido por detrás de los momentos triviales, cuando se tiene objetivos, y se es coherente, incluso frente al caos. En este sentido, las personas se sienten motivadas a encontrar un sentido en la vida, siendo esta búsqueda diferente de individuo a individuo. Esta búsqueda de significado en la vida se revela como una fuerza, intensidad y activación de los deseos y esfuerzos personales para establecer y/o aumentar su conocimiento del significado, significancia y objetivos en sus vidas. Es incluso una parte importante de la vida, que lleva a las personas a observar nuevas oportunidades y cambios, influenciando su deseo de comprender y organizar sus experiencias (Steger, Kashdan, Sullivan, \& Lorentz, 2008). Steger, Frazier, Oishi, y Kaler (2006) llegan a la conclusión de que, recentinamente, el constructo de significado en la vida ha venido teniendo atención y legitimidad, ya que revela un crecimiento centrado en rasgos positivos y fuerzas psicológicas. Señalan incluso, que este constructo es considerado una variable positiva, un indicador de bienestar, un facilitador de coping adaptativo, y/o un marco en el crecimiento terapéutico. Con respecto a su ausencia en la vida de las personas, los resultados de la investigación sugieren que un significado de vida disminuido está asociado a una mayor necesidad de apoyo terapéutico, a estados depresivos y ansiógenos, a ideación suicida y abuso de substancias, entre otros. Cuando en la vida prevalece un significado considerable, éste parece estar relacionado con la satisfacción profesional, la satisfacción en la vida, la felicidad y un funcionamiento 
psicológico sano. De esta forma, definen el significado en la vida como un sentido y una significación construida, orientadores de la naturaleza del ser humano y de su existencia.

Considerando las diferencias interindividuales en la atribución de significado, Steger (2009) afirma que los estímulos que nos circundan pueden ser los mismos, pero las interpretaciones divergen en los significados de persona a persona. Por consiguiente, la capacidad de obtener significado de las experiencias y del ambiente es fundamental para el éxito de la humanidad. El autor presenta definiciones generales acerca del significado, asociándolo a los términos objetivo/propósito, significación y constructo multifacético. Con respecto al objetivo/propósito, este se relaciona con las orientaciones que los sujetos tienen de sus mayores esfuerzos y objetivos de vida. La significación es la semántica única de la vida personal, basada en el punto de vista de información significativa. Es lo que la vida significa y cómo la persona vive el significado personal, y cuándo su vida tiene sentido o alguna información o mensaje comprensible. La vida tiene de esta forma significado, cuando tiene algo que esperar. En el constructo multifacético, emergen dos componentes principales, la motivación primaria (definiciones centradas en el propósito) y la cognitiva (definiciones centradas en la significancia). Las definiciones multidimensionales del significado en la vida combinan estos dos componentes con una dimensión afectiva referente a la realización personal en sus vidas. De acuerdo a esta relación dimensional, se señala la relación bidireccional entre los estados emocionales positivos y el significado, surgiendo, ambas, del significado para emociones positivas, como de las emociones para el significado.

Steger et al. (2006) le añaden otra dimensión al significado en la vida, en lo que concierne a la búsqueda de significado, distinguiendo el "tener" y el "buscar" significado. Los que buscan, remiten al esfuerzo y el deseo de establecer y/o aumentar 
su conocimiento del significado, de la significación y objetivos en su vida, y presentan motivación para establecer significado en su vida. Los resultados empíricos de esta búsqueda, revelan que los sujetos que se describen como buscando significado, presentan una mayor neurosis, afecto negativo, ansiedad y depresión. Con todo, las personas que refieren tener significado en la vida, reportan a un funcionamiento humano más positivo. En este ámbito, Jim (2004) defiende la perspectiva anteriormente descrita del significado en la vida a través de un constructo multidimensional, proponiendo varias dimensiones, como, por ejemplo, un esquema de vida, propósito de vida, satisfacción en la vida, un sentido de coherencia, robustez en el valor, fragilidad, belleza de la vida, y método y justicia en el mundo. Todas estas aproximaciones teóricas se unen en una misma definición, o sea, que el significado de la vida puede ser conceptuado a través de una serie de creencias que remiten a la coherencia del mundo y de los objetivos de la propia vida. El autor defiende que el significado en la vida puede ser conceptuado en cuatro dimensiones. Una de las cuales está relacionada con la "paz", que transmiten las emociones y pensamientos positivos que transfieren un sentido de harmonía, serenidad, y agrado. La segunda dimensión, se relaciona con la "satisfacción en la vida y el futuro", inherente a planes y objetivos concretos, tales como, las interacciones con otras personas y con el ambiente. La tercera dimensión, de la "espiritualidad y de la fe", presupone la creencia en el orden y en la estructura coherente del universo, favoreciendo una comprensión existencial de la vida en un amplio contexto. La última dimensión, la "pérdida de significado y confusión”, se centra en la falta de motivación para objetivos importantes y la falta del propósito general en la vida.

Considerando las múltiples teorías del significado en la vida, Battista y Almond (1973), encuentran una distinción entre las teorías con visión relativista/terrestre versus última/cósmica. Las primeras, se centran en el sistema de creencias y pensamientos que 
tiene en cuenta el exterior y el trabajo que el sujeto realiza, siendo el proceso de creencias más importante que sólo el contenido de las mismas. El significado se entiende en la medida en que se considera a la vida como positiva, en la cual el sujeto es un agente activo. La visión más cósmica, tiene en cuenta este contenido de las creencias, considerando que hay un significado en la vida intrínseco derivado de Dios, del Ser, del humanismo o de la autotranscendencia. Con respecto a los componentes estructurales del significado, Reker y Wong's (1988) destacan las modalidades cognitiva, motivacional y afectiva. En términos cognitivos, el significado crea sentido en las experiencias de vida a través de la construcción de un sistema de valores o de una perspectiva del mundo. A través de este sistema no sólo el significado cósmico es comprendido, sino los sucesos diarios. El componente cognitivo, refleja las creencias religiosas de los individuos, o una serie de creencias, como la de creer en un mundo justo. Este sistema ejerce igualmente influencia en los actos individuales. El componente motivacional está influenciado por los valores, y sirve de guía para elegir objetivos y determinar cómo vamos a conducir nuestras vidas. Los valores, a su vez, derivan de nuestras necesidades, creencias, y cultura. En este sentido, el significado y el propósito surgen para seguir y mantener los objetivos. Este componente engloba, incluso, los valores y los comportamientos personales. El componente afectivo, se refiere a los sentimientos de satisfacción y realización, los cuales prevalecen cuando el significado personal se realiza y los objetivos son alcanzados.

La conceptuación de objetivos de vida es inherente a la teoría de Frankl complementando su concepto central de Sentido en la Vida, esta teoría será posteriormente descrita. Los objetivos de vida son considerados una capacidad de establecer objetivos, obtener metas y aspiraciones, teniendo en cuenta la experiencia personal. La creación de objetivos se basa en una base afectiva, en la cual la persona 
considera sus experiencias pasadas y las relaciona con el presente (Peralta \& Silva, 2003). En este mismo sentido, las autoras concluyen que los seres humanos tienen como objetivo vital, encontrarle un sentido a su existencia. Las dimensiones afectiva y cognitiva se refieren a los factores del significado identificados en el instrumento de medida de las autoras, el vivencial y el existencial. De una forma general, los instrumentos psicométricos apuntan a dos factores, siendo considerados generalmente como la identificación/presencia y la búsqueda de significado (Bronk, Hill, Lapsley, Talib, \& Finch, 2009; Steger, 2009). En este sentido, los objetivos de vida remiten a una construcción que nos lleva a la continuidad de vivir, anticipando, de esta forma, las razones para perpetuar nuestras vidas y atrasar la muerte, y orientar nuestra conducción actitudinal. El significado existencial surge, así, como sano y adaptativo (Mascaro \& Rosen, 2008). Ulmer, Range, y Smith (1991) refuerzan la adaptabilidad al encontrarle un sentido, en la medida en que un objetivo de vida se asocia a una mejor satisfacción, razones más fuertes para vivir, más apoyo social y un menor impacto de la pérdida. De acuerdo a Compton, Conway, Stinson, y Grant (2006), el variable significado existencial se presenta con un rol de prevención de la depresión potencial.

Con respecto a la vivencia de una vida con sentido, Wong (1998) ha identificado siete características: la realización (ej. en el mantenimiento y concreción de objetivos de vida significativos), la afinidad (ej. una adaptación social general), la religión (ej. tener creencias realistas sobre su relación con Dios), la autotranscendencia (ej. dar continuidad a los objetivos que reportan efectos benéficos en el interior de los individuos), la autoaceptación (ej. aceptación humilde de las propias limitaciones), la intimidad (ej. tener relaciones de proximidad afectiva), y la justicia (ej. percibir la injusticia en la vida). 


\subsection{Fuentes de significado}

Las fuentes de origen de significado tienen que ver con los valores creadores de experiencia y de sufrimiento de Frankl (2006), y con los cuatro dominios de Baumeister (1991) que son: poseer un sentido de propósito/objetivo, tener una base de auto dignidad, aclarar el sistema de valores con los cuales juzgamos lo que está incorrecto o correcto, y desarrollar un sentido de eficacia en el mundo. De acuerdo a Baumeister (1991), las narrativas y las historias de vida permiten iluminar la creación de significado, y añade resultados que legitiman que quien narra una historia con la capacidad personal de sobrepasar un suceso adverso, dirige sus esfuerzos hacia una adaptación más eficaz.

Concerniente al método para alcanzar las fuentes de significado, Steger (2009) señala la formulación de cuestiones, del tipo “¿qué le otorga sentido a su vida?” y analizar y codificar sus respuestas. Las fuentes más comunes recogidas son las relaciones personales, creencias religiosas, salud, placer, o crecimiento personal. Más allá de la formulación de cuestiones, existe otro método que consiste en solicitar a la persona que cree una lista de las fuentes potenciales de significado, y preguntar el grado de importancia de cada fuente mencionada. El resultado de este método, confluye con el primero descrito, al destacar las relaciones personales como la mayor fuente de significado.

Edwards (2007) alerta sobre el papel de los sucesos y fuentes negativas, que normalmente no se consideran en la literatura de las fuentes de significado. En este ámbito, destaca un estudio de Baum y Stewart (1990) en el cual sondearon a personas de entre 17 y 96 años de edad sobre los sucesos más importantes de sus vidas. La mayoría de las mujeres, mencionaron como sucesos significativos los nacimientos de los hijos, el amor/matrimonio y el trabajo. Para los hombres, el trabajo y el 
amor/matrimonio también son mencionados, pero añaden objetivos independientes (ej. viajes, descanso). Las experiencias reveladas como más significativas no se relacionan con el aumento de la edad. Algunos sucesos significativos descritos son de cariz negativo, tales como, accidentes, enfermedades, muertes, y divorcios. Estos resultados les permitieron a los autores llegar a la conclusión de que los sucesos negativos ejercen una influencia importante en el sentido de significado. Neimeyer (2001) refuta la conclusión anterior, refiriendo que el "crecimiento postraumático" lleva a las personas a redirigir las prioridades vitales, los valores humanos y a encontrar un sentido de significado progresivo, y también objetivos de la historia de vida.

Los modelos teóricos posteriores evidencian la pertinencia del significado en situaciones de vida negativas, en las cuales se experimenta estrés y/o sufrimiento.

\subsection{Modelo del sentido en la vida de Frankl (1986)}

La logoterapia se fundó en base a una terapia en la cual se busca el sentido de la vida de la persona como principal motivación del ser humano. Se la considera más fidedigna en lo referente al análisis existencial, en la medida en que logos significa sentido. Y, siendo que sus objetivos terapéuticos se enfocan en sobrepasar un mero análisis existencial, se defiende una verdadera psicoterapia basada en el sentido, que le da al paciente una nueva orientación de vida (Frankl, 1975).

Frankl (1990) a través de su investigación alude a que la mayoría de los sujetos en seguimiento clínico revelaron la necesidad de tener algo en función del cual poder vivir. Evidenciando esta conclusión, en una conferencia del XIV Congreso Internacional de Filosofía, relata que el objetivo último del hombre no es la felicidad en sí misma, sino un motivo para ser feliz (Frankl, 1990). En este sentido, Frarnsworth (1968, citado por 
Frankl, 1990), en el mismo congreso afirma que "Actualmente la mayor enfermedad es una vida vacía, monótona, sin sentido y propósito" (p.20).

La búsqueda de sentido provoca un desequilibrio a través de la tensión interior, siendo esta tensión un prerrequisito indispensable para mantener la salud mental. El ser humano precisa no de homeostasis, sino de "noodinámica", o sea, de la dinámica existencial en un campo polarizado de tensión, en el cual uno es representado por un sentido a realizarse y el otro por la persona que lo debe realizar. Por consiguiente, la tensión permitirá una reorientación del sentido de la vida, en la medida en que toman consciencia de un vacío existencial. De acuerdo a Gillies y Neimeyer (2006), el distrés (ansiedad y depresión) es considerado como el probable impulsador de la búsqueda de significado, o una señal de reconstrucción de contemplación provisoriamente exitosa, orientada por lo que Frankl (1986) refiere como "optimismo trágico". El concepto optimismo trágico se asocia a otro termino logoterapéutico, el Kairós, que significa la calidad de una situación para transformarse en una "oportunidad para", es así, un momento único e irrepetible en la vida personal para cumplir el sentido inherente y latente de esa situación. Caso contrario, esa oportunidad no volverá a surgir (Guberman \& Soto, 2006).

De acuerdo a la logoterapia, el descubrimiento del sentido ocurre a partir de tres formas, más específicamente, a través de la creación de un trabajo o porque ocurre un comportamiento, al probar algo o encontrar una persona, y por la actitud desarrollada frente al sufrimiento inevitable. La primera, se refiere al medio de la realización, la segunda se relaciona con la bondad, la verdad y la belleza al probar la naturaleza y la cultura, y también en la interrelación humana. La tercera, y última, es el sufrir, en el cual surge el afrontamiento de una situación sin esperanza y/o una fatalidad irreversible. Frankl (1990) ejemplifica con la situación de cáncer sin posibilidad de tratamiento, 
donde el paciente no tiene capacidad de alteración, pero le queda cambiarse a sí mismo. En este ámbito, el sufrimiento se extingue cuando el paciente encuentra en sí mismo un sentido. El sentido de la vida, se revela así un sentido incondicional, porque incluye hasta el sentido potencial del sufrimiento inevitable. El sufrimiento no es siempre un fenómeno patológico, definido por síntomas de neurosis. Por el contrario, el sufrimiento podrá ser una realización humana, especialmente si el sufrimiento deriva de una frustración existencial (Frankl, 1990). De acuerdo a lo expuesto, el sufrimiento significa trabajar, crecer y madurar, y se comprende debido a la madurez del alcance de la libertad interior, a pesar de encontrarnos sometidos al destino (Guberman \& Soto, 2006).

Al término significado, se le asocia la responsabilidad del sujeto, acompañándolo a lo largo de su desarrollo, en la medida en que cada situación es irrepetible. La irreversibilidad y el "carácter de algo único" son elementos constitutivos de la vida humana. El sujeto es responsable de atribuirle un sentido a su existencia. La no inmortalidad responsabiliza al individuo de atribuirle un concepto a la vida, siendo, precisamente, la muerte la que señala el límite temporal de la vida. Por consiguiente, la finitud y la temporalidad son igualmente componentes esenciales de su sentido. En la responsabilidad por una vida que sólo se vive una vez, surge el sentido de la existencia humana fundada en su carácter irreversible. Pero se señala la diferencia entre temporalidad y duración, ya que no se puede evaluar la plenitud de sentido de una vida en base a su duración. Incluso, en relación a la responsabilidad humana, se relaciona el destino biológico con la libertad, en la medida en que ésta podrá estar restringida por impedimentos externos o por las inhibiciones internas, a las cuales el hombre se deberá adaptar (Frankl, 1986). 
Finalmente, en el constructo del sentido en la vida, Frankl (1986) señala tres categorías de valores: los creadores, los vivenciales y los de actitud. Los creadores se relacionan con el hacer, los vivenciales se realizan con el Yo mediante una orientación transmitida por el Yo al mundo, los de actitud se realizan cuando algo ineludible tiene que ser aceptado sin irreversibilidad. La plenitud de la vida surge en el crear y probar, así como en el sufrimiento. En la vida es posible adquirir su último sentido no sólo a través de la muerte, sino, igualmente, en la propia muerte, en la cual el dolor permite la madurez y el crecimiento personal. El sufrimiento desencadena una "tensión revolucionaria" que permite fomentar la iniciativa de buscar sentido, consiguiendo así, una comprensión emocional humana, anterior a cualquier racionalidad. En el plano biológico, el dolor se vuelve una señal porque tiene el papel de guardián y custodio, contenido de sentido. Mientras vivimos el sufrimiento, estamos vivos y nos fortalecemos. Cuando el sujeto no tiene ninguna posibilidad de realizar valores creadores, está limitado al planeamiento del futuro y puede realizar solamente los valores de actitud.

\subsection{Modelo del mantenimiento de significado (MMS) de Heine, Proulx, y}

\section{Vohs (2006)}

Los seres humanos son creadores de significado, conducidos para realizar conexiones, encontrar señales en el ruido, identificar compañeros, y establecer asociaciones en espacios en los cuales inherentemente no existen. Son constructores cuando están obligados a establecer representaciones mentales de las relaciones esperadas, que tienen unidos los elementos de su mundo externo, elementos del Yo, y más importante, cuando lo lleva del Yo a este mundo exterior. Cuando se encuentran los elementos de la realidad percibida, parecen no formar parte de las estructuras de la existencia relacional de las personas, o resisten a la integración relacional. Estos 
elementos inconsistentes provocan "sentimientos de absurdo" al desconcertar el sentido de incongruencia fundamental, motivando a las personas a restablecer el sentido de normalidad y coherencia en sus vidas (Heine, Proulx, \& Vohs, 2006).

Estos autores, crearon el Modelo de la Manutención de Significado (MMS) delineado por tres puntos fundamentales. Primero, el significado es relación, en otras palabras, el significado une a las personas, lugares, objetos e ideas a los otros por caminos esperados e inesperados. Aceptan el significado, la relación y la asociación como sinónimos en este contexto. Utilizando estos términos como interdependientes, este significado es el observador de las relaciones o asociaciones que los seres humanos construyen e imponen en sus mundos. Las relaciones más importantes se dan entre el Yo y el mundo externo, y los debilitamientos percibidos en las representaciones mentales de estas relaciones, llevan al esfuerzo para reconstruir asociaciones significativas.

El segundo punto central del modelo implica que los humanos son criadores de significado. En este concepto, los humanos poseen una capacidad innata para identificar y construir representaciones mentales, esperadas en las relaciones entre las personas, lugares, objetos e ideas. Los humanos tienen la capacidad de autoconsciencia, permitiendo reconocer los debilitamientos e inconsistencias de las representaciones, y llevando a la insignificancia. Este reconocimiento favorece, por otro lado, la necesidad de recuperar el significado.

El tercer punto, remite a la centralidad del modelo, en la medida en que los sujetos deben compensar el trabajo realizado cuando está influenciado por distorsiones, la compensación deriva en trabajos nuevos. Los autores proponen un modelo de compensación fluida, en el cual, prevalece la capacidad para construir y hallar matrices relacionales alternativas, en la presencia de amenazas a otra fuente de significado. Cuando uno de los dominios (autoestima, convicción, afiliación e inmortalidad 
simbólica) es amenazado, tiene la capacidad para compensar los otros dominios, redirigiendo los sistemas de significado alternativos.

De acuerdo a la identidad, que evoluciona con la edad, el significado se construye paralelamente, en esta comparación surgen los sujetos en el estadio de difusión de significado (baja presencia, baja búsqueda), otros en el estadio de clausura de significado (alta presencia, baja búsqueda), o en el estadio de moratoria de significado (baja presencia, alta búsqueda), o en el último estadio, el de realización de significado (alta presencia, alta búsqueda) (Steger et al., 2006). Se agrega a la perspectiva de desarrollo de significado, a través del MMS (Heine et al., 2006), la proposición de que los seres humanos son incontestablemente creadores de significado. Y, en este ámbito, los autores afirman que desde el nacimiento y de forma progresiva, las personas automáticamente buscan, construyen y apelan a las representaciones mentales basadas en las informaciones recogidas en las relaciones. Esta estructura relacional, a su vez, se encuentra en lugares y acontecimientos que son evaluados, retirándoles significados, y facilitan la identificación de la importancia de estos mismos lugares y acontecimientos para el sujeto (Heine et al., 2006).

En este sentido, Bruner (1990) enfatiza la preponderancia de las relaciones, en las cuales compartimos nuestras narrativas y a éstas se les atribuye significados personales. De este modo, el significado se convierte en una creación cultural, en relación con los otros. Esta capacidad da como resultado una práctica social, la cual le confiere estabilidad a la vida social del niño. La constitución de esta estabilidad se realiza al compartir historias de diversidad humana, y volviendo las interpretaciones de las personas congruentes a nivel moral y cultural. En el sentido de alcanzar este nivel de creación de significado cultural, los seres humanos más jóvenes inician su aprendizaje de atribución de sentido, sobre todo un sentido narrativo que considera el mundo a su 
alrededor. Para el autor, en el momento que inicia el lenguaje el niño es capaz de atribuir sentido, significado. Va convirtiendo las experiencias en términos de narrativa, no sólo como un juego de niños, sino igualmente utilizando esta conversión en un instrumento de producción de significado.

A través del énfasis del desarrollo del significado, en un primer nivel, con menor complejidad los niños perciben la diferencia entre significados positivos y negativos a través de la observación de los otros en sus microsistemas (percepción y evaluación de significados), en un segundo nivel inicia su creación de significado con las personas y objetos más cercanos (creación inicial de significados personales), en el tercer nivel crea significados teniendo en consideración los significados de los otros (creación de significados personales considerando los significados de los otros). Y finalmente, en un nivel de mayor complejidad e intensidad, en términos de capacidad para atribuir o buscar un significado, o sentido, surge el último y cuarto, en el cual los sujetos se vuelven capaces de escoger y reconstruir valores, experiencias, emociones $\mathrm{y}$ sentimientos, y personas para crear o buscar sentido y/o significado, como también presentan una madurez significativa en términos cognitivos y emocionales para crear objetivos de vida (reevaluación y reconstrucción de significados personales y creación de objetivos de vida) (Heine et al., 2006).

\subsection{Modelo de atribución de significado de Park y Folkman (1997)}

En el Modelo de Atribución de Significado de Park y Folkman (1997), se encuentra subyacente el significado global, preconizado por la construcción más importante en nuestro mundo interior y personal y el significado situacional, que identifica la interacción entre el significado global y las situaciones contextuales específicas (Figura 2). 


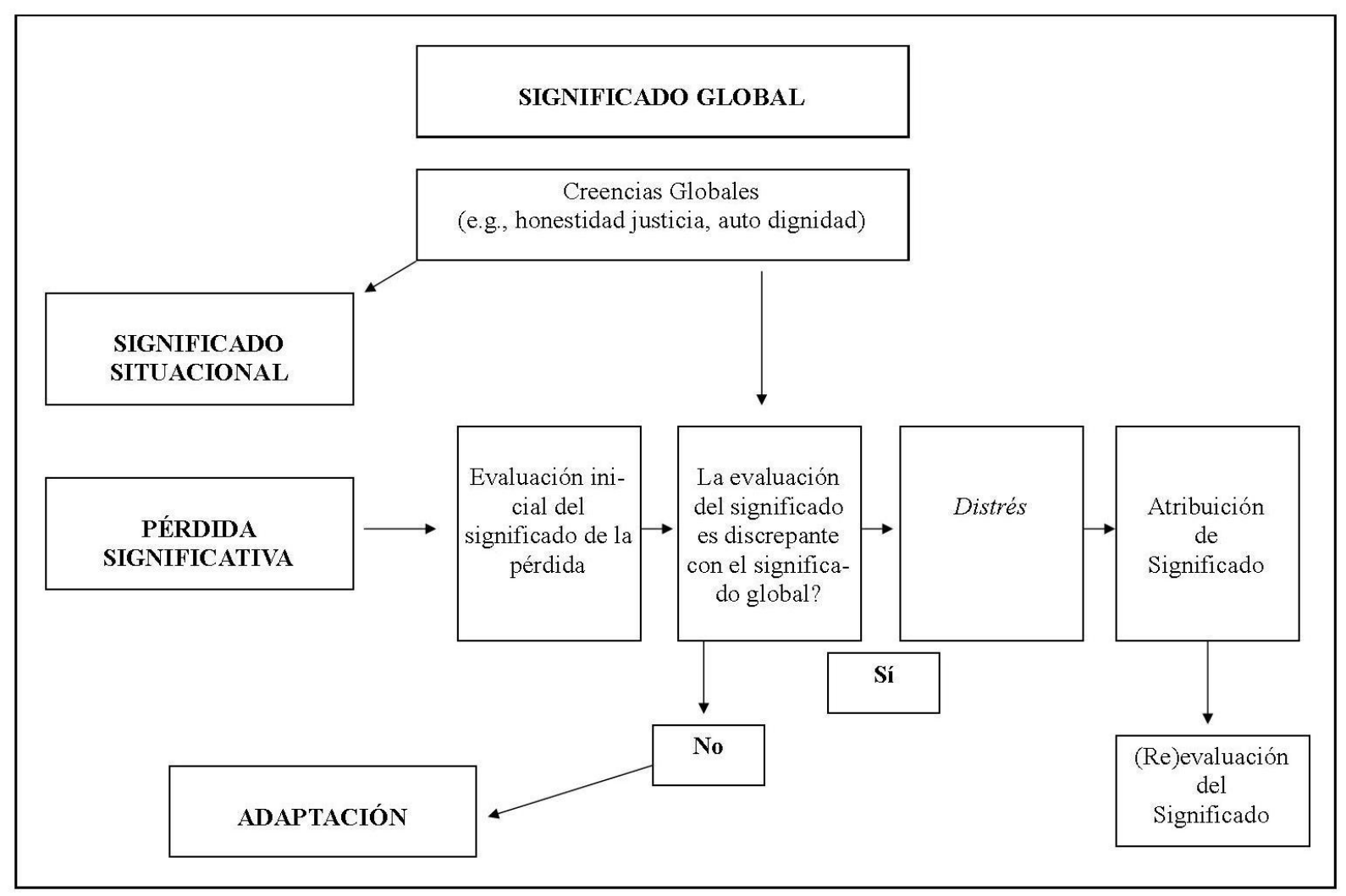

Figura 2: Modelo de Atribución de Significado de Park y Folkman (adaptado por Park, 2008)

De acuerdo al modelo, en la dimensión "Significado Global” los sujetos poseen sistemas globales de significado, constituyéndose en creencias y objetivos. Las creencias globales son los esquemas de pensamientos con los cuales las personas interpretan sus experiencias, integrando los dominios de la honestidad, justicia, destino, control, predictibilidad, coherencia, benevolencia y vulnerabilidad personal. Los objetivos globales, a su vez, se refieren a estos ideales, estados u objetos mediante los cuales las personas trabajan, e intentan mantener todos sus contextos de vida, como en sus relaciones, trabajo, riqueza, conocimiento y realización.

La dimensión de "Significado Situacional", ocurre cuando el sujeto se encuentra frente a un potencial estresante o sucesos traumáticos, a los cuales le atribuyen significado. Esto constituye una evaluación de significado, comparándose a su significado global. Por ejemplo, el estrés o trauma se piensa así, como resultado, cuando 
la evaluación de significado comparte o viola algunos de los aspectos de las creencias y objetivos globales del sujeto. Los objetivos globales son violados cuando un suceso se evalúa como divergente del que las personas quieren. Las discrepancias entre la evaluación de significado y el significado global, puede llevar a la pérdida del sentido de control, previsibilidad, o comprensión del mundo, creando, de esta forma, una intensificación del humor negativo y perjudicial. Tras la vivencia de un suceso potencialmente estresante, las personas que no viven esta divergencia presentan menos distrés. La percepción de discrepancias, se inicia en el pensamiento y se esfuerza por reducir el distrés, desarrollándose a través de la atribución de significado.

La atribución de significado, ocurre como un esfuerzo para reponer el significado global, cuando este es violado o destruido. Esta dimensión se refiere a intentar ver o comprender la situación de una forma diferente, y a revisar y reformular las creencias y objetivos globales personales, para reconstituir consistencia. El proceso por el cual las personas reducen esta divergencia implica la alteración de la evaluación de significado de la situación (ej., asimilación), y el cambio de las creencias y objetivos globales (ej., acomodación), o ambas, en el sentido de integrar la evaluación de significado del suceso y de su sistema global de significado global. Los cambios en el significado global o situacional son productos de este proceso, reduciendo la divergencia y dando lugar a una mejor adaptación al suceso. La atribución de significado, surge, de este modo, prediciendo la adaptación sana a sucesos estresantes y/o negativos.

Folkman y Moskowitz (2007) alteraran la lista de categorías en este proceso para incluir los resultados encontrados en la literatura, que se expandió rápidamente tras el presente trabajo/modelo, dando lugar a cinco categorías: el beneficio encontrado, el beneficio recordado, los procesos de objetivos adaptativos, la reordenación de prioridades y la inclusión de acontecimientos comunes con significado positivo. En 
primer lugar, Folkman (2008) explica que el beneficio encontrado es frecuentemente evaluado en términos de desarrollo de sabiduría, paciencia y competencia, así como, una mejor apreciación de la vida, mejor claridad de lo que realmente importa, fortalecimiento de la fe o espiritualidad y de priorizar la cualidad de las relaciones sociales. Este es el tipo de coping enfocado en el significado más comúnmente observado.

El segundo, el beneficio recordado, es la forma de coping enfocado en el significado que ocurre durante la situación estresante, dando lugar a pensamientos sobre los posibles beneficios de la situación en cuestión. Tercero, los objetivos se encuentran envueltos en las funciones del coping enfocado en el significado, que motivan la toma de decisión de los sujetos, y recordan su propio orden de objetivos, lo que ayuda a mantener los esfuerzos para realizarlos, sobre todo cuando se encuentran amenazados. Por último, la necesidad de reordenación de prioridades puede surgir en respuesta a un acontecimiento de estrés, siendo este agudo o crónico. De esta forma, el sujeto presenta su respuesta de coping ante una realidad modificada, obligando a aceptar que su mundo cambió, desarrollando un proceso básico de valores para reordenar lo que a partir de ese momento es realmente importante. La creación de momentos positivos o acontecimientos comunes se sostienen en la idea de que las personas, de una forma general, pretenden "sentirse bien". Este deseo presenta una importancia crítica en la manutención del bienestar físico y mental durante períodos de tiempo difíciles.

\subsection{Inteligencia emocional y significado}

La relación entre significado e IE se pone en evidencia, por ejemplo, en la integración de la IE por Lyusin (2006), en las inteligencias múltiples de Gardner (1995), en la medida en que la inteligencia intrapersonal remite al "acceso a la vida sentimental de cada persona, repleta de afectos y emociones: la capacidad instantánea para 
realizar discriminaciones a lo largo de estos sentimientos y, eventualmente, para nivelarlos creando códigos simbólicos de los mismos, para retirarles el significado de comprensión y orientación de los comportamientos de cada persona” (p. 239).

Mayer y Cobb (2000) realzan esta relación al afirmar que Payne (1986) fue quien estudió por primera vez el concepto de IE, cuando refiere que "los hechos, significados, verdades, relaciones, son lo que realmente existe en la emoción. Los significados sintieron significados: las verdades son verdades emocionales; las relaciones son relaciones interpersonales. $Y$, los problemas que resolvemos son problemas emocionales, o sea, problemas en la forma como sentimos." (p.165). En este sentido, la construcción de significado sobreviene de nuestras relaciones sociales, estando estrictamente relacionado con el contexto cultural de cada individuo. En este ámbito, la perspectiva constructivista realza nuestra construcción narrativa enraizada en su influencia cultural, porque un sujeto es un agente relacional (Bruner, 1990).

Por consiguiente, la capacidad para reconocer los significados de las emociones y relaciones, y para pensar y resolver problemas basándose en estos significados es descrita como la capacidad integrante de la IE (Mayer, Caruso, \& Salovey, 2000). El reconocimiento y construcción de significado basados en las emociones, remiten al proceso cognitivo, a través del cual el sujeto inicia la reevaluación positiva que implica la reinterpretación del acontecimiento a nivel de los beneficios, de los valores, creencias y objetivos personales. A través de esta reevaluación, surgen los acontecimientos significativamente positivos, relacionados con las emociones positivas, porque reafirman lo que cada uno valora, y apoyan el enfoque en estos valores para afrontar acontecimientos estresantes (Folkman \& Moskowitz, 2004). La reevaluación o la nueva interpretación de la situación remite al proceso de regulación emocional, que señala la influencia previa de la emoción en el proceso cognitivo, y el énfasis dirigido a la 
respuesta emocional, relacionándose con el manejo de las emociones ya existentes (Gross, 1998).

La regulación emocional es así, una de las dimensiones fundamentales en el constructo de la IE, al señalar el esfuerzo del sujeto para eliminar, mantener o alterar su estado emocional. En otras palabras, la construcción de una nueva situación emocional es el resultado de la reevaluación cognitiva que implica el cambio cognitivo, que a su vez, lleva a la disminución del impacto emocional en el sujeto. El proceso emocional inherente a la regulación emocional enfoca los intentos activos de conocer, explorar los significados, y comprender las emociones (Cabello, Fernández-Berrocal, ExtremeraPacheco, \& Ruiz Aranda, 2007).

Por último, es importante comentar que la relación entre IE y significado no ha sido punto de interés en las investigaciones en el área de la enfermedad. Donohoe y Greene (2009) analizan la relación de la IE y significado concluyendo que la relación de estos dos constructos es mediada por la cualidad de las relaciones sociales de los sujetos. Tambien, Zysberg (2012) refiere que la IE influencia de forma significativa la realización con la felicidad y el bienestar, factores decisivos para encontrar significado en la vida. Tan sólo estos dos estudios, en toda la búsqueda bibliográfica realizada, con resultados empíricos, analizan la relación de la IE y el significado en poblaciones generales. 
Coping 


\section{COPING}

El término coping se define por Lazarus y Folkman (1984) cómo los esfuerzos personales para gestionar o controlar la situación percibida como estresante, o como pérdida, o cambio mediante sus recursos. Posteriormente, Lazarus (1991) presenta una definición más amplia, como los esfuerzos comportamentales y cognitivos, cuyo objetivo es gestionar exigencias internas o externas específicas (y los conflictos entre las mismas), evaluadas como excediendo o no los recursos personales. En la misma línea de pensamiento, Folkman y Moskowitz (2004), lo definen como los pensamientos y comportamientos utilizados para gestionar las exigencias internas y externas en las situaciones evaluadas como estresoras.

El Modelo Transaccional de Estrés y Coping (Lazarus \& Folkman, 1984), propone que la adaptación a un estresor se ve influenciada por los procesos de coping que las personas siguen ante un estresor. El proceso de evaluación implicado en la ocurrencia de un acontecimiento se orienta a su significado personal (evaluación primaria) y a la evaluación de las opciones para afrontarlo (evaluación secundaria). Paralelamente, las dos formas de evaluación determinarán la extensión de la transición sujeto-medio, pudiendo esta ser evaluada como una pérdida, amenaza o cambio. En este sentido, Folkman y Lazarus (1985) indican que una percepción de pérdida se asocia a emociones negativas, tales como la tristeza y la rabia, mientras que en la percepción de amenaza surgen igualmente emociones negativas, tales como la ansiedad o el miedo. La percepción de un cambio se orienta hacia emociones positivas como la excitación, el ansia y la confianza. De este modo, el proceso de coping se inicia en respuesta a las exigencias evaluadas en una situación específica. El coping enfocado en el problema de tipo instrumental se utiliza más en situaciones en las cuales se puede hacer algo/resolver el problema, mientras que a través del coping enfocado en las emociones, se regula el 
distrés, y se usa con más frecuencia en situaciones que deben ser sólo aceptadas y no modificables. Cuando una situación se resuelve favorablemente surgen emociones positivas, como la felicidad, el alivio o el orgullo.

Las estrategias de coping basadas en las emociones y en la resolución de problemas surgen generalmente asociadas, verificándose que el coping orientado a las emociones ocurre inmediatamente tras los acontecimientos, y es gradualmente sustituido por estrategias que buscan la resolución del problema. Las estrategias de coping no son en sí mismas adecuadas o inadecuadas, eficientes o ineficientes. La eficacia del coping se debe al equilibrio entre el control de la incomodidad emocional y la gestión del problema que origina la incomodidad. Las estrategias de coping utilizadas tienen que ir al encuentro de los valores, objetivos, convicciones y estilos de coping del sujeto (Lazarus \& Folkman, 1984). El Modelo se encuentra descrito en la Figura 3.

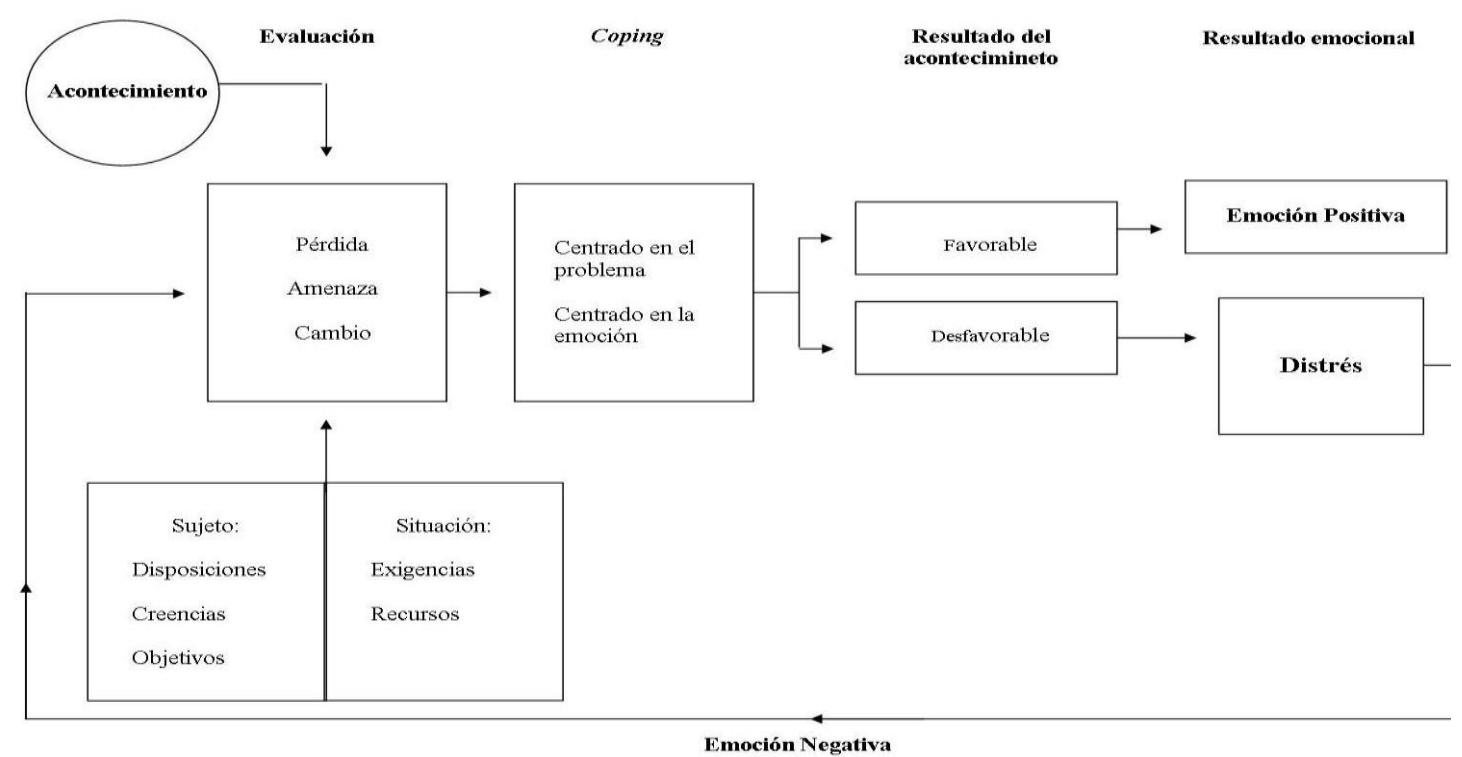

Figura 3: Modelo original de Estrés y Coping de Lazarus y Folkman (1984)

Desde otra perspectiva, Folkman y Moskowitz (2004) defienden que el proceso de coping se inicia en respuesta a la evaluación primaria realizada por el sujeto, donde los objetivos pueden ser construidos, dañados o amenazados. Las respuestas de coping dan 
comienzo en el ambiente emocional, y promueven las primeras tareas de coping para regular las emociones negativas, igualmente estresantes, que interfieren con las formas instrumentales de coping. Cuando la resolución es eficaz, predominan las emociones positivas; cuando es ineficaz, predominan las negativas. Realzando el componente emocional en el proceso de coping, Folkman (1992) dice que la evaluación primaria (si la situación es estresante o no) y la evaluación secundaria (las opciones de coping a poner en marcha) dan la intensidad y cantidad emocional, influyendo en la respuesta de coping. Según Lazarus (1991), el proceso de coping funciona como mediador de la respuesta emocional a la situación estresante, siendo el objetivo, tanto del enfocado en el problema como del enfocado en la emoción, equilibrar el estado emocional en el afrontamiento.

Taylor (1983) asocia tres supuestos al coping, la búsqueda de significado en la experiencia, el desarrollo de la maestría en el acontecimiento particular y en otros en la vida en general, y reforzar la autoestima sintiéndose bien con uno mismo. Pearlin y Schooler (1978) añaden que el coping presenta tres funciones protectoras: eliminar y modificar las condiciones que causan distrés en la gestión del problema, alterar el significado de la experiencia, neutralizando el cariz problemático de la situación (alterar el control de percepción) y regular el distrés emocional producido por el problema. Estas mismas funciones son descritas por Moos y Schaefer (1984) y por Folkman y Lazarus (1980), como los tres tipos de estrategias de coping: coping instrumental o enfocado en el problema, coping enfocado en la evaluación y coping paliativo o enfocado en la emoción.

Moos y Schaefer (1984) presentan el coping en los tres dominios señalados anteriormente, enfocado en el significado o sentido, en aspectos prácticos y en las emociones. En relación al enfocado en el significado, se aborda la comprensión y 
atribución de sentido a la situación de crisis. Al evaluar y reevaluar la situación, el sujeto modifica el sentido y trata de comprender mejor la amenaza inherente a la situación, para ello, hace un análisis mental y una preparación lógica, a través de las cuales analiza un aspecto de cada vez, dividiendo el problema en unidades menores, para controlarlas más fácilmente, teniendo en cuenta su experiencia pasada. La redefinición cognitiva ayuda al sujeto a aceptar la realidad de la situación reestructurándola cognitivamente de forma más positiva. La evitación o negación pueden surgir cuando el sujeto niega o minimiza la gravedad de la situación. En lo que concierne a la dimensión enfocada en el problema, el sujeto objetiva de forma práctica construir una situación más positiva, al gestionar las consecuencias de la misma. Para ello, procura información o apoyo que le transmita más conocimiento sobre la situación, para emitir comportamientos alternativos, consiguiendo resultados más positivos. De este modo, se involucra en acciones de resolución de problemas respondiendo directamente a la crisis, y busca recompensas alternativas en la modificación de sus actividades y en la creación de nuevas fuentes de satisfacción que compensen las pérdidas sufridas en la crisis. Por último, el coping enfocado en las emociones busca la gestión y el mantenimiento del equilibrio emocional en la crisis. En este sentido, el sujeto se esfuerza por mantener la esperanza y el control de las emociones, alcanzando la regulación afectiva. Esta regulación se beneficia por la descarga emocional, al aliviar sentimientos negativos como la rabia y la desesperación, sin embargo, en ocasiones los sujetos producen respuestas que violan las normas sociales. Al final de la crisis, surge la aceptación resignada, asumiendo que no se pueden producir respuestas o comportamientos que alteren la situación o se vuelva irreversible, volviéndose ésta una fatalidad. 


\subsection{Coping e inteligencia emocional}

La cuestión de la emoción versus la razón existe desde los inicios de la filosofía. Sin embargo, el debate más reciente en torno a esta diferenciación y superposición, ha llevado al consenso de que ambas influencian el comportamiento del sujeto. En este sentido, Damásio (2003) refiere que los sistemas cognitivos y los sistemas emocionales trabajan juntos, al informar e intervenir en las estrategias de afrontamiento inteligente. El autor ha señalado la posibilidad de que uno de los propósitos centrales de la emoción sea ayudar al procesamiento cognitivo y al comportamiento estratégico. En esta relación entre emoción y pensamiento, Mayer y Salovey (1993) refieren que las personas que viven múltiples emociones desarrollan múltiples pensamientos y mediante esta influencia mutua, señalan incluso que las personas con estado de humor positivo sienten más acontecimientos positivos que negativos, y viceversa. De esta forma, el estado del humor puede facilitar la priorización de las tareas en la vida, en la medida en que las emociones orientan la atención hacia los estímulos, permitiendo aclarar la experiencia y llevar a respuestas adaptativas.

En la misma línea, Palmero y Mestre (2004) revelan que las emociones contienen energía, organizan y motivan el funcionamiento adaptativo. Así, las emociones y la inteligencia provienen de información recíproca, la cual puede ser procesada y utilizada de forma adaptativa (Salovey et al., 1995). La información emocional, a su vez, deriva de las relaciones interpersonales, y sólo a través del análisis de estas relaciones es posible comprender la interacción entre el sujeto y su medio (Mayer et al., 2001). En esta interacción las emociones subrayan su importancia, o sea, en la adaptación personal al medio, teniendo en cuenta que las emociones son acontecimientos internos que coordinan múltiples subsistemas psicológicos, incluyendo las respuestas fisiológicas, las cogniciones y la vitalidad consciente (Mayer et al., 2000). Más allá de los 
acontecimientos internos, las emociones marcan una secuencia temporal de los acontecimientos externos, en los cuales los sentimientos hacen de intermediario entre los antecedentes y las consecuencias específicas. A través de los acontecimientos, las emociones se pueden vivir intensamente, y cuando lo son, el sujeto tiende a fijar los recuerdos asociados a las experiencias (Lazarus \& Lazarus, 1994). De este modo, al recurrir a la memoria, el sujeto discrimina la información relacionada con las emociones vividas durante las experiencias, a las consecuencias de las estrategias utilizadas en esas mismas experiencias, y a la cultura y/o contexto en el que ocurren. Estos aspectos son tenidos en cuenta por la persona emocionalmente inteligente, a priori para elegir su acción (Salovey \& Mayer, 1990). La emocionalidad personal se revela así, susceptible de hacerse más positiva, en la medida en que se reformula la percepción de las situaciones (Beck, Rush, Shaw, \& Emery, 1979). En este sentido, el sujeto, al regular su emocionalidad personal, tiene en cuenta las emociones positivas que puede ampliar temporalmente el reportorio de pensamientos, lo que favorecerá la resolución creativa de problemas (Frederickson, 1998).

En este proceso de regulación emocional, Mozaz, Mestre, y Vásquez (2007) señalan su importancia y repercusión en la adaptación de la persona a las adversidades de la vida. Esta adaptabilidad a través de las emociones está inherentemente asociada, a la capacidad de resolución de problemas, a la evaluación adecuada de las situaciones, y a la flexibilidad para adaptarse a las mismas (Regner, 2008). Las personas emocionalmente inteligentes, viven los sentimientos de forma clara, confían en sus capacidades para regular su afecto, se recuperan del humor negativo con mayor facilidad, y pasan por experiencias negativas de forma eficaz (Salovey et al., 1995).

Este fomento de la inteligencia a través de las emociones concuerda con la Teoría Triárquica de Stenberg (1988), que defiende tres dimensiones de la inteligencia. 
Primero, la "componencial" centrada en los componentes mentales implicados en el análisis de la información para resolver problemas; segundo, la "vivencial", enfocada en la forma mediante la cual las experiencias previas de una persona afectan a su inteligencia, y la forma como estas experiencias se aplican a la resolución de problemas; por último, la "contextual", se relaciona con el éxito que las personas obtienen para comprender las exigencias cotidianas y su mundo interno. Este equilibrio entre la experiencia y la expresión de emociones, es la clave para una regulación adaptativa de las emociones. No olvidando que en la mayor parte de la nuestras vidas este equilibrio no es alcanzado, sin embargo, es posible obtenerlo, a través de su aplicación en determinadas situaciones, tales como las experiencias de emociones negativas, por medio de un proceso de socialización adaptativa de las emociones (Guil, Mestre, \& Guillén, 2003).

La interdependencia entre el sistema cognitivo y el emocional proviene de las experiencias de los sujetos. Así, las emociones no surgen solamente a través de nuestras reacciones corporales (Schachter \& Singer, 1962), sino también, a través de la evaluación de experiencias previas, en la medida en que el primer paso en la secuencia emocional es la evaluación cognitiva de la situación (Lazarus, 1991).

La Teoría Cognitiva de la Emoción de Smith y Lazarus (1990, 1993), identifica dos tipos de procesos cognitivos asociados a la respuesta emocional. El primer proceso incluye la evaluación primaria y secundaria a través de las cuales el individuo evalúa la naturaleza de la situación. En la evaluación primaria subsiste la relevancia y la congruencia motivacional que contiene el significado de la situación en la promoción del bienestar. La relevancia motivacional se refiere al grado de importancia de la situación para los sujetos en términos de sus objetivos personales, mientras que la congruencia motivacional se relaciona con la situación, siendo facilitadora o no de la 
realización de estos mismos objetivos. En este sentido, si la situación se construye con relevancia motivacional, la evaluación de la misma denotará o no congruencia motivacional mediante las emociones vividas. Posteriormente, una de las cuatro evaluaciones secundarias determinan las especificidades de esta experiencia emocional: la "responsabilidad" es direccionar la culpa o la honra hacia uno mismo o hacia otro, el "potencial del coping enfocado en los problemas" se asocia al grado en el cual el individuo acredita que puede cambiar la situación para volverla más congruente con sus objetivos, el "potencial del coping enfocado en las emociones" expresa como las creencias personales pueden ajustar psicológicamente al sujeto a la situación y por último, la "expectativa de futuro" revela el grado en el cual los sujetos acreditan que en el futuro la situación irá mejorar.

Se subraya al sujeto como un agente activo en este proceso de adaptación emocional, es el único capaz de relatar lo que siente en cada acontecimiento. De esta forma se aprende la importancia de la información obtenida mediante los cuestionarios de autoevaluación individual, los cuales se acercan a las emociones como eventos subjetivos, personales e idiosincráticos (Salovey et al., 1995). Es en esta individualidad emocional, que Gardner (1995) señala las diferencias individuales de la capacidad para utilizar la información que proviene de la adaptación emocional, creando la tipología de inteligencia personal. Esta reside en el acceso a nuestra vida sentimental, influenciada por los afectos o emociones, que lleva a la capacidad inmediata para realizar distinciones entre estos sentimientos, y eventualmente manejarlos, al atribuirles códigos simbólicos, orientados hacia un significado de conocimiento y para guiar nuestros propios comportamientos.

En este ámbito, Linley, Felus, Gillett, y Joseph (2012) refieren que la expresión emocional es un mediador de la relación entre las experiencias subjetivas de miedo, 
desesperanza y horror en acontecimientos adversos y crecimiento en la adversidad. Estos mecanismos apoyan a la persona a transformar experiencias traumáticas perturbadoras en crecimiento. Acrecientan que estos efectos en la expresión emocional son, a su vez, moderados por la IE.

Las personas que regulan sus emociones tanto negativas como positivas, y que utilizan la información proveniente de esta regulación, moderan las emociones reiterando las positivas y realzan un índice mayor de adaptación a situaciones de estrés agudo (Lepore, Fernández-Berrocal, Ragan, \& Ramos, 2004; Ruiz-Aranda, FernándezBerrocal, Extremera-Pacheco, \& Salguero-Noguera, 2005).

Ruiz-Aranda, Fernández-Berrocal, González-Ordi, Miguel-Tobal, y SalgueroNoguera (2007) se basan en el trabajo de Mayer y Salovey (1997) para comprender la adaptación de las personas a experiencias estresantes a través de la capacidad para prestar atención, reflexionar, discriminar y reparar sus estados emocionales. Los autores valoran la relación entre IE y estrés, en la medida en que el estrés lleva a emociones negativas y éstas aumentan el estado de estrés, dando como resultado una disfunción en la relación sujeto-medio. En este proceso, las capacidades para identificar y reparar las emociones se hacen modeladoras, se añaden al tipo de estresante, que puede ser crónico (como una enfermedad) y/o puntual (como una tarea).

Gawali (2012) defiende que las personas emocionalmente inteligentes tienden a ser emocionalmente resilientes, más capaces de afrontar las crisis o traumas en la vida. Afirma que la IE es una capacidad que se puede desarrollar en los sujetos, y así se debería equipar a los sujetos y a la sociedad de forma integral para hacer frente a las situaciones traumáticas. En este ámbito, destaca cinco dominios de competencias: la autoconsciencia para reconocer los sentimientos cuando surgen; la gestión emocional, en el sentido de controlar los sentimientos adecuándolos a las situaciones; la auto 
motivación para mantener las acciones dirigidas al objetivo cuando se distrae con emociones; la empatía para interpretar correctamente las necesidades y voluntades de los otros; y la gestión relacional para anticipar, comprender y apropiar la respuesta a las emociones de los otros. El autor afirma que estas competencias deberían formar parte de programas de entrenamiento en escuelas y organizaciones fomentando una mejor adaptación de los sujetos a situaciones estresantes futuras.

De acuerdo a lo expuesto, se ha comprobado empíricamente la relación benéfica entre las emociones y/o IE y el estrés en la adaptación personal, como podemos observar en la Tabla 6.

Tabla 6: Relación entre emociones/IE y estrés en la adaptación personal

\begin{tabular}{l} 
Autores \\
\hline Salovey et al. (1995) \\
Ruiz-Aranda et al. (2007) \\
\\
Fernández-Berrocal y \\
Extremera-Pacheco (2006); \\
Extremera-Pacheco y \\
Fernández-Berrocal (2005) \\
Extremera-Pacheco y \\
Fernández-Berrocal (2007)
\end{tabular}

\section{Investigaciones}

Las capacidades emocionales contribuyen a reducir los medios ineficaces de adaptación frente a acontecimientos estresantes, como también, a suprimir los pensamientos intrusivos.

Uno de los aspectos más atractivos y difundidos inherentes a la IE es su poder predictivo de la adaptación del sujeto a su medio, dotada de capacidades que favorecen y facilitan la realización de metas del sujeto en su misión de vida a todos los niveles.

La IE permite disminuir la intensidad y la frecuencia de estados de humor negativo, mejora el afrontamiento de acontecimientos de vida y se vuelve un buen indicador de percepción subjetiva de satisfacción en la vida.

Han correlacionado la percepción de IE a los estilos de afrontamiento, revelando que valorizar las experiencias emocionales y tener autoconfianza en la capacidad de prestar atención, comprender y regular nuestras emociones se traduce en un estilo de afrontamiento más adaptativo, utilizando estrategias de reinterpretación positiva y crecimiento, un mayor afrontamiento activo, planeamiento de la acción y una mayor búsqueda de apoyo social y emocional. Las personas que mejor sienten la IE, tienden a centrarse y a compartir sus emociones, y no evitan la situación de estrés a través de la supresión mental. Agregan que, las personas emocionalmente inteligentes procesan y expresan las emociones de una forma útil, teniendo un reportorio de estrategias de afrontamiento relacionadas con la información, proporcionada por su estado emocional. La IE demuestra igualmente, una fuerte asociación con la salud mental, un balance afectivo y ajuste social y, simultáneamente, un perfil adaptativo de afrontamiento del estrés.

Matthews y Zeidner (2000)

En situaciones estresantes, un bajo nivel de IE puede interferir en la selección de mecanismos de defensa más adaptativos.

Un alto índice de IE se relaciona con mecanismos de defensa adaptativos, como la sublimación y se relaciona menos con la negación. 
Bar-On (2000)

Goldenberg et al.(2006)

Salovey, Detweiler-Bedell, Detweiler-Bedell, y Mayer (1999)

Stanton y Franz (1999)

Gohm, Corser, y Dalsky (2005)

Salovey, Stroud, Woolery, y Epel (2002)

Folkman, Lazarus, Gruen, y Delongis (1986)

Ciarrochi, Deane, y Anderson (2002)

Bhullar et al. (2012)
El control emocional se relaciona con el mantenimiento de la calma y un alto nivel de funcionamiento bajo estrés, y conseguir afrontar el estrés y el conflicto en el contexto social.

Relacionan la IE y estrategias de coping adaptativas, inherente a la función de las emociones que guían los comportamientos y objetivos de los individuos. Realzan, incluso, en este proceso emocional, la regulación de las emociones, asociadas positivamente a estrategias de coping constructivas, tales como las estrategias enfocadas en la resolución de problemas, y asociada negativamente con las estrategias menos adaptativas, como la evasión, la negación y la ventilación.

Destacan que una persona emocionalmente inteligente afronta el estrés de una forma eficaz, dando como resultado capacidades emocionales básicas, de un buen conocimiento emocional y de una regulación emocional igualmente eficaz.

En términos psicoterapéuticos, señalan que para ayudar a las personas a afrontar experiencias estresantes, éstas deben tener conciencia de sus sentimientos y necesidades, en el sentido de aceptarlos y expresarlos, y recurrir a los mismos, como guías para la emoción. Presentan resultados terapéuticos positivos, en la medida en que demuestran que el proceso emocional y su expresión facilitan a los individuos el afrontamiento eficaz de experiencias traumáticas y estresantes, tales como padecer cáncer o abuso sexual.

Las reacciones intensas a acontecimientos de vida negativos también se pueden interpretar como una indicación de la dificultad del acontecimiento que incrementa a su vez, los sentimientos de desesperanza. Los autores realzan que la atención atribuida en exceso, maneja la asimilación del negativismo de los acontecimientos que viven. Teniendo en consideración las diferencias individuales, concluyen que la IE puede ayudar a algunas personas con falta de autocontrol.

La percepción de IE está asociada al coping adaptativo, a la disminución del cortisol y a una mejor habituación ante la presencia repetida de estresantes.

El coping antecedido de emoción, puede inducir a la capacidad de controlar la intensidad emocional de las situaciones negativas, o sea, al despertar las emociones la persona maneja más eficazmente la situación.

Revelan que el rasgo de la IE modera la relación entre experiencias estresantes en la vida y la salud mental.

Defienden el papel moderador de la IE en la relación entre el distrés psicológico y la satisfacción en la vida, estando positivamente relacionada con la satisfacción en la vida y negativamente con el distrés psicológico. Afirman que el efecto moderador significativo de la IE indica que los sujetos con altos niveles de IE tienden a evaluar su satisfacción en la vida de forma más positiva frente a experiencias estresantes. 
La pertinencia de las capacidades inherentes al constructo de la IE se pone en evidencia en la adaptación sana a acontecimientos o situaciones estresantes, los modelos que se describirán posteriormente son los soportes teóricos de esta misma adaptabilidad al estrés, por medio de las capacidades desarrolladas por personas emocionalmente inteligentes.

\subsubsection{Modelo de la relación entre la autopercepción de inteligencia emocional y}

estrés de Gohm, Corser, y Dalsky (2005)

La relación entre IE objetiva y estrés como sentimientos de control, ha llevado a la creación de modelos de acceso a la autopercepción de esta relación (Ciarrochi et al., 2002; Matthews \& Zeidner, 2000). Gohm, Corser, y Dalsky (2005) han adecuado el modelo de Mayer y Salovey (1997) a situaciones de estrés. De esta forma, describen esta adaptación a lo largo de las dimensiones del referido modelo (Tabla 7).

Tabla 7: Modelo de la Relación entre la Autopercepción de IE y Estrés de Gohm, Corser, y Dalsky (2005)

\begin{tabular}{ll}
\hline Dimensión & \\
\hline Percepción de nuestras emociones & La percepción de cómo nosotros y los otros sentimos se relaciona con los \\
y de los otros & sentimientos intensificados de habilidad para soportar diversas relaciones \\
& entre la persona y el ambiente, este componente informativo de las \\
& emociones actúa como fuente de información importante en múltiples \\
& situaciones. Por ejemplo, al sentir miedo recogen otros datos, como una \\
& información relevante en la situación que implica afrontamiento, esta \\
percepción del miedo emite una señal para indicar que otras estrategias & alternativas pueden ser más ventajosas.
\end{tabular}

Usar la emoción para facilitar el pensamiento

Comprender la emoción
Esta capacidad implica el uso de la emoción para enfocar la atención, y para pensar de forma más racional. A través de esta perspectiva funcional, las emociones pueden indicar aspectos del ambiente que requieren atención inmediata. Al ignorar estos aspectos (menos IE), se puede iniciar una adaptación ineficaz de la situación. Estas inadaptaciones surgen con frecuencia, lo que lleva a las personas a asumir que no tienen control sobre sus vidas, intensificando de este modo las fuentes de estrés.

Es la capacidad para etiquetar las emociones, comprender cómo las emociones se interrelacionan, comprender el significado de las emociones, y la forma de asociarlas, progresar o transitar entre ellas. Al conocer el origen de las propias emociones, y las emociones que esperamos desarrollar, se asocian los sentimientos de predictibilidad y control. Este conocimiento puede indicar si el distrés sentido en situaciones que surgen frecuentemente, es normal, natural y pasajero. 
La capacidad para regular las propias emociones y las de los otros consiste en ser capaz para subdividir o dirigirse a experiencias emocionales, lo que remite a sentimientos de autocontrol. Regular las emociones del otro remite igualmente a sentimientos de control situacional. Esta dimensión se asocia a la satisfacción y a la calidad de la ligazón personal en las relaciones sociales, y del soporte que reciben de las mismas. Esta perspectiva, se asocia a menos estrés, teniendo en cuenta la influencia de las diferencias individuales. Sin embargo, poseer esta capacidad no indica que la persona la utilice, y muchas personas saben también manejar su estado de humor pero no ponen en práctica este conocimiento. A este nivel se debe considerar la importancia de las diferencias individuales en esta relación entre el estrés y la IE.

\subsubsection{Modelo dinámico del afecto (MDA) de Zautra, Smith, Affleck, y Tennen} (2001)

Durante mucho tiempo las emociones fueron vistas como una función adaptativa en períodos de estrés (Folkman \& Lazarus, 1985; Frijda, 1988; Levenson, 1988). Bajo este principio, los autores enfocan los efectos de las emociones positivas como promotores de flexibilidad de pensamiento y en la resolución de problemas, obstruyen los efectos de las emociones negativas, facilitan el coping adaptativo y apoyan la construcción de fuentes sociales de protección. La importancia de las emociones positivas en la adaptación eficaz se pone en evidencia en el Modelo Dinámico del Afecto (MDA) de Zautra, Smith, Affleck, y Tennen (2001). Este modelo propone que la adaptación emocional regula psicológicamente el distrés. De esta forma el MDA tiene en consideración las emociones negativas, pero, igualmente, las positivas en el proceso de estrés, prediciendo que bajo circunstancias agresivas las emociones negativas y positivas son relativamente independientes, verificándose durante el encuentro estresante, una correlación inversa entre las emociones positivas y negativas. En otras palabras, las emociones positivas disminuyen las negativas en las situaciones de estrés elevado. El modelo defiende incluso que, un déficit relativo en la experiencia emocional positiva, hace a los individuos más vulnerables a los efectos del estrés. En términos de 
la aplicación del modelo en la investigación, se llega a la conclusión de que la experiencia de emociones positivas se apoya en el cambio y en la adversidad, contribuyendo de esta forma a la resistencia y adaptación, interrumpiendo la prolongación de las emociones negativas en períodos de estrés. El trabajo empírico y teórico revela que las emociones positivas asumen una función protectora y reestructuradora, protegiendo a los individuos de las emociones negativas, y de las consecuencias y/o efectos de las mismas (Ong, Bergeman, Bisconti, \& Wallace, 2006).

Affleck y Tennen (1996) demuestran que los individuos resilientes, tienden a caminar hacia estrategias de coping que promocionan la emoción positiva para la regulación de experiencias emocionalmente negativas. A través de esta evaluación positiva, se da la búsqueda de beneficios, de humor, de la atribución de un significado positivo a acontecimientos adversos, y del coping enfocado en el problema y la creación de objetivos directivos. Fredrickson, Tugade, Waugh, y Larkin (2003) asocian la resiliencia, a beneficios psicológicos en el afrontamiento de las crisis diarias, este rasgo se relaciona incluso con una mayor satisfacción de vida, optimismo y tranquilidad. Afirma que las emociones positivas, incrementan la resiliencia frente a los estados de humor depresivos y las crisis.

\subsubsection{Teoría construida y amplia de las emociones positivas de Fredrickson} (1998)

Los investigadores del coping estudian la utilidad de las emociones positivas en contextos estresantes (Tugade \& Fredrickson, 2004). Se asocia a estas investigaciones la Teoría Construida y Amplia de las Emociones Positivas de Fredrickson (1998), que defiende que las emociones positivas y negativas tienen funciones adaptativas distintas y complementarias, así como efectos psicológicos y cognitivos. En este sentido, las emociones negativas describen reportorios momentáneos de pensamientos-acciones de 
las personas, preparándolas para un camino específico (ej., atacar cuando siente rabia, escapar cuando siente miedo). Para Fredrickson (2000), la clave es la parte "construida" del modelo, en la cual a través de las experiencias de emociones positivas se revelan antecesores construidos por sus fuentes personales, incluyendo las fuentes físicas (ej., la capacidad para manejar mejor al predador), las fuentes intelectuales (ej., un mapa cognitivo detallado para orientación), y las fuentes sociales (ej., alguien a quien pedir ayuda). Sugieren que las emociones positivas son esenciales desde el inicio del desarrollo infantil. El autor señala que las emociones positivas sirven para múltiples propósitos en la vida, como si la "búsqueda de la felicidad" no fuera un reflejo de que las emociones positivas son reconfortantes. Este tipo de emociones iluminan el camino de que los humanos en su vida diaria tienen que desplegar emociones positivas, para mejorar su salud y bienestar.

En este ámbito, existen críticas al modelo. Brackett y Salovey (2007) refieren la necesidad de la comprensión de la selección de estrategias de afrontamiento adaptativo de personas con alta IE para los diferentes tipos de situaciones, señalando el impacto inmediato de eventos negativos de la vida. Matthews y Zeidner (2000) realzan la poca evidencia en los estudios en el área del estrés que refuerce la idea de que individuos con problemas de vida graves puedan ser diferenciados en un continuo de IE. Franco (2007) rechaza esta idea de investigación futura, al realzar que los estudios de validez predictiva no han conseguido correlacionar la IE con datos y testimonios reales de vida, enfatizando que la forma de recogida de datos debería ser más ecológica, o sea, en los contextos de vida de los sujetos.

\subsubsection{Coping, inteligencia emocional y salud}

La relación entre coping y los resultados adaptativos, como tener salud física y psicológica han ganado cada vez más relieve (Lazarus, 1993). De acuerdo con 
Matthews y Zeidner (2000), el coping eficaz se considera como un componente central de la IE. Salovey, Detweiler-Bedell, Detweiler-Bedell, y Mayer (2000) destacan que las investigaciones que relacionan la IE con el coping, en sucesos estresantes y de autorregulación, han sido prometedores. Tomando en consideración la imposibilidad de anular acontecimientos pasados, el coping desarrollado en estas situaciones vividas se vuelve el centro de comprensión del acontecimiento, así como la forma de reinterpretarlo de un modo más significativo. En estos casos, las emociones presentan un papel fundamental, en la medida en que los sujetos responden a estas emociones intensas recurriendo a acontecimientos de vida pasados. El coping adaptativo, remite a competencias emocionales, pues el déficit en estas competencias lleva a una interferencia en el desarrollo e implementación de estrategias complejas de coping, como la regulación emocional. Corroborando lo expuesto, para Matthews y Zeidner (2000) el coping adaptativo se conceptualiza como IE a través de la acción, maestría en el soporte emocional, crecimiento emocional y en la diferenciación cognitiva y emocional presentes en los cambios constantes de la vida. De este modo, los sujetos emocionalmente inteligentes afrontan de un modo más eficaz las experiencias negativas y estresantes. Así, la IE se tiene en cuenta como una cualidad de la persona, al presentar una serie de competencias para resolver eficazmente cualquier situación, las cuales permiten prever resultados adaptativos futuros (por ejemplo, transferibilidad). En este sentido, estas competencias se encuentran en la memoria a largo plazo, lo que implica que la IE puede ser alterada y aprendida a través del entrenamiento en comportamientos adaptativos. En situaciones de cambio o exigencia estas competencias influyen en la selección y control de las estrategias de coping dirigidas a la situación inmediata. La regulación del coping se realiza a la par de sus cogniciones de autorreferencia, como el significado personal de los acontecimientos y con el estímulo interno 
(metacogniciones). Una mala adaptación se puede observar a través de la pérdida de la obtención de una dirección significativa, distrés subjetivo, adquisición de creencias y comportamientos autodestructivos, y problemas de salud.

La investigación sobre la regulación emocional ha alcanzado un lugar significativo realzando la pertinencia del proceso emocional en la promoción de adaptación, específicamente en la adaptación a la enfermedad (Cameron \& Jago, 2008). Reardon y Buck (1989), sugieren que cualquier análisis de coping con la enfermedad tiene que tener en cuenta el proceso lógico y racional utilizado para monitorizar la emoción, y definen los estilos de coping como racional y emocional, porque el proceso de coping da como resultado el desarrollo de las normas del fenómeno emocional. Estas normas se mantienen o alteran de acuerdo con el feedback recibido por el propio cuerpo y por la comunicación con los otros.

Para Salovey (2001) la IE es una fuente de motivación en la inteligencia de la autorregulación, porque los sujetos que presentan conocimiento y competencias emocionales, tendrán de una forma facilitada el proceso de autorregulación orientado hacia sus objetivos. Al abordar la IE en el proceso de regulación, destacan las situaciones traumáticas del pasado que no pueden ser modificadas, pero que pueden ser trabajadas a través de estrategias de coping que se dirigen a un conocimiento y a una reinterpretación con más significado de estas mismas situaciones, orientando a un coping ante la memoria. En este sentido, el éxito del coping resulta de la operación integral de una serie de competencias emocionales, donde su déficit en la percepción o expresión emocional, interfiere con el desarrollo e implementación de las estrategias de coping más complejas, como por ejemplo, la regulación emocional. Concluye que los individuos con competencias emocionales significativas, afirman ser capaces de reconocer sus respuestas emocionales como naturales ante el trauma, asumir sus 
emociones y traumas como parte integrante de su vida, y realizar atribuciones positivas sobre el trauma y sus emociones.

\subsection{Coping y significado}

La experiencia humana se construye a través de las historias de vida, viviendo las historias, y no por las estadísticas. Al reflexionar, interpretar y reinterpretar lo que sucede en nuestras vidas, y al contar y recontar nuestras historias a otras personas y a nosotros mismos, desarrollamos la continuidad de nuestra autoría vivencial, cargada de significado personal (Gonçalves, 2002). Este significado personal se eleva como una necesidad psicológica, para encontrar un sentido y propósito en la vida, siendo que el encuentro da como resultado una orientación, en la formulación de objetivos y en la facilidad del afrontamiento de las experiencias, inclusive, las más estresantes (Frankl, 2006).

A su vez, el mantenimiento de objetivos es fundamental para ser capaz de encontrar sentido, porque un sistema de objetivos permite mantener la esperanza que compone substancialmente los significados asociados al bienestar (Feldman \& Snyder, 2005). El cumplimiento de los objetivos personales se muestra más difícil frente a acontecimientos de vida negativos, poniendo en jaque el bienestar mencionado (Emmons, Colby, \& Kaiser, 1998). Tal como refiere Folkman (2001), el encuentro de significado minimiza esta dificultad para concretar los objetivos personales, como también el encuentro de beneficios en experiencias negativas favorece la relación con el estrés, en la medida en que un afrontamiento adaptativo y el humor positivo permiten la realización de una evaluación positiva, favoreciendo una reformulación cognitiva de la situación que, consecuentemente, lleva a perspectivas positivas. En su modelo, la autora describe esta reformulación como un estilo de coping basado en el significado, donde emerge la atribución de significados específicos a la situación. 
En el ámbito de la salud, señalan un estudio realizado con enfermos VIH positivo, revelando que los pacientes que le encontraban un significado a su situación, tenían más cuidados personales, espiritualidad, brindaban más ayuda a otros y mantenían mejores relaciones con los cónyuges, familiares y amigos, entre otros. Thompson (1991) alude al trabajo de psicólogos sociales que evalúan la relación de los sujetos con acontecimientos de vida traumáticos, como el diagnóstico de una enfermedad grave o ser víctima de un crimen, fundamentándose en teorías de adaptación a acontecimientos negativos, las cuales enfatizan la importancia de las cogniciones, atribuciones e interpretaciones en el proceso de adaptación. Los acontecimientos suscitan alteraciones en la robustez, sentido en la vida, autocontrol y autoconcepto llevando a que el individuo busque significado, recuperando el sentido de que su vida es significativa y que pese a las infelicidades que ocurren en la vida, continúan siendo buenas personas.

Davis, Wortman, Lehman, y Silver (2000) investigaron la busca de significado en la pérdida de un hijo o cónyuge. Las pérdidas, caracterizadas como inesperadas y traumáticas, normalmente llevan a una búsqueda persistente de alguna razón, explicación o significado en su pérdida. En esta misma área de estudio, Gillies y Neymeyer (2006) llegan a la conclusión de que encontrarle un sentido es importante para un ajuste psicológico adaptativo cuando se obtiene rápidamente tras el evento, como también encontrar o reconstruir sentido al duelo adaptado, a un mundo alterado, a una adaptación en los dominios sociales, actitudinales, psicológicos y fisiológicos. Los autores proponen que las personas se involucran en tres grandes actividades en la reconstrucción de sentido como respuesta a la pérdida: atribuirle sentido, encontrar beneficios y alterar la identidad. Con respecto a tener sentido, Neimeyer (2001) refiere que las pérdidas más difíciles son aquellas a las que les falta el sentido, y que llevan a cuestionar todo lo que ha tenido significado. Encontrar beneficios es descrito en las 
teorías cognitivas y de coping, como una evaluación positiva que direcciona un papel adaptativo al acontecimiento. Los autores agregan que esta adaptación depende de la madurez personal y de los recursos sociales. Concretamente la alteración de la identidad, como respuesta a la pérdida, se refiere a la reconstrucción del sentido en nuestras vidas, que lleva necesariamente a la reconstrucción de nosotros mismos. Con respecto a la alteración de identidad, Tedeschi, Park, y Calhoun (1998) refieren que el dolor y la culpa son sentimientos esperados en la experiencia, que llevan a que ocurran transformaciones positivas y originan el fenómeno al que llaman "crecimiento postraumático", siendo prevalente en las personas que reaccionan a la pérdida de forma adaptativa. De este modo, los sujetos que viven este crecimiento, demuestran tener un sentido de sí mismos diferente, se vuelven más resilientes, independientes y confiados, desarrollan igualmente nuevos roles, una buena robustez frente a las fragilidades de la vida, y se hacen menos vulnerables a pérdidas consecutivas. Sus relaciones sociales se alteran, aumenta su capacidad empática, y se vuelven más cercanos emocionalmente a otros. Revelan, incluso, tener experiencias espirituales o un crecimiento existencial.

La importancia del significado en el afrontamiento de la pérdida es una línea de investigación reciente, que valora el papel del significado en el coping frente a la pérdida y otros acontecimientos altamente estresantes. La construcción teórica de este tema crea un modelo conceptual común, descrito por múltiples autores, por ejemplo, el sujeto posee una serie básica de creencias y objetivos globales que resultan de la esencia de un propósito o significado de vida, siendo éste el sistema global de significado. Cuando un sujeto se enfrenta a un potencial estresor, le atribuye un significado, haciendo, de esta forma, una evaluación de significado. Por consiguiente, esta evaluación de significado depende del sistema global de significados del sujeto, que determinará la experiencia de humor negativo (distrés), vivida en cada acontecimiento. 
Este humor negativo lleva a la necesidad de atribución de significado, emergente paralelamente al sistema global de significado. A su vez, este sistema se apoya en el control de los cambios en una situación significativa (asimilación) que ocurre con menos frecuencia, cuando no altera el significado global (acomodación). En este sentido, la existencia de discrepancias reducidas entre el significado global y la situación, conlleva una mejor adaptación (Park, 2008).

En la evolución teórica sobre el afrontamiento de situaciones estresantes, surgen algunos autores que argumentan que el Modelo Transaccional de Estrés y Coping (Lazarus \& Folkman, 1984), presenta limitaciones en el estudio de traumas significativos y de situaciones de pérdida (Mikulincer \& Florian, 1996). En esta critica está subyacente la idea de que con respecto a los acontecimientos de los problemas que no se pueden resolver, las estrategias de coping implican una interacción eficaz entre procesos cognitivos intra psíquicos o "significado", con el pensamiento de adaptación cognitiva, a través del cual los individuos pueden transformar el significado de las experiencias estresantes (Park, 2005). Esta conceptualización del coping es más fácil de entender a través del beneficio de alguna introspección, remitiendo al encuentro de significado. En este ámbito, Folkman (2008) refiere que el modelo original, el Modelo Transaccional de Estrés y Coping, no es suficientemente explicito cuando el resultado es negativo/desfavorable para el sujeto, excepto cuando el proceso de evaluaciónemoción-coping-reevaluación se repite, produciendo así las condiciones para el estrés crónico. Teniendo en cuenta este aspecto negativo, cuando las situaciones no son resueltas de forma favorable, en la revisión más reciente del modelo introduce una nueva categoría de coping, el enfocado en el significado, y las emociones positivas. De esta forma, el modelo sugiere que, después de una resolución fracasada, surge la necesidad de una nueva tentativa activa de coping enfocado en el significado. La autora 
lo describe como específico para la creación de emociones positivas y de sus evaluaciones subyacentes. En este sentido, estas emociones y evaluaciones influencian el proceso de estrés a través del restablecimiento de los recursos de coping y de la promoción de la motivación necesaria para mantener el coping enfocado en el problema a largo plazo. Para ella las emociones positivas promueven el alivio en el distrés. La autora presenta su revisión al modelo original en la Figura 4.

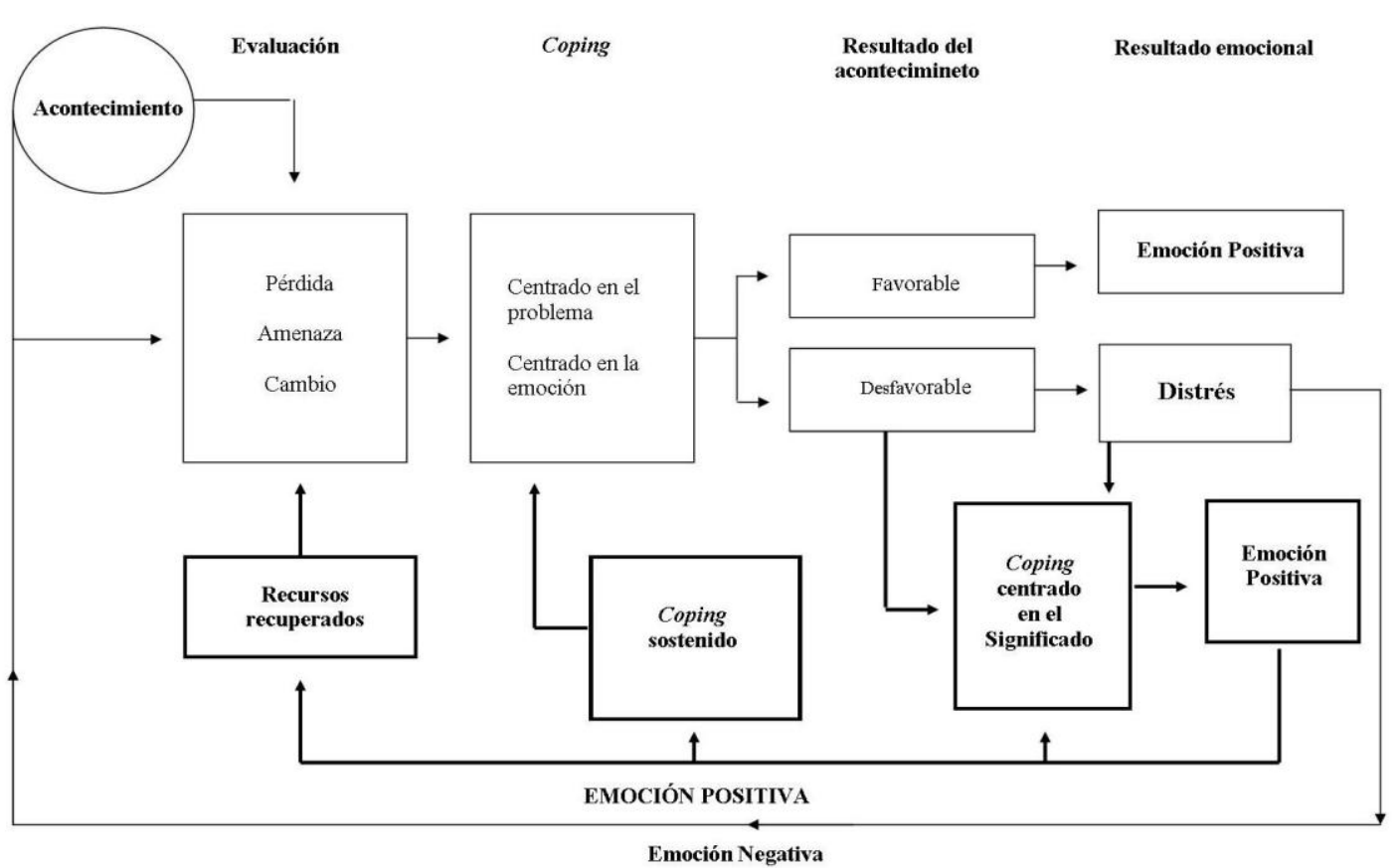

Figura 4: Modelo de Estrés y Coping de Lazarus y Folkman revisado (adaptado por Folkman, 1997)

El Modelo de Coping de Atribución de Significado en Acontecimientos Estresantes de Park (2005) se basa en el Modelo de Atribución de Significado (Park \& Folkman, 1997) descrito anteriormente. Este modelo tiene en cuenta situaciones estresantes y las estrategias de coping desarrolladas, teniendo como base la reevaluación de estas situaciones. En este sentido, este modelo refiere que el significado evaluado de los acontecimientos incluye evaluaciones de pérdidas, amenazas o cambios. Así, son estas atribuciones iniciales las que explican el porqué de la ocurrencia de los acontecimientos, la determinación de su continuidad discrepante con el sistema global 
de significado, y las decisiones tomadas frente a lo que se puede hacer para afrontar el acontecimiento (Figura 5).

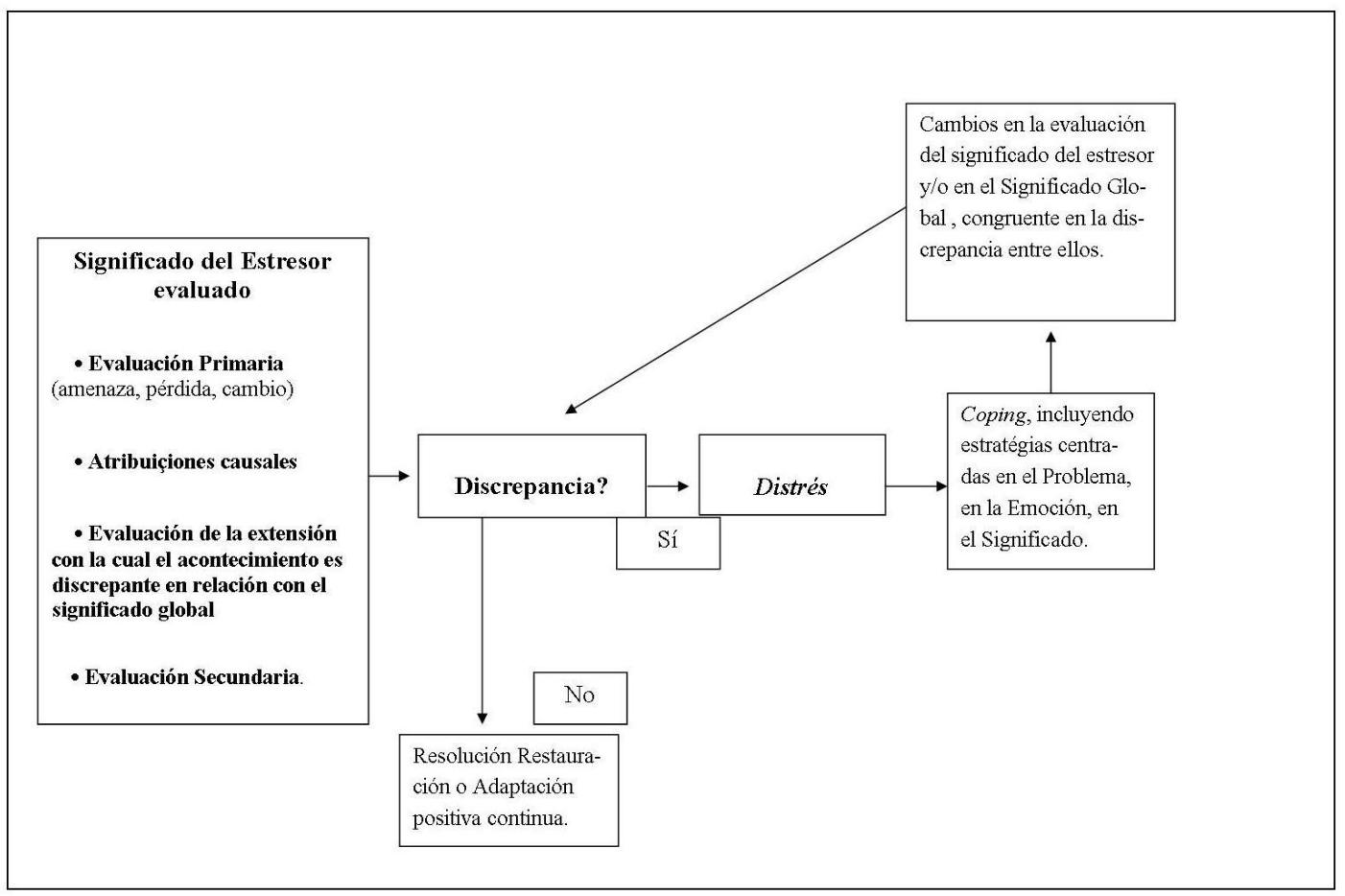

Figura 5: Modelo de Coping de Atribución de Significado en Acontecimientos Estresantes (Park, 2005)

El modelo constituye una ampliación del Modelo Transaccional de Estrés y Coping (Lazarus \& Folkman, 1984), reforzando los aspectos dinámicos del coping de atribución de significado, siendo importante en situaciones irreversibles o irresolubles, como un trauma o una pérdida. Este modelo realza la interacción entre las evaluaciones situacionales, las creencias y objetivos globales de las personas, y su influencia para reevaluaciones más positivas (Park, 2005).

La pertinencia de la influencia religiosa también se incluye en este modelo, en la medida en que la atribución de significado en algunos acontecimientos implica un cambio en los sistemas de fundamentos filosóficos, religiosos o existenciales, o la construcción de jerarquías de objetivos drásticamente alteradas. A través de su investigación, Park (2008) asocia el tipo de significado religioso al estilo de coping de 
atribución de significado, porque se refleja en la reevaluación del coping positivo, y en la adaptación a nivel del bienestar subjetivo y en el crecimiento relacionado con el estrés. Concluye que, esta asociación entre la religión y la adaptación es mediada mediante la reevaluación positiva en el coping. De esta forma, el significado religioso ofrece influencias fuertes y diversas en el bienestar de los individuos, siendo de extrema importancia el papel de la religión a lo largo del desarrollo humano, y en el afrontamiento de las experiencias estresantes de la vida de las personas. La influencia religiosa es igualmente enfocada por Folkman y Moskowitz (2004), al señalar que las personas usan específicamente la religión para afrontar las exigencias inmediatas de los acontecimientos estresantes, especialmente para encontrar fuerza para continuar creando objetivos y significado en las circunstancias que alteran sus creencias. En general, Park (2005) refiere que varios aspectos religiosos ejercen influencia en lo cotidiano e, incluso, en el contexto del afrontamiento de la adversidad, fomentando el bienestar psicológico.

A través de este modelo se remite a la interacción entre el significado y la adaptación que se aprende cuando las personas se cuestionan sobre las narrativas de acontecimientos estresantes, incluyendo lo que ocurrió, las emociones que vivieron, y lo que pensaron e hicieron cuando ocurrió la situación. De esta forma, las aproximaciones narrativas apoyan la comprensión de lo que las personas afrontan, principalmente, cuando el acontecimiento estresante no es un acontecimiento específico designable para el investigador. Muchos investigadores consideran el coping enfocado en el problema y en la emoción como un buen punto de partida, pero consideran igualmente que el coping enfocado en el significado es un tipo diferente de coping, a través del cual las estrategias cognitivas son utilizadas para manejar el significado de la situación (Park, 2005). 


\subsubsection{Coping, inteligencia emocional y significado}

Existen diferencias individuales en las capacidades humanas para representar cognitivamente sus emociones y ejercer un control efectivo en sus vidas emocionales, prolongando el manejo de sus emociones durante situaciones estresantes, siendo posible que el conocimiento y uso efectivo de las emociones positivas, puedan proveer ventajas en el proceso de coping (Salovey, Hsee, y Mayer, 1993). Se revela, en este sentido, la preponderancia de la IE en la vida de personas resilientes, destacando que lo que distingue a la persona resiliente es su capacidad para aprender con el revés de su vida y utilizar el conocimiento derivado de la experiencia para afrontar más eficazmente otras situaciones (Salovey et al., 1999). Fredrickson (2000), refuerza la idea anterior al relacionar el conocimiento con la obtención de bienestar cuando se encuentra un significado positivo para la situación, por ejemplo, a través de beneficios o de aprendizajes. Los beneficios del coping revelan la construcción de los efectos de las emociones positivas, incrementando la búsqueda de significado positivo en circunstancias estresantes. En este ámbito, el autor subraya la pertinencia de la relación recíproca entre el significado positivo y las emociones positivas, ya que un significado positivo no sólo alcanza la emoción positiva, sino que, igualmente, a las emociones positivas, porque construyen el pensamiento, induciendo, a su vez, a la probabilidad de encontrar un significado positivo a los acontecimientos subconsecuentes.

La emoción surge como respuesta a un acontecimiento, ya sea interno o externo, que creará un significado positivo o negativo para el sujeto. Para Fredrickson (2000), un proceso emocional se inicia con el acceso individual al significado personal antecedente a algún acontecimiento, relacionándose con el concepto de relación persona-ambiente el encuentro adaptativo, propuesto por Lazarus (1991). 
Con respecto a esta relación sujeto-medio, Basabe et al. (1989) refieren que la experiencia emocional es producto de una activación fisiológica indiferenciada, cuya cualidad afectiva está definida mediante las creencias, etiquetas verbales e indicadores atribuidos por el contexto en que se encuentra el sujeto. Los autores afirman que una respuesta emocional se puede considerar, a nivel intra psíquico, como un esquema dotado de afectividad o como un escenario de interacción con fuertes repercusiones afectivas. En su conjunto, la activación emocional seria preatencional, inconsciente, y automática. Para Greenberg y Zafran (1989), lo que sería consciente consistiría en un producto final compuesto por la combinación del acontecimiento activador de la reacción expresivo-motora innata, de la activación de la memoria esquemáticoemocional, y de los procesos conceptuales de atribución de significado.

Las crisis en la vida son reconocidas como "puntos de mudanza" y momentos de oportunidades a la par del riesgo, prevaleciendo una promoción de crecimiento (Caplan, 1964). Segundo Schaefer y Moos (1992), las crisis en la vida orientan a enfrentamientos constructivos, defienden que el crecimiento personal surge en la disrupción que la crisis genera y en su reorganización subsecuente. A través del proceso de afrontamiento se promueve la diferenciación cognitiva, autoconfianza, y una mayor proximidad a la vida. Los sujetos que vivencian la perdida y dolor desenrollan una mayor comprensión y empatía por otros con problemas semejantes, bien como la exposición a nuevas situaciones de crisis que alteran la perspectiva personal, promoviendo nuevas capacidades de coping y proporcionan nuevos recursos personales y sociales. Los acontecimientos de vida negativos crean cambios a nivel cognitivo $y$ de comportamiento, y llevan a una revisión de objetivos de vida y reorientación en los valores y creencias. Los autores aseguran que estos cambios en la vida modifican 
igualmente el estado de recepción emocional, volviendo al sujeto más sensible a su contexto y más abierto a nueva información e ideas.

En este ámbito, presentan un Modelo Conceptual de Comprensión de Resultados Positivos en Crisis o Transiciones de Vida (Schaefer \& Moos, 1992), creado con el objetivo de analizar los determinantes que benefician las consecuencias de las crisis o transiciones de vida. Subdividirán en dimensiones los determinantes, así en la primera y segunda dimensión se encuentra el sistema envolvente/medio y el personal respetivamente. El sistema envolvente está compuesto por los aspectos personales en su contexto de vida, como el nivel financiero, doméstico, comunitario y por las relaciones afectivas. El sistema personal incluye las características sociodemográficas, algunos recursos personales, como la capacidad cognitiva, estado de salud, motivación y autoeficacia. La tercera dimensión se refiere a las características de la crisis o transición de vida. Las respuestas de coping componen la cuarta dimensión, discriminando en tres tipos: coping enfocado en la evaluación que incluye los esfuerzos para definir, interpretar y comprender la situación. El coping enfocado en el problema, remite a los esfuerzos para resolver o gestionar los estresores procurando información, teniendo acciones directas y encontrando alternativas. El coping enfocado en la emoción incluye la gestión de reacciones emocionales ante el estresor, regulando los propios sentimientos, la expresión de la rabia y la aceptación de la situación. Tales estilos de coping son afectados por las otras tres dimensiones, y la relación entre todas las dimensiones promueve resultados positivos (quinta dimensión). Los resultados aparecen a nivel de los recursos sociales, como el desarrollo de relaciones de confianza, mejores relaciones con familiares y amigos, y la formación de nuevas relaciones y contactos. A nivel de recursos personales, destacan el aumento de la diferenciación cognitiva e intelectual, la autocomprensión, la empatía, el altruismo y la madurez, y los cambios en 
los valores y en las prioridades básicas. Y, por último, a nivel del desarrollo de nuevas capacidades de coping, como estrategias cognitivas de coping, resolución de problemas y autoayuda, y la capacidad de regulación y control afectivo. 
Satisfacción con la vida 


\section{SATISFACCIÓN CON LA VIDA}

La satisfacción con la vida (SCV) hace referencia a la evaluación global del sujeto de cara a su vida y a su felicidad, a través de la cual pondera los afectos positivos (frecuencia de emociones positivas) y los afectos negativos (frecuencia de las emociones negativas) en la experiencia inmediata (Keyes, Shmotkin, \& Ryff, 2002). A su vez, Cavanaugh (1994) define la SCV como la medida de "cuán felices están las personas con su vida actual" (p. 763). En otras palabras, indica cuán próximo o distante se percibe el sujeto de sus aspiraciones, pudiendo englobar también la satisfacción del sujeto a nivel de salud, familiar y social.

La SCV cambia significativamente de persona para persona, dependiendo de las expectativas y ambiciones personales. Las personas tienden a reaccionar de forma diferente ante situaciones idénticas, aunque influenciadas por sus valores, experiencias y expectativas. Al evaluar su grado de SCV, el individuo se encuentra evaluando de forma global sus condiciones de vida. En este sentido, la satisfacción refleja una comparación entre los objetivos conquistados y los objetivos deseados, o entre una situación real y una situación deseada (Caspi \& Elder, 1986).

La SCV se revela como una variable de la psicología positiva, así como el bienestar subjetivo (BES) y el bienestar psicológico (BEP), la felicidad y la calidad de vida (CDV). Estos conceptos son frecuentemente concebidos y empleados como sinónimos debido a la correlación significativa existente entre ellos (Veenhoven, 2000). En este mismo sentido, Sirgy (2002) destaca que la CDV incluye aspectos subjetivos, tales como el afecto positivo y negativo, la felicidad, la SCV, el BES y la percepción de CDV. A su vez, Pais-Ribeiro (2012) señala que la felicidad es un constructo semejante al BES. Como Snyder y Lopez (2004) que definen la felicidad como un estado emocional positivo definido de forma subjetiva por el sujeto y es utilizado como 
sinónimo de BES, concepto que se emplea a nivel científico. Para Veenhoven (1997), la felicidad es el grado según el cual la persona evalúa la CDV positivamente de forma global, o sea, cuánto le gusta su vida. De acuerdo con Díaz-Llanes (2001), la investigación sobre el BES surgió de la ampliación del concepto de CDV. Este último, es un constructo multidimensional y amplio que engloba aspectos del BEP y el bienestar social, del funcionamiento emocional, de la condición de salud, del desempeño funcional, de la SCV, del soporte social y del estilo de vida (Barros, Gropo, Petribú, \& Colares, 2008). Huebner, Seligson, Valois, y Suldo (2006) añaden que con el objetivo de evaluar la subjetividad de la CDV, se recurre con frecuencia a la SCV. Finalmente, Diener, Oishi, y Lucas (2003) entienden el BES como lo que las personas denominan felicidad, satisfacción o placer en la vida, contribuyendo a la comprensión y mejoría de la CDV de las personas.

\subsection{Satisfacción con la vida e inteligencia emocional, significado y coping}

La SCV es uno de los tres componentes integrantes del BES. Diener, Oishi, y Lucas (2009) lo definen como "las evaluaciones cognitivas y subjetivas que la persona hace acerca de su vida en general” (p. 187). En este sentido, según Diener (2000, 2009), el BES se compone de tres factores asociados, el afecto positivo, el afecto negativo y la SCV. Los dos primeros se presentan como respuestas afectivas y la SCV remite a respuestas evaluativas cognitivas. La dimensión afectiva integra el afecto positivo y el afecto negativo. El afecto positivo revela el grado de motivación de la persona, activa y vigilante, así como si siente alegría, gratitud, esperanza y orgullo (Diener, Suh, \& Oishi, 1997). El afecto negativo, a su vez, se relaciona con la angustia e insatisfacción, y contiene estados de humor negativos como la rabia, culpa, disgusto y el miedo. Por consiguiente, la dimensión de evaluación cognitiva revela la SCV a través de la cual el sujeto evalúa su propia vida, incluyendo los aspectos racionales e 
intelectuales. La evaluación puede realizarse de modo global, cuando se tiene en cuenta la vida como un todo, pero puede, igualmente, ser específica, cuando remite a dominios como la familia, la escuela, entre otros (Diener, 2009).

En este caso, el nivel de SCV es susceptible de ser un regulador emocional, tanto si las emociones son positivas como negativas, estas aumentan o disminuyen de acuerdo con los pensamientos del sujeto (Diener et al., 1997). La investigación del constructo de la felicidad ha reforzado el conocimiento científico sobre la dimensión positiva de las emociones humanas y de la CDV, en el sufrimiento humano (Galinha \& Pais-Ribeiro, 2005). De acuerdo con lo expuesto, se considera esencial el uso inteligente de nuestras emociones para la adaptación física y psicológica, en la medida de que cuanto mayor sea la IE mayor será la estabilidad emocional, tolerándose mejor la frustración al verse capaz de controlar los estados de tensión así como el comportamiento de uno mismo en situaciones adversas, llevando a la relación positiva entre IE y bienestar (Zaccagnini, 2004). En esta misma línea de pensamiento, González, Fernández-Berrocal, RuizAranda, y Extremera-Pacheco (2006), señalan que las capacidades de regulación emocional son pronosticadoras de efectos positivos para la mejoría de los demás contextos del funcionamiento personal, social y profesional, tales como una mejor calidad de las relaciones sociales y de BES.

No obstante, la autorregulación se clarifica a través del papel de los significados globales del sujeto que llevan a la atribución de un significado a acontecimientos estresantes y a la acciones subsecuentes (Schroevers, Kraaij, \& Garnefski, 2008). En este sentido, la Teoría de la Autorregulación de Carver y Scheier (2000) propone que las personas se empeñan en una asociación a sus objetivos personales y que de forma continua comparan si estos se acercan a lo que desean. Los objetivos conceden a las personas un sentido de identidad y un significado en la vida, revelando una enorme 
importancia en el BEP. La reducción del mismo surge cuando la persona se enfrenta a obstáculos en esta asociación con sus objetivos personales. De esta forma, para restaurar el bienestar en varias circunstancias es necesario retirar el esfuerzo y el compromiso de los objetivos inaccesibles y restablecer los objetivos importantes alternativos. Tal adaptación de objetivos se asocia a un mayor bienestar, menos depresión y a un mejor sentido de propósito en la vida (Wrosch, Scheier, Miller, Schulz, \& Carver, 2003). Además del presente proceso acerca del empeño y adaptación de objetivos, la autorregulación contiene también la monitorización del afecto y las estrategias que las personas aplican para regular sus emociones (Carver \& Scheier, 1999). La gestión de estrés es tradicionalmente estudiada por la perspectiva del estrés-coping, mientras que se considera reducida la comprensión de cómo las personas negocian en relación a la adaptación de objetivos.

Diener (2009) presenta en su Modelo sobre el Bienestar Subjetivo o Bienestar Emocional, que las personas al evaluar sus vidas captan la esencia del bienestar y realzan la dimensión subjetiva, donde sólo el sujeto es capaz de indicar lo que le hace feliz y le trae satisfacción en la vida. A su vez, Ryff y Keyes (1995) defienden que, a partir de las descripciones objetivas del sujeto, es posible obtener una mayor comprensión sobre el bienestar. En este punto, las autoras subrayan igualmente la necesidad de abordar el BEP. Según Keyes et al. (2002), el BEP, es la percepción de compromiso con los desafíos existenciales de la vida y un nivel de funcionamiento psicológico positivo activo en los sujetos, asociándose a la adaptación emocional y social adecuada, y a una suficiente madurez personal. En este sentido, cada dimensión del constructo del BEP destaca el recurso interno del sujeto para obtener éxito en los diferentes desafíos existenciales e igualmente, para mantener un funcionamiento lógico positivo. 
Las dimensiones del BEP, según Ryff (1989), hacen referencia a seis componentes distintos del ajuste personal y de la salud psicológica, principalmente, la autoaceptación, las relaciones positivas con los demás, la autonomía, el propósito de vida, el dominio del ambiente y el crecimiento personal. El Modelo de Ryff y Keyes (1995), se basa en una perspectiva de Bienestar Psicológico y Social, y defiende que los seis componentes señalados anteriormente se identifican como los ingredientes del funcionamiento positivo. La autoaceptación se considera la característica central de la salud mental y remite a la autoactuacción, al funcionamiento psicológico positivo y a la madurez. La dimensión de las relaciones positivas con los demás, a su vez, se asocia con la capacidad del sujeto para mantener relaciones interpersonales positivas, o lazos significativos, cálidos y de confianza. Se obtiene tanto con la capacidad de empatía, comprensión y afecto, así como con la capacidad de amar en las relaciones íntimas, mantener amistades e identificarse con los demás, revelando un indicador de madurez. La autonomía se relaciona con la autodeterminación, con el sentido de independencia en varios contextos de la vida y la capacidad de autorregulación del comportamiento mediante pensamientos y acciones asertivas. El dominio del ambiente hace referencia a la capacidad de escoger o crear ambientes satisfactorios, gestionar, controlar actividades complejas en diversos contextos, así como, de modificar situaciones negativas con creatividad. La dimensión del propósito de vida, se basa en la existencia de múltiples propósitos y metas en la vida del sujeto, en un sentido de dirección y en las intenciones que llevan a construir una vida con significado. Un sujeto con propósito en la vida es productivo y creativo, de la misma manera, alcanza una integración emocional en situaciones del presente y del futuro. La última dimensión, el crecimiento personal, se enfoca en el desarrollo continuo del potencial del sujeto, en la posibilidad de crecer y expandirse como persona. De este modo, el sujeto se encuentra ante la mayoría de sus 
potencialidades y al estar abierto a nuevas experiencias no desarrolla sentimientos de estancamiento. Se enfrenta a tareas y acepta nuevos desafíos, resolviendo los problemas que surgen en la vida. Ambiciona alcanzar la autorrealización y presenta un verdadero interés por la vida, queriendo perfeccionar sus conocimientos, competencias y comportamientos.

En este sentido, las personas que pretenden sentirse bien, incluso cuando son conscientes de sus condiciones (Autoaceptación), procuran desarrollar y mantener sus relaciones significativas (Relación con los demás), del mismo modo que tratan de adaptarse a su contexto de forma asertiva (Dominio del ambiente). En este mismo contexto social, busca su sentido de autodeterminación y autoridad personal (Autonomía). Encontrar significado en los esfuerzos y desafíos (Propósitos de vida) resulta crucial en la vida del sujeto, así como, promover sus talentos y capacidades (Crecimiento personal) son componentes centrales del BEP.

Existen seis tipos de modelos teóricos que explican el BES (Casas, 1996; Diener, 1984; Diener, Suh, Lucas, \& Smith, 1999). Las Teorías Finalistas señalan que el bienestar se alcanza cuando se adquiere un estado o situación deseada, enmarcan las Teorías de la Necesidad debido a la satisfacción de las necesidades. Las Teorías Placer - Dolor, que sitúan el bienestar en las combinaciones entre placer y displacer, en la medida en que cuanto mayor es la privación, mayor es el bienestar posterior, es decir, cuando no existe privación no existe posibilidad de sentirse feliz al saciarse. Las Teorías de la Actividad, identifican el bienestar como producto de la actividad humana, dando como resultado la felicidad de las actividades humanas. Si la actividad es fácil en relación a la competencia del sujeto, este se desmotiva, mientras que si es compleja, el sujeto desarrolla una ansiedad beneficiosa para su propia activación. Las Teorías Asociacionistas aluden a que algunas personas presentan un temperamento con 
predisposición a la felicidad, por ejemplo, cómo el sujeto recuerda situaciones emocionales semejantes al momento presente. Las Teorías de Juicio, en las cuales el bienestar es el producto de comparaciones entre situaciones reales y los modelos elegidos por el sujeto. Finalmente, surgen las Teorías Bottom-up versus Top-down.

En el área Bottom-up surgen estudios sobre la influencia de los factores externos, situaciones y variables sociodemográficas en el BES. Considerando este tipo de teorías, se deduce el presupuesto de que las necesidades humanas universales y básicas conducen a la felicidad (Giacomoni, 2004). Diener, Sandvik, y Pavot (2009), añaden que los acontecimientos de vida agradables están asociados al afecto positivo, del mismo modo que, los desagradables se asocian al afecto negativo. En este sentido, la felicidad o el BES resultan de la acumulación de estos momentos y experiencias felices. A su vez, Giacomoni (2004) destaca que de acuerdo con los resultados poco significativos de la influencia de las variables biosociodemográficas en el BES, la investigación se ha orientado hacia una perspectiva del impacto de que estas variables sean mediadas por procesos psicológicos, como metas/objetivos y estrategias de coping.

Teniendo en cuenta las Teorías de Top-down, estas defienden que la interpretación subjetiva del sujeto repercute directamente en su BES, pues al percibir las situaciones y experiencias de vida de forma positiva o negativa, influirá en su evaluación sobre la vida. Este proceso de interpretación es considerado desde tres perspectivas, principalmente, las Teorías de Personalidad, las Teorías de Discrepancia y las Teorías de los Procesos de Adaptación y Coping (Giacomoni, 2004).

Diener et al. (1999) concluyen que la personalidad es un pronosticador importante para el BES, de este modo, la investigación se enfoca en los rasgos de personalidad que se correlacionan más con el BES (por ejemplo el neuroticismo y la extroversión), así como, en qué medida interaccionan con las condiciones de vida (por ejemplo, el 
ambiente). En las Teorías de Discrepancia, como en las de Comparación social, de Aspiraciones Modestas y de Discrepancia en las Metas, los autores destacan la comparación entre los sujetos y las condiciones pasadas, los niveles de aspiraciones, los ideales de satisfacción y las necesidades y objetivos. En este sentido, si los sujetos utilizan un modelo de comparación elevado, sentirán un descenso en su satisfacción y viceversa. Por último, las Teorías de Procesos de Adaptación y Coping remiten a que la adaptación a situaciones sucesivas y el modo de enfrentar experiencias estresantes se presentan como componentes importantes del BES (Diener et al., 1999; Giacomoni, 2002). Según los autores, el proceso de adaptación del sujeto interfiere con el sistema emocional, llevando al sujeto a reaccionar de forma más intensa en acontecimientos recientes y estas reacciones van desapareciendo a lo largo del tiempo. De este modo, por un lado, la adaptación posee un carácter biológico, pasivo y automático. Por otro lado, el coping implica un papel activo del sujeto, encontrándose varias estrategias de coping relacionadas con el BES. En un estudio longitudinal, con los cuidadores de compañeros con VIH, Folkman y Moskowitz (2000) describen tres estrategias de coping significativamente correlacionadas a altos niveles de bienestar, principalmente, el dar significado positivo a los acontecimientos, las reevaluaciones positivas y el coping enfocado en el problema. De este modo, Resende, Silva, Marques, y Abreu (2008) revelan que una situación de enfermedad, como la del VIH no resulta en la percepción de muerte, sino en un nuevo crecimiento personal, en el que las estrategias de afrontamiento son el medio primordial para que el enfermo acepte su condición, viva bien y encuentre satisfacción en la vida.

También en el ámbito de la Adaptación, surge la Teoría Homeostática del Bienestar Subjetivo (Cummins 2000; Cummins, Eckersley, Pallant, Van Vugt, \& Misajon, 2003). El indicador principal del modelo es la SCV y defienden que el BES 
actúa en un nivel abstracto, personalizado y sólo percibido por el mismo sujeto en su evaluación global. Este se evalúa a través de la pregunta “¿Cuánta satisfacción siente en relación a su vida, considerada como un todo?’. La respuesta indica el estado general de BES. En esta medida, para recoger información sobre los componentes de la vida, es necesario recurrir a la evaluación de la SCV en relación a múltiples dominios, pudiendo variar por encima o por debajo del punto homeostático. Esta teoría expresa que cada sujeto presenta un punto de estabilidad propio y su percepción de bienestar se encuentra en un valor normal y específico para sí (Cunnins, 2003).

Tras esta exposición teórica sobre la relación entre la SCV y la IE, cabe destacar los estudios realizados en población general (Augusto-Landa, López-Zafra, Antoñana, \& Pulido, 2006; Extremera, Durán, \& Rey, 2007; Extremera \& Fernández-Berrocal, 2005a; Fernández-Berrocal, Extremera, \& Ramos, 2004; Gannon \& Ranzijn, 2005; Lazzari, 2000; Martínez-Pons, 1997; Palmer, Donaldson, \& Stough, 2002; Salami, 2010; Saklofske, Austin, \& Minski, 2003). Las investigaciones analizan la relación de la IE con la SCV en tres conceptualizaciones distintas. Principalmente, la IE como capacidad, que corresponde a la mayoría de los aspectos de la inteligencia tradicional, al presentarla como la capacidad de procesar la información emocional de forma eficaz y correcta para resolver problemas personales y interpersonales (e.g., Bastian, Burns, \& Nettelbeck, 2005; Ciarrochi et al., 2000; Mayer et al., 2000; Zysberg, 2012). La IE como rasgo, que relaciona la IE con otros constructos, resultando en una miscelánea de características asociadas a la personalidad (e.g., Austin, Saklofske, \& Egan, 2005; BarOn, 2005; Petrides, Pita, \& Kokkinaki, 2007). Y la IE percibida, que se relaciona con el auto-conocimiento del sujeto sobre sus capacidades emocionales (e.g., Avsec \& Kavcic, 2011; Augusto-Landa, Pulido-Martos, \& Lopez-Zafra, 2011; Fernández-Berrocal \& Extremera, 2008; Gignac, 2006; Rey, Extremera, \& Pena, 2011; Salovey et al., 2002; 
Thompson, Waltz, Croyle, \& Pepper, 2007). Algunos estudios recorren a términos idénticos para las capacidades de IE que se modifican de acuerdo a los instrumentos psicométricos utilizados, como por ejemplo, la Trait Meta-Mood Experience Scale (TMMS; Salovey, Mayer, Goldman, Turvey, \& Palfai, 1995) el Multifactor Emotional Intelligence Test (MEIS; Mayer, Caruso, \& Salovey, 2000) y el Mayer-Salovey-Caruso Emotional Intelligence Test (MSCEIT; Mayer, Salovey, \& Caruso, 2002). Específicamente, la percepción se refiere a la atención, la comprensión a la claridad, y la regulación a la reparación emocional, presentando las mismas funciones.

Existen, también, muchos estudios con muestras sanas que realzan la relación significativa entre SCV y el significado (e.g., Bronk et al., 2009; Latha, Sahana, Mariella, Subbannayya, \& Asha, 2013; Lightsey, 2006; Pan, Wong, Joubert, \& Chan, 2008; Park, Park, \& Peterson, 2010; Peterson, Park, \& Seligman, 2005; Steger \& Kashdan, 2007; Steger et al., 2006; Steger, Kawabata, Shimai, \& Otake, 2008; Triplett, Tedeschi, Cann, Calhoun, \& Reeve, 2012). Así como la SCV se relaciona con el Coping (Charbonneau \& Nicol, 2002; Deniz, 2006; Goldenberg et al., 2006; Grajales \& Araya, 2001; Mahmoud, Staten, Hall, \& Lennie, 2012).

Todos estos constructos objetivan que las personas vivan una buena vida, el BES y la SCV son pues variables integradas en la Psicología Positiva, donde se realza el hecho de que las personas no sólo evitan el malestar, sino que, igualmente, procuran la felicidad (Galinha \& Pais-Ribeiro, 2005). 


\section{Enfermedad Oncológica}




\section{ENFERMEDAD ONCOLÓGICA}

El cáncer se ha convertido en Portugal en una de las prioridades a nivel de la política de la salud, ya que se ha identificado como una de las principales causas de muerte. Se pondera la posibilidad de denominarlo como enfermedad epidémica o incluso pandémica, teniendo en cuenta el aumento de supervivencia con el desarrollo de las técnicas de diagnóstico y terapéuticas. Irónicamente, su incidencia alcanza igualmente tasas más elevadas. No obstante, se destaca el factor del envejecimiento de la población portuguesa (Barros \& Lunet, 2006; Macedo et al., 2008). Corroborando lo expuesto, se encuentran los datos obtenidos por el Instituto Nacional de Estatística [INE], el cual señala que las enfermedades circulatorias (32\%), los tumores malignos (23\%) y las enfermedades respiratorias $(11,1 \%)$ son, para ambos sexos, las principales causas de mortalidad (INE, 2012). Recurriendo a datos del Instituto Português de Oncologia do Porto, la patología oncológica más frecuente en los enfermos adscritos en 2010, fue la del aparato digestivo (23\%), seguida de la de los órganos genito-urinarios y de mama. En el hombre, el cáncer de próstata fue el tumor maligno más frecuente (21\%), registrándose un aumento de un 3\% en relación al año anterior. Los cánceres de pulmón y de estómago contribuyeron el $12 \%$ y $8 \%$ de los tumores de los hombres, respectivamente. En la mujer, el cáncer más frecuente fue el de mama (40\%), seguido de los cánceres de tiroides, útero y colon (Registo Oncológico do IPO-Porto, 2012).

Segundo Pais-Ribeiro (2010), la The Imperial Cancer Research Fund de Inglaterra, señala el cáncer como la segunda causa de muerte en los adultos del mundo occidental. Blanco, Antequera, y Aires (2002) indican que entre los muchos eventos negativos que pueden sucederle al ser humano, el cáncer se evalúa en el mundo moderno como uno de los que mayor recelo y ansiedad provocan en la población en general. 
La enfermedad oncológica desde el año de 1800 se señaló como una "sentencia de muerte", esta percepción acarrea consecuencias sociales como la estigmatización, aislamiento y humillación ya vividas por los enfermos de lepra y sífilis. En simultáneo al contexto social, la vivencia personal de un diagnóstico de cáncer alude a problemas como el dolor, el desfiguramiento, el miedo al contagio, la pérdida de atractivo y de autoimagen y la pérdida de la función sexual (Holland, 1989a). Durante muchas décadas el miedo al cáncer ha persistido, incluso actualmente, abordándose el tema de una forma más abierta, esta actitud social de estigma y recelo hacia la enfermedad gana fuerza. En 1975, en la sociedad americana, la "Cancerophobia" se consideraba un problema muy serio, exacerbado por la prensa. La fobia al cáncer se refería a un síntoma de distrés psicológico, el cual precisaba de una evaluación juiciosa para determinar su etiología y adecuar el tratamiento. Se trataba así, de una reacción normal en la salud física del individuo, el cual interfería en su funcionamiento, frecuentemente asociado a problemas emocionales situados en una escala entre medios a severos (Holland, 1989b).

El miedo, de hecho, parece permanecer en el enfermo, teniendo en cuenta las secuelas psicológicas de los supervivientes de cáncer y se relacionan con cinco fuentes: los efectos secundarios de los tratamientos, las complicaciones sexuales, los efectos neuropsicológicos a largo plazo, la experiencia de tratamientos continuados y los problemas prácticos y sociales en la reentrada en la vida familiar y profesional (Tross \& Holland, 1989). Taylor (1993) señala como preocupaciones más frecuentes de los enfermos oncológicos: el miedo a reincidir, al dolor, a la muerte, a la mutilación corporal a través de cirugía, a los efectos de la enfermedad y del tratamiento sobre las actividades diarias y las dificultades en el trabajo y familiares. Holland y Rowland (1989) presentan los miedos universales del enfermo de forma esquemática y 
mnemotécnica, "las seis D's", específicamente: la muerte (death), la dependencia (dependency), la desfiguración (disfigurement), la incapacidad (disability), los cambios en las relaciones interpersonales (disruption of interpersonal relationship), y el dolor (discomfort). Más tarde las autoras aumentaron un miedo a la lista, en relación al equipo sanitario que acompañaba al enfermo, o sea, la desvinculación con el mismo que suscita incertidumbre y ansiedad (disengagement).

Por consiguiente, Pais-Ribeiro (2010) evidencia que una enfermedad crónica es un acontecimiento no normativo que se presenta como un enorme agente estresor, a pesar de que el enfermo sea la variable dependiente de la enfermedad, este es también la variable independiente, porque su acción podrá controlar y gestionar el proceso de la enfermedad. En este sentido, Carapinheiro (2002) dice que el cáncer equivale a uno de los mayores desórdenes de la vida en general, en los pensamientos y sentimientos del individuo, afectando a su sentido existencial y como ser social. A su vez, Justo (2002) señala que con el aumento del índice de supervivencia se presenta un desafío enorme, al existir más supervivientes prevalece una mayor necesidad de intervención y comprensión del fenómeno, con el objetivo de mantener y recuperar la calidad de vida de los supervivientes en sus múltiples facetas (Hewitt, Greenfield, \& Stovall, 2006). O sea, se evidencia la pertinencia de tener que considerar el aumento de los años de vida a la par que la calidad de vida (Pais-Ribeiro, 2002).

García-Camba (1999) destaca el pronóstico actual de la enfermedad como más positivo, causando un cambio en la actitud social ante la enfermedad oncológica y los enfermos. Se genera así, una mayor preocupación por la autonomía y por los componentes personales y sociales del propio enfermo, en una época en la que el cáncer se asociaba inherentemente a cuidados en fase terminal. 


\subsection{Enfermedad oncológica, emociones y IE}

Las emociones son una parte integral y fundamental en la existencia humana. A pesar de que la gestión emocional forma parte de la condición humana, poco se sabe del impacto de las emociones primarias en la adaptación a la enfermedad (Bowman, 2000). Las emociones se consideran, por un lado, como un componente del sistema general de autorregulación que modifica el patrón de nuestras respuestas, orientándonos hacia la realización de nuestros objetivos. Por otro lado, el sistema emocional opera sobre el proceso de feedback interno con el cerebro, y entre el cerebro y el cuerpo, manteniendo el equilibrio de los sistemas físico y psicológico a un nivel óptimo de funcionamiento. Se añade también que la emoción influye en los esfuerzos del proceso de autorregulación, en el sentido de hacer que el enfermo trate de sentirse mejor (Butler, 2011). La investigación epidemiológica señala que los resultados de la salud, tal como las enfermedades autoinmunes, cardiovasculares y cánceres, se encuentran asociados a variables psicosociales, identificando el proceso emocional como el mediador de estas asociaciones (Leventhal \& Patrick-Miller, 2000). Smith, Lumley, y Longo (2002) señalan los beneficios del proceso emocional en la salud física, en el sentido de prestar atención, identificar, expresar y reconstruir cognitivamente las experiencias emocionales negativas. Además, los procesos emocionales contribuyen a la regulación del comportamiento ante las diferentes condiciones del medio del sujeto, tratándose generalmente de emociones adaptativas. Por ejemplo, la rabia, proporciona energía para la acción, fomentando la concretización de objetivos. La tristeza y la depresión, a su vez, inhiben la acción y desmotivan la concretización de objetivos. De este modo, las emociones positivas, principalmente el interés, la satisfacción y la esperanza promueven una conducta eficaz, manteniendo y persiguiendo la realización de objetivos (PaisRibeiro, 2010). 
Massie y Holland (1989) defienden que los acontecimientos catastróficos, como la experiencia en campos de concentración, Hiroshima o desastres naturales, se revelaron como un apoyo en la comprensión de las respuestas a nivel de la salud psicológica en enfermos con un diagnóstico de cáncer, revelándose estas acciones, similares a los individuos que vivieron los referidos acontecimientos catastróficos. En este caso, se evidencia la modulación de las respuestas, habiendo una variación en los niveles de distrés conforme a la existencia de recursos moderadores, así como, el apoyo social y la naturaleza o significado de la crisis en la fase del ciclo de vida en la que se encuentra el enfermo. Esta situación se encuentra influenciada porque la evaluación psicológica puede ser dañada por déficits de atención, concentración, juicio, y por la existencia de sensación de desorganización y de un autoconcepto disminuido, frecuentemente desarrollados al recibir un diagnóstico de cáncer. De este modo, la incapacidad para poner en práctica las estrategias de adaptación eficaz a la situación de estrés, aumentará los niveles de ansiedad y depresión.

En este ámbito, las alteraciones psicológicas más frecuentes en enfermos oncológicos son la depresión y la ansiedad (Llorca-Ramón et al., 1999). Por un lado, a los enfermos les tranquiliza que se les informe de que su estado emocional es común al de la mayoría de los enfermos, por otro, tienen miedo de que el estado depresivo pueda afectar a los resultados del tratamiento. En ocasiones, los pacientes solicitan un "check up" de salud emocional, con la intención de evaluar si poseen un estado emocional que aporte beneficios al tratamiento. Las alteraciones de humor subsisten en un proceso de adaptación a la enfermedad, no remitiendo a efectos negativos, aunque el paciente puede presentar optimismo, el hecho de adherirse terapéuticamente y asumir el compromiso son componentes esenciales durante la fase de tratamiento (Massie \& Holland, 1989). García-Camba (1999) destaca que el humor depresivo en un paciente 
oncológico es un acompañante habitual, definiéndose incluso como un fenómeno normal. La ansiedad por sí sola es una constante en cualquier enfermedad grave, volviéndose igualmente un hábito en la historia clínica de cáncer.

En el siglo XVI, se atribuía el cáncer al desequilibrio del humor negro, explicándose las metástasis y zonas del cuerpo con ese mismo humor, prevaleciendo este supuesto hasta el siglo XVIII. Hipócrates, abordaba la importancia que tenía el sujeto sobre la enfermedad oncológica, valorando la indivisibilidad entre el cuerpo y el alma (Ibáñez, Valiente, \& Soriano, 2002). En el siglo II antes de Cristo, Galeno destacaba que las mujeres melancólicas padecían con mayor incidencia el cáncer de mama en comparación con las más sanguíneas. A pesar de que se encontraban muchas objeciones a tales supuestos, en el siglo XVII se aceptaba la conexión directa entre las emociones y el cáncer. El médico Johannes Pechlin, pensaba que existía una relación entre el miedo y la tristeza y la transformación maligna de los tumores de mama. A nivel transversal en los siglos XVIII y XIX, se investigaba de forma significativa la relación entre el estrés grave o la pérdida emocional y el desarrollo subsecuente del cáncer (Andréu, 2002).

Empíricamente, desde la década de los 70 se encuentran niveles significativos de alteración emocional en los enfermos oncológicos, alcanzando el $80 \%$ niveles elevados de ansiedad y depresión, en momentos de crisis o de transición en la enfermedad o en el tratamiento, pudiendo el enfermo normalizarse tras restablecerse de estos momentos, añaden que el 50\% los enfermos experimentan inicialmente un distrés más severo, en la fase reactiva de ansiedad y depresión (Massie \& Holland, 1989).

Holland (1989c), presenta una serie de estudios sobre la relación entre el tipo de personalidad y las respuestas psicológicas antes, durante y tras el proceso de enfermedad oncológica. Defendía el papel influyente de las emociones en el riesgo para 
desarrollar cáncer y en su proceso. Describió así, en base a estos estados emocionales negativos frecuentes en los enfermos oncológicos, un tipo de personalidad propenso a padecer cáncer, con características peculiares, tales como presentar tendencia para reprimir y negar las emociones, así como una expresión emocional pobre, esencialmente a nivel de las emociones negativas.

Morris y Greer (1980) presentaron la primera investigación que destacó la importancia que la personalidad tenía en la aparición del cáncer, describiendo los sujetos con personalidad Tipo $\mathrm{C}$ como los contenidos emocionalmente, revelando supresión o una expresión emocional inadecuada ante situaciones estresantes. Temoshok (1987) en la misma línea de investigación, presenta un modelo en el cual conjuga los resultados contradictorios sobre la relación de personalidad con el cáncer e identifica un estilo de afrontamiento tipo $\mathrm{C}$ en el cual el individuo revela poca expresión emocional ante acontecimientos estresantes, asociada a una disforia crónica, refiere, también que el individuo tipo $\mathrm{C}$ es cooperativo, poco asertivo, paciente, sumiso a la autoridad, y tiende a no expresar las emociones negativas, principalmente la ira. Este tipo de personalidad está compuesto por un bloqueo de expresión emocional y una tristeza crónica enmascarada, tales características influyen en resultados adversos a nivel inmunológico y hormonal en la enfermedad oncológica.

Otros resultados realzan la importancia de la expresión emocional, incluyendo la expresión de emociones negativas, que repercute en el BEP. El acceso a emociones como el miedo, la tristeza y la rabia en procesos de terapia llevan a una mayor adaptación mental así como, a una mejor comprensión de sí mismo y de los demás (Greenberg, Ford, Alden, \& Johnson, 1993). La incapacidad de verbalizar los propios sentimientos originó el concepto de alexitimia en 1973, esta incapacidad se asocia significativamente con alteraciones psicosomáticas (Reardon \& Buck, 1989). 
Actualmente los estudios se dirigen hacia una expresión emocional escrita, dado que a través de las emociones la persona ventila y reformula su estado emocional. Como una forma de acceso más fácil, así como más confidencial, muchas han sido las investigaciones llevadas a cabo con pacientes oncológicos que cumplimentan escalas o responden a entrevistas cualitativas vía Internet (Lepore \& Smyth, 2002; Pennebaker \& Lee, 2002).

Suárez-Löcher y Cynthia-Pérez (2011) estudiaron la influencia de la expresión emocional escrita confrontada con el dolor en la enfermedad oncológica. Teniendo esta un impacto positivo, influyendo en el incremento de estrategias de afrontamiento, como la búsqueda de apoyo social y emocional. Además, la expresión emocional escrita pone de relieve la influencia en aspectos de la evaluación de la salud, como en la percepción del dolor corporal y en el papel social. Añaden que las creencias religiosas y culturales dispares, influyen por sí solas en la forma en que los enfermos se enfrentan a la enfermedad.

En lo que concierne a teorías de la personalidad y enfermedad, Millon (1999) presenta un modelo integrado que compara los aspectos psicológicos con las posibles alteraciones físicas. Sugiere así una analogía en la cual los rasgos de personalidad son equivalentes al sistema inmunológico, donde los factores psicosociales son los agentes infecciosos y los síntomas clínicos de la enfermedad en cuestión. Añade que los rasgos de personalidad surgen como determinantes en la aparición de los síntomas clínicos o ante situaciones de estrés. A su vez, estos síndromes como la depresión, la ansiedad o las alteraciones somatoformes pueden relacionarse con la configuración de la propia personalidad y con la evolución y agravamiento de la enfermedad física. Los estilos de personalidad se relacionan directamente con las dificultades de expresión emocional, más precisamente, con rasgos de evitación, depresivos y dependientes. Tales rasgos, 
momentáneamente, dificultan el reconocimiento de las necesidades personales y emocionales, así como conflictos de expresión adecuada de las emociones. Los rasgos esquizoides indican distanciamiento emocional y, ya más extremo, los histriónicos suponen una expresión excesiva e inadecuada de las emociones (Millon \& Davis, 1998, 2001).

En el contexto de la expresión emocional, Saxena et al. (2012), destacan que siempre que las emociones negativas no se expresan y alivian por medios convencionales, llevan a la estimulación crónica automática, incrementando la vulnerabilidad para el desarrollo de enfermedades y alteraciones físicas. De acuerdo con el paradigma psicosomático, la supresión de emociones negativas es el elemento central asociado al desarrollo o expresión de la enfermedad física. El miedo, la agresión y los continuos deseos denotan resultados represores en la tensión emocional persistente, alterando el funcionamiento corporal y potenciando la enfermedad física.

Según Justo (2002), un funcionamiento psicológico que no se expresa en sus manifestaciones externas de la personalidad, pero que de forma continuada y silenciosa crea distorsiones emocionales, limitan el desarrollo del sujeto e intensifica el estado depresivo en acontecimientos de vida negativos. En este sentido, afirma que el funcionamiento depresivo debilita el sistema inmunológico, siendo este último necesario en el combate con las células cancerígenas y en su reproducción, entendiéndose un cariz negativo de la secuencia desarrollada a nivel emocional de estos pacientes. A su vez, el autor señala que los enfermos afectados emocionalmente por la gravedad de la enfermedad o del tratamiento, son menos colaboradores, menos creyentes y menos capaces de beneficiarse de los cuidados de salud. De este modo constatamos, un doble efecto de las emociones en el proceso de la enfermedad. 
Además de la influencia señalada de la personalidad en el área oncológica, Holland (1989c) aclara un abanico de investigaciones que sugieren que las variables psicosociales parecen contribuir a la supervivencia. Y su contribución biológica en el pronóstico favorece la identificación de determinantes importantes, como las relaciones sociales, el estado civil, la satisfacción laboral, el uso de psicofármacos, la satisfacción en la vida, la salud y los estados de esperanza-desesperanza/fatalismo. Es, en este sentido, que surge la idea de que los factores psicológicos influyen en el pronóstico de la enfermedad oncológica, interfiriendo en la relación entre el cerebro y los sistemas inmunológico y endocrino. Esta línea de investigación ha creado una nueva área en el cáncer, la Psiconeuroinmunología (Holland, 1989c). Bovbjerg (1989) destaca que los factores psicológicos y sociales pueden modificar el riesgo de desarrollar cáncer, el progreso de la enfermedad y la respuesta al tratamiento. Ante la ejecutabilidad de la relación psicoinmunológica en el cáncer surgen tres investigaciones independientes, que exploran tres hipótesis específicas. Primero, la incidencia y progresión del cáncer son afectadas por variables psicosociales; segundo, se ven influenciadas por actividades del sistema inmunológico y, finalmente, el tipo de respuestas inmunológicas que influyen en la incidencia y progresión de la enfermedad se ve igualmente afectado por las variables psicosociales. Se añade que los estresores psicológicos pueden causar respuestas fisiológicas de estrés, exacerbando el proceso de la enfermedad (Hansen \& Sawatzky, 2008).

Se han desarrollado múltiples estudios en este ámbito, desde la evaluación del estrés y del sistema inmunológico en animales, en humanos con situaciones provocadas, o a través de testigos de pacientes, enfocando la importancia de su voluntad de vivir en el proceso de supervivencia en el cáncer. En este contexto, los factores emocionales destacan la posibilidad de que los factores psicológicos afecten al riesgo de sufrirlo, en 
la medida en que contribuyen de forma más directa a prolongar la vida de un superviviente de cáncer. El impacto del distrés percibido como la respuesta emocional en acontecimientos estresantes de la vida y en pérdidas, fue evaluado en supervivientes de cáncer. El sufrimiento asociado a acontecimientos traumáticos, así como, el efecto de la desesperanza y la tristeza, dan como resultado una depresión crónica, influyendo negativamente en el riesgo de cáncer y en la supervivencia al mismo (Holland, 1989c).

Vallath (2006), señala que, al igual que el cerebro, el sistema inmunitario tiene una capacidad significativa para aprender, memorizar y producir mucha información. Son dependientes de la información entre ellos mismos y entre otros sistemas, estableciendo un feedback seguro entre las emociones, los nervios y los sistemas endocrino e inmunológico para la regulación de las respuestas psicológicas. Recientemente, la investigación se encuentra enfocada en la identificación de sustancias químicas que puedan ser utilizadas en la modificación de este feedback, un proceso al que se refiere con el nombre de "inmunomodelación". Aún no es clara la información pero parece que el proceso consiste en que la reproducción del cáncer incrementa las estrategias de supervivencia. A nivel de la "psiconeuroinmunomodelación", la modelación del sistema inmunitario es prometedora. La transformación del estado psicológico da como resultado la salud del sistema biológico. En este sentido, el autor destaca la pertinencia de las intervenciones psicológicas en el cáncer no sólo con resultados en la alteración del humor, en el coping y percepción del dolor, como destaca la mayor supervivencia de los participantes.

En resumen, Padellano y Torrubia (1999) defienden que el sujeto enferma de una forma global y la etiología de la enfermedad se revela multifactorial, subrayando la relación mente - cuerpo como un todo continuo. En este sentido, las alteraciones mentales pueden provocar problemas físicos, de la misma forma, que los físicos pueden 
provocar los mentales. Esta visión holística, contraria al supuesto de la medicina moderna, "curar la enfermedad", destaca que lo más importante es "curar a la persona que tiene la enfermedad".

\subsubsection{Inteligencia emocional y salud-enfermedad}

Indudablemente ha surgido un interés significativo en estudiar la relación entre el proceso de salud-enfermedad y variables positivas, tales como la IE (Martínez, 2009). Juárez (2011) presenta un Modelo de Salud como IE que fomenta el enriquecimiento del trabajo profesional, así como el uso eficiente de los recursos de salud. Destaca entre varias concepciones teóricas de la IE, el modelo mixto general o de personalidad, dividiéndolo en modelos de competencia o modelos de bienestar, a pesar de que la IE presente bajas correlaciones con la personalidad, empíricamente se revela como una competencia en el uso cognitivo y adaptativo de las emociones (Augusto-Landa \& Montes-Berges, 2009). En este sentido, se considera la IE como un constructo de salud o generador de salud, al ser la salud interpretada como adaptación, utilización adecuada de los recursos y sensación de bienestar emocional. Sin embargo, por no poder recurrir a este recurso de forma indiscriminada, en ocasiones es difícil aplicar este modelo (Juárez, 2011).

Pandey y Choubey (2010) evidencian algunos constructos relacionados con la emoción que pueden influir a la salud física de una persona, tales como, la alexitimia, a través de los déficits en el proceso cognitivo de las emociones, traduciéndose en una regulación indiferenciada y pobre; la regulación emocional, como la capacidad de influir cognitivamente o a través del comportamiento en lo sucedido, la intensidad, la duración y la expresión de las emociones (Gross \& Thompson, 2007); la IE, como capacidad para percibir, expresar, comprender, monitorizar y gestionar las emociones (Salovey \& Mayer, 1990); la intensidad del afecto, que se corresponde con la 
disposición para experimentar el extremo de estados emocionales independientes de la valencia emocional (Larsen \& Diener, 1987); el afecto positivo y negativo, a través de la disposición afectiva para experimentar emociones positivas o negativas; y la supresión emocional, con la incapacidad de expresar y compartir experiencias emocionales, principalmente las emociones negativas (Pandey \& Choubey, 2010). De modo general, a través de la revisión de la literatura, los autores sugieren que algunos de estos constructos como la regulación cognitiva de la emoción, apertura/expresión emocional, experiencias emocionales positivas, y la mayoría de las dimensiones de la IE, presentan una influencia beneficiosa en el estado de salud del sujeto. Mientras tanto, otras variables emocionales como la supresión de emociones, la alexitimia, la intensidad afectiva y las experiencias emocionales negativas conducen a consecuencias adversas para la salud (Pandey \& Choubey, 2010).

Lizeretti y Rodríguez (2011) presentan un artículo de revisión de los estudios realizados sobre la IE en el ámbito de la salud mental. Enfocan las variables del bienestar, de la adaptación psicológica y la psicopatología. En relación a los estudios sobre la IE y el bienestar, indican que los sujetos emocionalmente inteligentes se sienten mejor consigo mismos, están más satisfechos con su vida, y se perciben más felices, posiblemente debido a que tienen una mayor capacidad empática, mayor nivel de autoestima, son más optimistas, presentan más capacidades sociales, mejores relaciones interpersonales y más conductas prosociales. Concluyen así, que la IE es un buen indicador de bienestar psicológico, que directa o indirectamente ha contribuido al bienestar en general. En relación a la adaptación psicológica, las autoras señalan que un alto nivel de IE proporciona más competencias para enfrentar de forma adaptativa situaciones estresantes, permitiendo distinguir los diferentes estados emocionales y comprenderlos, así como, las competencias para regularlos correctamente, se vuelven 
imprescindibles y constituyen factores de protección para la salud física y mental. Finalmente, en el área de la psicopatología, las autoras no disponen de datos que permitan afirmar que una IE baja sea un factor que influya en el desarrollo de enfermedades mentales o, si por el contrario, las enfermedades mentales limitan el desarrollo de las capacidades emocionales. Sin embargo, revelan que las personas con rasgos de personalidad patológica se autoperciben con pocas capacidades emocionales, así como la presencia de perturbación y la gravedad de los síntomas se asocia a una IE disminuida. Los pacientes con alteraciones psicopatológicas revelan niveles de IE bajos y se autoperciben como menos capaces de gestionar sus emociones, llevando a las autoras a afirmar que sin ser la causa directa de los trastornos, las capacidades de IE contribuyen significativamente tanto hacia la presencia de la alteración como a mitigar o aumentar su gravedad. Teniendo en cuenta toda la investigación revisada, consideran interesante la IE como una variable clínica implicada en el proceso de salud enfermedad.

A su vez, Zeidner, Matthews, y Roberts (2012) en un artículo de revisión, sugieren que la IE tiene un papel influyente en el bienestar y en la salud, observando la utilidad de la IE en la predicción de la salud y bienestar, y refieren que es un campo para investigaciones futuras dada que la aplicabilidad del papel de la IE se encuentra estudiada sólo en el dominio educacional y profesional. Por consiguiente, destacan que los sujetos emocionalmente inteligentes, además de las competencias emocionales inherentes, presentan la capacidad de afrontar de forma adaptativa los estresores y las complicaciones del día a día, en comparación con los sujetos que evidencian un nivel bajo de IE. Teniendo en cuenta que muchas de las causas de morbilidad y muerte se asocian al estrés crónico, a los estilos de vida negativos y a los comportamientos relacionados con la salud/de riesgo, provocando un incremento de costes de salud. En 
este punto la IE se muestra como un factor de protección contra los riesgos de salud actuales. Los autores añaden que los modelos contemporáneos biopsicosociales de la enfermedad, consideran la salud y la enfermedad como una amalgama de factores biológicos, psicológicos y sociales, atribuyendo más recientemente énfasis al papel de las emociones en estos procesos.

En este sentido, Diener y Chan (2011) en su meta análisis evidencia que la felicidad (BES) contribuye a la salud y a la longevidad. Destacan la relación fisiológica directa con las emociones, estrés y la enfermedad, así como, el papel moderador de las diferencias individuales en el modo en que las personas perciben, expresan, experimentan, afrontan las experiencias de distrés, y cómo regulan sus comportamientos relacionados con la salud. Una vez más, los autores aluden a la importancia del factor de la IE en este área (Zeidner et al., 2012).

En cuanto a los comportamientos de salud, la IE ha sido definida como facilitadora de prácticas de salud positivas, dado que los sujetos emocionalmente inteligentes mantienen prácticas proactivas de autocuidado, como ejercicio regular, dietas regulares, sexo seguro, así como presentan una autorregulación eficaz en comportamientos de salud, como consultas periódicas de prevención médica, adhesión terapéutica y una dieta libre de comida rápida. Añaden, también, el componente interpersonal de la IE, que facilita la interacción con los profesionales de la salud (Johnson, Batey, \& Holdsworth, 2009).

Zeidner et al. (2012) destacan la investigación de la IE en relación al estrés, en la medida en que una menor reactividad al estrés se asocia a la IE, siendo un mecanismo potencial que relaciona la competencia emocional con el funcionamiento, con resultados en la salud (Salovey, Mayer, \& Caruso, 2002). Ejemplifican cómo el ser emocionalmente inteligente lleva a percibir los contextos estresores e impedimentos, 
más como cambios que como factores estresantes, relacionándolos con comportamientos menos adversos psicológicamente y con resultados de salud en las interacciones medio - sujeto. Señalan también que la IE se relaciona negativamente con la alexitimia, siendo esta un obstáculo para la regulación eficaz de las emociones negativas. La resiliencia, a su vez, asociada a la IE, induce a menores niveles de emociones negativas, tales como la ansiedad y depresión, resultando en una mejor gestión del estrés (Dawda \& Hart, 2000; Slaski \& Cartwright, 2002).

Salovey, Rothman, Detweiler-Bedell, y Steward (2000) indican que la IE apoya el desarrollo de recursos de coping positivos y comportamientos de coping habitual con beneficios para la salud. Las competencias relacionadas con la IE facilitan un mayor coping activo durante el tratamiento, la evaluación y adhesión a regímenes médicos, reduciendo la cronicidad y la severidad de la propia experiencia de enfermo. Zidner (2007) destaca que los sujetos con altos niveles de IE tienen relaciones de apoyo social, llevándolos a sentir satisfacción con el apoyo social, aspecto importante en situaciones de estrés o enfermedad.

Finalmente, Zeidner et al. (2012) observan que los sujetos con mayor IE desarrollan menos hábitos problemáticos o la preocupación excesiva por el alcohol, el tabaco o las drogas. A través de la capacidad significativa de autoconciencia y autorregulación, previenen el desarrollo de comportamientos de riesgo, incluyendo el coping desadaptativo. Concluyen que la IE promueve un estilo de vida más positivo, incrementando la longevidad y el bienestar físico. En la Figura 6 se presentan los factores mediadores de la relación IE - salud. 


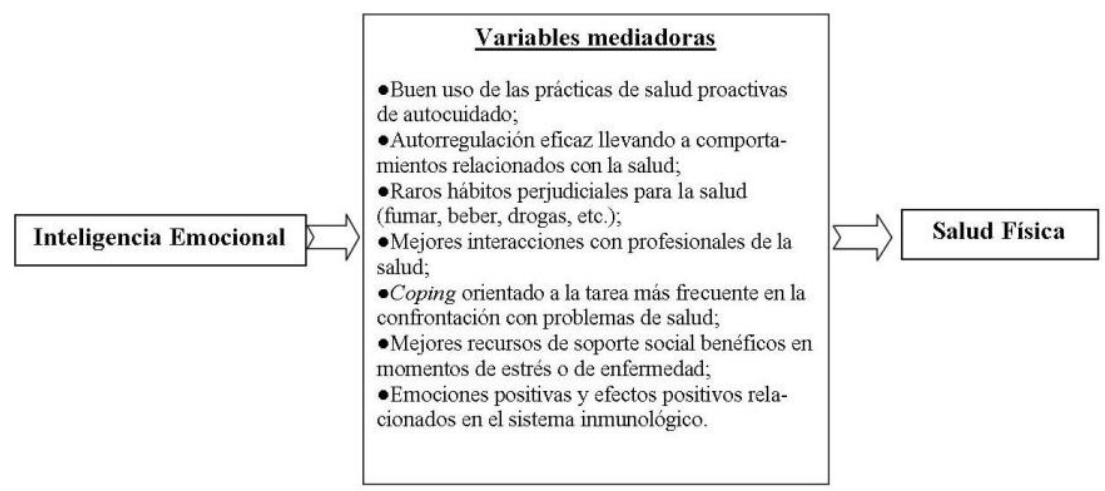

Figura 6: Algunos factores mediadores en la relación IE-salud, adaptado por Zeidner, Mayer, y Roberts (2012)

A nivel de la salud mental, en los estudios relacionados con la ansiedad y la depresión, la personalidad y el consumo de drogas, la IE surge como un factor de prevención y de adaptación. En el ámbito de la IE y la salud física, se destaca la poca investigación en el área. Por consiguiente, la IE está asociada a comportamientos de salud y a una menor necesidad de recurrir a servicios de salud. Más específicamente, en el área de la enfermedad crónica, los pocos estudios encontrados asocian la IE, a la artritis y a la fibromialgia, al dolor postoperatorio y al cáncer de mama con un contexto social negativo, revelando la IE resultados beneficiosos en la adaptación a las respectivas situaciones (Gonzáles, Piqueras, \& Linares, 2010). Martins et al. (2010) presentan un meta análisis acumulado sobre la relación entre la IE y la salud enfocada en las publicaciones posteriores al meta análisis de Schutte et al. (2007), revelando que la salud mental y la psicosomática presentan una relación con la IE más significativa que con la salud física. Sin embargo, concluyen que, de hecho, la IE puede ser considerada como pronosticadora de salud.

También en el dominio de la salud mental, los factores emocionales poseen un papel crítico determinando la salud mental y el BES de uno mismo, así como las disfunciones emocionales ejercen un papel importante en el desarrollo de la enfermedad mental. En el ámbito de la psicología positiva, la IE enfatiza su papel en el crecimiento 
personal y en la autoactualización, estando la IE correlacionada con varios resultados, como señal de bienestar socio-emocional o calidad de vida en general (Austin et al., 2005), con la felicidad (Chamorro-Premuzic, Bennett, \& Furnham, 2007), el optimismo y el humor (Mikolajczak, Luminet, \& Menil, 2006; Pérez-González et al., 2007), y se relaciona con menos estrés y un mayor BES (Austin, Saklofske, \& Mastoras, 2010).

Batool y Khalid (2009) realzan que los especialistas en salud mental han enfatizado la correlación de la IE con alteraciones psicológicas, porque la inteligencia para usar las emociones se considera esencial en la salud física de la persona, así como en la adaptación psicológica. Añaden también que la IE se asocia al sistema inmune.

Por consiguiente, Woolery y Salovey (2004) señalan la IE como un factor potencial de riesgo o de protección en la salud mental y física, especialmente en caso de depresión.

También en el área de la salud mental y física, Veríssimo (2003) relacionó la alexitimia y el control emocional con la IE en estudiantes universitarios, concluyendo que la alexitimia y el control emocional son componentes relevantes de la IE. Indica que, teniendo en cuenta estudios previos, es posible que la IE tenga implicaciones a nivel de la salud mental y física, dado que el control emocional ya fue empíricamente comprobado como factor protector del estado de salud subjetiva, así como la alexitimia que se encuentra asociada a situaciones de enfermedad y a un aumento de mortalidad.

Múltiples enfermedades crónicas se asocian a comportamientos de riesgo y estilos de vida, tales como en el cáncer. Y el cáncer se relaciona con la IE, ya que se considera pronosticadora de comportamientos de la salud y está inherentemente relacionada con las enfermedades crónicas (Zeidner et al., 2012). En el ámbito de la IE aplicada al área de la psicooncología, la investigación que se encuentra es escasa, los estudios siguientes 
son los primeros pasos para definir el constructo de la IE como crucial en la adaptación a la enfermedad oncológica.

Rodríguez (2004) analizó la relación de la IE y la ansiedad en enfermos oncológicos, siendo esta estadísticamente significativa. Tales resultados llevan al autor a defender que la IE es una variable importante que genera condiciones favorables en el sujeto y reduce aquellas situaciones que llevan a los enfermos a desarrollar trastornos de ansiedad, además de ayudar al paciente a aceptar su proceso de enfermedad, así como a adherirse terapéuticamente. Añade que la intervención psicológica deberá enfocar la dimensión de la IE con la finalidad de proporcionar capacidades de adaptación en el proceso de la enfermedad, aumentando a corto/medio plazo su calidad de vida.

A través del reclutamiento vía Internet, Schmidt y Andrykowski (2004) evaluaron en un grupo de apoyo de mujeres con cáncer de mama, la adaptación psicológica como función de la IE y del soporte social. Concluyen que cuanto más constreñimiento social vive el sujeto y menos capacidades de IE presenta, mayor será el distrés resultante. En este sentido, la IE funciona como un amortiguador contra acontecimientos negativos y traumáticos, revelando la investigación la eficacia de la IE en la adaptación a situaciones traumáticas. Añaden que, por un lado, la IE se asocia de forma significativa con menos depresión y ansiedad en mujeres con cáncer de mama, pudiendo compensar las limitaciones de un contexto social pobre. Por otro lado, sugieren que la IE posee una enorme importancia en el proceso de adaptación psicológica al cáncer de mama, en la medida en que la IE facilita el proceso cognitivo y emocional en la experiencia de cáncer de mama, promoviendo la capacidad de prestar atención, discriminar y regular las emociones. Sin embargo, afirman que no analizaron el papel de la IE en la adaptación psicológica en situaciones de diagnóstico y tratamientos de cáncer, datos importantes para futuras investigaciones. 
Guzmán y Alarcón (2007) estudiaron la relación de la IE y el bienestar personal en 80 mujeres con cáncer de mama. Los resultados son congruentes con estudios recientes sobre la IE, ya que revelan la naturaleza desadaptativa y nociva de prestar demasiada atención a las propias emociones, pero específicamente a las emociones negativas (Extremera-Pacheco \& Fernández-Berrocal, 2006). El estudio confirma que en las mujeres con cáncer de mama existe una relación directa entre la claridad de las emociones y el bienestar personal, denotándose más entre la reparación emocional y el bienestar personal. Se defiende la importancia de trabajar la IE de las mujeres con cáncer de mama, con la finalidad de mejorar su bienestar personal. En otras palabras, se juzga esencial el trabajo sobre la variable reparación emocional, porque al reparar adecuadamente las emociones negativas, se verifica una mejora visible en el bienestar personal, siendo una capacidad que se puede desarrollar a través de una intervención psicológica específica.

Cerezo, Ortiz-Tallo, y Cardenal (2010) evaluaron en 40 mujeres con cáncer de mama las características de la personalidad, las capacidades de IE y el bienestar personal, posteriormente, implementaron una intervención psicológica en grupo. Los resultados indican que las participantes en la intervención psicoterapéutica, en comparación con el grupo de control, mejoraron la regulación de las emociones negativas y su bienestar personal.

Kieszkowska-Grudny et al. (2010) observaron que el estado emocional, más precisamente, una baja IE se relaciona con un alto nivel de fatiga crónica en pacientes sometidos a quimioterapia.

Brown y Swartz (2012), investigaron la IE y el locus de control en una población adulta de enfermos con cáncer de mama en tratamiento. Exponen la importancia de estos dos constructos en la promoción de BEP, y en la reducción de la vulnerabilidad 
física de la enfermedad durante y después del tratamiento. A través de la comprensión del impacto de las variables psicosociales en un diagnóstico de enfermedad crónica, pueden desarrollarse intervenciones en el campo de la psicología positiva, considerando que la IE y el locus de control son mediadores importantes en el tratamiento y en la gestión del cáncer de mama.

Smith, Petrides, Green, y Sevdalis (2012) estudiaron la relación entre la IE y la preocupación de 64 enfermos en diferentes estadios de un cáncer urológico. Los resultados evidencian una relación negativa entre la IE y la preocupación. O sea, una baja IE es pronosticadora de mayores niveles de preocupación en los primeros estadios de la enfermedad.

Rey, Extrema-Pacheco, y Trillo (2013) investigaron la relación entre la IE y la personalidad con la calidad relacionada con la salud en 62 enfermos oncológicos. La IE reveló una capacidad predictiva en las diferentes dimensiones de la vida asociadas con la calidad relacionada con la salud. Tales resultados proponen evidencias preliminares sobre si las competencias de la IE son o no útiles al campo de la psicooncología. Divulgando de una forma hipotética su potencial valor en la inclusión de programas, para complementar orientaciones psicoeducacionales, y para promover o preservar en los pacientes con cáncer la calidad de vida relacionada con la salud.

Entre los pocos estudios realizados en Portugal sobre la IE, salvo el área psicométrica, Gomes (2011) observa que aquellos pacientes oncológicos con índices elevados de IE, evidencian niveles satisfactorios en el estado general de salud/calidad de vida y bajos niveles de ansiedad, depresión y distrés emocional. No se verificaron relaciones estadísticamente significativas entre IE y las variables sociodemográficas, ni entre las variables clínicas estudiadas, presentando sólo correlaciones entre la IE con la depresión y la ansiedad. 


\subsection{Enfermedad oncológica y significado}

Encontrar significado en la vida se revela como un recurso psicológico positivo, influyendo en la sociedad de forma saludable, y contribuyendo al mantenimiento del estado emocional y motivacional para realizar los objetivos. Una vida con significado ha demostrado estar positivamente relacionada con el bienestar en general, un alto nivel de autoeficacia, coping enfocado en el problema, la religiosidad y el apoyo social, entre otros (Kállay \& Miclea, 2007). La investigación ha puesto en evidencia que en un funcionamiento normal en situaciones cotidianas, las emociones positivas superan a las negativas. En este sentido, la capacidad para vivir la vida con significado, con un sentido y objetivos, ayudan a las personas en situaciones futuras, siendo un pronosticador constante de bienestar en todas las fases del desarrollo humano. En este contexto, los acontecimientos traumáticos parecen tener de una forma general un impacto negativo en los individuos. Por un lado, los sujetos pueden bloquear y ceder a la situación, así como sufrir las consecuencias del impacto, mientras que por otro, pueden recuperar su funcionamiento anterior y superar la situación negativa al percibirla como un cambio positivo, dando lugar a un crecimiento personal. En este ámbito, el proceso de construcción de significado contribuye a la optimización del balance entre las emociones positivas y negativas durante la vivencia de acontecimientos traumáticos, trascendiendo en un coping saludable. Se concluye que, además de la información anterior, encontrar significado en la vida contribuye seriamente al proceso de adaptación, que se ha revelado importante para los enfermos diagnosticados de cáncer con mal pronóstico, contribuyendo a una mejor calidad de vida. Añaden que un afrontamiento exitoso al inicio del acontecimiento negativo, activa un estado emocional positivo que motiva la búsqueda de significados positivos en el futuro. 
En este contexto, Krauss, Rodrigues, y Dixe (2009), en un artículo de revisión, afirman que la atribución de significado en la experiencia cotidiana permite que el sujeto desarrolle dignidad y esperanza en relación al futuro, siendo crucial en el desarrollo humano, teniendo efectos terapéuticos.

Helgeson, Reynolds, y Tomich (2006), en su meta análisis de relación entre beneficio encontrado y salud mental y física, destacan los efectos positivos que resultan de un acontecimiento traumático. Más en concreto, el beneficio encontrado en como el coping que reduce el distrés, durante una situación difícil, y el beneficio encontrado como resultado que se refiere al cambio o crecimiento actual. El aspecto que sobresale es que el beneficio encontrado se relaciona significativamente con el bienestar positivo en el ámbito de la salud.

Boyraz, Horne, y Sayger (2010) añaden que el significado positivo encontrado, o el también mencionado beneficio encontrado, tras la pérdida incluyen la determinación del valor y significado del acontecimiento en la vida personal, pudiendo incluir ganancias personales como el poder y la confianza, un insight sobre el significado de la vida, perfeccionar las relaciones, así como el crecimiento postraumático. Tal crecimiento corresponde a cambios positivos en el crecimiento personal que incrementan la espiritualidad y apreciación de la vida, la mejoría de las relaciones y el encuentro de nuevas posibilidades en la vida. Por consiguiente, el significado positivo encontrado se asocia a una reconstrucción cognitiva positiva de la pérdida o de un acontecimiento traumático, y a una transformación ampliada de crecimiento.

Según Pais-Ribeiro (2010), la experiencia de una enfermedad se vive individualmente, y el mismo tipo de enfermedad tiene significados diferentes para cada sujeto. La investigación en la adaptación a enfermedades graves, como el cáncer, se ha centrado significativamente en el constructo del significado personal. No obstante, las 
preocupaciones existenciales influyen en la respuesta a enfermedades fatales y a tratamientos penosos (Sherman, Simonton, Latif, \& Bracy, 2010).

El significado se operacionaliza como un constructo existencial definido en la literatura del pos trauma, asumiendo niveles diferentes, tales como el significado asociado a acontecimientos como el diagnóstico de cáncer (significado situacional, por ejemplo "¿Por qué se me ha diagnosticado un cáncer?”), significado de la propia vida (significado global, por ejemplo "¿Qué hace que mi vida sea significativa y tenga sentido?"), y el significado de la vida en general (significado existencial, por ejemplo “¿Cuál es el significado de la vida y la muerte?”). Muchos enfermos oncológicos reflexionan sobre la configuración de los acontecimientos de su vida en el pasado, en el presente $\mathrm{y}$, potencialmente, en el futuro. Esta reflexión puede facilitar la adaptación psicológica al cáncer, promoviendo la resiliencia y el crecimiento, con el sentido de que los pacientes aprendan con su enfermedad, una experiencia de vida más plena en el presente, a reorientar prioridades, valores y objetivos de vida (Henry et al., 2010).

El concepto de significado gana relieve en el área de la psicooncología, porque la enfermedad amenaza el sentido de la vida del sujeto a través de sentimientos de vulnerabilidad y miedo a la muerte (White, 2004), modificando la visión de sí mismo, del mundo y del futuro (Moadel et al., 1999). Las características específicas del cáncer alteran la experiencia del sentido en la vida del paciente, implicando incertidumbre sobre la muerte y posibles recidivas, y la presencia de pérdidas, como de la salud, el empleo y los amigos (Jaarsma, Pool, Ranchor, \& Sanderman, 2007). Chan, Ho, y Chan (2007), mencionan también, en el contexto de la enfermedad oncológica, la dificultad que los pacientes tienen para comprender la posibilidad de la muerte, la causa de la enfermedad, así como el propósito de tal sufrimiento. Estas cuestiones existenciales van al encuentro de la definición de Kissane (2000) sobre el distrés existencial, siendo un 
estado en que el sujeto se enfrenta a su mortalidad, ante sentimientos de debilidad, desilusión, futilidad, desvalorización, remordimientos, ansiedad ante la muerte y ruptura con su compromiso y objetivos en la vida.

A nivel empírico se reconoce que la atribución de significado aumenta el sentido de bienestar en los supervivientes, consiguiendo integrar los sentimientos y cogniciones de amenaza en su sistema de creencias, y obteniendo un mayor nivel de calidad de vida y disminución del distrés. Tras la sumisión al tratamiento, se vuelve más eficaz la construcción de significado, momento en el que el enfermo afronta las consecuencias físicas y psicosociales del diagnóstico y del tratamiento. El significado se relaciona más con la intensidad en la contribución a un mejor funcionamiento de la salud mental, que al funcionamiento social (Fleer, Hoekstra, Sleijfer, Tuinman, \& Hoekstra-Weebers, 2006).

Jim y Andersen (2007) al estudiaren el funcionamiento social y físico, identifican que las consecuencias físicas inherentes al proceso de la enfermedad y a los tratamientos llevan a estados depresivos, debido a la disminución de contactos sociales y aislamiento del enfermo, intensificando la pérdida de sentido en la vida del mismo. Defienden que la construcción de significado facilita el coping eficaz y las emociones positivas, mientras que la ausencia de la construcción/búsqueda, provoca estrés, afecto negativo, tristeza y desesperanza. Concluyen que el significado es un mecanismo específico, potencialmente importante en la adaptación al proceso del superviviente para su funcionamiento físico y social. En este sentido se reitera lo expuesto anteriormente sobre el significado, que el coping de atribución de significado hace referencia a la evaluación del cáncer, al proceso de búsqueda de orden y sentido en la vida, así como al resultado de una adaptación positiva a la enfermedad (e.g., Lee, Choen, Edgar, Laizner, \& Gagnon, 2004; Park \& Folkman, 1997). 
Schroevers, Kraaij, y Garnerfski (2011) señalan que los enfermos oncológicos experimentan cambios positivos y negativos resultantes de la enfermedad. Estos cambios están significativamente relacionados con el bienestar del paciente, y con sus estrategias de coping y de recuperación de objetivos. La revisión de varios estudios sobre los cambios positivos destacan cambios tales como tener mejores relaciones con los demás, la alteración de prioridades y objetivos en la vida, y presentar un mayor sentido de significado y apreciación de la vida. Estos cambios se relacionan con el coping adaptativo por la reevaluación y aceptación positiva de la situación, recurriendo a estrategias de coping de aproximación. Este conocimiento es pertinente para la intervención psicológica, en la medida que los enfermos aprenden a reconocer los cambios en su vida y se aproximan, preferentemente, en lugar de evitar las situaciones difíciles. Los enfermos pueden beneficiarse también al comprometerse con objetivos alternativos en la vida, resultando en un encuentro de significado positivo.

Progresivamente el significado ha enfatizado la necesidad de comprensión de los medios por los cuales las personas asimilan las experiencias traumáticas en sus creencias preexistentes en relación al mundo. White (2004) señala la importancia de comprender, igualmente, los significados que favorecen la adaptación a la enfermedad, que han sido desarrollados y aplicados a la comprensión de las experiencias de los enfermos oncológicos. Evalúan así, como una parte esencial en la comprensión del sufrimiento de los enfermos, la relación del significado con el modo en que se experimenta la enfermedad.

\subsubsection{Significado y salud-enfermedad}

Una vida con significado es un factor importante para el funcionamiento humano saludable y para la promoción de la salud (Haugan, 2013; Steger et al., 2006). El significado en la vida se relaciona así de una forma positiva con la salud y de forma 
negativa con la enfermedad crónica, como por ejemplo, el cáncer, la enfermedad cardiovascular y la muerte prematura (Skrabski, Kopp, Rózsa, Réthelyi, \& Rahe, 2005). Existen evidencias de la correlación entre el significado en la vida con la salud física (Isaia, Parker, \& Murrow, 1999; Krause, 2004), y con una mayor percepción de satisfacción con la salud (Sherman, Michel, Rybak, Randall, \& Davidson, 2011). En el contexto de las enfermedades crónicas el significado en la vida revela resultados positivos, siendo un factor importante del bien-estar en el proceso de enfermedad (e.g., Dezutter et al., 2013; Jim \& Andersen, 2007; Mehnert \& Koch, 2008). De igual modo, tener un sentido general de propósito o compromiso en la vida se asocia a una mejor adaptación a las exigencias de enfermedades fatales (e.g., Fleer, Hoekstra, Sleijfer, Tuinman et al., 2006; Sherman et al., 2010; Vickberg, Bovbjerg, DuHamel, Currie, \& Redd, 2000; Vickberg et al., 2001). En la enfermedad oncológica, promueve una adaptación más eficaz y una mejor calidad de vida (Sherman et al., 2010), incluso en enfermos con enfermedades más graves (Kállay \& Miclea, 2007). En psicooncología, el significado tiene cada vez más importancia, siendo una necesidad relatada por los pacientes que solicitaren apoyo para descubrir el significado en la vida (Moadel et al., 1999). En este sentido, el diagnóstico o el padecer un cáncer parece ser impulsor para la búsqueda de significado en la vida (Schlegel, Manning, \& Bettencourt, 2013). La tensión revolucionaria o el sufrimiento existencial (Frank1, 1990) lleva el enfermo a evaluar su vida, a sí mismo y a su biografía y simultáneamente a procurar un sentido en su vida y en la enfermedad. Conseguir atribuir un significado positivo o encontrar beneficios en el proceso de enfermedad revela la capacidad de reestructuración de la enfermedad a través del sufrimiento que direcciona al crecimiento postraumático (Neimeyer, 2001). Este crecimiento personal ante la adversidad o el trauma de eventos negativos es un factor benéfico para su adaptación (Dunn, Campbell, Penn, Dwyer, \& 
Chambers, 2009), facilitando la percepción de beneficios en la experiencia de enfermedad (Andrykowski et al., 1996), y resultados positivos en la salud (e.g., Thombre, Sherman, \& Simonton, 2010). Adicionalmente, los cambios positivos que surgen de este crecimiento aumentan la SCV (Park \& Blank, 2012). En este sentido, los enfermos oncológicos que consiguen encontrar significado en la vida revelan paralelamente SCV (Schlegel et al., 2013).

El significado en la vida se tiene identificado como un mediador en la salud psicológica y física (Chan, 2009; Halama \& Dedova, 2007; Ho, Cheung, \& Cheung, 2010; Holahan, Holahan, \& Suzuki, 2008; Kleftaras \& Psarra, 2012; Low \& Molzahn, 2007; Reker \& Wong, 2012). De hecho, el significado parece tener un poder predictivo importante en la salud mental (Melton \& Schulenberg, 2008), facilita estrategias que nos orientan para sentirnos mejor (Baumeister, 1991), y promueve el bien-estar general (Byron \& Miller-Perrin, 2009). De este modo, el significado se comporta como un mediador entre las variables psicológicas y SCV en muestras sanas. Principalmente, en la relación entre el estrés (Wallace \& Lahti, 2004), el estrés de la aculturación (Pan et al., 2008), la ideación suicida (Heisel \& Flett, 2004), la vocación (Duffy, Allan, \& Bott, 2012), las cogniciones positivas, el afecto positivo (Lightsey \& Boyraz, 2011), las experiencias espirituales (Wnuk \& Marcinkowski, 2014), la religiosidad (Steger \& Frazier, 2005), al igual que en los alcohólicos (Wnuk, 2010). En enfermos oncológicos, el significado media la relación entre las secuelas físicas y la depresión (Simonelli, Fowler, Maxwell, \& Andersen, 2008), el impacto del cáncer de mama y el BEP (Meraviglia, 2006), las respuestas psicológicas y el ajuste al cáncer (Anagnostopoulos, Slater, \& Fitzsimmons, 2010), y entre el funcionamiento social y físico y el distrés (Jim \& Andersen, 2007). 


\subsection{Enfermedad oncológica y coping}

La enfermedad, principalmente el cáncer, es incuestionablemente el mayor estresor en la vida del individuo. Sin embargo, el cáncer se vive de forma diferente a nivel emocional en cada sujeto, al revelarse como una amenaza a la vida e integridad, exige un afrontamiento en todos los pacientes. Subyacente al proceso de la enfermedad, surge la necesidad de adaptación, tanto en el sentido de la calidad de vida, como en el aumento de la longevidad (Rowland, 1989). Nordin y Glimelius (1998), señalan que la adaptación mental al cáncer puede ser definida como una serie de respuestas de comportamiento, cognitivas y emocionales, que el paciente expone ante el diagnóstico y los tratamientos. Rodríguez (1999) pone en evidencia que el cáncer es un proceso continuo que contiene varias etapas, y cada una tiene problemas asociados. La adaptación al impacto del diagnóstico se relaciona con la vida previa y la actual del sujeto, alterándose conforme trascurre la enfermedad y el tratamiento. Meyerowitz, Heinrich, y Schag (1983), señalan que el diagnóstico y el tratamiento del cáncer desarrollan problemas graves a nivel psicológico y médico. La duración de estos problemas está influida por los métodos que los pacientes usan para afrontar la enfermedad.

Watson et al. (1988) definieron la adaptación al cáncer como "respuestas cognitivas y comportamentales que el paciente exhibe ante el diagnóstico de cáncer" (p. 203). A su vez, Lazarus (1999) sugiere que la adaptación consiste en procesos psicológicos, lo que significa que el individuo manipula sus recursos ante las múltiples exigencias y presiones.

Corroborando la importancia del coping en la adaptación psicosocial al cáncer, Livneh (2000) alega que, cuando se afrontan acontecimientos de la vida potencialmente traumáticos, los individuos normalmente recurren a una amplia serie de estrategias de 
coping para aliviar el estrés resultante. Varios estudios aluden a estrategias/estilos de coping más eficaces en el ajuste a la enfermedad, como el espíritu de lucha, así como para los estilos asociados a una peor adaptación a la situación de la enfermedad, como la inhibición/represión emocional, el estoicismo y la desesperanza (Rowland, 1989).

De este modo, Rodríguez (1999) aclara que existen estilos de afrontamiento activos y pasivos. De los activos, surgen los luchadores, un enfermo que acepta el diagnóstico y adopta una actitud optimista, presentando iniciativa en participar en las decisiones relativas al tratamiento. Los enfermos pasivos serían los que tienden a evitar o negar la enfermedad, encauzados por el fatalismo, presentan una preocupación excesiva y una actitud de desesperanza ante la enfermedad. La investigación en esta área ha destacado que los estilos pasivos se asocian a una evolución negativa. El autor añade que los enfermos con una adaptación eficaz a la enfermedad recurren a sus recursos para obtener apoyo emocional, enfrentarse a la situación, buscan información, emiten una actitud positiva, conservan el espíritu de lucha, y tratan de encontrar alivio en su religión.

A su vez, Rowland (1989) indica tres aspectos centrales en el constructo del coping. En primer lugar, las estrategias o estilos que promueven una respuesta activa en la resolución de problemas, siendo el comportamental el más eficaz. En segundo lugar, se añade que el coping con la enfermedad representa un proceso dinámico, alterándose según las circunstancias y a través del cual el individuo da continuidad a la evaluación del significado de su propia supervivencia, de su futuro, de sus relaciones, de su autoestima, y en la creación de objetivos. En tercer y último lugar, destaca que los pacientes que presentan mayor flexibilidad en sus esfuerzos poseen una mayor capacidad de afrontamiento. 
La presencia de la enfermedad física hace que los individuos evalúen la enfermedad y usen posteriormente una diversidad de tareas adaptativas y de competencias de coping que, a su vez, van a determinar los resultados. Sin embargo, no todos los sujetos responden a la enfermedad del mismo modo. El uso de estas tareas y competencias se encuentra determinado por tres factores: los factores demográficos (como la edad, el sexo, la clase social y la religión), los factores físicos y socio/ambientales (como la accesibilidad a las redes de apoyo social y la aceptabilidad del ambiente físico, por ejemplo, los hospitales pueden ser tristes y deprimentes) y los factores relacionados con la enfermedad (como el dolor consecuente, la desfiguración o estigma) (Moos \& Schaefer, 1984). En este ámbito, Lipowski (1969) indica que existen tres factores determinantes en el coping con la enfermedad oncológica, como la naturaleza del estrés, o sea, la enfermedad en sí (el lugar/órgano afectado, estado, tratamiento y recorrido); las variables individuales, destacando en qué momento del ciclo vital surge la enfermedad y los recursos emocionales y sociales disponibles; y, el clima socio-cultural en el cual tiene lugar la recepción del diagnóstico y del tratamiento.

Watson et al. (1988) recurrieron al término adaptación mental con la finalidad de denotar el estilo de coping en individuos con un diagnóstico de cáncer, desarrollando la escala Mental Adjustment to Cancer (MAC), que identifica cinco estilos comportamentales de coping, principalmente, negación/evitación, espíritu de lucha, fatalismo, desamparo/desesperanza y preocupación ansiosa. Estos autores encuentran que los últimos tres estilos de coping están significativamente asociados con la depresión evaluada por la escala The Hospital Anxiety and Depression Scale (HADS) administrada simultáneamente. Watson et al. (1991) en estudios que recurrieron a la escala original MAC, con el objetivo de evaluar la adaptación emocional en pacientes con cáncer, concluyeron que la mayoría de los pacientes tenían altos niveles de 
ansiedad y depresión, estando estos niveles correlacionados con actitudes de desamparo/desesperanza, fatalismo y preocupación ansiosa. Las áreas del espíritu de lucha estaban negativamente asociadas a estados de ansiedad y depresión. De conformidad con el estudio descrito previamente, Schnoll, Mackinnon, Stolbach, y Lorman (1995), demostraron que el espíritu de lucha estaba asociado con una mejor adaptación emocional, y el desamparo/desesperanza y la preocupación ansiosa con una percepción pobre.

Recurriendo a un estudio de meta análisis sobre el proceso de evaluación y coping en pacientes oncológicos, Franks y Roesch (2006) señalan que los enfermos emplean múltiples tipos de estrategias para gestionar el estrés asociado al cáncer. Los autores concluyen que los enfermos que evalúan la enfermedad como daño o pérdida desarrollan estrategias de coping enfocado en la evaluación, finalmente, los enfermos que perciben la enfermedad como un desafío recurren al coping de proximidad. En este estilo de coping, resaltan la búsqueda de apoyo por parte de los amigos, la creencia en la eficacia en su gestión personal sobre la enfermedad, la presencia de optimismo, el autocontrol y una interpretación y aceptación positiva del cáncer.

O’Brien y Moorey (2010) verificaron que el espíritu de lucha en un estado precoz del cáncer comprende optimismo sobre el pronóstico, la creencia de que la enfermedad y/o sus efectos son controlables, y la determinación para afrontar la situación recurriendo a varios métodos activos de coping, orientando el sujeto a una mejor adaptación. En una fase más avanzada de la enfermedad, la utilidad de este estilo de coping es discutible, teniendo en cuenta los múltiples estudios que analizaron las cualidades de un cáncer avanzado. De este modo, una actitud positiva y la autoeficacia pueden asociarse a una mejor adaptación emocional; el coping activo enfocado en el 
problema surge como adaptativo; y la evitación surge como un estilo de coping desadaptativo.

Ogden (1999) destaca la actitud ante la enfermedad y no al tipo de estrategias al que recurre el sujeto al enfrentarse a la misma, concluyendo que el enfermo que responde más velozmente a los cambios provocados por su condición, al desarrollar nuevas estrategias afronta mejor la situación de enfermedad. En este sentido, los individuos que utilizan estrategias de coping más adecuadas a las circunstancias, que mantienen expectativas elevadas en cuanto a los resultados de sus acciones, y sienten que tienen control sobre el proceso de la enfermedad, presentan una mayor calidad de vida.

\subsection{Enfermedad oncológica, satisfacción con la vida y salud-enfermedad}

En la segunda revolución de la salud, el concepto de BES gana relieve asociado a la salud mental, descuidando los aspectos negativos fuertemente asociados a la salud mental, convirtiéndose en un concepto emergente de la psicología positiva. En este sentido, uno de los objetivos de la American Psychologycal Association [APA] en 1998 fue definido por Seligman, descrito para investigar lo que activamente lleva a que los sujetos se sientan completos, involucrados y significativamente felices. A través de este supuesto se produjo un arranque en la investigación de variables positivas, como el optimismo, la felicidad, las emociones positivas y los rasgos de personalidad más saludables (Galinha \& Pais-Ribeiro, 2005).

Como ya se ha referido en el capítulo de la SCV, muchas de las variables positivas han sido centro de confusión y uso simultáneo como sinónimos. En la investigación sobre la SCV y/o bienestar en el ámbito de la salud/enfermedad, los constructos más utilizados son los de CDV y BES. 
En este sentido, Pais-Ribeiro (1997) indica que el aumento del interés al estudiar la CDV en el contexto de la enfermedad, se denomina como "Calidad de Vida relacionada con la salud", en otras palabras, la CDV que se encuentra dependiente de la enfermedad que la persona presenta. En este ámbito, Pimentel (2006) señala que el concepto de CDV relacionado con la salud es diferente de la CDV general, teniendo en cuenta que no existe una única definición de "Calidad de Vida relacionada con la salud", describiéndola como la percepción de los enfermos sobre sus capacidades en cuatro dimensiones: el bienestar físico y las actividades cotidianas, el BEP, las relaciones sociales y los síntomas. A su vez, Leydy, Revicki, y Genesté (1999) mencionan que en el área de la salud, la CDV se asocia a la percepción subjetiva de felicidad o SCV en dominios importantes en la vida del sujeto. De este modo, la CDV puede o no ser influenciada por las condiciones de salud o por el modo en que el sujeto la percibe. En este sentido, se trata de una evaluación subjetiva del enfermo sobre el impacto de su estado de salud en la capacidad de vivir plenamente (Patrick, 2008; Silva \& Derchain, 2006).

Pais-Ribeiro (2006) señala que con tantas definiciones de la CDV relacionada con la salud se engloba una gran amplitud del concepto, revelando su complejidad y la extensión con la que se utiliza. Se refuerza la dificultad de los conceptos utilizados, teniendo en cuenta que la CDV relacionada con la salud es difícil de definir, al considerar su significado personal, histórico, cultural, social, científico y filosófico que remiten a los diversos contextos de la experiencia humana (Pais-Ribeiro, 1997). El autor especifica que las distintas definiciones empleadas incluyen conceptos, tales como, el bienestar, la satisfacción, la felicidad, las expectativas o la funcionalidad (Pais-Ribeiro, 2004). 
Fleer, Hoekstra, Sleijfer, Tuinman, Klip, et al. (2006) ponen en evidencia esta relación al señalar dos modelos teóricos, el Modelo de Satisfacción y el Modelo Funcionalista. El modelo de Satisfacción se basa en las perspectivas de felicidad y bienestar, dado que la CDV está relacionada con la satisfacción en los diferentes contextos de la vida, definidos como importantes para el sujeto. En el modelo Funcionalista hace referencia a la CDV como la forma en que el sujeto desempeña sus papeles sociales y sus funciones, porque el sujeto evalúa positivamente su CDV cuando convive de forma satisfactoria con sus dificultades y limitaciones, comparando su percepción con lo que es posible acceder (Cella \& Cherin, 1988; Fleer, Hoekstra, Sleijfer, Tuinman, Klip et al., 2006).

La mayor parte de la investigación se enfoca más hacia la CDV en el contexto de la salud que del bienestar, siendo necesario el desarrollo de trabajos no sólo para la evaluación de los dominios de la CDV, sino también para la comprensión de los sentimientos del sujeto y de su grado de satisfacción como los agentes activos en el proceso de salud-enfermedad. La comprensión del BES como indicador de CDV permite acceder al conocimiento global y profundo de este concepto en lo cotidiano del sujeto, en sus diferentes dominios y, en especial, en el aspecto psicológico (Naves, 2013).

A nivel de la CDV en el contexto de la enfermedad, se afirma que la investigación de la CDV en la enfermedad oncológica es significativa, ya que "los estudios de cáncer tienden a constituir cerca de un cuarto de todos los estudios sobre la calidad de vida" (Pais-Ribeiro, 2001, p.75). En el ámbito de la oncología, la CDV se define como la percepción individual de bienestar, de un modo multidimensional que generalmente incluye la dimensión física, psicológica, social y espiritual (Ferrel, Dow, \& Grant, 1995). A su vez, Cella y Cherin (1988), definen CDV de enfermos de cáncer como la 
evaluación/satisfacción con respecto al nivel de funcionamiento comparado con lo que entienden como posible o ideal. El interés por la CDV en enfermos oncológicos especifica varias áreas de estudio, como: la prevención, el estilo de vida y compromisos de riesgo, el diagnóstico precoz y factores genéticos, el control sintomático, los protocolos y modalidades del tratamiento, los efectos colaterales, los aspectos psicosociales y de la personalidad, y la fase, tipo y pronóstico de la enfermedad (CostaNeto \& Araújo, 2008; Franco \& Kovács, 2008).

De este modo, se afirma que la CDV de los enfermos oncológicos está influenciada por el tiempo de diagnóstico, por el local/órgano de la enfermedad y por el tipo de tratamiento utilizado (Santos, Moura, Santos, Figueiroa, \& Souza, 2012). La investigación señala también que los efectos secundarios del tratamiento proporcionan datos importantes para la evaluación de la CDV en relación a la salud, y el miedo a la recidiva predice un peor funcionamiento psicológico, estando este miedo influenciado por el tipo de cáncer o por el tipo de tratamiento (Kim, Carver, Spillers, Love-Ghaffari, \& Kaw, 2012; Philip, Merluzzi, Peterman, \& Cronk, 2009). Se observa también que gran parte de las investigaciones sobre CDV se centra en las dificultades enfrentadas por los pacientes durante la fase de la enfermedad, pero pocos realzan los cambios positivos que los supervivientes experimentan (Eiser, 2009).

El bienestar integra la definición de salud, y la salud a su vez, es la variable que mejor explica la CDV (Pais-Ribeiro, 1998). El concepto de CDV se considera abarcador, incluyendo las condiciones de vida y la experiencia de vida, esta última es dominio del BES (Hughes, 1993). Así, Pais-Ribeiro (2006) indica que la psicología positiva señala varias variables psicológicas como amortiguadoras entre condiciones amenazadoras/estresantes y la integridad personal, la enfermedad y el bienestar 
personal, entre las que, principalmente, se encuentran el coping, el BES, el optimismo, la felicidad y el BEP.

De acuerdo con lo expuesto, la psicología positiva se enfoca a comprender el bienestar humano, estudiando múltiples variables psicológicas que promueven o se relacionan con las causas de bienestar (Seligman, Steen, Park, \& Peterson, 2005). La psicooncología estudia las variables y/o los factores positivos para la promoción o protección del bienestar ante la adversidad de la enfermedad oncológica (Ruini \& Vescovelli, 2013). En este punto, el BES predice una adaptación eficaz al cáncer (Hou \& Lam, 2014), y la percepción de satisfacción en la vida se asocia a una mayor percepción de salud en enfermos oncológicos (Matthews, Baker, Hann, Denniston, \& Smith, 2002). En este sentido se concluye que la satisfacción y la CDV deben ser tenidas en cuenta en la gestión y tratamiento de enfermos oncológicos (Fasching et al., 2007). 


\section{Objetivos e Hipótesis}




\section{OBJETIVOS E HIPÓTESIS}

Tras la revisión de la literatura que hemos realizado, nos planteamos los siguientes objetivos:

Objetivo 1: Construir y adaptar a la población portuguesa un cuestionario basado en el modelo teórico de Inteligencia emocional desarrollado por Mayer y Salovey (1997)

Objetivo 2: Analizar las relaciones entre la Inteligencia emocional, el Significado en la vida y la Satisfacción con la vida en personas saludables y en enfermos oncológicos.

Objetivo 3: Evaluar los efectos de la mediación de las variables del Coping en la relación entre la Inteligencia emocional y la Satisfacción con la vida en enfermos oncológicos.

Para conseguir los objetivos 2 y 3 se formularon las siguientes hipótesis:

$\mathbf{H}_{1.1}$ : La Inteligencia emocional se relaciona de forma positiva con la Satisfacción con la vida.

$\mathbf{H}_{1.2}$ : La Inteligencia emocional se relaciona de forma positiva con la dimensión Vivencial del Significado en la vida.

$\mathbf{H}_{1.3:}$ La Inteligencia emocional se relaciona de forma positiva con la dimensión Existencial del Significado en la vida.

$\mathbf{H}_{1.4:}$ El Significado en la vida se relaciona de forma positiva con la Satisfacción con la vida.

$\mathbf{H}_{2:}$ Las estrategias de Coping positivas son mediadoras de la relación entre la Inteligencia emocional y la Satisfacción con la vida en los enfermos oncológicos. 
Construcción y validación
del CIE-AP 


\section{CONSTRUCCIÓN Y VALIDACIÓN DEL CUESTIONARIO DE} AUTOPERCEPCIÓN DE INTELIGENCIA EMOCIONAL (CIE-AP)

Para la consecución del primer objetivo el presente estudio está enfocado hacia la construcción y validación del Cuestionario de Autopercepción de Inteligencia Emocional (CIE-AP). Para ello, y utilizando dos muestras independientes primero se efectúa un análisis factorial exploratorio (AFE) y luego un análisis factorial confirmatorio (AFC).

Ante la dificultad de encontrar un instrumento que tuviese por base un modelo teórico representativo del constructo en medida, se optó por construir y validar un cuestionario basado en el modelo teórico de Mayer y Salovey (1997) que ha sido señalado como el mejor modelo para evaluar y comprender la IE, tanto en su definición como en sus métodos de medida (Extremera \& Fernández-Berrocal, 2005b; Mayer et al., 2000; Roberts et al., 2001), además, porque su teoría no se basa en promesas insostenibles en relación al potencial de la IE (Woyciekoski \& Hutz, 2009).

\subsection{Construcción del instrumento}

Se decidió explorar la composición factorial y la estructura del CIE-AP para determinar el grado de correspondencia de la serie de ítems iniciales con las dimensiones del modelo de Mayer y Salovey (1997), correspondientes a los factores de Percepción, evaluación y expresión emocional; Facilitación emocional en el pensamiento; Comprensión y análisis emocional; y Regulación emocional.

\subsubsection{Material y método}

\subsubsection{Instrumentos}

Con la finalidad de concretizar el objetivo del presente estudio se recurrió a un cuestionario socio-demográfico y a la construcción de un cuestionario sobre la 
Autopercepción de Inteligencia Emocional (CIE-AP). El Cuestionario sociodemográfico recogía las siguientes variables: sexo, edad, profesión, estado civil, escolaridad y municipio en el que habitan.

Por los motivos señalados y que se exploran en el capítulo 2.4, se procedió a la elaboración de un instrumento de raíz, basado en el Modelo de Inteligencia Emocional de Mayer y Salovey (1997), pioneros en el ámbito del tratamiento científico de la IE. El modelo está constituido por cuatro dimensiones: a) Percepción, evaluación y expresión emocional; b) Facilitación emocional en el pensamiento; c) Comprensión y análisis emocional; y, d) Regulación emocional. Para la selección de los ítems fueron considerados los principios de Freire y Almeida (2001), con recurso a "contacto con otras escalas, el empleo de bibliografía en el área y el contacto con especialistas en los dominios a evaluar" (p.113), construyéndose varios ítems para cada dimensión componente del modelo teórico, siendo este listado valorado por especialistas en el área. De este modo, la versión experimental del cuestionario fue analizada por un comité compuesto por cuatro peritos con el objetivo de verificar la claridad, equivalencia y ambigüedad de los ítems en la población portuguesa. Los criterios de inclusión de los peritos fueron la experiencia reconocida en el desarrollo de investigación y la práctica en el área de la psicología de la salud y su experiencia en el desarrollo de instrumentos psicométricos en el contexto clínico. Los ítems fueron construidos bajo la forma de pregunta cerrada, optándose por el uso de una escala tipo Likert de cinco alternativas (1 - Totalmente en desacuerdo a 5 - Totalmente de acuerdo), por ser más consensuado (Freire \& Almeida, 2001; Hill \& Hill, 2005). Mientras que algunos ítems fueron formulados de modo positivo, otros se formularon en negativo, obligando a que algunas cuestiones fuesen inversamente puntuadas (Hill \& Hill, 2005). 
La versión experimental fue posteriormente objeto de un estudio piloto, consistiendo en la cumplimentación del cuestionario y en la realización de una entrevista (reflexión hablada) a un grupo piloto $(n=10)$, con el propósito de verificar si existían problemas en la comprensión y en el formato del cuestionario. Tras el análisis, ningún ítem fue modificado. Este pretest, de acuerdo con Fortin (1999), es el "ensayo de un instrumento de medida (...) antes de su utilización a mayor escala (...) medida de una variable efectuada en los sujetos antes de que se aplique el tratamiento experimental" (p.373). El objetivo de su aplicación es evaluar la eficacia de un cuestionario, verificando si el lenguaje empleado es perceptible, si las cuestiones recogen la información pretendida, si el cuestionario es demasiado largo, provocando desinterés o si las cuestiones son ambiguas. La "reflexión hablada" consiste en un proceso de perfección de los ítems a través del intercambio de comentarios, de la verificación de la comprensibilidad de los ítems y de las instrucciones de cumplimentación y del análisis de las interpretaciones llevadas a cabo. Se trata de una fase más cualitativa de la construcción de la escala que guía el análisis, la reformulación y la selección de los ítems (Freire \& Almeida, 2001).

\subsubsection{Muestra y procedimiento}

Para construir el cuestionario se recurrió a una muestra de conveniencia, constituida por ciudadanos de la población portuguesa que habitan en el norte y centro de Portugal. Se ha recogido la muestra en instituciones públicas, como escuelas para obtener edades más jóvenes e instituciones sociales para los adultos, siempre con la autorización previa de las mismas. En la recogida de datos todos los participantes fueron previamente informados sobre los objetivos y procedimientos de la investigación, asumiendo la confidencialidad de los datos, todos otorgaron su 
consentimiento informado, previamente a la aplicación de los instrumentos, cumplimentándolos frente a la investigadora. Los criterios de inclusión fueron:

- tener nacionalidad y dominio de la lengua portuguesa,

- edad comprendida igual o superior a los 16 años,

- saber leer y escribir y

- no padecer de enfermedad crónica.

La muestra quedó constituida por 191 sujetos, siendo el 64,4\% de género femenino y el 35,6\% de género masculino, con edades comprendidas entre los 16 y los 75 años, presentando una media de 31 años de edad $(D T=12,983)$. El estado civil más frecuente fue el de soltero(a), dado que representaba un $52,4 \%$ de la muestra, siendo precedido por el estado civil de casado con un 38,7\% (Figura 7). La mayoría de la población es estudiante $(27,2 \%)$, especialistas de profesiones intelectuales y científicas $(24,6 \%)$, y personal de servicios y vendedores (23\%) de acuerdo con la clasificación portuguesa de profesiones (CPP) (Figura 8), creada por el Instituto de Empleo y Formación Profesional (INE, 2011). A nivel educacional destaca que el 27,2\% tienen la Enseñanza Secundaria completa, el $26,7 \%$ es licenciado y el 16,2\% posee la Enseñanza Secundaria incompleta (Figura 9).

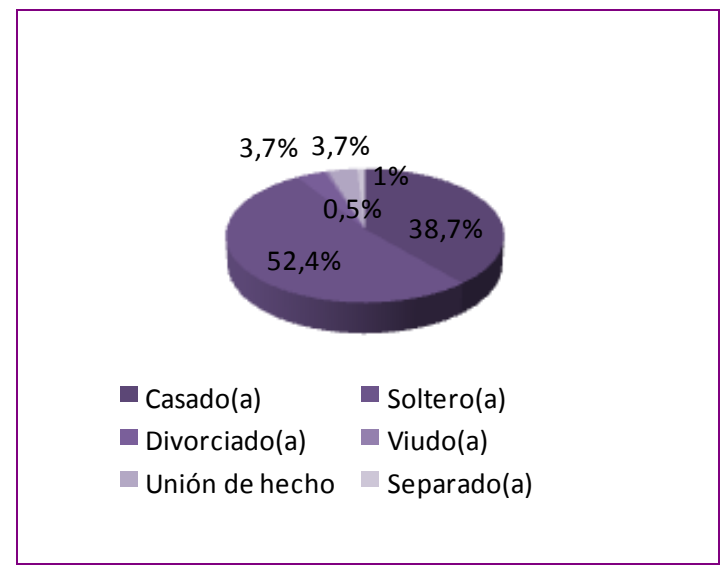

Figura 7: Estado Civil

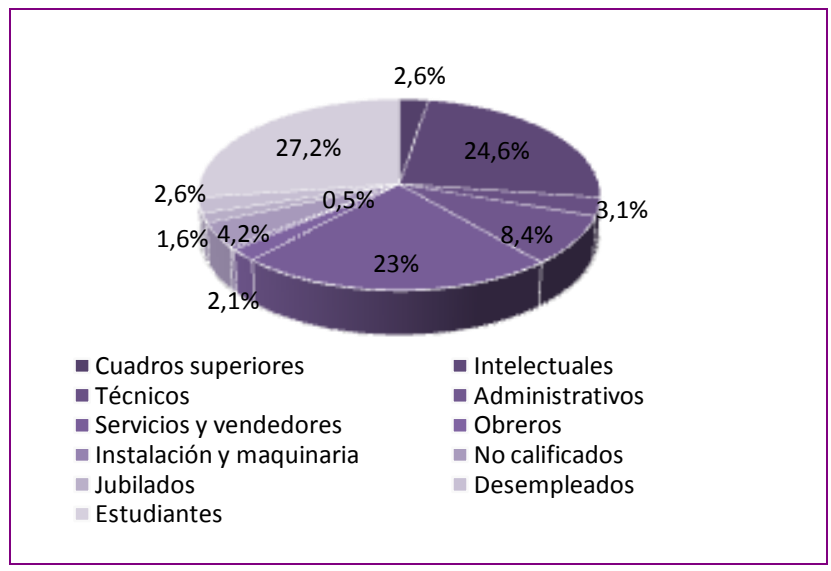

Figura 8: Profesiones 


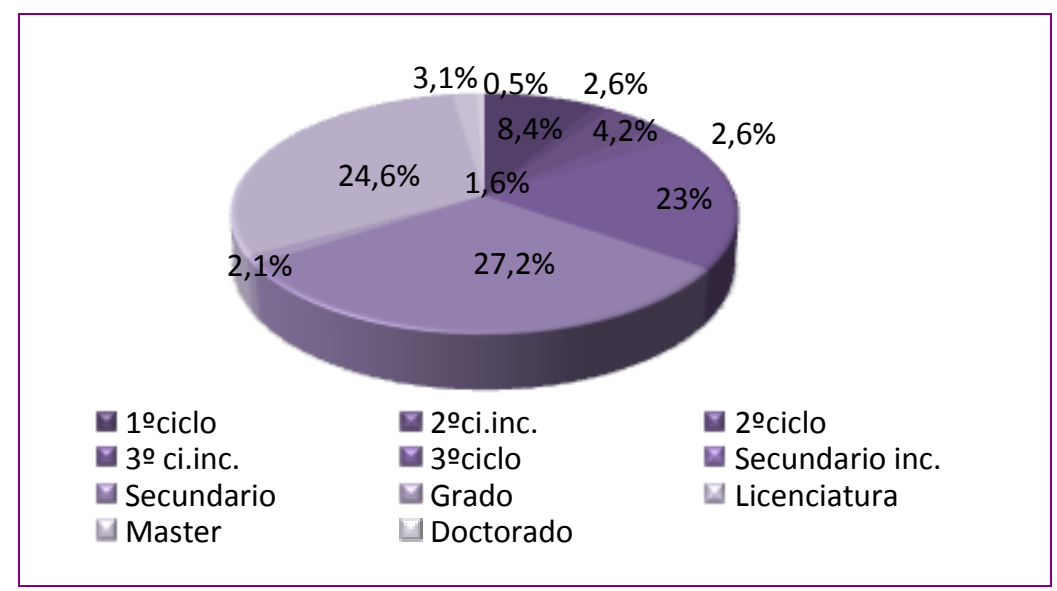

Figura 9: Nivel Educativo

\subsubsection{Análisis de datos}

Se procedió al análisis de los datos a través del programa de tratamiento estadístico Statistical Package for Social Sciences (SPSS), versión 20.0 para Windows. La estructura factorial del CIE-AP fue examinada inicialmente a través del análisis factorial exploratorio (AFE), utilizando el método de extracción de los componentes principales, seguido de la rotación oblicua de los factores, para que se pueda obtener una solución factorial más clara y objetiva, maximizando así los pesos factoriales de los ítems (Brown, 2006). El análisis de los datos siguió seis etapas fundamentales: 1) Criterio de Kaiser-Meyer-Olkin (KMO): retener factores con valor propio igual o superior a 1 ; 2) peso factorial: retener ítems con pesos iguales o superiores a 0,$4 ; 3$ ) pesos factoriales cruzados: inexistencia de ítems con pesos factoriales con alguna relevancia $(>0,30)$ en más que un factor. En caso de que suceda y la diferencia entre ellos no sea superior a 0,15 , el ítem deberá ser eliminado; 4) porcentaje de la variancia: el conjunto de los factores retenidos deben explicar por lo menos un $40 \%$ de la variancia de los resultados; 5) consistencia interna: la fiabilidad interna del factor deberá ser igual 
o superior a 0,70 (Nunnaly \& Bernstein, 1994); y 6) sólo se deberán retener los factores con por lo menos 3 ítems.

\subsubsection{Resultados}

La medida de adecuación de la muestra (test $\mathrm{KMO}=0,83$ ) indicó que el análisis de los componentes principales puede ser realizado y el test de esfericidad significativo $(2701,002 ; p<0,05)$ reveló que los ítems son interdependientes (Worthington \& Whittaker, 2006). Así, a través de los resultados del AFE, presentados en el Scree plot (Figura 10), verificamos una solución de cuatro factores que explican el 51,32\% del total de la variancia de los resultados. En la Tabla 8 sólo se indican los pesos factoriales correspondientes a la matriz de estructura que tienen en consideración la correlación entre los factores, así como aquellos que se consideran relevantes como valor mínimo para poder ser interpretados $(0,40)$ (Hair, Black, Babin, \& Anderson, 2010). En este sentido, los pesos factoriales varían entre 0,49 y 0,83 y los coeficientes de consistencia interna del $\alpha$ de Cronbach son aceptables (Nunnaly \& Bernstein, 1994): 0,73 (F1: Percepción, evaluación y expresión emocional), 0,70 (F2: Facilitación emocional en el pensamiento), 0,73 (F3: Comprensión y análisis emocional), y 0,77 (F4: Regulación emocional). La versión final de la escala quedó con 18 ítems y obtuvo un índice general de consistencia interna de 0,83 ( $\alpha$ de Cronbach). 
Tabla 8: Medias, desviación típica, comunalidades y la solución de 4 factores del CIE-AP (rotación oblicua)

\begin{tabular}{|c|c|c|c|c|c|c|}
\hline Ítems & $M \pm D t$ & Comunalidades & Factor 1 & Factor 2 & Factor 3 & Factor 4 \\
\hline Ítem 23 & $4,01 \pm 0,85$ & 0,58 & 0,73 & & & \\
\hline Ítem 16 & $3,97 \pm 0,91$ & 0,51 & 0,67 & & & \\
\hline Ítem 29 & $3,83 \pm 0,90$ & 0,45 & 0,65 & & & \\
\hline Ítem 3 & $4,67 \pm 0,63$ & 0,41 & 0,60 & & & \\
\hline Ítem 10 & $4,14 \pm 0,88$ & 0,37 & 0,50 & & & \\
\hline Ítem 20 & $4,25 \pm 0,78$ & 0,41 & 0,49 & & & \\
\hline Ítem 18 & $3,87 \pm 0,97$ & 0,60 & & 0,76 & & \\
\hline Ítem 14 & $4,07 \pm 0,85$ & 0,59 & & 0,73 & & \\
\hline Ítem 9 & $3,69 \pm 0,89$ & 0,54 & & 0,72 & & \\
\hline Ítem 30 & $4,08 \pm 0,93$ & 0,45 & & 0,64 & & \\
\hline Ítem 4 & $4,55 \pm 0,90$ & 0,54 & & & 0,71 & \\
\hline Ítem 6 & $4,13 \pm 0,97$ & 0,52 & & & 0,67 & \\
\hline Ítem 12 & $4,30 \pm 0,83$ & 0,57 & & & 0,66 & \\
\hline Ítem 26 & $4,09 \pm 1,00$ & 0,42 & & & 0,62 & \\
\hline Ítem 2 & $4,33 \pm 0,83$ & 0,39 & & & 0,52 & \\
\hline Ítem 19 & $4,14 \pm 0,91$ & 0,71 & & & & 0,83 \\
\hline Ítem 21 & $4,05 \pm 0,84$ & 0,67 & & & & 0,80 \\
\hline Ítem 24 & $4,34 \pm 0,85$ & 0,60 & & & & 0,75 \\
\hline Variancia (\%) & & & 14,06 & 12,88 & 12,86 & 12,50 \\
\hline$\alpha$ Cronbach & & & 0,73 & 0,70 & 0,73 & 0,77 \\
\hline
\end{tabular}

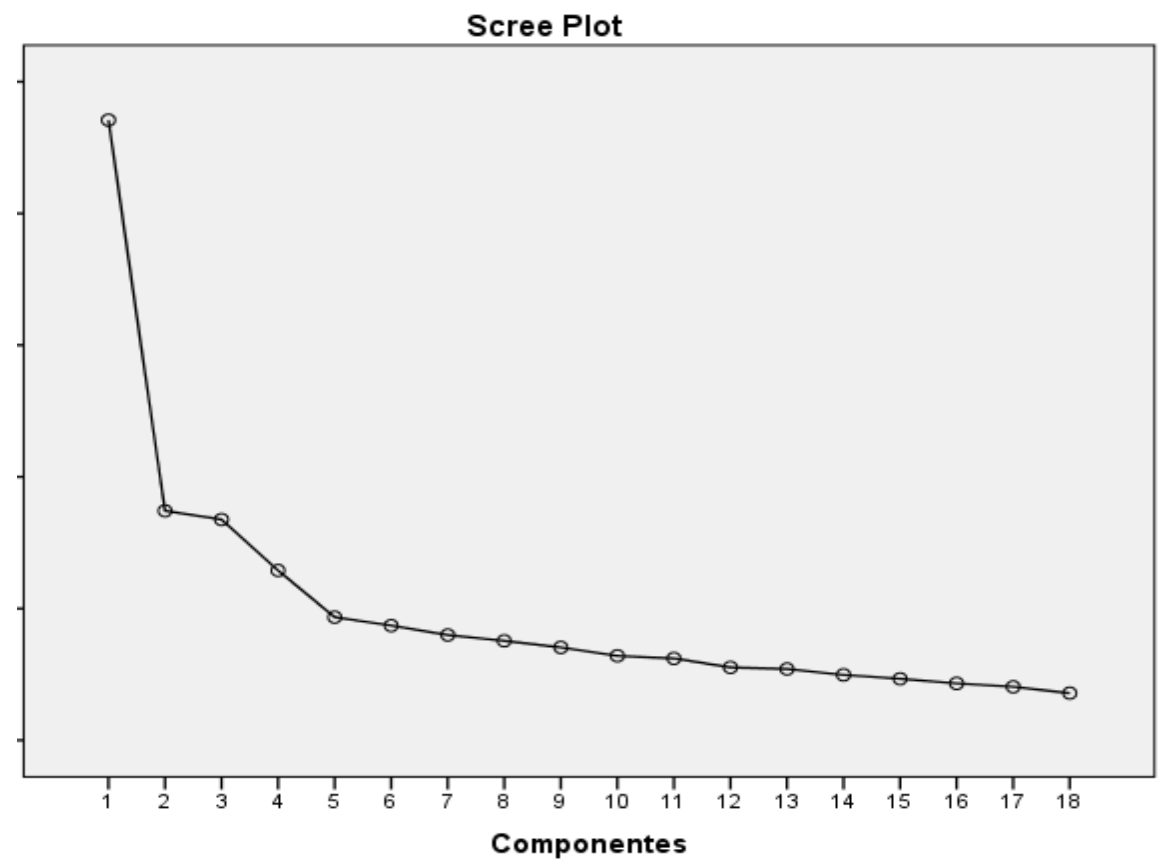

Figura 10: Scree plot de la extracción de los factores 
El objetivo del estudio fue explorar la dimensionalidad latente y la estructura de los ítems del CIE-AP y analizar las interrelaciones entre los constructos del CIE-AP. Los resultados indican que los 18 ítems del CIE-AP exhiben una estructura simple interpretable, siendo consistente con el Modelo de Inteligencia Emocional (Mayer \& Salovey, 1997). Se añade que la estructura psicométrica del CIE-AP reveló fiabilidad.

\subsection{Validación del instrumento}

Tiene por objetivo ampliar la validez del constructo de las puntuaciones del CIEAP, testando el ajuste del modelo identificado en el Subestudio 1, usando el análisis factorial confirmatorio (AFC) con una muestra independiente. Adicionalmente, se efectuaron dos análisis multigrupos para determinar la invariancia de las puntuaciones del CIE-AP entre las muestras independientes de los dos subestudios, y entre los géneros. La invariancia se refiere al significado equivalente de las puntuaciones en grupos diferentes (Cheung \& Rensvold, 2002), siendo las comparaciones entre grupos de base una consideración importante en el desarrollo de escalas de medida (Hoyle \& Smith, 1994; Loehlin, 2004).

\subsubsection{Material y método}

\subsubsection{Instrumentos}

Los instrumentos utilizados fueron los mismos del estudio anterior, el Cuestionario sociodemográfico y el CIE-AP resultado del análisis factorial exploratorio realizado.

El CIE-AP está constituido por cuatro dimensiones consistentes con el Modelo de Inteligencia Emocional de Mayer y Salovey (1997): a) percepción, evaluación y expresión emocional - está compuesta por cuatro ítems (por ejemplo, “Existen personas que se muestran más felices de lo que realmente son.", "A través del tono de voz y de 
los gestos de los demás, soy capaz de percibir si están tristes o enfadados."), y su escala de respuesta se sitúa entre 1 (Totalmente en desacuerdo) y 5 (Totalmente de acuerdo), esta dimensión evalúa la capacidad de la persona para describir y distinguir sus emociones y las de otras personas; b) facilitación emocional en el pensamiento presenta cinco ítems (por ejemplo, "Me siento feliz al pensar en las cosas buenas que tengo.", "Cuando estoy más triste tengo menos ganas de hacer cosas."), los participantes responden en la misma escala de Likert de 1 a 5, esta dimensión pretende comprender si los sujetos apoyan su proceso de información y decisión en las emociones sentidas; c) comprensión y análisis emocional - está constituida por seis ítems (por ejemplo, "La pérdida de alguien a quien quiero me deja triste.", "Existen personas a las que quiero y otras que me son indiferentes.”), y presenta el mismo patrón de respuesta de 1 a 5, esta dimensión se relaciona con la capacidad con que el sujeto asocia las emociones a situaciones y personas específicas; d) regulación emocional - está formada por tres ítems (por ejemplo, "Procuro hacer lo que me da más placer.", "Intento realizar actividades de las que disfrutamos los demás y yo.”). La respuesta es igualmente dada en una escala de 1 a 5 . Se relaciona con la capacidad de la persona controlar su postura, expresión y decisión comportamental ante emociones positivas o negativas, llevando a la ampliación de las situaciones placenteras y a evitar las situaciones que conllevan emociones negativas, sin perjudicar el suceso personal y social, connotando siempre un aprendizaje y crecimiento emocional favoreciendo su bienestar, así como el de los demás. Los ítems invertidos del CIE-AP son "Cuando me siento feliz me siento con menos energía.” y “Cuando estoy triste tengo pensamientos más positivos.”.

\subsubsection{Muestra y procedimiento}

Los procedimientos de recogida y los criterios de inclusión fueron los mismos de la muestra anterior. La muestra está constituida por 210 sujetos, 73,3\% de género 
femenino y el $26,7 \%$ de género masculino, con edades comprendidas entre los 16 y los 71 años presentando una media de 32,65 años de edad $(D T=15,414)$. El estado civil más frecuente fue el de soltero(a) (55,2\%), seguido de casado con un 36,2\% (Figura 11). La mayoría de la población es estudiante (40,5\%), especialistas de profesiones intelectuales y científicas $(28,6 \%)$, y personal de servicios y vendedores $(12,9 \%)$ de acuerdo con la clasificación portuguesa de profesiones (CPP) (Figura 12), creada por el Instituto de Empleo y Formación Profesional (INE, 2011). A nivel educacional destaca que el 28,6\% tienen la Enseñanza Secundaria incompleta, el 27,6\% es licenciado y el 23,3\% posee la Enseñanza Secundaria completa (Figura 13).

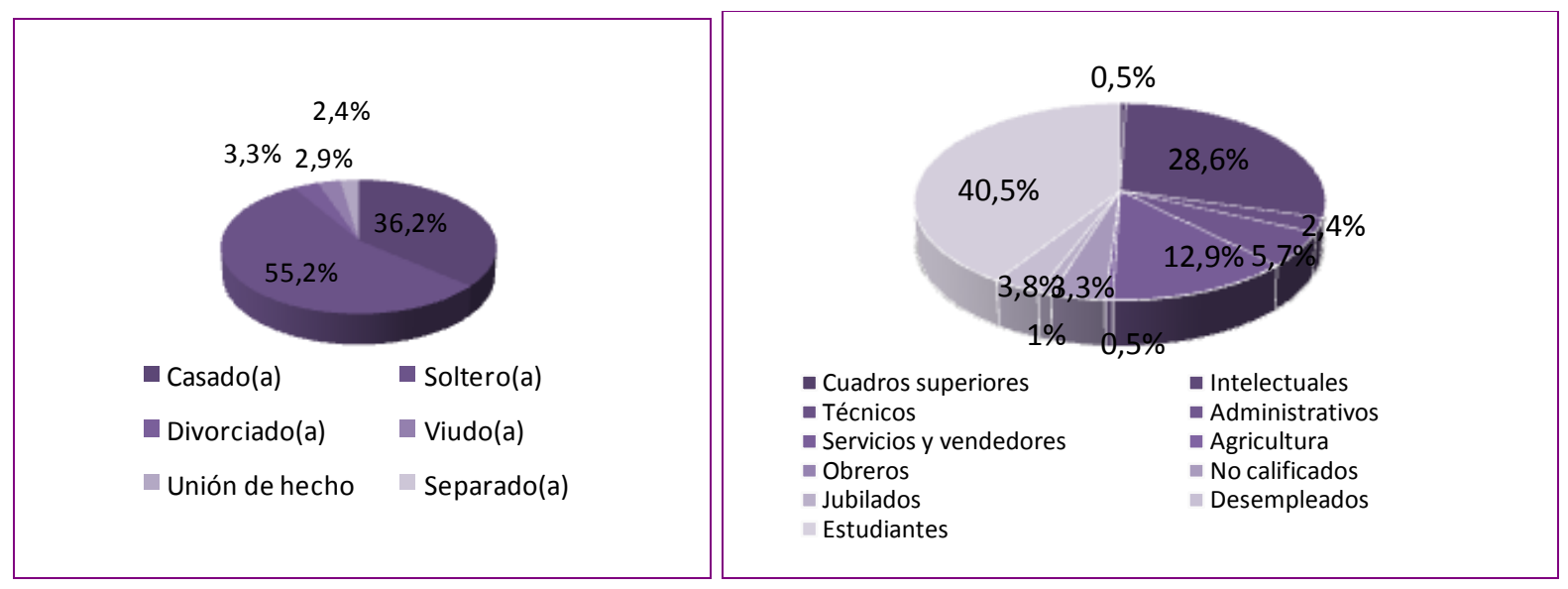

Figura 11: Estado Civil

Figura 12: Professiones

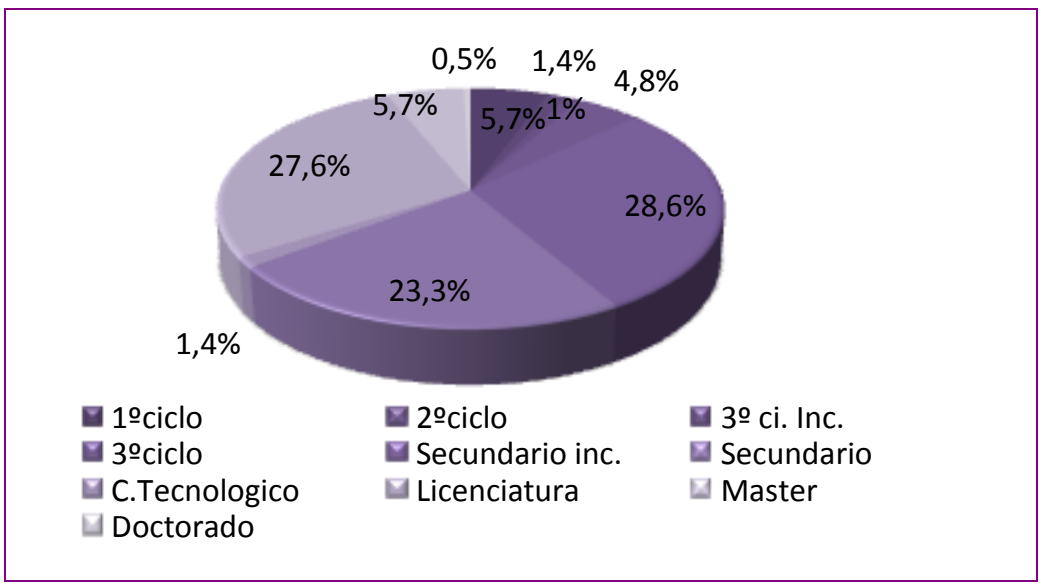

Figura 13: Nivel Educativo 


\subsubsection{Análisis de datos}

El análisis de los datos se realizó en cinco etapas. En primer lugar, los datos fueron analizados para identificar potenciales valores discrepantes, no respuestas o discrepancias que influyen de forma negativa en los análisis subsecuentes. En segundo, fueron calculadas las estadísticas descriptivas de los ítems del CIE-AP para seleccionar el procedimiento estadístico apropiado para el análisis factorial confirmatorio (AFC). En tercero, se ejecutó el AFC recurriendo al AMOS 20 (SPSS Inc, Chicago IL) para determinar el ajuste de la medida oblicua de los cuatro factores del modelo para explicar los resultados observados del CIE-AP. En este ámbito, el ajuste del modelo fue evaluado por un conjunto de índices de ajuste. Específicamente, se consideró buen ajuste cuando el Chi-cuadrado $\left(\chi^{2}\right)$ y sus grados de libertad son inferiores a 3,0, y el Comparative-of-fit-index (CFI) y el Tucker-LewisIndex (TLI) fueron superiores a 0,90 (Hair et al., 2010). Valores del Root mean square error of approximation (RMSEA) por debajo de 0,06 son indicadores de un buen ajuste, mientras que si son entre 0,08 y 0,10 se consideran aceptables (Byrne, 2010). En cuarto lugar se analizaron los principios de fiabilidad, validez convergente y discriminante. La fiabilidad de los constructos fue estimada a través del coeficiente del $\alpha$ Cronbach y valores por encima de 0,70 fueron considerados aceptables (Nunnaly \& Bernstein, 1994). La variancia extraída media (VEM) fue evaluada como criterio de validez convergente y valores superiores a 0,50 fueron considerados adecuados para demostrar validez convergente (Fornell \& Larcker, 1981; Hair et al., 2010). La validez discriminante fue asumida cuando la VEM de cada constructo es superior al cuadrado de las correlaciones entre los otros constructos (Fornell \& Larcker, 1981).

En último lugar, se ejecutaron dos análisis multigrupos con el objetivo de testar la invariancia del modelo entre las muestras independientes del Subestudio 1 y del 
presente estudio, y la invariancia de las respuestas entre géneros. A la invariancia entre modelos se accedió a través del test de la significancia del chi-cuadrado y de la diferencia de los valores del CFI ( $\triangle C F I$ ) (Cheung \& Rensvold, 2002). Si los valores del $\chi^{2}$ en la comparación entre modelos no fuese estadísticamente significativo $(p>0,05)$, la hipótesis de invariancia debería ser considerada. Sin embargo, Cheung y Rensvold (2002) señalan que el test del chi-cuadrado se ve influido por el tamaño de la muestra. En este sentido, propone el análisis de las alteraciones en el $\triangle C F I$ superiores a 0,01 , como un criterio alternativo para evaluar la invariancia multigrupos. La evaluación de la invariancia entre grupos se ejecuta por el test secuencial de los siguientes modelos: Modelo 1 - no constreñido; Modelo 2 - pesos factoriales; Modelo 3 - varianciascovariancias.

\subsubsection{Resultados}

Se analizó la normalidad de los datos y la existencia de no respuestas (Tabachnick \& Fidell, 2007). No se encontraron no respuestas, ni se identificaron outliers, tanto univariados (valores de skewness $<3$; valores de kurtosis $<7$ ) como multivariados $\left(\right.$ distancia Mahalanobis $\left.<\chi^{2}(3)=40,236\right)($ Kline, 2011).

Los resultados obtenidos por el modelo de medida indican un ajuste aceptable $\left[\chi^{2} / d f=1,76 ; \mathrm{CFI}=0,955, \mathrm{TLI}=0,946, \mathrm{RMSEA}=0,044(\mathrm{IC}=0,03 ; 0,05)\right] . \mathrm{La}$ estadística del $\chi^{2}$ y de sus grados de libertad presenta valores adecuados. Sin embargo, es importante considerar otros índices debido a que la estadística del $\chi^{2}$ es sensible al tamaño de la muestra (Hair et al., 2010). Ambos valores del CFI y del TLI, se encuentran en los criterios aceptables, mientras que el valor del RMSEA es indicador de un buen ajuste. Adicionalmente, tal como consta en la Tabla 9, los ítems demuestran pesos factoriales entre 0,46 y 0,85 . Los coeficientes del $\alpha$ Cronbach soportan la 
fiabilidad de los constructos, entre 0,70 (Percepción, evaluación y expresión emocional) y 0,77 (Regulación emocional) (Tabla 9).

Tabla 9: Pesos factoriales y coeficientes de consistencia interna ( $\alpha$ Cronbach)

\begin{tabular}{|c|c|c|}
\hline Constructos/Ítems & $\begin{array}{l}\text { Pesos } \\
\text { factoriales }\end{array}$ & a \\
\hline Percepción, evaluación y expresión emocional & & 0,73 \\
\hline $\begin{array}{l}\text { 5. Existen personas que parecen más felices de lo que } \\
\text { realmente son. }\end{array}$ & 0,69 & \\
\hline $\begin{array}{l}\text { 8. A través del tono de voz y de los gestos de los demás, soy } \\
\text { capaz de percibir si están tristes o enfadados. }\end{array}$ & 0,77 & \\
\hline $\begin{array}{l}\text { 10. Algunas personas son capaces de fingir que están tristes } \\
\text { para llamar la atención. }\end{array}$ & 0,68 & \\
\hline 18. Los animales de compañía pueden hacernos sentir bien. & 0,69 & \\
\hline Facilitación emocional en el pensamiento & & 0,70 \\
\hline 1. Soy feliz cuando pienso en las cosas buenas que tengo. & 0,63 & \\
\hline 3. Cuando me siento feliz, me siento con menos energía. (-) & 0,68 & \\
\hline 4. Cuando estoy más triste tengo menos ganas de hacer cosas. & 0,64 & \\
\hline 7. Cuando estoy alegre hago más cosas. & 0,73 & \\
\hline 16. Cuando estoy triste tengo pensamientos más positivos. (-) & 0,51 & \\
\hline Comprensión y análisis emocional & & 0,73 \\
\hline 2. La pérdida de alguien a quien quiero me deja triste. & 0,67 & \\
\hline $\begin{array}{l}\text { 6. Existen personas a las que quiero y otras me son } \\
\text { indiferentes. }\end{array}$ & 0,66 & \\
\hline $\begin{array}{l}\text { 9. En un mal momento se pueden sentir varias emociones } \\
\text { como miedo, tristeza, rabia. }\end{array}$ & 0,70 & \\
\hline $\begin{array}{l}\text { 12. Cuando me elogian siento alegría y orgullo al mismo } \\
\text { tiempo. }\end{array}$ & 0,65 & \\
\hline $\begin{array}{l}\text { 14. Los pensamientos negativos me dejan triste o } \\
\text { desanimado(a). }\end{array}$ & 0,45 & \\
\hline $\begin{array}{l}\text { 17. Cuando tengo en cuenta mis sentimientos es más fácil } \\
\text { tomar decisiones. }\end{array}$ & 0,84 & \\
\hline Regulación emocional & & 0,77 \\
\hline 11. Procuro hacer lo que me da más placer. & 0,74 & \\
\hline $\begin{array}{l}\text { 13. Intento realizar actividades de las que disfrutamos los } \\
\text { demás y yo. }\end{array}$ & 0,74 & \\
\hline $\begin{array}{l}\text { 15. Convivo cuanto puedo con las personas que me hacen } \\
\text { sentir bien. }\end{array}$ & 0,52 & \\
\hline
\end{tabular}

La Facilitación emocional en el pensamiento fue la variable con la media más elevada $(M=4,21 ; D T=0,69)$, mientras que la Percepción, evaluación y expresión emocional presentó la media más baja $(M=3,94 ; D T=0,67)$. Los constructos de Percepción, evaluación y expresión emocional $(0,51)$ y Regulación emocional $(0,61)$ revelaron validez convergente (VEM $\geq 0,50$ ) (Loehlin, 2004). Mientras tanto, los valores de la VEM referentes a la Facilitación emocional en el pensamiento $(0,41)$ y a la Comprensión y análisis emocional $(0,38)$ revelaron ser insuficientes para garantizar una 
validez convergente. Y al evaluar por la matriz de correlación, se verifica que los cuatro factores se correlacionan entre ellos. A su vez, la evidencia de validez discriminante quedó demostrada, dado que ningún cuadrado de las correlaciones excedió los valores de la VEM asociados a cada constructo (Tabla 10). Considerando la originalidad de los fundamentos teóricos de la escala, no se introdujo ninguna reespecificación a la estructura del modelo.

Tabla 10: Correlaciones, medias, desviación típica y variancia extraída media

\begin{tabular}{lllll}
\hline \multirow{2}{*}{ Constructos } & \multicolumn{4}{c}{ Matriz de correlación } \\
\cline { 2 - 5 } & $\mathbf{1}$ & $\mathbf{2}$ & $\mathbf{3}$ & $\mathbf{4}$ \\
\hline Percepción & 1 & & & \\
Facilitación & $0,27^{*}$ & 1 & 1 & \\
Comprensión & $0,30^{*}$ & $0,42^{*}$ & $0,22^{*}$ & 1 \\
Regulación & $0,16^{*}$ & $0,23^{*}$ & 4,09 & 4,10 \\
$M$ & 3,94 & 4,21 & 0,59 & 0,82 \\
$D T$ & 0,67 & 0,69 & 0,38 & 0,61 \\
$V E M$ & 0,51 & 0,41 & & 0,38 \\
\hline
\end{tabular}

Nota. El cuadrado de la correlación más elevada es inferior a los valores de la VEM, revelando validez discriminante en todos los factores; * $p<0,01$.

Se ejecutaron los análisis multigrupo para testar la invariancia del modelo en los momentos independientes de evaluación utilizando las muestras del subestudio anterior $(n=191)$ y del presente $(n=210)$, y en las respuestas entre mujeres $(n=277)$ y hombres $(n=124)$. Primero, el análisis ejecutado con las dos muestras independientes reveló buenos índices de ajuste del modelo no constreñido [Modelo 1: $\chi^{2}(258)=392,62$ $(p=0,000)$, TLI $=0,90$, CFI $=0,93$, RMSEA $=0,03]$. Los modelos con los pesos factoriales constreñidos [Modelo 2: $\chi^{2}(272)=404,39(p=0,000)$, TLI $=0,90$, CFI $=$ $0,94, \operatorname{RMSEA}=0,03]$ y con las variancias-covariancias constreñidas revelaron ajustes adecuados $\left[\right.$ Modelo 3: $\chi^{2}(282)=423,82(p=0,000)$, TLI $=0,89$, CFI $=0,93$, RMSEA $=$ 0,03]. El test de la significancia del chi-cuadrado $\left(\chi^{2}\right)$ y a las diferencias del CFI $(\Delta C F I)$ no demostraron alteraciones significativas al ser comparados los Modelos 1 y 2 
$\left[\chi^{2^{\mathrm{dif}}}(14)=11,77 ; p=0,62 ; \Delta C F I \leq 0,01\right]$, así como los modelos 1 y $3\left[\chi^{\chi^{\mathrm{dif}}}(24)=31,20 ; p\right.$ $=0,14 ; \Delta C F I \leq 0,01]$.

Segundo, el análisis multigrupos que accedió a la sensibilidad de las respuestas entre géneros, el modelo constreñido reveló valores ajustados [Modelo 1: $\chi^{2}(258)=$ 373,48 $(p=0,000), \mathrm{TLI}=0,90, \mathrm{CFI}=0,94, \mathrm{RMSEA}=0,03]$, así como para los modelos con pesos factoriales constreñidos [Modelo 2: $\chi^{2}(272)=395,08(p=0,000)$, TLI $=0,90$, $\mathrm{CFI}=0,94, \mathrm{RMSEA}=0,03], \mathrm{y}$ variancias-covariancias constreñidas [Modelo $3: \chi^{2}(282)$ $=443,99(p=0,000), \mathrm{TLI}=0,88, \mathrm{CFI}=0,92, \mathrm{RMSEA}=0,03]$. El test de significancia del chi-cuadrado $\left(\chi^{2}\right)$ y las diferencias del CFI $(\triangle C F I)$ no demostraron alteraciones significativas al ser comparados con los Modelos 1 y $2\left[\chi^{2^{\mathrm{dif}}}(14)=21,59 ; p=0,08\right.$; $\Delta C F I \leq 0,01]$. Sin embargo, se encontraron diferencias significativas en la comparación de los Modelos 1 y 3 , tanto a nivel del chi-cuadrado $\left[\chi^{\text {dif }}(24)=70,50 ; p=0,000\right]$, como del CFI $[\Delta C F I \geq 0,01]$ (Tabla 11).

Tabla 11: Resultados de los análisis multigrupo testando la invariancia del modelo entre los subestudios $(n=191 ; n=210)$ y los géneros $(n=277 ; n=124)$

\begin{tabular}{lccccccc}
\hline Modelos & $\chi^{2}$ & Df & P & CFI & $\Delta \boldsymbol{C F I}$ & TLI & RMSEA (IC $90 \%)$ \\
\hline Sub-estudio 1 vs Sub-estudio 2 & & & & & & & \\
M1 - No constreñido & 392,62 & 258 & 0,000 & 0,93 & - & 0,90 & $0,03(0,02,0,04)$ \\
M2 - Pesos factoriales & 404,39 & 272 & 0,285 & 0,94 & $\leq 0,01$ & 0,90 & $0,03(0,02,0,04)$ \\
M3 - Variancias-covariancias & 423,82 & 282 & 0,172 & 0,93 & $\leq 0,01$ & 0,89 & $0,03(0,02,0,04)$ \\
Mujeres vs Hombres & & & & & & & \\
M1 - No constreñido & 373,48 & 258 & 0,000 & 0,95 & - & 0,90 & $0,03(0,02,0,04)$ \\
M2 - Pesos factoriales & 395,08 & 272 & 0,087 & 0,95 & $\leq 0,01$ & 0,90 & $0,03(0,02,0,04)$ \\
M3 - Variancias-covariancias & 443,99 & 282 & 0,000 & 0,94 & $\geq 0,01$ & 0,88 & $0,03(0,03,0,04)$ \\
\hline
\end{tabular}

El propósito del Subestudio 2 fue evaluar la validez de constructo de los resultados del CIE-AP a través de la confirmación del ajuste del modelo de medida derivado del Subestudio 1. Los resultados del AFC corroboran el ajuste de la solución oblicua de cuatro factores del modelo de medida del CIE-AP. Cada uno de los factores reveló consistencia interna aceptable, corroborando también con los valores alcanzados en el Subestudio 1. Adicionalmente, los resultados sugieren que los factores de la 
Percepción, evaluación y expresión emocional y Regulación emocional presentan validez convergente. Sin embargo, los factores de Comprensión y análisis emocional y Facilitación emocional en el pensamiento revelaron valores insuficientes en relación a la validez convergente. A su vez, los cuatro factores presentan valores que apoyan la evidencia de validez discriminante. Por último, el modelo de medida del CIE-AP reveló ser invariante en las dos muestras independientes, tanto a nivel de sus pesos factoriales como de las variancias-covariancias, siendo interpretado como identificador de validez cruzada (Loehlin, 2004). En relación a la invariancia entre hombres y mujeres, el modelo reveló ser parcialmente invariante, sugiriendo invariancia en los pesos factoriales, aunque variando entre las variancias-covariancias.

\subsection{Discusión de los resultados}

El propósito del presente estudio era el de analizar las propiedades psicométricas del CIE-AP en la población portuguesa general. Los resultados de ambos subestudios revelan que la estructura de los factores y la composición del CIE-AP reflejan los cuatro factores del Modelo de Inteligencia Emocional de Mayer y Salovey (1997), y sugieren que el CIE-AP es una medida idéntica a través de la cual cada ítem mide un único constructo latente (Kline, 2011). Por consiguiente, los resultados del AFC atestaron un ajuste bueno de los datos, revelando una estructura de cuatro factores delineada para acceder a la autopercepción de IE, siendo consistente con el modelo teórico de base (Mayer \& Salovey, 1997).

Combinando la evidencia de validez estructural de las puntuaciones del CIE-AP, el primer análisis multigrupos apoya la invariancia de las puntuaciones del CIE-AP entre las dos muestras, existiendo evidencia de validez cruzada (Loehlin, 2004). El segundo análisis multigrupos demostró invariancia parcial entre géneros, dando soporte inicial para el uso del CIE-AP en hombres y mujeres. La descripción de la invariancia 
en esta fase del desarrollo del CIE-AP es positiva permitiendo las comparaciones en los grupos de base entre hombres y mujeres, sin necesidad de diferenciar en el futuro los ítems entre los géneros.

En otro ámbito, todos los factores del CIE-AP parecen ser fidedignos (Nunnaly \& Bernstein, 1994) y revelaron validez discriminante, visto que la VEM de cada constructo dio un resultado superior al cuadrado de las correlaciones entre los otros constructos (Tabachnick \& Fidell, 2007). Sin embargo, los valores de la VEM referentes a los constructos de la Facilitación emocional en el pensamiento y de la Comprensión y análisis emocional revelaron ser insuficientes para garantizar validez convergente $(<0,50)$ (Fornell \& Larcker, 1981). En general, estos resultados que consideran el criterio de VEM para evaluar la validez convergente y discriminante, sugieren que los cuatro factores del CIE-AP son mutuamente exclusivos, pero pueden no medir conjuntamente la autopercepción de IE. Sin embargo, de acuerdo con el método de la correlación entre factores empleado en otros estudios, se ha verificado que todos los factores se correlacionan significativamente, providenciando apoyo para su convergencia (e.g., Lahaye, Luminet, Van Broeck, Bodart, \& Mikolajczak, 2010). De este modo, los futuros estudios deberán analizar estas contradicciones, específicamente relacionadas con los métodos de análisis de la validez convergente del CIE-AP.

El CIE-AP al revelar propiedades psicométricas adecuadas, parece cortar con la serie negativa de instrumentos poco fiables que se han estado desarrollando en el ámbito de la autopercepción de IE (e.g., Mayer, 2006). Las dificultades de operacionalización del constructo de la IE han sido sus múltiples definiciones, la falta de convergencia entre sus modelos conceptuales, las dificultades inherentes a su medida, y por consecuencia, la cuestionabilidad de su validez predictiva e incremental (Christiansen, Janovics, \& Siers, 2010; Landy, 2005; Mayer et al., 2008; Zeidner, Matthews, \& 
Roberts, 2004). En este sentido, la existencia de diversos modelos teóricos lleva a una falta de definición consensual sobre el constructo de la IE y de sus dimensiones. En esta perspectiva, si consideramos la IE como una capacidad mental compuesta por procesos emocionales básicos, se revela más adecuado utilizar las propuestas de evaluación enumeradas por Mayer y Salovey (1997), tanto si son de auto-cumplimentación o de ejecución. Si el investigador tiene como objetivo evaluar habilidades interpersonales, las medidas de auto-llenado son una opción bastante adecuada, ya que al confiar en la introspección, permite evaluar procesos emocionales subyacentes, difícilmente medidos a través de tareas de capacidad. Se destaca que el objetivo más importante de la construcción del CIE-AP fue el de convertirse en una herramienta con capacidad predictiva, en lugar de enfocarse en taxonomías de personalidad o capacidades (Regner, 2008).

A pesar de los resultados alentadores de los dos subestudios, deberán presentarse algunas limitaciones y trazarse direcciones futuras para la investigación. En primer lugar, el presente estudio se basa en procedimientos de muestra no probabilísticos donde constan, fundamentalmente jóvenes. En este sentido, la generalización de los resultados para otros grupos (por ejemplo, ancianos, poblaciones enfermas) considerando los factores de la IE, deberá ser el enfoque de estudio de próximas investigaciones. Segundo, ambas fases del presente estudio consideran exclusivamente métodos cuantitativos de respuesta a los ítems. Tal vez, investigaciones futuras puedan combinar otros métodos (por ejemplo, entrevista) y relacionar otros instrumentos (e.g., EQ-I de Bar-On, 1997), con vista a evaluar la posible concurrencia de los resultados del CIEAP. Finalmente, ambas fases son estudios transversales, enfocándose en un conjunto limitado de indicadores de autopercepción de IE. En este ámbito, los estudios futuros 
podrán considerar diseños longitudinales que permitan evaluar la estabilidad e invariancia temporal de los resultados del CIE-AP.

En resumen, el propósito del presente estudio fue evaluar la validez de constructo de los resultados de las escalas del CIE-AP, designadas para medir la Percepción, Facilitación, Comprensión y Regulación emocional, considerando el Modelo de Inteligencia Emocional (Mayer \& Salovey, 1997). Los resultados del Subestudio 1 ofrecen apoyo preliminar a la estructura del modelo de medida del CIE-AP derivado en el modelo teórico de Mayer y Salovey (1997), mientras que los resultados del Subestudio 2 confirman el ajuste del modelo de medida del CIE-AP y sugieren su invariancia entre muestras, revelando validez cruzada. Además, los resultados permiten asegurar fiabilidad y validez discriminante. En relación a la validez convergente, se encontraron resultados contradictorios concernientes a las escalas de Facilitación y Comprensión emocional. Sin embargo, el presente estudio parece ser una contribución sostenida por la creación de un instrumento multidimensional delineado para medir el constructo contestable de la autopercepción de IE (e.g., Martins et al., 2010; PérezGonzález et al., 2007), considerando el modelo de Mayer y Salovey (1997). Conjuntamente, los resultados de los dos subestudios apoyan la validez de constructo del CIE-AP y sugieren que el instrumento es una herramienta prometedora en la evaluación de la autopercepción de IE. 
Metodologia 


\section{METODOLOGÍA}

\subsection{Muestra y procedimiento}

En el presente estudio recurrimos a dos muestras de conveniencia. La muestra de la población general está constituida por ciudadanos de la población portuguesa que habitan en el norte y centro de Portugal, recogida en instituciones sociales para obtener población adulta, siempre con la autorización previa de las propias instituciones. En la recogida de datos todos los participantes fueron previamente informados sobre los objetivos y procedimientos de la investigación, asumiendo la confidencialidad de los datos, y todos otorgaron su consentimiento informado previamente a la aplicación de los instrumentos, cumplimentándolos frente a la investigadora. Los criterios de inclusión fueron:

- tener nacionalidad y dominio de la lengua portuguesa,

- edad comprendida igual o superior a los 16 años,

- saber leer y escribir y

- no padecer de enfermedad crónica.

La muestra quedó constituida por 214 sujetos, siendo el 75,3\% de género femenino y el $24,7 \%$ de género masculino, con edades comprendidas entre los 24 y los 79 años, presentando una media de 53 años de edad $(D T=19,211)$. El estado civil más significativo fue el casado(a) con $61 \%$ de la muestra, siendo seguido por los viudos con un 14,6\% (Figura 14). La mayoría de la población es personal de servicios y vendedores (48,6\%), jubilados (23\%), y especialistas de profesiones intelectuales y científicas (13\%) de acuerdo con la clasificación portuguesa de profesiones (CPP), creada por el Instituto de Empleo y Formación Profesional (INE, 2011). A nivel educativo se destaca 
que el $42,1 \%$ tiene la Enseñanza Primaria y el 18,5\% posee la Enseñanza Secundaria incompleta (Figura 15).

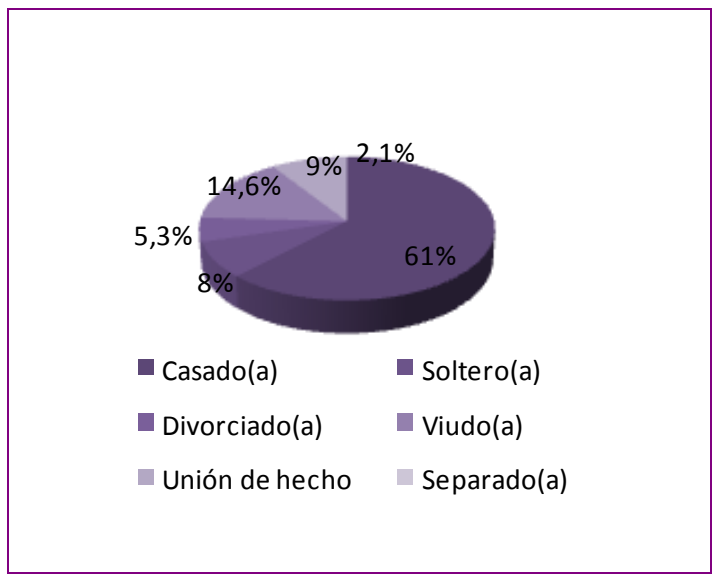

Figura 14: Estado Civil

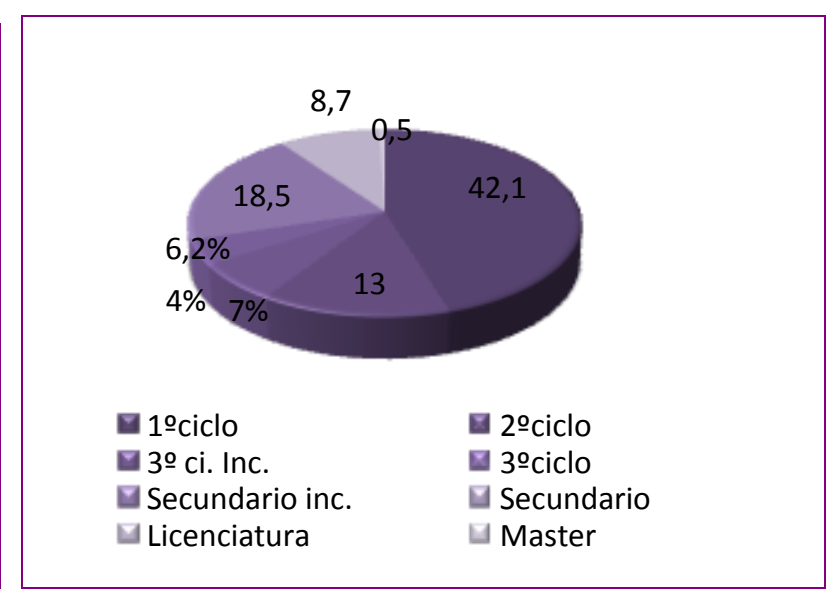

Figura 15: Nivel Educativo

La muestra de enfermos oncológicos se recogió de dos Hospitales de la zona norte de Portugal, con los mismos criterios de inclusión que la muestra anterior, aunque se añade el criterio de padecer enfermedad oncológica. Todo el proceso de investigación fue sometido y aprobado por la dirección de los hospitales. Entre los años 2011 y 2012 la investigadora ha entregado en manos a los enfermos la batería de test, y a veces los ayudaba a cumplimentarlos sin influenciar en sus respuestas en gabinetes libres de los servicios de Oncología, mientras aguardaban sus consultas o tratamientos. Anteriormente a la recogida de datos todos los participantes fueron previamente informados sobre los objetivos y procedimientos de la investigación, asumiendo la confidencialidad de los datos $\mathrm{y}$ facultando a todos su consentimiento informado previamente a la aplicación de los instrumentos.

La muestra está constituida por 202 enfermos, 80,2\% son del género femenino y 19,8\% son del género masculino, tienen edades comprendidas entre los 27 y los 87 años 
de edad, presentando una media de 58,65 años $(D T=11,968)$. La mayoría de los sujetos están casados (73,8\%), seguido de viudos con 11,9\% (Figura 16). A nivel profesional, el 46,5\% de los sujetos están jubilados, el 19,3\% pertenecen a la categoría profesional de personal de servicios y vendedores y el $11,9 \%$ se presenta como trabajadores no cualificados, de acuerdo con la clasificación portuguesa de profesiones, creada por el Instituto de Empleo y Formación Profesional (INE, 2011) (Figura 17). La mayoría tienen como nivel educacional el $1^{\mathrm{er}}$ ciclo completo $(46 \%)$, seguidos del $2^{\circ}$ ciclo completo, la Enseñanza Secundaria completa y el $3^{\text {er }}$ ciclo completo, los porcentajes son $12,9 \%, 12,4 \%$ y $11,4 \%$, respectivamente. En el ámbito familiar, un $36,6 \%$ de los enfermos tiene hijos a su cargo.

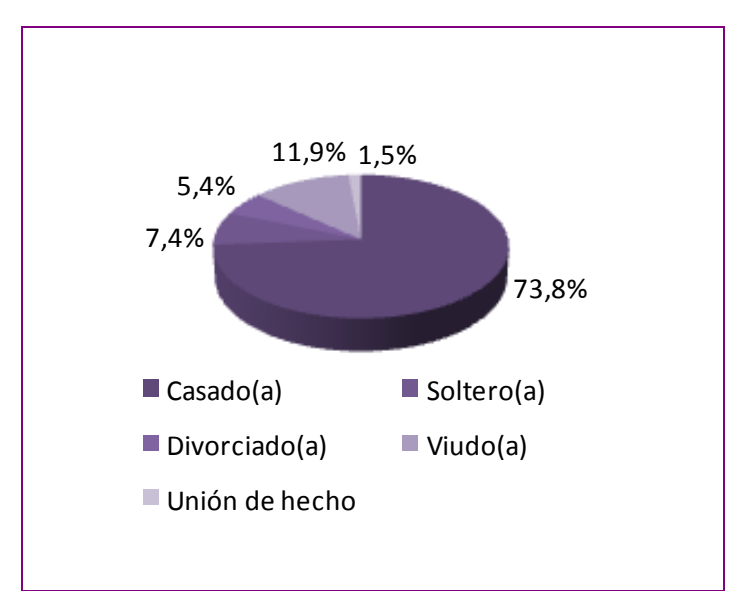

Figura 16: Estado Civil

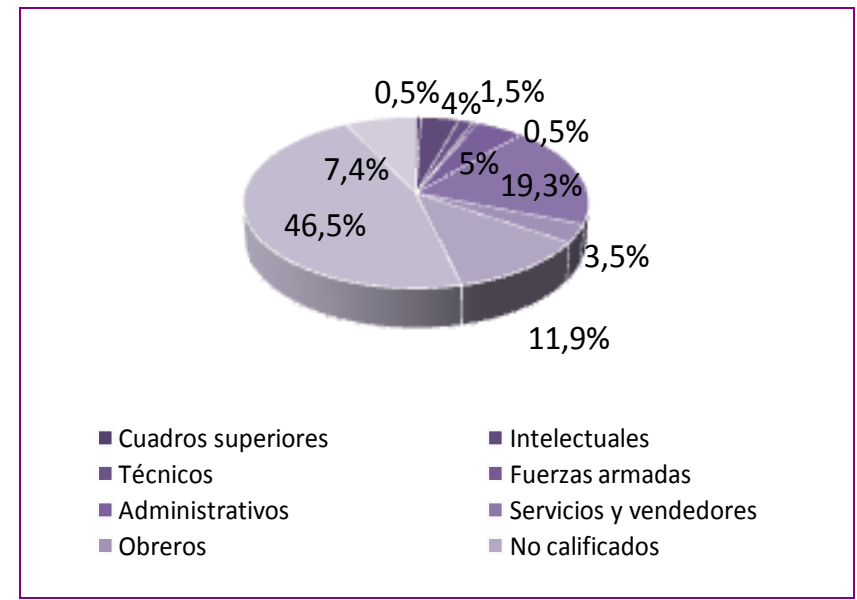

Figura 17: Profesiones

Casi la totalidad de los enfermos presenta conocimiento sobre su enfermedad. Un $53 \%$ se refiere a la misma con el término “cáncer", el 10,4\% emplea el término “enfermedad oncológica" y el 7,4\% la denomina "tumor". Sólo un 9,9\% prefiere no responder y un 5\% indica que "no sabe". Destaca el cáncer de mama con un 49,5\% de enfermos, el 17,8\% padece cáncer de intestino y el 7,9\% cáncer de estómago (Figura 18). La duración media de la enfermedad se encuentra entre los 2 años y los 7 meses, 
presentando como mínimo una semana y como máximo, 16 años. La mayor parte de la muestra se encuentra en la fase de postratamiento $(55,9 \%)$, seguida de la fase de tratamiento $(34,7 \%)$, fase de recidiva $(7,4 \%), 1,5 \%$ en la fase de diagnóstico y $0,5 \%$ en la fase paliativa. En relación a los tratamientos a los que se sometieron, surge la cirugía con un $12,9 \%$, igual que la asociación de quimioterapia, radioterapia, cirugía y medicación. Con un 10,4\% surge el grupo de quimioterapia, radioterapia, hormonoterapia, cirugía y medicación, con valores aproximados se encuentra: la quimioterapia conjuntamente con la cirugía $(8,9 \%)$, el conjunto de quimioterapia, cirugía y medicación $(8,4 \%)$, y la quimioterapia $(8,4 \%)$. En el momento actual de la investigación, un $34,7 \%$ se encontraba sometido a medicación, un 17,8\% a quimioterapia, mientras que un $24,3 \%$ no se encontraba bajo tratamiento terapéutico. Por último, se indica que el $63,9 \%$ se encuentra bajo el régimen de tratamiento del tipo de "rutina/control" y un 36,1\% bajo el régimen "ambulatorio" (Figura 19).

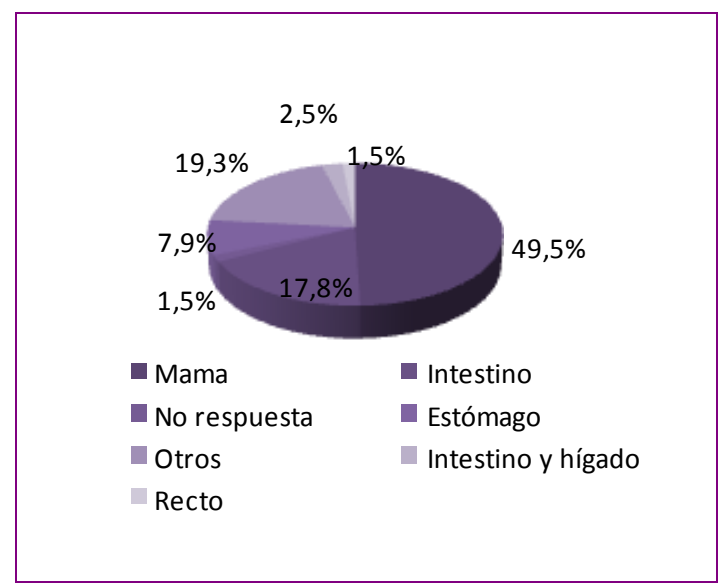

Figura 18: Tipos de cáncer

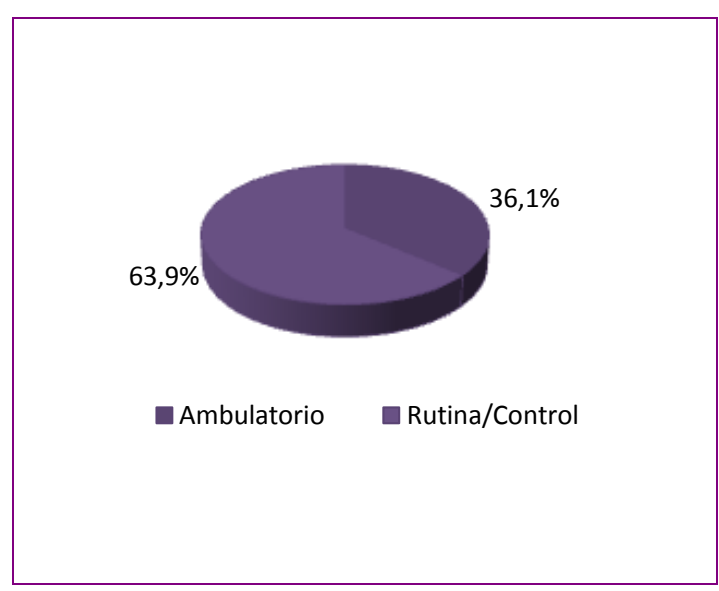

Figura 19: Régimen de tratamiento

\subsection{Batería de instrumentos}

El protocolo de investigación utilizado con la población general estaba constituido por la siguiente serie de tests psicológicos: el Cuestionario sociodemográfico; el "Cuestionario de Autopercepción de Inteligencia Emocional" [“CIE-AP”; de Pereira- 
Teques, Llorca-Ramón, Bueno-Carrera, Pais-Ribeiro, \& Teques, in press]; la "Escala de Satisfacción con la Vida" [“SWLS”; versión original de Diener, Emmons, Larsen, \& Griffin (1985), traducida y adaptada para la población portuguesa por Neto (1993)] y el "Test de Objetivos de Vida" ["PIL-R"; versión original de Crumbaugh \& Maholick (1969), traducida y adaptada para la población portuguesa por Peralta y Silva (2003)]. Todos los instrumentos son utilizados en ambas poblaciones, diferenciándose en la población de enfermos oncológicos, el Cuestionario sociodemográfico y clínico y la “Escala Reducida de la Adaptación Mental al Cáncer" ["Mini-MAC”; versión original de Watson, Law, Santos, Greer, Baruch, \& Bliss (1994), traducida y adaptada para la población portuguesa por Pais-Ribeiro, Ramos, y Samico (2003)]. Los respectivos instrumentos, así como, las autorizaciones de los autores y de los hospitales para su aplicación se encuentran en los anexos.

\subsubsection{Cuestionario sociodemográfico y clínico}

El cuestionario sociodemográfico permitió recoger en la población general, datos sobre el sexo, la edad, la profesión, el estado civil, la escolaridad y el municipio en el que habitan. En la muestra de enfermos oncológicos, permitió, además, recoger datos sobre los hijos a cargo. A nivel clínico se cuestionó el nombre de la enfermedad, la parte del cuerpo afectada, la duración de su conocimiento, la fase de enfermedad, el/los tratamiento/s bajo los que se encuentran y el régimen de tratamiento actual.

\subsubsection{Cuestionario de Autopercepción de Inteligencia Emocional (CIE-AP)}

Permite analizar el nivel de Inteligencia emocional de los sujetos. Este cuestionario auto-administrado está constituido por 18 ítems, distribuidos en cuatro dimensiones, principalmente: Percepción, evaluación y expresión emocional; Facilitación emocional en el pensamiento; Comprensión y análisis emocional y 
Regulación emocional. En el presente estudio, los coeficientes de $\alpha$ Cronbach fueron de 0,73, 0,70, 0,73, y 0,77 para la Percepción, Facilitación, Comprensión y Regulación emocional, respectivamente. Para cada uno de los ítems, los sujetos señalan su grado de concordancia, en una escala de Likert de cinco puntos (de 1 - Totalmente en desacuerdo a 5 - Totalmente de acuerdo). Los ítems invertidos son el 3 y el 16. La puntuación de cada subescala traduce el sumatorio de los ítems que la integran. En el presente estudio el CIE-AP presentó un $\alpha$ de Cronbach global de 0,83.

\subsubsection{Escala de Satisfacción con la Vida (SWLS)}

La Escala de Satisfacción con la Vida (SWLS), en versión original de Diener, Emmons, Larsen, y Griffin (1985), traducida y adaptada para la población portuguesa por Neto (1993), tiene como objetivo evaluar el juicio subjetivo que los individuos hacen sobre la calidad de sus propias vidas. Está constituida por cinco ítems formulados en sentido positivo con una escala de respuesta tipo Likert de 7 puntos ( 1 - Totalmente en desacuerdo a 7 - Totalmente de acuerdo), por lo que la puntuación del sujeto puede variar entre 5 y 35 puntos, representando la puntuación 20 el punto medio. En el presente estudio la SWLS presentó un $\alpha$ de Cronbach global de 0,83.

\subsubsection{Test de Objetivos de Vida (PIL-R)}

El Test de Objetivos de Vida (PIL-R), versión original de Crumbaugh y Maholick (1969), traducida y adaptada para la población portuguesa por Peralta y Silva (2003) está compuesto por 20 ítems y evalúa los objetivos, ambiciones, metas y aspiraciones que revelan un sentido y significado personal en la existencia del propio individuo. Es un instrumento para autocumplimentar que solicita al sujeto que señale para cada ítem el grado de concordancia en una escala de formato de respuesta tipo Lickert, con siete categorías de respuesta (1-Estoy totalmente en desacuerdo; 7-Estoy totalmente de 
acuerdo). Para controlar la tendencia a la aquiescencia, 9 ítems son formulados de forma positiva (ítems $2,7,10,12,14,15,17,18$ y 19) y 11 ítems de forma negativa (ítems 1 , $3,4,5,6,8,9,11,13,16$, y 20$)$.

La escala se subdivide en dos dimensiones: la vivencial y la existencial. En el respetivo estudio, la dimensión vivencial presentó un $\alpha$ de Cronbach de 0,78 y la existencial 0,35. La dimensión existencial, como el significado en el estudio original de la escala (Crumbaugh \& Maholick, 1969), así como en el estudio de validación del Test de Objetivos de Vida (Peralta \& Silva, 2003), presentó una consistencia interna muy baja $(0,35)$, sin embargo, tal como los autores, nosotros asumimos la dimensión para efectos de resultado. En la dimensión vivencial se incluyen los contenidos implicados en la satisfacción con la vida (ítems 1, 6, 9, 11 y 16), el sentimiento de responsabilidad personal (ítem 13), y la forma cómo el individuo evalúa los objetivos, las ambiciones, metas y progresos alcanzados (ítems 3, 4, 8 y 20). En términos generales, estos contenidos remiten al modo en cómo cada uno evalúa sus vivencias (experiencias de vida) y el tipo de relación que establece con su propia vida, tal como fue vivida. La dimensión existencial presenta los ítems asociados a la consciencia del significado y del sentido de la existencia del ser humano. A ésta se añade la representación simbólica y consciente de las creencias y actitudes del individuo ante su propia muerte (ítem 15), la evaluación de la consistencia/coherencia de las convicciones, valores y decisiones consideradas por el propio individuo como determinantes para dar sentido a la vida (ítems 2, 5, 14 y 19), la convicción de tener capacidad para lograr objetivos y metas que confieran un sentido a su existencia (ítem 17) y la creencia sobre el control que el individuo tiene sobre la vida (ítem 18). El resto de los ítems destacan la actitud con relación a los proyectos de futuro (ítem 7), la actitud con relación a la vida (ítem 10) y el ítem 12 revela la visión del mundo visto por el individuo en función del sentido 
atribuido a su propia vida. Estos ítems se relacionan más con la consciencia que el individuo tiene del sentido de la existencia del ser humano, es decir, con la comprensión analítica e intuitiva del self del mundo y de "estar en el mundo". Cuando el valor medio obtenido varía entre 92 y 112, se considera que el sujeto tiene un nivel de objetivos de vida medio, cuya característica principal es haber logrado un sentido de vida común y adecuado al contexto de la realidad; valores medios superiores a 113 indican un nivel de objetivos de vida elevados, caracterizado por sujetos con sentimientos de realización de sí mismos y de plenitud personal; valores medios inferiores a 91 indican objetivos de vida reducidos, cuya característica principal es la pérdida de interés por la vida, sentimiento de tedio, apatía y vacío existencial. En el presente estudio el PIL-R presentó un $\alpha$ de Cronbach global de 0,84 .

\subsubsection{Escala Reducida de la Adaptación Mental al Cáncer (Mini-MAC)}

La Escala Reducida de la Adaptación Mental al Cáncer (Mini-MAC), versión original de Watson, Law, Santos, Greer, Baruch, y Bliss (1994), traducida y adaptada para la población portuguesa por Pais-Ribeiro, Ramos, y Samico (2003), permite analizar el modo en que los sujetos hacen frente al diagnóstico y tratamiento del cáncer. Esta escala auto administrada está constituida por 29 ítems, distribuidos en cinco subescalas: la dimensión Desánimo/debilidad, Preocupación ansiosa, Espíritu de lucha, Evitación cognitiva y Fatalismo. En el presente estudio, los coeficientes de $\alpha$ Cronbach fueron de 0,89, 0,88, 0,72, 0,78, y 0,46 para el Desánimo, Preocupación, Espíritu, Evitación y Fatalismo, respectivamente. Cabe destacar que la dimensión Fatalismo, no fue analizada por presentar una consistencia interna muy baja, pudiendo interferir en el análisis de los datos. Para cada uno de los ítems, los sujetos señalaron su grado de concordancia, en una escala tipo likert de cuatro puntos. La puntuación de cada 
subescala traduce el sumatorio de los ítems que la integran. En el presente estudio la Mini-MAC presentó un $\alpha$ de Cronbach global de 0,82 . 


\section{Resultados y Discusión}




\section{RESULTADOS Y DISCUSIÓN}

10.1. Primera(s) Hipótesis

Hipótesis 1.1 - La Inteligencia emocional se relaciona de forma positiva con la Satisfacción con la vida.

Hipótesis 1.2 - La Inteligencia emocional se relaciona de forma positiva con la dimensión Vivencial del Significado en la vida.

Hipótesis 1.3 - La Inteligencia emocional se relaciona de forma positiva con la dimensión Exitencial del Significado en la vida.

Hipótesis 1.4 - El Significado en la vida se relaciona de forma positiva con la Satisfacción con la vida. 
De forma concisa, las presentes hipótesis sugieren que las personas que se perciben emocionalmente inteligentes se sienten satisfechas con su vida, y que al tener objetivos en la vida aumentan su satisfacción con la vida, sea en la muestra sin enfermedad como con enfermedad oncológica. Este modelo hipotético se encuentra representado en la Figura 20.

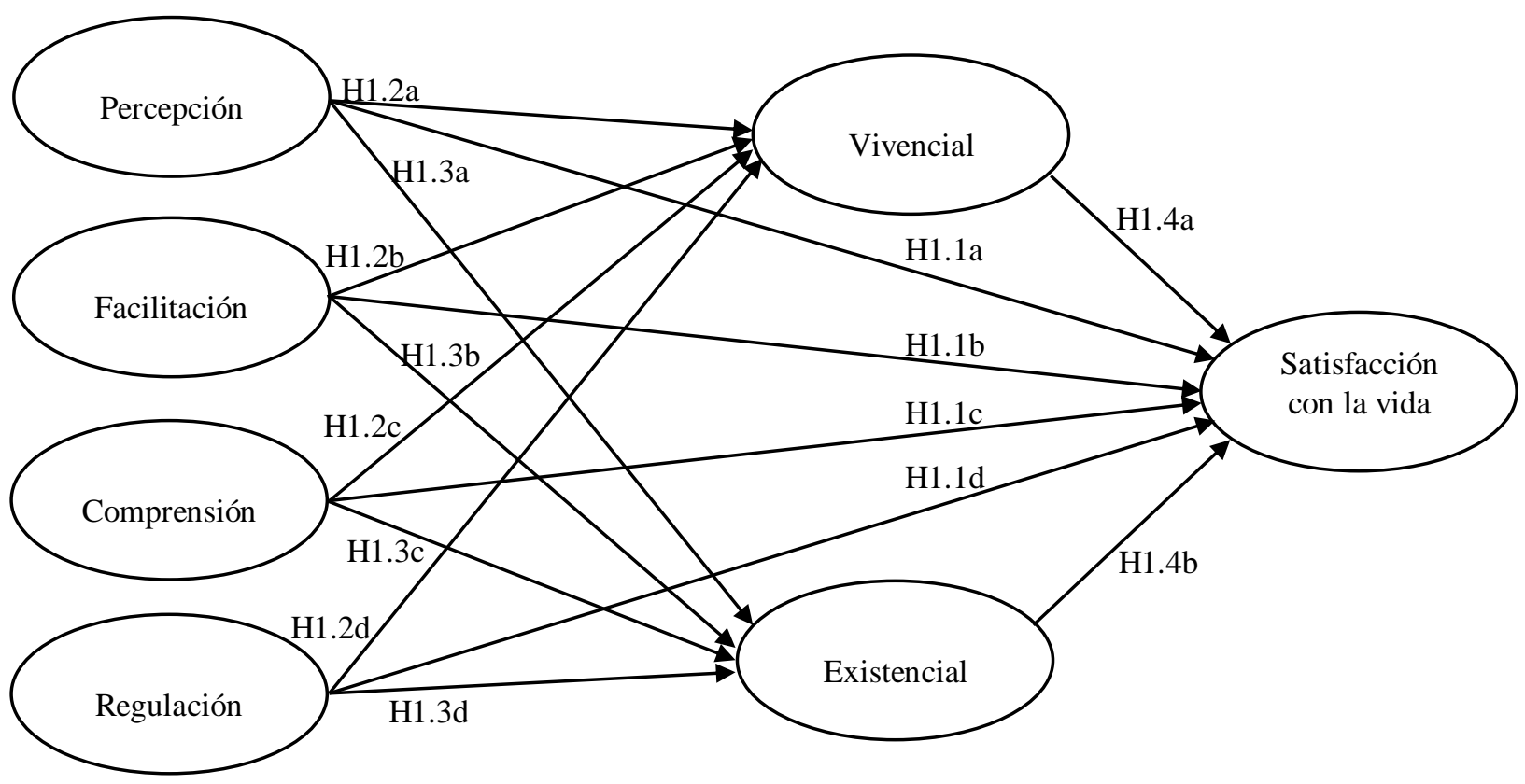

Figura 20: Modelo propuesto con las relaciones entre la percepción de capacidades de inteligencia emocional, el significado en la vida y la satisfacción con la vida en enfermos oncológicos y en la población saludable.

Para comprobar las hipótesis se procedió a la identificación del modelo estructural con variables latentes que siguió dos etapas (Kline, 2011) utilizando el AMOS 20. En primer lugar, se ejecutó el análisis factorial confirmatorio (AFC) para determinar el ajuste de la medida. La fiabilidad de los constructos fue estimada a través de la fiabilidad compuesta y valores por encima de 0,70 fueron considerados aceptables (Hair et al., 2010). La variancia extraída media (VEM) fue evaluada como criterio de validez convergente y valores superiores a 0,50 fueron considerados adecuados para demostrar la validez convergente (Fornell \& Larcker, 1981; Hair et al., 2010). La validez discriminante fue asumida cuando la VEM de cada constructo es superior al cuadrado de las correlaciones entre ese y los otros constructos (Fornell \& Larcker, 1981). La 
validad convergente y discriminante fueran evaluadas para testar la validad de constructo. La calidad del ajuste del modelo fue considerada adecuada cuando los valores del Comparative-of-fit-index (CFI) y el Tucker-Lewis index (TLI) fueron superiores a 0,90. Adicionalmente, el Root mean square error of approximation (RMSEA) y el Standardized root mean square residual (SRMR) fueran considerados aceptables con valores por debajo de 0,08 (Hair et al., 2010). En segundo lugar, el modelo estructural fue especificado para testar las hipótesis, de acuerdo con la Figura 20.

Cerca de 3,6\% de los datos fueran no respuestas, pero sin patrón fijo. De este modo, las no respuestas fueran imputadas utilizando los procedimientos de regresión del AMOS. Se identificaran nueve casos con respuestas extremas, tanto a nivel univariado $(z>3,00)$, como multivariado (distancia Mahalanobis $=p 1<0,001, p 2<0,001$ ). Estos sujetos fueron extraidos antes de se ejecutar los análisis posteriores. Los valores Skewness usados para los ítems oscilaron entre $-0,12$ y 2,89, y los de kurtosis entre 1,78 y 4,51. Estos valores no representan anormalidad univariada (Kline, 2011). De acuerdo con el Mardia's coefficient $(88,16)$ se exceden los valores esperados y se puede considerar que existe una normalidad multivariada (Byrne, 2010). Para lidiar con la anormalidad de los datos, fue aplicado el procedimiento bootstrap de Bollen-Stine con 2000 muestras en los análisis posteriores, tal como recomiendan Nevitt y Hancock (2001). Adicionalmente, fue testada la colinealidad de las variables en estudio, resultando en factores de inflación de la variancia entre 1,06 (percepción emocional) y 1,41 (SCV), dentro de los límites aceptables para los análisis de regresión (Hair et al., 2010). Los resultados del AFC en el modelo de las dos muestras revelaron que los pesos factoriales de cinco ítems de la dimensión existencial y tres de la dimensión vivencial no excedían el valor de corte de 0,50 propuesto por Hair et al. (2010), y 
consecuentemente, fueron eliminados del modelo (Tabla 12). La reespecificación de estas dos dimensiones es consistente con Steger et al. (2006).

Tabla 12: Pesos factoriales, coeficientes de Cronbach $(\alpha)$ y variancia extraída media (VEM)

\begin{tabular}{|c|c|c|c|c|c|c|}
\hline \multirow[b]{2}{*}{ Constructos/Ítems } & \multicolumn{3}{|c|}{ Enfermos oncológicos } & \multicolumn{3}{|c|}{ Población general } \\
\hline & Peso & $\alpha$ & VEM & Peso & $\alpha$ & VEM \\
\hline Percepción & & 0,76 & 0,48 & & 0,73 & 0,51 \\
\hline CIE5 & 0,755 & & & 0,712 & & \\
\hline CIE8 & 0,765 & & & 0,773 & & \\
\hline CIE10 & 0,679 & & & 0,689 & & \\
\hline CIE18 & 0,693 & & & 0,701 & & \\
\hline Facilitación & & 0,71 & 0,55 & & 0,73 & 0,56 \\
\hline CIE1 & 0,592 & & & 0,621 & & \\
\hline CIE3 & 0,705 & & & 0,688 & & \\
\hline CIE4 & 0,666 & & & 0,645 & & \\
\hline CIE7 & 0,743 & & & 0,712 & & \\
\hline CIE16 & 0,552 & & & 0,531 & & \\
\hline Comprensión & & 0,78 & 0,62 & & 0,74 & 0,65 \\
\hline CIE2 & 0,721 & & & 0,671 & & \\
\hline CIE6 & 0,654 & & & 0,665 & & \\
\hline CIE9 & 0,703 & & & 0,712 & & \\
\hline CIE12 & 0,692 & & & 0,674 & & \\
\hline CIE14 & 0,566 & & & 0,543 & & \\
\hline CIE17 & 0,798 & & & 0,854 & & \\
\hline Regulación & & 0,81 & 0,67 & & 0,76 & 0,65 \\
\hline CIE11 & 0,789 & & & 0,765 & & \\
\hline CIE13 & 0,768 & & & 0,744 & & \\
\hline CIE15 & 0,593 & & & 0,532 & & \\
\hline Vivencial & & 0,76 & 0,64 & & 0,74 & 0,62 \\
\hline Obj1 & 0,569 & & & 0,652 & & \\
\hline Obj3 & 0,634 & & & 0,729 & & \\
\hline Obj4 (a) & & & & & & \\
\hline Obj6 & 0,543 & & & 0,587 & & \\
\hline Obj8 (a) & & & & & & \\
\hline Obj9 & 0,732 & & & 0,767 & & \\
\hline Obj11 & 0,812 & & & 0,789 & & \\
\hline Obj13 (a) & & & & & & \\
\hline Obj16 & 0,589 & & & 0,546 & & \\
\hline Obj20 & 0,566 & & & 0,551 & & \\
\hline Existential & & 0,61 & 0,53 & & 0,64 & 0,56 \\
\hline Obj2 & 0,522 & & & 0,541 & & \\
\hline Obj5 (a) & & & & & & \\
\hline Obj7 (a) & & & & & & \\
\hline Obj10 & 0,617 & & & 0,688 & & \\
\hline Obj12 (a) & & & & & & \\
\hline Obj14 (a) & & & & & & \\
\hline Obj15 & 0,722 & & & 0,745 & & \\
\hline Obj17 & 0,776 & & & 0,876 & & \\
\hline Obj18 (a) & & & & & & \\
\hline Obj19 & 0,799 & & & 0,823 & & \\
\hline Satisfacción con la vida & & 0,83 & 0,68 & & 0,79 & 0,66 \\
\hline 1 & 0,661 & & & 0,698 & & \\
\hline 2 & 0,687 & & & 0,589 & & \\
\hline 3 & 0,569 & & & 0,567 & & \\
\hline 4 & 0,874 & & & 0,866 & & \\
\hline 5 & 0,833 & & & 0,832 & & \\
\hline
\end{tabular}


Después de esta revisión del modelo, todos los ítems mostraran pesos factoriales entre 0,52 y 0,87 (en enfermos oncológicos), y entre 0,53 y 0,87 (población general), evidenciando que los ítems representan adecuadamente el respectivo factor. Tal como se presenta en la Tabla 12, los valores de la fiabilidad compuesta están por encima de 0,70 en los dos modelos, menos en la dimensión existencial del significado $(\alpha=0,61$ para los enfermos oncológicos, y $\alpha=0,64$ para la población general). Esta dimensión ha revelado con frecuencia una baja consistencia interna (e.g., Peralta \& Silva, 2003), pero teniendo en cuenta su importancia teórica la mantenemos en el modelo para los próximos análisis. Los valores de la VEM fueron iguales o superiores a 0,50, revelando validez convergente (Fornell \& Larcker, 1981), variando entre 0,48 y 0,68 (enfermos oncológicos), y entre 0,51 y 0,66 (población general).

En la Tabla 13 se presenta la estadística descriptiva de las medidas usadas en ambos modelos y los cuadrados de las correlaciones. Los valores medios de los constructos obtenidos en las dos muestras revelan que la población general presenta más SCV $(M=4,91, D T=1,02)$. Mientras, los enfermos oncológicos revelan más capacidad de regulación emocional $(M=4,95, D T=0,77)$ y significado existencial $(M=5,44, D T$ $=1,06)$. La validez discriminante de las medidas fue aceptable, dado que el cuadrado de las correlaciones entre los constructos se posicionó por debajo de los valores de la VEM en los dos modelos. A su vez, el modelo de medida reveló un ajuste aceptable a los datos en los enfermos oncológicos $\left[\chi^{2}(443)=661,15, \mathrm{~B}-\mathrm{S} p<0,001, \mathrm{CFI}=0,94, \mathrm{TLI}=\right.$ 0,93, RMSEA $=0,05(\mathrm{CI}=0,041,0,052), \mathrm{SRMR}=0,05]$ y en la población general $\left[\chi^{2}(443)=589,46, \mathrm{~B}-\mathrm{S} p<0,001, \mathrm{CFI}=0,95, \mathrm{TLI}=0,95, \mathrm{RMSEA}=0,04(\mathrm{CI}=0,033\right.$, 0,041), SRMR $=0,05]$. Los valores del CFI y TLI fueran superiores al valor mínimo recomendado de 0,90 (Hair et al., 2010). Adicionalmente, los valores del RMSEA y del SRMR revelan un buen ajuste a los datos $(<0,08)$. En general, el modelo de medida para 
cada grupo de participantes demostró un ajuste adecuado a los datos, y seguidamente, el modelo estructural fue identificado.

Tabla 13: Medias (M), desviaciones típicas (DT) y matriz de correlaciones

\begin{tabular}{|c|c|c|c|c|c|c|c|c|c|}
\hline \multirow{2}{*}{\multicolumn{2}{|c|}{ Constructos }} & \multirow[b]{2}{*}{$M$} & \multirow[b]{2}{*}{$D T$} & \multicolumn{6}{|c|}{ Matriz de correlación } \\
\hline & & & & 1 & 2 & 3 & 4 & 5 & 6 \\
\hline \multicolumn{10}{|c|}{ Enfermos oncológicos } \\
\hline 1. & Percepción & 4,02 & 0,57 & 1,00 & & & & & \\
\hline 2. & Facilitación & 4,22 & 0,71 & $0,31 * *$ & 1,00 & & & & \\
\hline 3. & Comprensión & 4,25 & 0,65 & $0,38 * *$ & $0,58 * *$ & 1,00 & & & \\
\hline 4. & Regulación & 4,66 & 0,68 & $0,43 * *$ & $0,34 * *$ & $0,35 * *$ & 1,00 & & \\
\hline 5. & Vivencial & 5,06 & 0,91 & $0,21 * *$ & $0,12 *$ & $0,34 * *$ & $0,41 * *$ & 1,00 & \\
\hline 6. & Existential & 5,44 & 1,06 & $0,09 *$ & 0,03 & $0,36^{* *}$ & $0,38 * *$ & $0,67 * *$ & 1,00 \\
\hline 7. & Satisfacción & 4,12 & 1,23 & $0,31 * *$ & 0,01 & $0,32 * *$ & $0,49 * *$ & $0,60 * *$ & $0,72 * *$ \\
\hline \multicolumn{10}{|c|}{ Población general } \\
\hline 1. & Percepción & 3,98 & 0,66 & 1,00 & & & & & \\
\hline 2. & Facilitación & 4,06 & 0,59 & $0,35 * *$ & 1,00 & & & & \\
\hline 3. & Comprensión & 4,17 & 0,50 & $0,41 * *$ & $0,44 * *$ & 1,00 & & & \\
\hline 4. & Regulación & 4,02 & 0,78 & $0,39 * *$ & $0,36 * *$ & $0,39 * *$ & 1,00 & & \\
\hline 5. & Vivencial & 4,88 & 0,98 & $0,34 * *$ & 0,02 & $0,08^{*}$ & $0,22 * *$ & 1,00 & \\
\hline 6. & Existential & 4,95 & 0,96 & $0,23 * *$ & 0,03 & 0,01 & $0,38 * *$ & $0,56 * *$ & 1,00 \\
\hline 7. & Satisfacción & 4,91 & 1,02 & $0,19 * *$ & 0,01 & 0,01 & $0,45 * *$ & $0,11 *$ & $0,28 * *$ \\
\hline
\end{tabular}

Nota. El cuadrado de las correlaciones entre cada uno de los constructos es inferior a la VEM de cada factor, siendo un criterio de validez discriminante. $* p<0,05, * * p<0,01$

La exploración del modelo estructural incluye el testado tanto del modelo general como del individual de las relaciones entre los constructos latentes. En términos generales los índices de ajuste de los modelos estructurales fueron aceptables para los enfermos oncológicos $\left[\chi^{2}(540)=546,16\right.$, B-S $p<0,001$, CFI $=0,96$, TLI $=0,95$, RMSEA $=0,05(\mathrm{CI}=0,041,0,052), \mathrm{SRMR}=0,04] \quad \mathrm{y}$ para la población general $\left[\chi^{2}(540)=689,46, \mathrm{~B}-\mathrm{S} p<0,001, \mathrm{CFI}=0,94, \mathrm{TLI}=0,93, \mathrm{RMSEA}=0,05(\mathrm{CI}=0,043\right.$, $0,056), \operatorname{SRMR}=0,05]$.

Los coeficientes de ligazón para cada modelo se encuentran en la Tabla 14, indicando que las relaciones propuestas difieren significativamente de acuerdo con los grupos. Más concretamente, la percepción emocional presenta un efecto significativo en la SCV en ambos los modelos $(p<0,01)$. El efecto de la facilitación emocional en la SCV no es significativo en ambos los modelos $(p>0,05)$. A su vez, el efecto de la comprensión emocional en la SCV es significativo en los enfermos oncológicos $(\beta=$ 
0,32, $p<0,01)$, mientras en la población general no es significativo $(p>0,05)$. La ligazón entre la regulación emocional y la SCV es significativa en ambos los grupos (enfermos oncológicos: $\beta=0,47, p<0,01$; población general: $\beta=0,33, p<0,01)$. Así como, la percepción, comprensión y regulación emocional revelan efectos significativos en el significado vivencial en los dos grupos $(p<0,05)$, al paso que la ligazón entre facilitación emocional y significado vivencial no es significativa en ambos los grupos $(p>0,05)$. La percepción y regulación emocional revelan efectos significativos en el significado existencial $(p<0,05)$. Por contrario, la facilitación emocional no se liga de forma significativa con el significado existencial en ambos los grupos $(p>0,05)$. Y la comprensión emocional revela efectos significativos en el significado existencial en los enfermos oncológicos $(\beta=0,39, p<0,01)$ pero no en la población general $(p>0,05)$. Los coeficientes de ligazón entre el significado existencial y la SCV son significativos tanto en los enfermos oncológicos $(\beta=0,75, p<0,01)$ como en la población en general $(\beta=$ $0,18, p<0,01)$. Contrariamente, el significado vivencial no es significativo en su ligazón a la SCV en la población en general $(p>0,05)$, pero revela un efecto significativo en el grupo de los enfermos oncológicos $(\beta=0,59, p<0,01)$. En conjunto, los componentes de las variables de la IE y del significado explican aproximadamente $24 \%$ de la variancia de la SCV en enfermos oncológicos $\left(R^{2}=0,24\right)$ y $16 \%$ en la población general respectivamente $\left(R^{2}=0,16\right)$.

Adicionalmente, el resumen de las diferencias en los coeficientes de ligazón en los dos modelos se encuentra en la Tabla 14. El ajuste del modelo no constreñido $\left[\chi^{2}(1080)=846,09, \mathrm{~B}-\mathrm{S} p<0,001, \mathrm{CFI}=0,93, \mathrm{TLI}=0,91, \mathrm{RMSEA}=0,03(\mathrm{CI}=0,032\right.$, 0,037), SRMR $=0,04]$ es aceptable, así como es el modelo constreñido de los pesos estructurales $\left[\chi^{2}(540)=936,61, \mathrm{~B}-\mathrm{S} p<0,001, \mathrm{CFI}=0,92, \mathrm{TLI}=0,90, \mathrm{RMSEA}=0,03\right.$ $(\mathrm{CI}=0,033,0,038), \quad \mathrm{SRMR}=0,04] . \mathrm{El} \chi^{2}$ indica que estos modelos son 
significativamente diferentes uno del otro $\left[\Delta \chi^{2}(28)=90,52, p=0,000\right]$, mientras los $Z$ tests para las diferencias entre los parámetros estructurales revelaran que siete relaciones propuestas difieren significativamente relativamente a las respuestas de los enfermos oncológicos y de la población general. Más específicamente, la comprensión emocional revela un efecto significativamente diferente en la $\operatorname{SCV}(Z=5,12, p<0,01)$, así como en el significado vivencial $(Z=2,89, p<0,01)$ y existencial $(Z=3,44, p<0,01)$. De igual modo, la regulación emocional presenta un efecto significativamente diferente en la $\operatorname{SCV}(Z=2,12, p<0,01)$, y en el significado vivencial $(Z=2,32, p<0,01)$. Se añade que la relación entre el significado vivencial $(Z=5,14, p<0,01)$ y el existencial $(Z=$ $4,88, p<0,01)$ en la SCV en los enfermos oncológicos es significativamente mayor que en la población general.

Tabla 14: Resumen de los resultados del modelo estructural para cada muestra

\begin{tabular}{|c|c|c|c|c|c|c|c|}
\hline & \multirow[b]{2}{*}{ Relación } & \multirow[b]{2}{*}{ Dif.? } & \multirow[b]{2}{*}{$\begin{array}{c}\text { Se } \\
\text { confirma? }\end{array}$} & \multicolumn{2}{|c|}{$\begin{array}{c}\text { Enfermos } \\
\text { oncológicos }\end{array}$} & \multicolumn{2}{|c|}{ Población general } \\
\hline & & & & $\beta$ & Z-valor & $\boldsymbol{B}$ & $Z$-valor \\
\hline H1a & Percepción $\rightarrow$ Satisfacción & No & Sí & $0,28 * *$ & 9,15 & $0,34 * *$ & 11,34 \\
\hline $\mathrm{H} 1 \mathrm{~b}$ & Facilitación $\rightarrow$ Satisfacción & No & No & 0,02 & 1,20 & 0,04 & 1,45 \\
\hline $\mathrm{H} 1 \mathrm{c}$ & Comprensión $\rightarrow$ Satisfacción & Sí & Parcial & $0,32 * *$ & 11,67 & 0,01 & 0,16 \\
\hline H1d & Regulación $\rightarrow$ Satisfacción & Sí & Sí & $0,47 * *$ & 22,55 & $0,33 * *$ & 11,15 \\
\hline $\mathrm{H} 2 \mathrm{a}$ & Percepción $\rightarrow$ Vivencial & No & Sí & $0,16^{* *}$ & 6,78 & $0,22 * *$ & 8,33 \\
\hline $\mathrm{H} 2 \mathrm{~b}$ & Facilitación $\rightarrow$ Vivencial & No & No & 0,02 & 0,12 & 0,01 & 0,09 \\
\hline $\mathrm{H} 2 \mathrm{c}$ & Comprensión $\rightarrow$ Vivencial & Sí & Sí & $0,34 * *$ & 12,86 & $0,08 *$ & 30,12 \\
\hline $\mathrm{H} 2 \mathrm{~d}$ & Regulación $\rightarrow$ Vivencial & Sí & Sí & $0,41 * *$ & 18,71 & $0,32 * *$ & 11,88 \\
\hline $\mathrm{H} 3 \mathrm{a}$ & Percepción $\rightarrow$ Existential & No & Sí & $0,22 *$ & 7,36 & $0,18^{*}$ & 7,16 \\
\hline $\mathrm{H} 3 \mathrm{~b}$ & Facilitación $\rightarrow$ Existential & No & No & 0,01 & 0,45 & 0,01 & 0,15 \\
\hline $\mathrm{H} 3 \mathrm{c}$ & Comprensión $\rightarrow$ Existential & Sí & Parcial & $0,39 * *$ & 17,54 & 0,01 & 0,17 \\
\hline $\mathrm{H} 3 \mathrm{~d}$ & Regulación $\rightarrow$ Existential & No & Sí & $0,45^{* *}$ & 21,34 & $0,41 * *$ & 20,56 \\
\hline $\mathrm{H} 4 \mathrm{a}$ & Vivencial $\rightarrow$ Satisfacción & Sí & Parcial & $0,59 * *$ & 33,21 & 0,03 & 1,34 \\
\hline $\mathrm{H} 4 \mathrm{~b}$ & Existential $\rightarrow$ Satisfacción & Sí & Sí & $0,75^{* *}$ & 39,91 & $0,18 * *$ & 7,55 \\
\hline
\end{tabular}

El propósito de la hipótesis en general se fundamentó en la importancia de la IE y del Significado en la vida en la SCV. En este sentido se estudiaran las relaciones entre las variables en personas sin enfermedad crónica y en enfermos oncológicos.

En primer lugar, se analizaron las relaciones entre las capacidades percibidas de IE y la SCV. Específicamente, en la población general la percepción emocional se 
relacionó significativamente con la $\mathrm{SCV}$, confirmándose la hipótesis 1.1a. La facilitación emocional no se relacionó con la SCV, no confirmando la hipótesis 1.1b. La comprensión emocional tampoco se relacionó con la SCV, no corroborándose la hipótesis 1.1c. Y la regulación emocional se relacionó de forma significativa con la SCV, aceptándose la hipótesis 1.1d. En los enfermos oncológicos, la percepción, la comprensión y la regulación emocional presentan una relación significativa con la SCV, afirmando las hipótesis 1.1a, 1.1c e 1.1d. La facilitación emocional no reveló una relación positiva con la SCV, recusándose la hipótesis 1.1b. En este ámbito, los resultados parecen evidenciar que los sujetos que se perciben emocionalmente inteligentes sienten SCV, conforme estudios previos que revelan esta relación positiva entre la IE y la SCV (e.g., Koydemir, Simsek, Schutz, \& Tipandjan, 2013; Saklofske et al., 2003; Thompson et al., 2007). Más concretamente, los sujetos que son conscientes de lo que sienten, resuelven mejor las situaciones emocionales, sintiendo un mayor bienestar, comparativamente a los que revelan menos claridad en relación a sus sentimientos (Gohm \& Clore, 2002). Todavía, no existe un consenso en la investigación sobre la relación entre la IE y la SCV, dado que algunos estudios realizados con muestras sin enfermedad crónica revelan relaciones diferentes para cada capacidad de IE. En este sentido, por un lado, Ciarrochi et al. (2000) evidencian que las cuatro capacidades de IE se relacionan con la SCV y, por otro lado, Mayer et al. (2000) refieren que solo la comprensión y la regulación emocional se relacionan. También Bastian et al. (2005) al evaluar la relación de la IE como capacidad y de la IE percibida con la SCV, verificaran resultados diferentes. Mientras que para la IE capacidad, sólo la regulación emocional se relaciona, para la IE percibida, la percepción, la comprensión y la regulación emocional se relacionan con la SCV. Según Gignac (2006) la percepción emocional no se relaciona con la SCV. Varios estudios que analizaron la relación entre 
la IE percibida y la SCV, apuntan una relación positiva entre la comprensión y la regulación emocional con la SCV (Extremera et al., 2007; Fernández-Berrocal et al., 2004; Martinez-Pons, 1997; Rey et al., 2011). Otros estudios revelan la comprensión emocional (Augusto-Landa et al., 2006; Extremera \& Fernández-Berrocal, 2005a), y la regulación emocional como las únicas pronosticadoras de SCV (Gannon \& Ranzijn, 2005; Thompson et al., 2007). No obstante, según Avsec y Kavsic (2011) la percepción y la comprensión emocional no contribuyen de forma significativa en cualquier dominio de la satisfacción. Y la comprensión emocional es mencionada en el estudio de Kampfe y Mitte (2010), por ser la única capacidad de IE que no explica el bienestar. A nivel de los estudios efectuados con enfermos oncológicos que evalúan la relación específica entre la IE y la SCV, Guzmán y Alarcón (2007) encontraron relaciones significativas entre la comprensión y la regulación emocional con la SCV. Los resultados obtenidos, es decir, el que los enfermos oncológicos presenten una relación más significativa entre la IE y la SCV que la población general, son curiosos, en la medida en que la IE se asocia y promueve estados de salud (e.g., Martins et al., 2010; Zeidner et al., 2012), bien como, los factores de la IE se asocian a más bienestar en personas saludables comparadas con personas con enfermedades crónicas (Costa et al., 2014). Sin embargo, Extremera-Pacheco y Fernandéz-Berrocal (2007) revelan los efectos positivos de la IE en el contexto del dolor y de las enfermedades crónicas, como el cáncer, dado que las capacidades de IE son preponderantes para afrontar el estrés asociado a la enfermedad, minimizar su impacto y facilitar la adaptación. Yalcin et al. (2008) confirman los efectos terapéuticos positivos de las intervenciones basadas en la IE con enfermos diabéticos, promoviendo un aumento de su CDV. Teniendo en cuenta uno de los modelos teóricos de base de la presente investigación, Mayer y Salovey (1997) refieren que en la regulación emocional, las personas presentan capacidades de pensar en sus 
experiencias traumáticas en el sentido de comprenderlas emocionalmente sin exagerar su importancia. Por consiguiente, la IE permite disminuir la intensidad y la frecuencia de estados de humor negativo, mejora el afrontamiento de acontecimientos de vida y es un buen indicador de percepción subjetiva de satisfacción en la vida (FernándezBerrocal \& Extremera-Pacheco, 2005, 2006; González \& Fernández-Berrocal, 2006). Lo que lleva a considerar a la IE como un moderador en la relación entre experiencias estresantes en la vida y la salud mental (Ciarrochi et al., 2002), que a su vez, indica que los sujetos con altos niveles de IE tienden a evaluar su satisfacción en la vida de forma más positiva frente a experiencias estresantes (Bhullar et al., 2012). En este punto se considera esencial el uso inteligente de nuestras emociones para la adaptación física y psicológica, en la medida de que cuanto mayor sea la IE mayor será la estabilidad emocional, tolerándose mejor la frustración, al verse capaz de controlar los estados de tensión así como el comportamiento de uno mismo en situaciones adversas, llevando a la relación positiva entre la IE y el bienestar (Zaccagnini, 2004). A su vez, los resultados obtenidos indican los beneficios del proceso emocional en la salud física, en el sentido de que prestar atención, identificar, expresar y reconstruir cognitivamente las experiencias emocionales negativas contribuyendo a la regulación del comportamiento ante las diferentes condiciones del medio del sujeto, tratándose generalmente de emociones adaptativas (Pais-Ribeiro, 2010; Smith et al., 2002). Por último, se remite a la relación de la IE y la SCV en situaciones negativas a través de la meta análisis de Diener y Chan (2011), que evidencia que la felicidad (BES) contribuye a la salud y a la longevidad. Pero en esta percepción de felicidad se encuentra la relación fisiológica directa con las emociones, estrés y la enfermedad, así como, el papel moderador de las diferencias individuales en el modo en que las personas perciben, expresan, 
experimentan, y afrontan las experiencias de distrés, y cómo regulan sus comportamientos relacionados con la salud.

En segundo lugar, se examinaron las relaciones entre las capacidades percibidas de IE con el significado en la vida en sus dos dimensiones, la vivencial (1.2) y la existencial (1.3). Concretamente, en la población general la percepción emocional se relacionó positivamente con las dimensiones vivencial y existencial del significado, aceptándose las hipótesis 1.2a y 1.3a. La facilitación emocional no se relacionó con ambas las dimensiones, rechazando las hipótesis $1.2 \mathrm{~b}$ y $1.3 \mathrm{~b}$. La comprensión emocional se relacionó con la dimensión vivencial de forma significativa, pero no con la dimensión existencial del significado, confirmándose la hipótesis $1.2 \mathrm{c}$ y rechazando la hipótesis 1.3c. La regulación emocional presenta una relación positiva con ambas las dimensiones del significado, confirmándose las hipótesis $1.2 \mathrm{~d}$ y $1.3 \mathrm{~d}$. La relación de las dimensiones vivencial y existencial del significado en los enfermos oncológicos es significativa con la percepción, comprensión y regulación emocional, afirmando las hipótesis 1.2a, 1.2c, 1.2d, 1.3a, 1.3c y 1.3d. La facilitación emocional no se relacionó de forma positiva con ambas las dimensiones, no se confirmando las hipótesis $1.2 \mathrm{~b}$ y $1.3 \mathrm{~b}$. Los resultados de la presente investigación vienen corroborar los resultados de Donohoe y Greene (2009), que evidencian que la regulación emocional se relaciona significativamente con el propósito en la vida. Otros estudios sostienen las relaciones positivas entre la IE y el significado personal, afirmando que la IE y el significado personal predicen el BEP en adolescentes (Lazzari, 2000). Augusto-Landa et al. (2011) afirman que la dimensión de la percepción emocional se relaciona positivamente con el propósito en la vida y el crecimiento personal, dimensiones evaluadas como sub-escalas del BEP. A su vez, los resultados del estudio de Zysberg (2012) no presento asociaciones positivas entre la IE y el significado. Debido a la inexistencia de estudios 
que aborden estas relaciones en enfermos oncológicos, la investigación futura deberá averiguar hasta qué punto la IE y el significado en la vida se relacionan en las enfermedades crónicas. Sin embargo, se puede decir que el encuentro de significado minimiza la dificultad para concretar los objetivos personales, como también que el encuentro de beneficios en experiencias negativas favorece la relación con el estrés, en la medida en que un afrontamiento adaptativo y un humor positivo permiten la realización de una evaluación positiva, favoreciendo una reformulación cognitiva de la situación que, consecuentemente, lleva a perspectivas positivas (Folkman, 2001). Esta reformulación es también parte de la autorregulación que se clarifica a través del papel de los significados globales del sujeto que llevan a la atribución de un significado a acontecimientos estresantes y a la acciones subsecuentes (Schroevers et al., 2008). Así, el ser emocionalmente inteligente lleva a percibir los contextos estresores y los impedimentos, más como cambios que como factores estresantes, relacionándolos con comportamientos menos adversos psicológicamente y con resultados de salud en las interacciones medio - sujeto (Salovey et al., 2002).

En tercer lugar, se testó la relación del significado en la vida con la SCV. En este punto, en la población general la dimensión vivencial del significado no presenta una relación positiva con la SCV, no aceptándose la hipótesis 1.4a. La dimensión existencial del significado se relaciona significativamente con la SCV, aceptándose la hipótesis 1.4b. Los enfermos oncológicos revelan una relación significativa entre las dimensiones vivencial y existencial del significado con la SCV, confirmándose las hipótesis $1.4 \mathrm{a}$ y 1.4b. Los resultados evidencian una relación positiva entre el significado en la vida y la $\mathrm{SCV}$, resultados que son similares a los encontrados en la literatura de la especialidad (e.g., Lazzari, 2000; Pan, 2011; Pan et al., 2008; Steger et al., 2006). En este mismo sentido, el propósito en la vida revela una relación positiva con la SCV en varios grupos 
etarios, más concretamente desde la adolescencia a la adultez (Bronk et al., 2009). Específicamente en el contexto oncológico, el significado en la vida se asocia al bienestar en general, y también se asocia y promueve CDV en los enfermos (Haugan, 2013; Jim \& Andersen, 2007; Kállay \& Miclea, 2007; Sherman et al., 2010). En este sentido, los enfermos oncológicos que consiguen encontrar significado en la vida revelan paralelamente SCV (Mols, Vingerhoets, Coebergh, \& Poll-Franse, 2009; Schlegel et al., 2013). Como en las hipótesis anteriores los resultados despiertan interés, principalmente, los enfermos presentan relaciones más significativas entre la IE, el significado y la SCV al ser comparados con la población general. En este sentido la literatura científica defiende que el significado se relaciona de forma positiva con una buena salud física y de forma negativa con la enfermedad crónica (Pinquart, 2002; Skrabski et al., 2005). Así, la presencia de una enfermedad como el cáncer lleva a un menor significado en la vida, teniendo en cuenta todas las dificultades que el proceso de enfermedad provoca en la vida y en el funcionamiento del sujeto, como las secuelas y perdidas subyacentes a los tratamientos y evolución de la enfermedad (e.g., Flerr, Hoekstra, Sleijfer, Tuinman et al., 2006; Jim \& Andersen, 2007; Simonelli et al., 2008). El estado debilitado de salud física lleva a pérdidas de significado (Edman, Larsen, Hagglund, \& Gardulf, 2001), ya que un estado pobre de salud puede igualmente acabar con las fuentes de significado, puesto que existen correlaciones significativas entre el funcionamiento físico y social, así como, entre el significado en la vida y un mejor funcionamiento, salud y bienestar (Bradley, Neumark, Luo, Bednarek, \& Schenk, 2005; Steger, Kashdan et al., 2008). Fegg (2010) encuentra resultados semejantes a los obtenidos en esta investigación, o sea, que los enfermos oncológicos en comparación con la población general obtienen significado en más áreas diferentes de la vida sintiendo una mayor satisfacción en esas mismas áreas. En este sentido, algunos 
supervivientes de cáncer revelan poseer más significado en la vida después de la experiencia de enfermedad que antes de ser diagnosticados (Speck, 2011). Se realza que un diagnóstico de cáncer puede impulsar la búsqueda de significado y cambios en la vida de las personas en términos de valores y estilos de vida, que incrementan la espiritualidad y apreciación de la vida, el encuentro de nuevas posibilidades, mejoran las relaciones afectivas, y se vuelven más conscientes de cómo deben vivir la vida (Boyraz et al., 2010; Carlsson, Hamrin, \& Lindqvist, 1999; Schlegel et al., 2013; Speck, Higginson, \& Addington-Hall, 2004). Este crecimiento postraumático se asocia a una SCV significativa en los enfermos y a los beneficios en la adaptación a la enfermedad (Dun et al., 2009; Frankl, 1990; Mols et al., 2009; Neimeyer, 2001; Park \& Blank, 2012). De este modo, los sujetos que viven este crecimiento, demuestran tener un sentido de sí mismos diferente, se vuelven más resilientes, independientes y confiados, desarrollan igualmente nuevos roles, una buena robustez frente a las fragilidades de la vida, y se hacen menos vulnerables a pérdidas consecutivas (Tedeschi et al., 1998). Así, cuando después de un proceso de búsqueda de significado, el significado es encontrado por los enfermos, estos experimentan más bienestar, menos distrés y presentan una adaptación más eficaz a la enfermedad (Speck, 2011). Esta búsqueda de significado es una de las funciones del coping de atribución de significado, tan importante en situaciones irreversibles o irresolubles, como un trauma o una pérdida (Park, 2005). Se concluye que las crisis en la vida orientan a enfrentamientos constructivos, y el crecimiento personal surge en la disrupción que la crisis genera y en su reorganización subsecuente (Schaefer \& Moos, 1992).

Los resultados obtenidos, o sea, la presencia de niveles elevados de IE y de significado en la vida surge como una posible justificación que no se fundamenta en supuestos e ideas preconcebidas. En concreto otros autores obtienen datos totalmente 
opuestos a los encontrados en el estudio, asi Strine, Chapman, Balluz, Moriarty, y Mokdad (2008) encuentran que los enfermos crónicos revelan una mayor falta de SCV en comparación con personas sin enfermedad, iguales resultados que los obtenidos en enfermos oncológicos por Bjordal, Mastekaasa, y Kaasa (1995) donde la percepción de SCV es menor al ser comparados con personas saludables, y datos semejantes obtienen en enfermos supervivientes de cáncer en la adolescencia que presentan menos SCV al ser comparados con población general (Seitz et al., 2010).

Aunque las contribuciones que los resultados puedan dar a la investigación sobre la relación entre la IE y el significado en el contexto de la salud y de la enfermedad, deberán ser tenidas en cuenta con limitaciones. Por un lado, el estudio es realizado en un único momento de evaluación, no permitiendo realizar conclusiones de causa-efecto entre las variables. Los próximos estudios podrán analizar la relación entre las variables en varios momentos de evaluación a lo largo del tiempo. Por otro lado, la IE fue evaluada apenas como capacidades percibidas, lo que apunta a otra indicación para la investigación futura, o sea, aplicar un instrumento de medida de la IE - capacidad, en el sentido de averiguar la presumible variación en los resultados, como por ejemplo, el MSCEIT (Mayer et al., 2002).

Se concluye que los resultados encontrados permiten ampliar la comprensión acerca de las relaciones entre la IE, el significado, y la SCV. Se vislumbran así nuevas y positivas direcciones para comprender los componentes primordiales a nivel de intervención, teniendo como metas la optimización del desarrollo y adquisición de competencias emocionales y de creación de objetivos en la vida. La eficacia de estas metas dará como resultado el aumento de la satisfacción en la vida de los participantes, principalmente ante un proceso de enfermedad. Por último, los resultados obtenidos señalan la convergencia entre los constructos de la IE, del significado y de la SCV, 
realzando los principios de la psicología positiva que propone encontrar las razones por las cuales unas personas son más felices o se encuentran más satisfechas que otras (BarOn, 2010; Kampfe \& Mitte, 2010). 


\subsection{Segunda Hipótesis}

\section{Las estrategias de Coping positivas son mediadoras de la relación entre la Inteligencia emocional y la Satisfacción con la vida en los enfermos oncológicos.}

Para comprobarla, en la estadística descriptiva realizada se recurrió a las medias, desviación típica y correlación de Pearson para analizar las relaciones entre la IE, la SCV y el coping. En la mediación de modelos se recurrió a procedimientos descritos por Preacher y Hayes (2004), utilizando el análisis de mediación múltiple. La IE es la variable independiente (percepción emocional, facilitación emocional, comprensión emocional y regulación emocional) de acuerdo con el Modelo de Mayer y Salovey (1997), la SCV es la variable dependiente, y las estrategias de coping son las variables mediadoras (espíritu de lucha, evitación cognitiva, desánimo-debilidad y preocupación ansiosa).

Preacher y Hayes (2008) desarrollaron un programa macro en el SPSS para el análisis siguiendo los métodos formales como criterio para la mediación desarrollada por Baron y Kenny (1986), incluyendo el test de Sobel, así como los resultados de remuestreado bootstrap. Para el análisis de los efectos indirectos específicos se utilizó el procedimiento de re-muestreado (5000 muestras bootstrap) y los intervalos de confianza del $95 \%$ para evaluar su significancia. Si el intervalo de confianza de $95 \%$ no incluye el cero, puede concluirse que existe un efecto indirecto significativo $(p<0,05)$. La colinariedad fue igualmente testada, resultando en los valores VIF (Variance infaction factor $)(1,10$ - 1,87) con los límites aceptables para el análisis de regresión (Cohen, Cohen, West, \& Aiken, 2003). 
Inicialmente se analizó la media, la desviación típica y las correlaciones entre las variables, es decir entre la IE, las estrategias de coping y la SCV.

Se evidencia que los enfermos oncológicos presentan puntuaciones medias elevadas en varias capacidades emocionales de la IE, sobre todo en la regulación emocional $(M=4,17)$ y en la comprensión emocional $(M=4,16)$. Al nivel del coping recurren a las estrategias de espíritu de lucha $(M=3,33)$ y evitación cognitiva $(M=$ 3,10) más frecuentemente. Y revelan una considerable percepción de SCV, encontrándose por encima del punto medio de la escala $(M=4,7)$, tal como se presenta en la Tabla 15.

Se demuestra con la correlación de Pearson, que todas las dimensiones de la IE se correlacionan positivamente con la SCV y con la dimensión del coping, espíritu de lucha; y de forma negativa con la preocupación ansiosa y el desánimo-debilidad. Específicamente, se revela la existencia de correlaciones significativas entre la dimensión percepción emocional y la dimensión facilitación emocional $(r=0,75$; $p<0,001)$; entre la dimensión percepción emocional y la dimensión comprensión emocional $(r=0,80 ; p<0,001)$; entre la dimensión percepción emocional y la dimensión regulación emocional ( $r=0,75 ; p<0,001)$. A nivel del coping, la dimensión desánimodebilidad se relaciona negativamente con la: dimensión percepción emocional $(r=-$ 0,41; $p<0,001)$; dimensión facilitación emocional $(r=-0,50 ; p<0,001)$; dimensión comprensión emocional ( $r=-0,47 ; p<0,001)$; dimensión regulación emocional ( $r=-$ 0,51; $p<0,001)$; y con otra dimensión del coping, espíritu de lucha $(r=-0,59 ; p<0,001)$. Se relaciona también, aunque positivamente, con la dimensión preocupación ansiosa ( $r$ $=0,42 ; p<0,001)$. La dimensión espíritu de lucha se correlaciona positivamente con la: dimensión percepción emocional $(r=0,55 ; p<0,001)$; dimensión facilitación emocional $(r=0,56 ; p<0,001)$; dimensión comprensión emocional $(r=0,60 ; p<0,001)$; dimensión 
regulación emocional $(r=0,56 ; p<0,001)$, y negativamente con la dimensión desánimodebilidad $(r=-0,59 ; p<0,001)$ y la dimensión preocupación ansiosa $(r=-0,21$; $p<0,001)$. A su vez, la SCV se presenta correlacionada de forma significativa y de forma positiva con la: dimensión percepción emocional $(r=0,51 ; p<0,001)$; dimensión facilitación emocional $(r=0,53 ; p<0,001)$; dimensión comprensión emocional $(r=$ $0,51 ; p<0,001)$; dimensión regulación emocional $(r=0,48 ; p<0,001) ; \mathrm{y}$ con la dimensión espíritu de lucha $(r=0,65 ; p<0,001)$. De forma negativa, se correlaciona con las dimensiones desánimo-debilidad $(r=-0,59 ; p<0,001)$ y la dimensión preocupación $\operatorname{ansiosa}(r=-0,30 ; p<0,001)$.

Tabla 15: Medias, desviación típica y correlaciones entre todas las variables del estudio $(\mathbf{n}=202)$

\begin{tabular}{llllllllll}
\hline Variables & $\mathbf{1}$ & $\mathbf{2}$ & $\mathbf{3}$ & $\mathbf{4}$ & $\mathbf{5}$ & $\mathbf{6}$ & $\mathbf{7}$ & $\mathbf{8}$ & $\mathbf{9}$ \\
1. Percepción & 1 & $0,75^{*}$ & $0,80^{*}$ & $0,75^{*}$ & $-0,41^{*}$ & $-0,10$ & $0,55^{*}$ & 0,02 & $0,51^{*}$ \\
2. Facilitación & & 1 & $0,85^{*}$ & $0,81^{*}$ & $-0,50^{*}$ & $-0,09$ & $0,56^{*}$ & 0,04 & $0,53^{*}$ \\
3. Comprensión & & & 1 & $0,83^{*}$ & $-0,47^{*}$ & $-0,05$ & $0,60^{*}$ & 0,07 & $0,51^{*}$ \\
4. Regulación & & & & 1 & $-0,51^{*}$ & $-0,10$ & $0,56^{*}$ & 0,02 & $0,48^{*}$ \\
5. Desánimo & & & & & 1 & $0,42^{* *}$ & $-0,59^{*}$ & $-0,07$ & $-0,59^{*}$ \\
6. Preocupación & & & & & & 1 & $-0,21^{*}$ & 0,09 & $-0,30^{*}$ \\
7. Espíritu & & & & & & & 1 & 0,11 & $0,65^{*}$ \\
8. Evitación & & & & & & & & 1 & 0,07 \\
9. Satisfacción & & & & & & & & & 1 \\
M & 3,94 & 4,16 & 4,07 & 4,17 & 1,62 & 2,40 & 3,33 & 3,10 & 4,71 \\
Dt. & 0,81 & 0,81 & 0,77 & 0,83 & 0,67 & 0,67 & 0,62 & 0,57 & 1,32 \\
\hline Nota. ${ }^{*} p<0,01$ & & & & & & & & &
\end{tabular}

El análisis de mediación fue ejecutado separadamente para cada una de las cuatro variables independientes (percepción emocional, facilitación emocional, comprensión emocional y regulación emocional), considerando simultáneamente como mediadores las variables del coping (espíritu de lucha, evitación cognitiva, desánimo-debilidad y preocupación ansiosa), y la SCV, como variable independiente. Se encontraron efectos directos e indirectos significativos de las variables del coping en la relación entre la IE y la SCV. Específicamente, las variables de espíritu de lucha y el desánimo-debilidad presentaron efectos directos e indirectos en la relación entre las variables de la IE (i.e., 
percepción, facilitación y comprensión emocional) y la SCV, sugiriendo una mediación parcial. Además, de acuerdo con los principios de Baron y Kenny (1986), los resultados sugieren una mediación total de las variables de espíritu de lucha y desánimo-debilidad entre la regulación emocional y la SCV, porque el efecto directo (c') deja de ser significativo $(p<0,05)$ cuando las variables mediadoras son insertadas en el análisis. Se encontraron también dos efectos directos entre la preocupación ansiosa en la relación entre la comprensión y la regulación emocional con la SCV. Sin embargo, la existencia de estos hechos no sugieren mediación - Tabla 16.

Tabla 16: Análisis de mediación para evaluar los efectos indirectos de las variables de la IE sobre la SCV a través de las categorías de coping $(\mathrm{n}=\mathbf{2 0 2})$

\begin{tabular}{|c|c|c|c|c|c|c|c|c|c|}
\hline VI & $\mathrm{M}$ & VD & $\begin{array}{l}a^{\prime} \\
(\mathrm{VI}-\mathrm{M})\end{array}$ & $\begin{array}{l}b^{\prime} \\
\text { (M- } \\
\text { VD) }\end{array}$ & $\begin{array}{l}c \\
\text { (efecto } \\
\text { total) }\end{array}$ & $\begin{array}{l}c^{\prime} \\
\text { (efecto } \\
\text { directo) }\end{array}$ & $\begin{array}{l}a b \\
\text { (efecto } \\
\text { indirecto) }\end{array}$ & $\begin{array}{l}D T \\
\text { (efecto } \\
\text { indirecto) }\end{array}$ & $\begin{array}{l}\text { Bootstrap } \\
\text { IC } 95 \%\end{array}$ \\
\hline \multirow[t]{4}{*}{ Percepción } & Esp. & Sat. & $0,43 * *$ & $0,79 * *$ & $0,84 * *$ & $0,31 *$ & 0,34 & 0,07 & $(0,20 ; 0,51)$ \\
\hline & Des. & Sat. & $-0,34 * *$ & $-0,48 * *$ & & & 0,16 & 0,06 & $(0,07 ; 0,30)$ \\
\hline & Evi. & Sat. & 0,01 & 0,04 & & & 0,00 & 0,00 & $(-0,00 ; 0,02)$ \\
\hline & Preoc. & Sat. & $-0,08$ & $-0,20$ & & & 0,01 & 0,01 & $(-0,00 ; 0,06)$ \\
\hline \multirow[t]{4}{*}{ Facilitación } & Esp. & Sat. & $0,43 * *$ & $0,82 * *$ & $0,87 * *$ & $0,31 *$ & 0,35 & 0,07 & $(0,21 ; 0,53)$ \\
\hline & Des. & Sat. & $-0,41 * *$ & $-0,43^{*}$ & & & 0,18 & 0,06 & $(0,05 ; 0,33)$ \\
\hline & Evi. & Sat. & 0,03 & 0,04 & & & 0,00 & 0,00 & $(-0,00 ; 0,02)$ \\
\hline & Preoc. & Sat. & $-0,08$ & $-0,22 *$ & & & 0,01 & 0,01 & $(-0,00 ; 0,06)$ \\
\hline \multirow[t]{4}{*}{ Comprensión } & Esp. & Sat. & $0,49 * *$ & $0,81 * *$ & $0,89 * *$ & $0,28 *$ & 0,40 & 0,09 & $(0,24 ; 0,61)$ \\
\hline & Des. & Sat. & $-0,41 * *$ & $-0,47 * *$ & & & 0,19 & 0,06 & $(0,08 ; 0,36)$ \\
\hline & Evi. & Sat. & 0,05 & 0,03 & & & 0,00 & 0,00 & $(-0,01 ; 0,03)$ \\
\hline & Preoc. & Sat. & $-0,04$ & $-0,22 *$ & & & 0,01 & 0,01 & $(-0,01 ; 0,05)$ \\
\hline \multirow[t]{4}{*}{ Regulación } & Esp. & Sat. & $0,42 * *$ & $0,90 * *$ & $0,76^{* *}$ & 0,15 & 0,38 & 0,08 & $(0,24 ; 0,57)$ \\
\hline & Des. & Sat. & $-0,42 * *$ & $-0,48 * *$ & & & 0,20 & 0,07 & $(0,07 ; 0,35)$ \\
\hline & Evi. & Sat. & 0,01 & 0,03 & & & 0,00 & 0,00 & $(-0,00 ; 0,02)$ \\
\hline & Preoc. & Sat. & $-0,08$ & $-0,20$ & & & 0,01 & 0,01 & $(-0,00 ; 0,05)$ \\
\hline
\end{tabular}

Nota. VI=Variables independientes; M=Mediadores; VD=Variable dependiente; $\mathrm{DT}=$ Desviación típica del efecto indirecto; Esp.=Espíritu de lucha; Des.=Desánimo; Evi.=Evitación; Preoc.=Preocupación; Sat.=Satisfacción; ${ }^{*} p<0,05 ; * * p<0,001$.

Hemos pretendido verificar la relación entre la IE, el coping y la SCV en enfermos oncológicos, además de los efectos directos e indirectos de mediación entre los respectivos constructos.

Cuanto a las relaciones de las variables del modelo de mediación, es importante señalar que los resultados confirman totalmente la hipótesis postulada. O sea, en premier la IE se relaciona significativamente con la SCV en los enfermos con cáncer. 
Así todas las capacidades percibidas de IE (percepción, facilitación, comprensión y regulación emocional) se encuentran relacionadas con la SCV conforme algunos estudios hechos en poblaciones sin enfermedad (Bastian et al., 2005; Ciarrochi et al., 2000). En enfermos oncológicos Guzmán y Alarcón (2007) encontraran relaciones significativas entre la comprensión y regulación emocional con la SCV. Otros estudios indican que la IE se relaciona positivamente con la SCV y negativamente con el distrés psicológico, influyendo las personas a evaluar su SCV de un modo más positivo, incluso de cara a experiencias estresantes, a solucionar problemas y emplear estrategias de afrontamiento que reducen la ansiedad (e.g., Bhullar et al., 2012). En este punto se realza los beneficios de la IE en el contexto de enfermedad, siendo una variable importante que genera condiciones favorables en el sujeto y reduce aquellas situaciones que lleva a los enfermos a desarrollar trastornos de ansiedad, además de ayudar al paciente a aceptar su proceso de enfermedad, así como a iniciar procesos terapéuticos y al producir un mayor bienestar personal (Cerezo et al., 2010; Extremera-Pacheco \& Fernández-Berrocal, 2006; Guzmán \& Alarcón, 2007; Rodríguez, 2004). Se revela aún un amortiguador contra acontecimientos negativos y traumáticos, disminuyendo el distrés en el cáncer de mama, la depresión y la ansiedad, la fatiga crónica en enfermos sometidos a quimioterapia, y la preocupación en los diferentes estados del proceso de cáncer urológico, así como reduce la vulnerabilidad física de la enfermedad durante y después del tratamiento (Brown \& Swartz, 2012; Gomes, 2011; Kieszkowska-Grudny et al., 2010; Schmidt \& Andrykowski, 2004; Smith et al., 2012). Se comprobé también que la IE tiene una capacidad predictiva en la CVD relacionada con la salud en las diferentes dimensiones de la vida de los enfermos oncológicos (Rey et al., 2013).

En segundo, se ha verificado una correlación positiva entre las cuatro capacidades percibidas de IE (percepción, facilitación, comprensión y regulación emocional) con el 
estilo espíritu de lucha y de forma negativa con el de preocupación ansiosa y de desánimo-debilidad, suportando la hipótesis. En este mismo sentido una vasta literatura confirma que una elevada percepción de IE asociase a la adopción de estrategias de afrontamiento positivas (e.g., Austin et al., 2010; Chan, 2003; Downey, Johnston, Hansen, Birney, \& Stough, 2010; Extremera-Pacheco \& Férnandez-Berrocal, 2007; Furnham \& Petrides, 2003; Gerits, Derksen, Verbruggen, \& Taylor, 2004; Gohm et al., 2005; Jordan, Ashkanasy, \& Hartel, 2002; Kim \& Agrusa, 2010; Mikolajczak, Nelis, Hansenne, \& Quoidbach, 2008; Mikolajczak, Petrides, \& Hurry, 2009; Pau, Croucher, Sohanpal, Muirhead, \& Seymour, 2004; Petrides \& Furnham, 2003; Petrides et al., 2007; Rogers, Qualter, Phelps, \& Gardner, 2006; Saklofske, Austin, Galloway, \& Davidson, 2007; Salovey et al., 1999; Shah \& Thingujam, 2008; Velasco, Fernández, Páez, \& Campos, 2006). El estilo espíritu de lucha es considerado como el estilo de coping más adaptativo, activo y eficaz, y la preocupación ansiosa y el desánimodebilidad se evalúan como estilos desadaptativos y pasivos (Christopher \& Thomas, 2009; Classen, Koopman, Angell, \& Spiegel, 1996; Kissane et al., 2004; Kulikowska \& Pokorski, 2008; Mattheus \& Zeidner, 2000; Nordin \& Glimelius, 1998; O’Brien \& Moorey, 2010; Pelletteri, 2002; Rowland, 1989; Salovey et al., 2002; Santos, 2003; Schnoll, Harlo, Satolbach, \& Brandt, 1998; Watson et al., 1991). Revelase así el papel decisivo de la IE en las estrategias de afrontamiento con el estrés, pudendo influir en la elección de los métodos de coping a los que recurren los sujetos bajo situaciones estresantes, en el sentido de preservar la salud mental (Baker \& Berenbaum, 2007; Montes-Berges \& Augusto-Landa, 2007; Noorbakhsh, Besharat, \& Zarei, 2010; Salovey et al., 1995). De esta forma, los estilos de coping característicos de las personas emocionalmente inteligentes confieren algunos beneficios en términos de bienestar, comportamientos adaptativos y de salud, a través de las capacidades para identificar y 
reparar las emociones, volviéndose modeladores de cualquier tipo de estresor que puede ser crónico (como una enfermedad) y/o puntual (como una tarea) (Ruiz-Aranda et al., 2007; Zeidner, Matthews, \& Roberts, 2006). En este punto, la IE facilita la identificación de las fuentes estresoras, permitiendo que el individuo dirija su atención a estrategias activas de coping, que llevan a su vez a una mayor comprensión, aceptación y adaptación en momentos de estrés continuo e intenso como son los procesos de dolor, enfermedad y muerte, reduciendo los niveles de ansiedad y de deterioro (AradillaHerrero \& Tomás-Sábado, 2006; González, Ramírez-Maestre, \& Herrero, 2007; Lyons \& Schneider, 2005). También utilizan estrategias para regular y minimizar las emociones negativas y mantener y potenciar las positivas, presentando menos sentimientos negativos a través de su relación mediada por la elección de estrategias de coping (Mikolajczak et al., 2008; Mikolajczak et al., 2009). En este ámbito, se realza el cariz adaptativo de la IE en situaciones exigentes y/o estrés pues se relaciona con la resolución de problemas, con la evaluación adecuada de las situaciones, y con la flexibilidad para adaptarse a las mismas (e.g., Bar-On, 1997; Petrides \& Furnham, 2001; Regner, 2008; Salovey et al., 1993; Salovey et al., 1995). A su vez, el coping adaptativo se conceptualiza como IE a través de la acción, maestría en el soporte emocional, crecimiento emocional y en la diferenciación cognitiva y emocional presentes en los cambios constantes de la vida, volviéndose la IE una calidad de la persona, al presentar una serie de competencias para resolver eficazmente cualquier situación, las cuales permiten prever resultados adaptativos futuros (Matthews \& Zeidner, 2000).

En tercer, se confirma la relación significativa entre las estrategias positivas del coping y la SCV, suportando la hipótesis. Los resultados se encuentran de acuerdo con la descripción de la SCV, como una evaluación cognitiva o un proceso de juicio crítico, visto como un índice en la adaptación psicológica a estresores en la vida (Diener, 1984). 
De este modo, la adaptación a situaciones sucesivas y la forma de afrontar experiencias estresantes se presentan, igualmente, como componentes importantes en el BES (e.g., Diener et al., 1999; Folkman \& Moskowitz, 2000; Giacomoni, 2002), siendo las estrategias de afrontamiento el medio primordial para que el enfermo acepte su condición, viva bien y encuentre satisfacción en la vida (Resende et al., 2008).

En cuarto, cuando las variables del coping se observaron como mediadoras en la relación entre la IE y la SCV, se ha confirmado la hipótesis. Concretamente, las variables del coping, como el espíritu de lucha y el desánimo-debilidad, sirven de mediadores parciales en la relación entre la percepción, facilitación y comprensión emocional y la SCV. Además, se presentan como mediadores totales de la relación entre la regulación emocional y la SCV. En general, estos resultados sugieren que los estilos de coping explican potencialmente la asociación entre la IE y la SCV en enfermos con cáncer. De hecho se tiene considerado que el proceso de coping funciona como mediador de la respuesta emocional a la situación estresante, siendo el objetivo, tanto del coping enfocado en el problema como en la emoción, equilibrar el estado emocional ante el estresor (Lazarus, 1991). Siendo importante en el estrés, mediando determinado acontecimiento y los resultados/consecuencias del mismo, considerándose que un proceso adecuado implica que los resultados obtenidos a largo plazo sean positivos, o que tenga efectos adaptativos (Adwin, 2004; Pais-Ribeiro \& Rodrigues, 2004). Se tiene revelado un mediador en la relación entre los acontecimientos estresantes y la ansiedad, la depresión, el distrés psicológico, las quejas somáticas, y el ajuste a la enfermedad, más precisamente a través de estrategias de aproximación/activas (Billings \& Moos, 1981, 1984; Coyne, Aldwin, \& Lazarus, 1981; Holland \& Holahan, 2003; Pearlin \& Schooler, 1978). Así como el coping media la relación entre la IE y la satisfacción conyugal (Zeidner et al., 2013). 
Teniendo en cuenta la relación de la regulación emocional y la SCV, totalmente mediada por el coping, más específicamente, cuando se recurre a estrategias del estilo espíritu de Lucha y en la ausencia de recurso al estilo desánimo-debilidad. Se encuentran varios estudios en que la regulación emocional se relaciona positivamente con un menor recurso a estrategias de coping pasivas y con un mayor recurso a estrategias de coping del tipo instrumental/activo y constructivas, tales como las estrategias enfocadas en la resolución de problemas (p. ej., espíritu de lucha), del mismo modo que se encuentra negativamente relacionada con la evitación cognitiva, el comportamiento emocional, la negación y la ventilación, resultando en un bienestar físico y psicológico, y en apoyo social (Augusto-Landa, López-Zafra, Berrios, \& Aguilar-Luzón, 2008; Extremera-Pacheco, Fernández-Berrocal, \& Durán, 2003; Fernández, Velasco, \& Campos, 2003; Goldenberg et al., 2006; Limonero, TomásSábado, Fernández-Castro, \& Gómez-Benito, 2004; Montes-Berges \& Augusto-Landa, 2007; Moreno-Jiménez, Garrosa, Losada, Morante, \& Rodríguez, 2004; Saklofske et al., 2007; Salovey et al., 2002; Velasco et al., 2006). La regulación emocional, surge así, como una de las dimensiones fundamentales en el constructo de la IE, al subrayar el esfuerzo del sujeto para eliminar, mantener o alterar su estado emocional, a través de la construcción de una nueva situación emocional, siendo el resultado de la reevaluación cognitiva que implica el cambio cognitivo que, a su vez, lleva a la disminución del impacto emocional de la situación en el sujeto (Salovey, 2001). En este ámbito, las personas que regulan sus emociones tanto negativas como positivas, y utilizan la información proveniente de esta regulación, median las emociones reiterando las positivas y realzan un mayor índice de adaptación a situaciones de estrés agudo (Lepore et al., 2004; Ruiz-Aranda et al., 2005). La regulación emocional se correlaciona por un lado con la disminución de la intensidad afectiva negativa y con situaciones 
desagradables, e por otro lado, se asocia a aumentos del afecto positivo, al refuerzo de situaciones agradables y al control de la experiencia emocional, a través de estrategias de coping efectivas y eficaces (Matthews \& Zeidner, 2000; Salovey et al., 2000). Esto componente de la IE es el que está más correlacionado con la salud mental positiva, por sus estrategias incrementaren el bienestar, el equilibrio afectivo, el ajuste social y el funcionamiento adaptativo (Ciarrochi \& Deane, 2001; Mayer \& Salovey, 1997; Schutte et al., 2002; Velasco et al., 2006). A nivel de la enfermedad, la investigación sobre la regulación emocional ha ganado un relieve significativo realzando la pertinencia del proceso emocional en la promoción de la adaptación, específicamente, a la enfermedad (Cameron \& Jago, 2008). En relación a la enfermedad oncológica, el coping con la enfermedad exige un nivel considerable de regulación emocional, teniendo en cuenta sus efectos adaptativos (Antoni, 2003; Cunningham et al., 1991; Giese-Davis et al., 2002). A nivel de la intervención psicológica enfocada en la regulación emocional, se presenta resultados positivos en los enfermos oncológicos, revelando estos reducciones significativas de ansiedad y preocupación por el cáncer, promoviendo igualmente bienestar emocional y el coping eficaz durante los tratamientos, existiendo una relación directa entre la regulación emocional y el bienestar personal en el cáncer (Cameron, Booth, Schlatter, Ziginskas, \& Harman, 2007; Extremera-Pacheco \& FernándezBerrocal, 2006).

Con el expuesto es viable considerar la IE como pronosticadora de adaptación al medio y a situaciones de estrés (e.g., Bar-On, 2000; Extremera-Pacheco \& FernándezBerrocal, 2005a; Férnandez-Berrocal \& Extremera-Pacheco, 2006; Gohm et al., 2005; Ruiz-Aranda et al., 2007; Salovey et al., 1995; Tugade \& Fredrickson, 2004). La importancia de la IE es evidente, mismo, en experiencias subjetivas de miedo, desesperanza y horror relacionadas con los acontecimientos adversos influyendo el 
crecimiento en la adversidad, apoyando así la persona a transformar experiencias traumáticas perturbadoras en crecimiento (Linley et al., 2012). En este sentido, los individuos con competencias emocionales significativas, revelan ser capaces de reconocer sus respuestas emocionales como naturales ante el trauma, asumir sus emociones y traumas como parte integrante de su vida, y de realizar atribuciones positivas sobre el trauma y sus emociones (Salovey et al., 2000). De esta forma a través del entrenamiento para desarrollar las capacidades de IE, se trabaja la resiliencia personal en el afrontamiento de las crisis o traumas en la vida, que a su vez promueve la salud, el bienestar y el funcionamiento, se consiguiendo así, hacer frente a situaciones traumáticas (Gawali, 2012; Slaski \& Cartwright, 2003).

De una forma general, se defiende que la psicología positiva señala múltiples variables psicológicas como amortiguadoras entre condiciones amenazadoras/estresantes y la integridad personal, la enfermedad y el bienestar personal, principalmente el coping, el BES, el optimismo, la felicidad, el BEP, y este punto se añade con el presente estudio, la IE (Pais-Ribeiro, 2006).

Se concluye que los resultados obtenidos se presentan como una contribución potencial tanto para el conocimiento del constructo de la IE en el área oncológica, relación esta analizada de forma escasa y simplificada en la poca información encontrada, como para la práctica clínica en el área de la Psicooncología. La IE revelase como un fundamento de base para intervenciones psicológicas en enfermos oncológicos, tanto de cariz educacional o cognitivo-comportamental, debiendo asociarse a técnicas de promoción de estrategias de coping activas y eficaces (e.g., Fawzy \& Fawzy, 1998; Matthews \& Zeidner, 2000).

Al nivel de las limitaciones presentes en este estudio, se resalta tratarse de un estudio transversal. En este sentido, es pertinente que las próximas investigaciones que 
relacionen la IE y el coping con la enfermedad oncológica, sean longitudinales, y como escenario ideal, el acompañamiento en todo el proceso de enfermedad, desde la fase de diagnóstico hasta la de remisión o muerte. Igualmente, destaca la evaluación del efecto psicoterapéutico de las intervenciones psicológicas que buscan el desarrollo de las competencias de la IE (Parker, 2002), con grupos de control de muestras homogéneas de enfermos oncológicos, así como el grado de supervivencia de los participantes. Con la finalidad de realzar el efecto directo de la IE en la reducción de los costes para los Sistemas Públicos de salud, testar si se trata de un indicador de salud per se, y publicar un programa de intervención que se vuelva en una herramienta útil en el área de la salud. Se añade por fin, la necesidad y pertinencia del desarrollo y validación de una escala de IE específica para la enfermedad oncológica, permitiendo una mayor contextualización de los objetivos e identificación de los participantes con la escala. 


\section{Conclusiones}




\section{CONCLUSIONES}

$1^{\text {a }}$. El constructo de la Inteligencia emocional, apoyado en los resultados obtenidos, con la construcción y validación del Cuestionario de Autopercepción de Inteligencia Emocional, contradicen las dudas teóricas postuladas en la literatura, así como sus incongruencias a nivel de su evaluación, revelando su carácter científico y su validez psicométrica.

$2^{\text {a }}$. La Inteligencia emocional se muestra como una variable potenciadora de bienestar, encontrándose asociada, significativamente, con tres de las variables centrales de la Psicología positiva, principalmente, el Significado en la vida, la Satisfacción con la vida y el Coping.

$3^{\mathrm{a}}$. La Inteligencia emocional y el Significado en la vida pronostican la Satisfacción con la vida tanto en personas saludables como en enfermos oncológicos. A través de los resultados de la investigación se pone de relieve que al contrario de los datos e ideas preconcebidas, los enfermos oncológicos consiguen experimentar Satisfacción con su vida independientemente del proceso de enfermedad.

$4^{\mathrm{a}}$. La Inteligencia emocional y el Significado en la vida parecen inducir una gestión emocional y el encuentro de una vida con significado ante experiencias de vida negativas. El cáncer en comparación a los estados de salud positivos, se presenta como un impulsor no sólo de una mayor búsqueda de significado, sino incluso de un mayor equilibrio emocional en favor de que los enfermos obtengan una vida con más Satisfacción.

$5^{\text {a }}$ El cariz adaptativo de la Inteligencia emocional se evidencia en base a su relación positiva con el Coping. Por sí sola puede promover la Satisfacción en la vida en el contexto de la enfermedad, se subraya que los enfermos oncológicos que se perciben emocionalmente inteligentes recurren con más frecuencia a las estrategias más eficaces 
y activas en el afrontamiento del proceso de cáncer. Es decir, cuanto más emocionalmente inteligentes se perciben mayor es su recurso a estilos de afrontamiento adaptativos, lo que permite a los enfermos experimentar una vida con más Satisfacción y consecuentemente, a adaptarse a la adversidad inherente al padecimiento de la enfermedad oncológica.

$6^{\mathrm{a}}$. Por último, a la par de los constructos referidos en la vasta literatura científica como factores del bienestar humano, o sea, el Significado en la vida y el Coping, surgen los beneficios de la Inteligencia emocional para obtener Satisfacción con la vida. En este sentido, por un lado, se refuerzan los resultados de la Inteligencia emocional en la manutención y promoción de la salud mental y por otro, se destaca la preponderancia del desarrollo de las capacidades de Inteligencia emocional en la salud física. Principalmente en el área de la Oncología, destacándose sus previsibles efectos para una Satisfacción significativa en la vida de los enfermos y subsecuentemente para la adaptación a la enfermedad del siglo, el cáncer. 


\section{Referencias Bibliográficas}




\section{REFERENCIAS BIBLIOGRÁFICAS}

Adwin, C. (2004). Stress, coping, and development: an integrative perspective. New York: The Guilford Press.

Affleck, G., \& Tennen, H. (1996). Construing benefits from adversity: Adaptational significance and dispositional underpinnings. Journal of Personality, 64, 899-922. doi:10.1111/j.14676494.1996.tb00948.x

Akerjordet, K.., \& Severinsson, E. (2010). The state of the science of emotional intelligence related to nursing leadership: An integrative review. Journal of Nursing Management, 18, 363-382. doi:10.1111/j.1365-2834.2010.01087.x

Alegre, A., \& Benson, M. J. (2010). Parental behaviors and adolescent adjustment: Mediation via adolescent trait emotional intelligence. Individual Differences Research, 8, 83-96.

Anagnostopoulos, F., Slater, J., \& Fitzsimmons, D. (2010). Intrusive thoughts and psychological adjustment to breast cancer: exploring the moderating and mediating role of global meaning and emotional expressivity. Journal of Clinical Psychology in Medical Settings 17, 137-49. doi:10.1007/s10880-010-9191-6

Andréu, Y. (2002). Personalidad tipo c: Historia y validez del concepto. In M. Dias \& E. Durá (Eds.), Territórios da Psicologia Oncológica (pp. 399-426). Lisboa: CLIMEPSI.

Andrykowski, M. A., Curran, S. L., Studts, J. L., Cunningham, L., Carpenter, J. S., McGrath, P. C., ...Kenady, D. E. (1996). Psychosocial adjustment and quality of life in women with breast cancer and benign breast problems: A controlled comparison. Journal of Clinical Epidemiology, 49, 827834. doi:10.1016/0895-4356(96)00028-5

Angerami, V. (2007). Psicoterapia existencial. São Paulo: Tomson.

Antoni, M. (2003). Stress management intervention for women with breast cancer: Therapist's manual. Washington, DC: American Psychological Association.

Aradilla-Herrero, A., \& Tomás-Sábado, J. (2006). Efectos de un programa de educación emocional sobre la ansiedad ante la muerte en estudiantes de enfermería. Enfermeria Clinica, 16, 321-326. doi:10.1016/S1130-8621(06)71239-6

Arora, S., Ashrafian, H., Davis, R., Athanasiou, T., Darzi, A., \& Sevdalis, N. (2010). Emotional intelligence in medicine: A systematic review through the context of the ACGME competences. Medical Education, 44, 749-764. doi:10.1111/j.1365-2923.2010.03709.x 
Augusto-Landa, J. M.., López-Zafra, E., Antoñana, R., \& Pulido, M. (2006). Perceived emotional intelligence and life satisfaction among university teachers. Psichotema, 18, 152- 157.

Augusto-Landa, J. M., López-Zafra, E., Berrios, M. P., \& Aguilar-Luzón, M. D. C. (2008). The relationship between emotional intelligence, occupational stress and health in nurses, a questionnaire survey. International Journal of Nursing Studies, 45, 888-901. doi: org/10.1016/j.ijnurstu.2007.03.005

Augusto-Landa, J. M., Pulido-Martos, M., \& López-Zafra, E. (2011). Does perceived emotional intelligence and optimism/pessimism predict psychological well-being? Journal of Happiness Studies, 12, 463-474. doi:10.1007/s10902-010-9209-7

Augusto-Landa, J. M., \& Montes-Berges, B. (2009). Perceived emotional intelligence, health and somatic symptomatology in nursing students. Individual Differences Research, 7, 197-211.

Austin, E. J., Saklofske, D. H., \& Egan, V. (2005). Personality, well-being and health correlates of trait emotional intelligence. Personality and Individual Differences, 38, 547-558. doi:10.1016/j.paid.2004.05.009

Austin, E. J., Saklofske, D. H., \& Mastoras, S. M. (2010). Emotional intelligence, coping, and examrelated stress in Canadian undergraduate students. Australian Journal of Psychology, 62, 42-50. doi:10.1080/00049530903312899

Avsec, A., \& Kavcic, T. (2011). Importance of the alternative five and trait emotional: Intelligence for agentic and communal domains of satisfaction. Psychological Topics, 20, 461-475.

Azimi, S., AsgharNejad-Farid, A. A., Kharazi Fard, M. J., \& Khoei, N. (2010). Emotional intelligence of dental students and patient satisfaction. European Journal of Dental Education, 14, 129-132. doi:10.1111/j.1600-0579.2009.00596.x

Bailey, C., Murphy, R., \& Porock, D. (2011). Professional tears: Developing emotional intelligence around death and dying in emergency work. Journal of Clinical Nursing, 20, 3364-3372. doi:10.1111/j.1365-2702.2011.03860.x

Baker, J. P., \& Berenbaum, H. (2007). Emotional approach and problem-focused coping: A comparison of potentially adaptive strategies. Cognition and Emotion, 21, 95-118. doi:10.1080/02699930600562276

Bar-On, R. (1997). Bar-On emotional quotient inventory: A measure of emotional intelligence. Toronto: O Multi-Health Systems Inc. 
Bar-On, R. (2000). Emotional and social intelligence: Insights from the emotional quotient inventory. In R. Bar-On \& J. Parker (Eds.), The Handbook of Emotional Intelligence (pp.363-388). San Francisco: Jossey-Bass.

Bar-On, R. (2005). The impact of emotional intelligence on subjective well-being. Perspectives in Education, 23, 41-61.

Bar-On, R. (2010). Emotional intelligence: an integral part of positive psychology. South African Journal of Psychology, 40, 54-62.

Baron, R.M., \& Kenny, D. A. (1986). The moderator-mediator variable distinction in social psychological research: Conceptual, strategic, and statistical considerations. Journal of Personality and Social Psychology, 51, 1173-1182. doi:10.1037/0022-3514.51.6.1173

Barros, L. P. D., Gropo, L. N., Petribú, K., \& Colares, V. (2008). Avaliação da qualidade de vida em adolescentes: Revisão da literatura. Jornal Brasileiro de Psiquiatria, 57, 212-217. doi:org/10.1590/S0047-20852008000300009

Barros, H., \& Lunet, N. (2006). Cancro: Uma perspectiva de saúde pública. Arquivos de Medicina, 20, 31-36.

Basabe, N., Celorio, M., Via, R., Echebarría, L., Hormaza, M., \& Páez, D. (1989). Introducción: Perspectivas psicosociales de las emociones, salud mental y psicología y psiquiatrías clínicas y comunitarias. In A. Echebarría \& D. Páez (Eds.), Emociones: Perspectivas psicosociales (pp. 939). Madrid: Editorial Fundamentos.

Bastian, V. A., Burns, N. R., \& Nettelbeck, T. (2005). Emotional intelligence predicts life skills, but not as well as personality and cognitive abilities. Personality and Individual Differences, 39, 11351145. doi:10.1016/j.paid.2005.04.006

Batool, S. S., \& Khalid, R. (2009). Emotional intelligence: A risk factor for depression. Journal of Pakistan Psychiatric Society, 6, 65-72.

Battista, J., \& Almond, R. (1973). The development of meaning in life. Psychiatry: Journal for the Study of Interpersonal Processes, 36, 409-427.

Baum, S. K., \& Stewart Jr, R. B. (1990). Sources of meaning through the lifespan. Psychological Reports, 67, 3-14. doi:10.2466/pr0.1990.67.1.3

Baumeister, R. (1991). Meanings of life. New York: Guilford Press. 
Beck, A., Rush, J., Shaw, B., \& Emery, G. (1979). Cognitive therapy for depression. New York: Guilford Press.

Bedwell, S. (2003). Emotional intelligence, personality revisited or something else. Proceedings of Symposium at the Annual Meeting of the Society of Industrial and Organizational Psychology, Orlando, Fl.

Bennett, K., \& Sawatzky, J. A. V. (2013). Building emotional intelligence: A strategy for emerging nurse leaders to reduce workplace bullying. Nursing Administration Quarterly, 37, 144-151. doi:10.1097/NAQ.0b013e318286de5f

Bhullar, N., Schutte, N. S., \& Malouff, M. J. (2012). Trait emotional intelligence as a moderator of the relationship between psychological distress and satisfaction with life. Individual Differences Research, 10, 19-26.

Billings, A. G., \& Moos, R. H. (1981). The role of coping responses and social resources in attenuating the stress of life events. Journal of Behavioral Medicine, 4, 139-157. doi:10.1007/BF00844267

Billings, A. G., \& Moos, R. H. (1984). Coping, stress, and social resources among adults with unipolar depression. Journal of Personality and Social Psychology, 46, 877-891. doi:10.1037/00223514.46.4.877

Bjordal, K., Mastekaasa, A., \& Kaasa, S. (1995). Self-reported satisfaction with life and physical health in long-term cancer survivors and a matched control group. European Journal of Cancer Part B: Oral Oncology, 31, 340-345. doi:10.1016/0964-1955(95)00039-9

Blanco, A., Antequera, R., \& Aires, M. (2002). Perception subjectiva del cáncer. In M. Dias \& E. Durá (Eds). Territórios da psicologia oncológica (pp.605-638). Lisboa: CLIMEPSI.

Blickle, G., Momm, T., Liu, Y., Witzki, A., \& Steinmayr, R. (2011). Construct validation of the test of emotional intelligence (TEMINT): A two-study investigation. European Journal of Psychological Assessment, 27(4), 1-7.

Bovbjerg, D. (1989). Psychoneuroimmunology and cancer. In J. Holland \& J. Rowland (Eds.), Handbook of psychooncology: Psychological care of the patient with cancer (pp.727-736). New York: Oxford University Press.

Bowman, G. (2000). Emotions and illness. Journal of Advanced Nursing, 34, 256-263. 
Boyraz, G., Horne, S. G., \& Sayger, T. V. (2010). Finding positive meaning after loss: The mediating role of reflection for bereaved individuals. Journal of Loss and Trauma, 15, 242-258. doi:10.1080/15325020903381683

Brackett, M. A., \& Mayer, J. D. (2003). Convergent, discriminant, and incremental validity of competing measures of emotional intelligence. Personality and social psychology bulletin, 29(10), 1-12. doi: $10.1177 / 0146167203254596$

Brackett, M. A., Mayer, J., \& Warner, R. M. (2004). Emotional intelligence and its relation to everyday behaviour. Personality and individual differences, 36, 1387-1402. doi:10.1016/S01918869(03)00236-8

Brackett, M. A., \& Salovey, P. (2007). La evaluación de la inteligencia emocional con el Mayer SaloveyCaruso emocional intelligence test (MSCEIT). In J. Navas \& P. Berrocal (Eds.), Manual de inteligencia emocional (pp. 69-80). Madrid: Ediciones Pirámide.

Brackett, M. A., Warner, R. M., \& Bosco, J. S. (2005). Emotional intelligence and relationship quality among couples. Personal Relationships, 12, 197-212. doi:10.1111/j.1350-4126.2005.00111.x

Bradley, C. J., Neumark, D., Luo, Z., Bednarek, H., \& Schenk, M. (2005). Employment outcomes of men treated for prostate cancer. Journal of the National Cancer Institute, 97, 958-965. doi:10.1093/jnci/dji171

Bronk, K. C., Hill, P. L., Lapsley, D. K., Talib, T. L., \& Finch, H. (2009). Purpose, hope, and life satisfaction in three age groups. Journal of Positive Psychology, 4, 500-510. doi:10.1080/17439760903271439

Brown, T. (2006). Confirmatory factor analysis for applied research. New York: Guilford.

Brown, O., \& Swartz, E. (2012). Emotional intelligence and locus of control of adult patients with breast cancer receiving treatment. South African Family Practice Journal, 54, 139-144.

Bruner, J. (1990). Acts of meaning. Cambridge, MA: Harvard University Press.

Butler, E. A. (2011). Three views of emotion regulation and health. Social and Personality Psychology Compass, 5, 563-577. doi:10.1111/j.1751-9004.2011.00372.x

Byrne, B. (2010). Structural equation modelling with AMOS: Basic concepts, applications, and programming. (2nd ed.). Mahwah, NJ: Lawrence Erlbaum Associates.

Byron, K., \& Miller-Perrin, C. (2009). The value of life purpose: Purpose as a mediator of faith and wellbeing. Journal of Positive Psychology, 4, 64-70. doi:10.1080/17439760802357867 
Cabello, R., Fernández-Berrocal, P., Extremera-Pacheco, N., \& Ruiz-Aranda, D. (2007). The relationship between emotional regulation measures. In Araújo, A. \& Almeida, L. (Eds.), Inteligência humana: Investigação e aplicações (Vol. 1, pp.421-435). Coimbra: Quarteto.

Cameron, L. D., Booth, R. J., Schlatter, M., Ziginskas, D., \& Harman, J. E. (2007). Changes in emotion regulation and psychological adjustment following use of a group psychosocial support program for women recently diagnosed with breast cancer. Psycho-Oncology, 16, 171-180. doi:10.1002/pon.1050

Cameron, L., \& Jago, L. (2008). Emotion regulation interventions: A common-sense model approach. British Journal of Health Psychology, 13, 215-221. doi:10.1348/135910708X288800

Caplan, G. (1964). Principles of preventive psychiatry. New York/London: Basic Books.

Carapinheiro, G. (2002). Territórios da psicologia oncológica. Lisboa: CLIMEPSI.

Carlsson, M., Hamrin, E., \& Lindqvist, R. (1999). Psychometric assessment of the Life Satisfaction Questionnaire (LSQ) and a comparison of a randomised sample of Swedish women and those suffering from breast cancer. Quality of Life Research, 8, 245-253. doi:10.1023/A:1008875306645

Caruso, D. R., Mayer, J. D., \& Salovey, P. (2002). Relation of an ability measure of emotional intelligence to personality. Journal of personality assessment, 79, 306-320. doi:10.1207/S15327752JPA7902_12

Carver, C. S., \& Scheier, M. F. (1999). Themes and issues in the self-regulation of behavior. In R. S. Wyer Jr. (Ed.), Advances in social cognition (Vol.12, pp. 1-105). Mahwah, NJ: Erlbaum.

Carver, C. S., \& Scheier, M. F. (2000). Scaling back goals and recalibration of the affect system are processes in normal adaptive self-regulation: Understanding "response shift" phenomena. Social Science \& Medicine, 50, 1715-1722. doi:10.1016/S0277-9536(99)00412-8

Casas, F. (1996). Bienestar social: Una introducción psicosociológica. Barcelona: PPU.

Caspi, A., \& Elder, G. (1986). Life satisfaction in old age: Liking social psychology and history. Journal of Psychology and Aging, 1, 18-26.

Cavanaugh, J. (1994). Aging. In A. Colman (Ed.), Companion encyclopedia of psychology (Vol. 2, pp.752-769). London: Routledge.

Cella, D. F., \& Cherin, E. A. (1988). Quality of life during and after cancer treatment. Cancer, 14, 69-75. 
Cerezo, M. V., Ortiz-Tallo, M., \& Cardenal, V. (2010). Expresión de emociones y bienestar en un grupo de mujeres con cáncer de mama: Una intervención psicológica. Revista Latinoamericana de Psicología, 41, 131-140. doi:org/10.14349/rlp.v41i1.561

Cha, C. B., \& Nock, M. K. (2009). Emotional intelligence is a protective factor for suicidal behavior. Journal of the American Academy of Child and Adolescent Psychiatry, 48, 422-430. doi:10.1097/CHI.0b013e3181984f44

Chaffey, L., Unsworth, C. A., \& Fossey, E. (2012). Relationship between intuition and emotional intelligence in occupational therapists in mental health practice. American Journal of Occupational Therapy, 66, 88-96. doi:10.5014/ajot.2012.001693

Chamorro - Premuzic, T., Bennett, E., \& Furnham, A. (2007). The happy personality: Mediational role of trait emotional intelligence. Personality and Individual Differences, 42, 1633-1639. doi:10.1016/j.paid.2006.10.029

Chan, D. W. (2003). Dimensions of emotional intelligence and their relationships with social coping among gifted adolescents in Hong Kong. Journal of Youth and Adolescence, 32, 409-418. doi:10.1023/A:1025982217398

Chan, D. W. (2009). Orientations to happiness and subjective well- being among Chinese prospective and in-service teachers in Hong Kong. Educational Psychology, 29, 139-151. doi:10.1080/01443410802570907

Chan, T. H., Ho, R. T., \& Chan, C. L. (2007). Developing an outcome measurement for meaning-making intervention with Chinese cancer patients. Psycho-Oncology, 16, 843-850. doi:10.1002/pon.1134

Chapman, B. P., \& Hayslip Jr, B. (2006).Emotional intelligence in young and middle adulthood: Crosssectional analysis of latent structure and means. Psychology and Aging, 21, 411-418. doi:10.1037/0882-7974.21.2.411

Charbonneau, D., \& Nicol, A. A. (2002). Emotional intelligence and leadership in adolescents. Personality and Individual Differences, 33, 1101-1113. doi:10.1016/S0191-8869(01)00216-1

Cherry, M. G., Fletcher, I., O’Sullivan, H., \& Shaw, N. (2012). What impact do structured educational sessions to increase emotional intelligence have on medical students? Medical Teacher, 34, 11-9. doi: 10.3109/0142159X.2011.614293

Cheung, G. W., \& Rensvold, R. B. (2002). Evaluating goodness-of-fit indexes for testing measurement invariance. Structural Equation Modeling, 9, 233-255. doi:10.1207/S15328007SEM0902_5 
Christopher, G., \& Thomas, M. (2009). Social problem solving in chronic fatigue syndrome: Preliminary findings. Stress and Health, 25, 161-169. doi:10.1002/smi.1233

Christiansen, N. D., Janovics, J. E., \& Siers, B. P. (2010). Emotional intelligence in selection contexts: Measurement method, criterion-related validity, and vulnerability to response distortion. International Journal of Selection and Assessment, 18, 87-101. doi:10.1111/j.14682389.2010.00491.x

Chrobot-Mason, D., \& Leslie, J. B. (2012). The role of multicultural competence and emotional intelligence in managing diversity. The Psychologist-Manager Journal, 15, 219-236. doi:10.1080/10887156.2012.730442

Ciarrochi, J. V., Chan, A. Y., \& Caputi, P. (2000). A critical evaluation of the emotional intelligence construct. Personality and Individual Differences, 28, 539-561. doi:10.1016/S01918869(99)00119-1

Ciarrochi, J. V., \& Deane, F. P. (2001) Emotional competence and willingness to seek help from professional and nonprofessional sources. British Journal of Guidance and Counselling, 29, 233246. doi:10.1080/03069880124843

Ciarrochi, J. V., Deane, F. P., \& Anderson, S. (2002). Emotional intelligence moderates the relationship between stress and mental health. Personality and Individual Differences, 32, 197-209. doi:10.1016/S0191-8869(01)00012-5

Classen, C., Koopman, C., Angell, K., \& Spiegel, D. (1996). Coping styles associated with psychological adjustment to advanced breast cancer. Health Psychology, 15, 434-437. doi:10.1037/02786133.15.6.434

Codier, E., Freitas, B., \& Muneno, L. (2013, January). Developing emotional intelligence ability in oncology nurses: a clinical rounds approach. In Oncology nursing forum (Vol. 40, No. 1, pp. 2229). Oncology Nursing Society. doi:10.1188/13.ONF.22-29

Cohen, J., Cohen, P., West, S., \& Aiken, L. (2003). Applied multiple regression/correlation analysis for the behavioral sciences (3rd ed.). Mahwah, NJ: Erlbaum.

Compton, W., Conway, K., Stinson, F., \& Grant, B. (2006). Changes in the prevalence of major depression and comorbid substance use disorders in the United States between 1991-1992 and 2001-2002. American Journal of Psychiatry, 163, 2141-2147. doi:10.1176/appi.ajp.163.12.2141 
Copestake, S., Gray, N. S., \& Snowden R. J. (2013). Emotional intelligence and psychopathy: A comparison of trait and ability measures. Emotion, 13, 691-702. doi:10.1037/a0031746

Costa, S., Petrides, K. V., \& Tillmann, T. (2014). Trait emotional intelligence and inflammatory diseases. Psychology, Health \& Medicine, 19, 180-189. doi:10.1080/13548506.2013.802356

Costa-Neto, S., \& Araújo, T. (2008). Qualidade de vida do enfermo oncológico: Um panorama sobre o campo e suas formas de avaliação. In V. Carvalho, M. Franco, M. Kovács, R. Liberato, M. Macieira, M. Gomes, \& L. Holtz (Eds.), Temas em psico-oncologia (pp. 195-208). São Paulo: Summus Editora.

Coyne, J. C., Aldwin, C., \& Lazarus, R. S. (1981). Depression and coping in stressful episodes. Journal of Abnormal Psychology, 90, 439-447. doi:10.1037/0021-843X.90.5.439

Crumbaugh, J., \& Maholick, L. (1969). Manual of instruction for the Purpose-in-Life Test. Munster: Psychometric Affiliates.

Cummins, R.A. (2000). Personal income and subjective well-being: A review. Journal of Happiness Studies, 1, 133-158. doi:10.1023/A:1010079728426

Cummins, R. A., Eckersley, R., Pallant, J., Van Vugt, J., \& Misajon, R. A. (2003). Developing a national index of subjective wellbeing: The Australian Unity Wellbeing Index. Social Indicators Research, 64, 159-190. doi:10.1023/A:1024704320683

Cunningham, A. J., Edmonds, C. V. I., Hampson, A. W., Hanson, H., Hovanec, M., Jenkins, G., \& Tocco, E. K. (1991). Helping cancer patients cope with, and combat, their disease: Report on a group psychoeducational program. Advances in Mind-Body Medicine, 7, 41-56.

Damásio, A. (2003). O erro de descartes. MemMartins: Edições Europa-América. (Original work published 1995)

Davies, K. A., Lane, A. M., Devonport, T. J., \& Scott, J. A. (2010). Validity and reliability of a brief emotional intelligence scale (BEIS-10). Journal of Individual Differences, 31, 198-208. doi:10.1027/1614-0001/a000028

Davis, C. G., Wortman, C. B., Lehman, D. R., \& Silver, R. C. (2000). Searching for meaning in loss: Are clinical assumptions correct?. Death studies, 24, 497-540. doi:10.1080/07481180050121471

Dawda, D., \& Hart, S. D. (2000). Assessing emotional intelligence: Reliability and validity of the bar-on emotional quotient inventory (EQ-i) in university students. Personality and Individual Differences, 28, 797-812. doi:10.1016/S0191-8869(99)00139-7 
Deniz, M. (2006). The relationships among coping with stress, life satisfaction, decision-making styles and decision self-esteem: An investigation with Turkish university students. Social Behavior and Personality, 34, 1161-1170. doi:org/10.2224/sbp.2006.34.9.1161

Dezutter, J., Casalin, S., Wachholtz, A., Luyckx, K., Hekking, J., \& Vandewiele, W. (2013). Meaning in life: An important factor for the psychological well-being of chronically ill patients? Journal Article Rehabilitation Psychology 58, 334-41. doi:10.1037/a0034393

Díaz-Llanes, G. (2001). El bienestar subjetivo: Actualidad y perspectivas. Revista Cubana de Medicina e Genética Integral, 17, 572-579.

Diener, E. (1984). Subjective well-being. Psychological Bulletin, 95, 542-575.

Diener, E. (2000). Subjective well-being: The science of happiness and a proposal for a national index. American Psychologist, 55, 34-43. doi:10.1037/0003-066X.55.1.34

Diener, E. (2009). Subjective well-being. In The science of well-being (pp. 11-58). Springer Netherlands. doi:10.1007/978-90-481-2350-6_2

Diener, E., \& Chan, M. Y. (2011). Happy people live longer: Subjective well-being contributes to health and longevity. Applied Psychology: Health and Well-Being, 3(1), 1-43. doi:10.1111/j.17580854.2010.01045.x

Diener, E. D., Emmons, R. A., Larsen, R. J., \& Griffin, S. (1985). The satisfaction with life scale. Journal of Personality Assessment, 49, 71-75. doi:10.1207/s15327752jpa4901_13

Diener E., Oishi, S., \& Lucas, R. (2003). Personality, culture and subjective well-being: Emotional and cognitive evaluations of life. Annual Review of Psychology, 59, 229-259.

Diener, E., Oishi, S., \& Lucas, R. (2009). Subjective well-being: The science of happiness and life satisfaction. In C. Snyder \& S. Lopez (Eds.), The handbook of positive psychology (Vol.2, pp. 187194). New York: Oxford University Press.

Diener, E., Sandvik, E., \& Pavot, W. (2009). Happiness is the frequency, not the intensity, of positive versus negative affect. In Assessing well-being (pp. 213-231). Springer Netherlands. doi: 10.1007/978-90-481-2354-4_10

Diener, E., Suh, E. M., Lucas, R. E., \& Smith, H. L. (1999). Subjective well-being: Three decades of progress. Psychological Bulletin, 125, 276-302. doi:10.1037/0033-2909.125.2.276

Diener, E., Suh, E., \& Oishi, S. (1997). Recent findings on subjective well being. Indian Journal of Clinical Psychology, 24, 25-41. 
Direção Geral da Saúde. (2013). Portugal: doenças oncológicas em números - 2013: programa nacional para as doenças oncológicas. Lisboa: Letra solúvel.

Donohoe, J., \& Greene, D. (2009). Social relationships mediate the relation between emotional intelligence and meaning in life. Psi Chi Journal of Undergraduate Research, 14, 59-64.

Downey, L. A., Johnston, P. J., Hansen, K., Birney, J., \& Stough, C. (2010). Investigating the mediating effects of emotional intelligence and coping on problem behaviors in adolescents. Australian Journal of Psychology, 62, 20-29. doi:10.1080/00049530903312873

Duffy, R. D., Allan, B. A., \& Bott, E. M. (2012). Calling and life satisfaction among undergraduate students: Investigating mediators and moderators. Journal of Happiness Studies, 13, 469-479. doi: $10.1007 / \mathrm{s} 10902-011-9274-6$

Dunn, J., Campbell, M., Penn, D., Dwyer, M., \& Chambers, S. K. (2009). Amazon heart: An exploration of the role of challenge events in personal growth after breast cancer. Journal of Psychosocial Oncology, 27, 119-135. doi:10.1080/07347330802616084

Edman, L., Larsen, J., Hagglund, H., \& Gardulf, A. (2001). Health-related quality of life, symptom distress and sense of coherence in adult survivors of allogenic stem-cell transplantation. European Journal of Cancer Care, 10, 124-130. doi:10.1046/j.1365-2354.2001.00251.x

Edwards, M. (2007). The dimensionality and construct valid measurement of life meaning. (Doctoral dissertation). Retrieved from library.queensu.ca.

Eiser, C. (2009). Assessment of health-related quality of life after bone cancer in young people: Easier said than done. European Journal of Cancer, 45, 1744-1747. doi:10.1016/j.ejca.2009.02.025

Emmons, R., Colby, P., \& Kaiser, H. (1998). When losses lead to gains: Personal goals and the recovery of meaning. In P. Wong \& P. Fry (Eds.), The human quest for meaning (pp. 163-178). Mahwah, NJ: Erlbaum.

Ermer, E., Kahn, R., Salovey, P., \& Kiehl, K. (2012). Emotional intelligence in incarcerated men with psychopathic traits. Jounal of Personality and social Psychology, 103, 194-204. doi:10.1037/a0027328.

Extremera-Pacheco, N., Durán, A., \& Rey, L. (2007). Perceived emotional intelligence and dispositional optimism pessimism: Analyzing their role in predicting psychological adjustment among adolescents. Personality and Individual Differences, 42, 1069-1079. 
Extremera-Pacheco N., \& Fernández-Berrocal, P. (2005a). Perceived emotional intelligence and life satisfaction: Predictive and incremental validity using the Trait Meta-Mood Scale. Personality and Individual Differences, 39, 937-948.

Extremera-Pacheco, N., \& Fernández-Berrocal, P. (2005b). Inteligencia emocional percibida y diferencias individuales en el meta-conocimiento de los estados emocionales: Una revisión de los estudios con el TMMS. Ansiedad y Estrés, 11, 101-122.

Extremera-Pacheco, N., \& Fernández- Berrocal, P. (2006). Emotional intelligence as predictor of mental, social and physical health in university students. The spanish journal of psychology, 9, 45-51.

Extremera-Pacheco, N., \& Fernández-Berrocal, P. (2007). Una guía práctica de los instrumentos actuales de evaluación de la inteligencia emocional. In J. Navas \& P. Berrocal (Eds.), Manual de inteligencia emocional (pp. 99-122). Madrid: Ediciones Pirámide.

Extremera-Pacheco, N., Fernández-Berrocal, P., \& Durán, A. (2003). Inteligencia emocional y burnout en profesores. Encuentros en Psicología Social, 1, 260-265.

Fasching, P.A., Thiel, F., Nicolaisen-Murmann, K., Rauh, C., Engel, J., Lux, M.P., . . Bani, M.R. (2007). Association of complementary methods with quality of life and life satisfaction in patients with gynecologic and breast malignancies. Supportive Care in Cancer, 15, 1277-1284. doi: 10.1007/s00520-007-0231-1

Fawzy, F., \& Fawzy, N. (1998). Group therapy in the cancer setting. Journal of Psychosomatic Research, 45, 191-200.

Fegg, M. J., Brandstätter, M., Kramer, M., Kögler, M., Haarmann-Doetkotte, S., \& Borasio, G. D. (2010). Meaning in life in palliative care patients. Journal of pain and symptom management, 40, 502-509. doi: 10.1016/j.jpainsymman.2010.02.010

Feldman, D. B., \& Snyder, C. R. (2005). Hope and the meaningful life: Theoretical and empirical associations between goal-directed thinking and life meaning. Journal of Social and Clinical Psychology, 24, 401-421. doi:10.1521/jscp.24.3.401.65616

Fernández-Berrocal, P., \& Extremera-Pacheco, N. (2006). Emotional intelligence and emotional reactivity and recovery in laboratory context. Psicothema, 18, 72-78.

Fernández-Berrocal, P., \& Extremera-Pacheco, N. (2007). Inteligencia emocional y salud. In J. Navas \& P. Berrocal (Eds.), Manual de inteligencia emocional (pp. 173-186). Madrid: Ediciones Pirámide. 
Fernández-Berrocal, P., \& Extremera-Pacheco, N. (2008). Inteligencia emocional, afecto positivo y felicidad. In G. Abascal (Ed.), Emociones positivas. Madrid: Ediciones Pirámide.

Fernández-Berrocal, P., Extremera, N., \& Ramos, N. (2004). Validity and reliability of the Spanish modified version of the Trait Meta-Mood Scale. Psychological Reports, 94, 751-755. doi:10.2466/pr0.94.3.751-755

Fernandez, R., Salamonson, Y., \& Griffiths, R. (2012). Emotional intelligence as a predictor of academic performance in first-year accelerated graduate entry nursing students. Journal of Clinical Nursing, 21, 3485-3492. doi:10.1111/j.1365-2702.2012.04199.x

Fernández, I., Velasco, C., \& Campos, M. (2003). Inteligencia emocional, alexitimia y factores psicosociales. Encuentros en Psicología Social, 1, 246-250.

Ferrel, B. R., Dow, K. H., \& Grant, M. (1995). Measurement of the quality of life in cancer survivors. Quality of life research, 4, 523-531. doi:10.1007/BF00634747

Fisher, C. D., \& Ashkanasy, N. M. (2000). The emerging role of emotions in work life: An introduction. Journal of organizational behaviour, 21, 123-129. doi:10.1002/(SICI)10991379(200003)21:2<123::AID-JOB33>3.0.CO;2-8

Fleer, J., Hoekstra, H. J., Sleijfer, D. T., Tuinman, M. A., \& Hoekstra-Weebers, J. E. (2006). The role of meaning in the prediction of psychosocial well-being of testicular cancer survivors. Quality of Life Research, 15, 705-717. doi:10.1007/s11136-005-3569-1

Fleer, J., Hoekstra, H. J., Sleijfer, D. T., Tuinman, M. A., Klip, E. C., \& Hoekstra-Weebers, J. E. (2006). Quality of life of testicular cancer survivors and the relationship with sociodemographics, cancerrelated variables, and life events. Support Care Cancer, 14, 251-259. doi:10.1007/s00520-0050879-3

Folkman, S. (1992). Improving coping assessment: Reply to Stone, AA, Kennedy-Moore, E. In H. Friedman (Ed.), Hostility, coping, and health. (pp. 215-223). Washington, DC: American Psychological Association.

Folkman, S. (1997). Positive psychological states and coping with severe stress. Social Science and Medicine, 45, 1207-1221. doi:10.1016/S0277-9536(97)00040-3

Folkman, S. (2001). Revised coping theory and the process of bereavement. In H. Schut (Ed.), Handbook of bereavement research: Consequences, coping, and care. Washington, DC: American Psychological Association. 
Folkman, S. (2008). The case for positive emotions in the stress process. Anxiety, Stress \& Coping: An International Journal, 21, 3-14. doi:10.1080/10615800701740457

Folkman, S., \& Lazarus, R. S. (1980). An analysis of coping in a middle-aged community sample. Journal of Health and Social Behavior, 21, 219-239. doi:10.2307/2136617

Folkman, S., \& Lazarus, R. S. (1985). If it changes it must be a process study of emotion and coping during three stages of a college examination. Journal of Personality and social Psychology, 48, 150-170. doi:10.1037/0022-3514.48.1.150

Folkman, S., Lazarus, R. S., Gruen, R. J., \& DeLongis, A. (1986). Appraisal, coping, health status, and psychological symptoms. Journal of Personality and Social Psychology, 50, 571-579. $10.1037 / 0022-3514.50 .3 .571$

Folkman, S., \& Moskowitz, J. T. (2000). Positive affect and the other side of coping. American Psychologist, 55, 647-654. doi:10.1037/0003-066X.55.6.647

Folkman, S., \& Moskowitz, J. T. (2004). Coping: Pitfalls and promise. Annual review of psychology, 55, 745-774. doi:10.1146/annurev.psych.55.090902.141456

Folkman, S., \& Moskowitz, J. T. (2007). Positive affect and meaning-focused coping during significant psychological stress. In M. Hewstone, H. Schut, J. de Wit, K. Van der Bos, \& M. Stroebe (Eds.), The scope of social psychology: Theory and applications (pp. 193-208). Hove, UK: Psychology Press.

Fornell, C., \& Larcker, D. F. (1981). Evaluating structural equation models with unobservable variables and measurement error. Journal of Marketing Research, 18, 39-50. doi:10.2307/3151312

Fortin, M. J. (1999). Effects of quadrat size and data measurement on the detection of boundaries. Journal of Vegetation Science, 10, 43-50. 10.2307/3237159

Franco, M. (2003). A gestão das emoções na sala de aula: Projecto de modificação das atitudes de um grupo de docentes do $1^{o}$ ciclo do ensino básico. Lisboa: FCT., Calouste Gulbenkian.

Franco, M. (2007). Inteligência emocional: Modelos, instrumentos de avaliação e limites. In A. Cadeias \& L. Almeida (Eds.), Inteligência humana: Investigação e aplicações (Vol.1, pp. 73-96). Coimbra: Quarteto.

Franco, M., \& Kovács, M. (2008). Pesquisa em Psico-Oncologia. In V. Carvalho, M. Franco, M. Kovács, R. Liberato, M. Macieira, M. Gomes, \& L. Holtz (Eds.), Temas em Psico Oncologia (pp. 590-595) São Paulo: Summus Editora. 
Frankl, V. (1975). The unconscious God: Psychotherapy and theology. Nem York: Simon and Schuster.

Frankl, V. (1986). Psicoterapia e sentido da vida: Fundamentos da logoterapia e análise existencial. São Paulo: Quadrante.

Frankl, V. (1988). La voluntad de sentido. Barcelona: Herder.

Frankl, V. (1990). Psicoterapia para todos. Petrópolis, RJ: Vozes. (Original work published 1905)

Frankl, V. (1992). Meaning in industrial society. International Forum for Logotherapy, 15, 66-70.

Frankl, V. (2006). Em busca de sentido: Um psicólogo no campo de concentração (23 rd ed.). Petrópolis, RJ: Vozes. (Original work published 1991)

Franks, H.M., \& Roesch, S. C. (2006). Appraisals and coping in people living with cancer: A metaanalysis. Psycho-Oncology, 15, 1027-1037. doi:10.1002/pon.1043

Freire, T., \& Almeida, L. (2001). Escalas de avaliação: Construção e validação. In E. Fernandes \& L. Almeida (Eds.), Métodos e técnicas de avaliação: Contributos para a prática e investigação psicológicas (pp. 109-128). Braga: Universidade do Minho, Centro de Estudos em Educação e Psicologia.

Freitas, F. A., \& Noronha, A. P. P. (2006). Inteligência emocional e avaliação de alunos e supervisores: Evidências e validade. Psicologia: Teoria e prática, 8, 77-93.

Fredrickson, B. L. (1998). What good are positives emotions? Review of general psychology, 2, 300-319. doi:10.1037/1089-2680.2.3.300

Fredrickson, B. L. (2000). Cultivating positive emotions to optimize health and well-being. Prevention \& treatment, 3, 140-165. doi:10.1037/1522-3736.3.1.31a

Fredrickson, B. L., Tugade, M. M., Waugh, C. E., \& Larkin, G. R. (2003). What good are positive emotions in crises? A prospective study of resilience and emotions following the terrorist attacks on the united states on September $11^{\text {th }}$, 2001. Journal of personality and social psychology, 84, 365-376. doi:10.1037/0022-3514.84.2.365

Frijda, N. H. (1988). The laws of emotion. American Psychologist, 43, 349-358. doi:10.1037/0003066X.43.5.349

Furnham, A., \& Petrides, K. V. (2003). Trait emotional intelligence and happiness. Social Behavior and Personality, 31, 815-823. doi:org/10.2224/sbp.2003.31.8.815

Galinha, I., \& Pais-Ribeiro, J.L. (2005). História e evolução do conceito de bem-estar subjectivo. Psicologia, Saúde e Doenças, 6, 203-214. 
Gadamer, H. (2003). Verdad y método (10th ed.). Salamanca: Sígueme. (Original work published 1960)

Gannon, N., \& Ranzijn, R. (2005). Does emotional intelligence predict unique variance in life satisfaction beyond IQ and personality? Personality and Individual Differences, 38, 1353-1364. doi:10.1016/j.paid.2004.09.001

Garaigordobil, M., \& Oñederra, J. A. (2010). Inteligencia emocional en las víctimas de acoso escolar y en los agresores. European Journal of Education and Psychology, 3, 243-256.

García-Camba, E. (1999). Psiquiatría de enlace y cancér. In E. García-Camba (Ed.), Manual de psicooncología (pp. 1-38). Madrid: Aula Médica.

Gardner, H. (1995). Inteligências múltiplas: A teoria na prática. Porto Alegre: Artmed. (Original work published 1993)

Gawali, K. C. (2012). Relationship between emotional intelligence and positive affectivity among college teachers. Golden Research Thoughts 1(7), 1-4.

Gerits, L., Derksen, J. J. L., Verbruggen, A. B., \& Taylor, S. J. (2004). Emotional intelligence and adaptive success of nurses caring for people with mental retardation and severe behavior problems. Mental Retardation, 42, 106-121. doi:org/10.1352/0047-6765(2004)42<106:EIAASO>2.0.CO;2

Giacomoni, C. (2002). Bem-estar subjetivo infantil: conceito de felicidade e construção de instrumentos para avaliação. (Doctoral dissertation). Retrieved from lume.ufrgs.br.

Giacomoni, C. (2004). Bem-estar subjetivo: em busca da qualidade de vida. Temas em Psicologia da Sociedade Brasileira de Psicologia, 12, 43-50.

Giese-Davis, J., Koopman, C., Butler, L. D., Classen, C., Cordova, M., Fobair, P., Benson, J., \& Spiegel, D. (2002). Change in emotion regulation strategy for women with metastatic breast cancer following supportive-expressive group therapy. Journal of Consulting and Clinical Psychology, 70, 916-925. doi:10.1037/0022-006X.70.4.916

Gignac, G. E. (2006). Self-reported emotional intelligence and life satisfaction: Testing incremental predictive validity hypotheses via structural equation modeling (SEM) in a small sample. Personality and Individual Differences, 40, 1569-1577. doi:10.1016/j.paid.2006.01.001

Gignac, G. (2010). Seven-factor model of emotional intelligence as measured by Genos EI. European Journal of Psychological Assessment, 26, 309-316. doi:10.1027/1015-5759/a000041

Gilbert, K. R. (2002). Taking a narrative approach to grief research: Finding meaning in stories. Death studies, 26, 223-239. doi:10.1080/07481180211274 
Gillies, J., \& Neimeyer, R. A. (2006). Loss, grief, and the search for significance toward a model of meaning reconstruction in bereavement. Journal of constructivist psychology, 19, 31-65. $10.1080 / 10720530500311182$

Gohm, C. L., \& Clore, G. (2002). Tour latent traits off emotional experiences and their involvement in attributional style, coping and well-being. Cognition and emotion, 16, 495-518.

Gohm, C. L., Corser, G. C., \& Dalsky, D. J. (2005). Emotional intelligence under stress: Useful, unnecessary, or irrelevant? Personality and individual differences, 39, 1017-1028. doi:10.1016/j.paid.2005.03.018

Goleman, D. (2003). Inteligência emocional. Lisboa: Temas e Debates. (Original work published 1995)

Goldenberg, I., Matheson, K., \& Mantler, J. (2006). The assessment of emotional intelligence: A comparison of performance-based and self-report methodologies. Journal of personality assessment, 86, 33-45. doi:10.1207/s15327752jpa8601_05

Gomes, J. (2011). Inteligência emocional, qualidade de vida e seus correlatos em doentes oncológicos em quimioterapia. (Master's thesis). Retrieved from bdigital.ufp.pt.

Gonçalves, O. (2002) Viver narrativamente: A psicoterapia como adjectivação da experiência. Coimbra: Quarteto.

González, R., Fernández-Berrocal, P., Ruiz-Aranda, D., \& Extremera-Pacheco, N. (2006). Una aproximación a la integración de diferentes medidas de regulación emocional. Ansiedad y estrés, 12, 155-166.

Gonzáles, A. E. M., Piqueras, J. A., \& Linares, V. R. (2010). Emotional intellignece in physical and mental health. Electronic Journal of research in educational Psychology 8, 861-890.

González, V. A. N. E. S. A., Ramírez-Maestre, C., \& Herrero, A. (2007). Inteligencia emocional, personalidad y afrontamiento en pacientes con dolor crónico. Revista Mexicana de Psicologia, 24, 185-195.

Görgens-Ekermans, G., \& Brand, T. (2012). Emotional intelligence as a moderator in the stress-burnout relationship: A questionnaire study on nurses. Journal of Clinical Nursing 21, 2275-2285. doi:10.1111/j.1365-2702.2012.04171.x

Grajales, T., \& Araya, E. (2001). Escala de Satisfacción en el trabajo en docentes universitarios. Informe de Investigacion no publicado. 
Greenberg, L. S., Ford, C. L., Alden, L. S., \& Johnson, S. M. (1993). In-session change in emotionally focused therapy. Journal of Consulting and Clinical Psychology, 61, 78-84. doi:10.1037/0022006X.61.1.78

Greenberg, L., \& Zafran, J. (1989). Emotion in psychoterapy. American Psychologist, 44, 19-29.

Gross, J. J. (1998). Antecedent- and response-focused emotion regulation: Divergent consequences for experience, expression, and physiology. Journal of Personality and Social Psychology, 74, 224237. doi: 10.1037/0022-3514.74.1.224

Gross, J. J., \& Thompson, R. (2007). Conceptual foundations for the field. In J. Gross (Ed.), Handbook of emotion regulation (pp. 3-24). New York: Guilford.

Guberman, M., \& Soto, E. (2006). Dicionário de Logoterapia. Lisboa: Paulus.

Guil, R., Mestre, J., \& Guillén, C. (2003). Socialización emocional. Encuentros en Psicología Social 1, 338- 342 .

Guzmán, M., \& Alarcón, M. (2007, September). Relación entre inteligencia emocional y bienestar personal en cancér de mama. I Congreso Internacional de Inteligencia Emocional, Málaga.

Hair, J., Black, B., Babin, B., \& Anderson, R. (2010). Multivariate Data Analysis. Saddle River, NJ: Prentice Hall.

Halama, P., \& Dedova, M. (2007). Meaning in life and hope as predictors of positive mental health: Do they explain residual variance not predicted by personality traits? Studia Psychologica, 49, 191200.

Hansen, F., \& Sawatzky, J. A. V. (2008). Stress in patients with lung cancer: A human response to illness. Oncology Nursing Forum, 35, 217-223. doi:10.1188/08.ONF.217-223

Harris, D. J., Reiter-Palmon, R., \& Kaufman, J. C. (2013). The effect of emotional intelligence and task type on malevolent creativity. Psychology of Aesthetics, Creativity, and the Arts, 7, 237-244. doi:10.1037/a0032139

Haugan, G. (2013). The relationship between nurse - patient interaction and meaning-in-life in cognitively intact nursing home patients. Journal of Advanced Nursing 70, 107-120. doi:10.1111/jan.12173

Heffernan, M., Quinn-Griffin, M. T., McNulty, S. R., \& Fitzpatrick, J. J. (2010). Self-compassion and emotional intelligence in nurses. International Journal of Nursing Practice, 16, 366-73. doi:10.1111/j.1440-172X.2010.01853.x. 
Heidegger, M. (2004). Ser e tempo (13rd ed., Vols. 1-2). Petrópolis: Editora Vozes. (Original work published 1927)

Heine, S. J., Proulx, T., \& Vohs, K. D. (2006). The meaning maintenance model: On the coherence of social motivations. Personality and social psychology review, 10, 88-110. doi:10.1207/s15327957pspr1002_1

Heisel, M. J., \& Flett, G. L. (2004). Purpose in life, satisfaction with life, and suicide ideation in a clinical sample. Journal of Psychopathology and Behavioral Assessment, 26, 127-135. doi:10.1023/B:JOBA.0000013660.22413.e0

Helgeson, V. S., Reynolds, K. A., \& Tomich, P. L. (2006). A meta-analytic review of benefit finding and growth. Journal of Consulting and Clinical Psychology, 74, 797-816. doi:10.1037/0022006X.74.5.797

Henry, M., Cohen, S. R., Lee, V., Sauthier, P., Provencher, D., Drouin, P. .. Mayo, N. (2010). The Meaning-Making intervention (MMi) appears to increase meaning in life in advanced ovarian cancer: a randomized controlled pilot study. Psycho-Oncology, 19, 1340-1347. doi:10.1002/pon.1764

Hewitt, M., Greenfield, S., \& Stovall, E. (2006). From cancer patient to cancer survivor: Lost in transition. Washington, DC: National Academies Press.

Hill, M., \& Hill, A. (2005). Investigação por questionário (2ª ed.). Lisboa: Edições Sílabo.

Hillner, B. E., \& Smith, T. J. (2009). Efficacy does not necessarily translate to cost effectiveness: a case study in the challenges associated with 21 st-century cancer drug pricing. Journal of Clinical Oncology, 27, 2111-2113. doi:10.1200/JCO.2008.21.0534

Ho, M. Y., Cheung, F. M., \& Cheung, S. F. (2010). The role of mean- ing in life and optimism in promoting well-being. Personality and Individual Differences, 48, 658-663. doi:10.1016/j.paid.2010.01.008

Holahan, C. K., Holahan, C. J., \& Suzuki, R. (2008). Purposiveness, physical activity, and perceived health in cardiac patients. Disability and Rehabilitation, 30, 1772-1778. doi:10.1080/10428190701661508

Holland, J. (1989a). Historical overview. In J. Holland \& J. Rowland (Eds.), Handbook of psychooncology: Psychological care of the patient with cancer (pp.3-12). New York: Oxford University Press. 
Holland, J. (1989b). Fears and abnormal reactions to cancer in physically healthy individuals. In J. Holland \& J. Rowland (Eds.), Handbook of psychooncology: Psychological care of the patient with cancer (pp.13-24). New York: Oxford University Press.

Holland, J. (1989c). Clinical course of cancer. In J. Holland \& J. Rowland (Eds.), Handbook of psychooncology: Psychological care of the patient with cancer (pp.75-100). New York: Oxford University Press.

Holland, K. D., \& Holahan, C. K. (2003). The relation of social support and coping to positive adaptation to breast cancer. Psychology and Health, 18, 15-29. doi:10.1080/0887044031000080656

Holland, J., \& Rowland, J. (1989). Handbook of psychooncology: Psychological care of the patient with cancer. New York: Oxford University Press.

Hou, W. K., \& Lam, J. H. M. (2014). Resilience in the year after cancer diagnosis: A cross-lagged panel analysis of the reciprocity between psychological distress and well-being. Journal of behavioral medicine, 37, 391-401. doi:10.1007/s10865-013-9497-6

Hoyle, R. H., \& Smith, G. T. (1994). Formulating clinical research hypotheses as structural equation models: A conceptual overview. Journal of Consulting and Clinical Psychology, 62, 429-440. doi:10.1037/0022-006X.62.3.429

Huebner, E. S., Seligson, J. L., Valois, R. F., \& Suldo, S. M. (2006). A review of the brief multidimensional student's life satisfaction scale. Social Indicators research, 79, 477-484. doi:10.1007/s11205-005-5395-9

Hughes, K. K. (1993). Psychosocial and functional status of breast cancer patients. Cancer Nursing, 16, 222-229.

Hurley, J. (2008). The necessity, barriers and ways forward to meet user-based needs for emotionally intelligent nurses. Journal of Psychiatric and Mental Health Nursing, 15, 379-385. doi:10.1111/j.1365-2850.2007.01243.x

Ibáñez, E., Valiente, M., \& Soriano, J. (2002). Una historia de la psico-oncologia: Del cáncer a la psicología e vice-versa. In M. Dias \& E. Durá (Eds.), Territórios da psicologia oncológica (pp. 347-380). Lisboa: CLIMEPSI.

Iliescu, D., Ilie, A., Ispas, D., \& Ion, A. (2013). Examining the psychometric properties of the MayerSalovey-Caruso Emotional Intelligence Test: Findings from an Eastern European culture. European Journal of Psychological Assessment, 29, 121-128. doi:10.1027/1015-5759/a000132 
Instituto Nacional de Estatística. (2011). Classificação Portuguesa das Profissões 2010. Lisboa: INE.

Instituto Nacional de Estatística. (2012). Destaque, informação à comunicação social: Conta Satélite da Saúde (2010 Dados Provisórios, 2011 Dados Preliminares). Lisboa: INE.

Isaia, D., Parker, V., \& Murrow, E. (1999). Spiritual well- being among older adults. Journal of Gerontological Nursing, 25, 15-21.

Jaarsma, T. A., Pool, G., Ranchor, A. V., \& Sanderman, R. (2007). The concept and measurement of meaning in life in Dutch cancer patients. Psycho-Oncology, 16, 241-248. doi:10.1002/pon.1056

Jim, H. (2004). Meaning in life mediates the relationships between physical and social functioning and distress in cancer survivors. (Doctoral dissertation). Retrieved from etd.ohiolink.edu/rws.

Jim, H. S., \& Andersen, B. L. (2007). Meaning in life mediates the relationship between social and physical functioning and distress in cancer survivors. British Journal of Health Psychology, 12, 363-681. doi:10.1348/135910706X128278

Johnson, S. J., Batey, M., \& Holdsworth, L. (2009). Personality and health: The mediating role of trait emotional intelligence and work locus of control. Personality and Individual Differences, 47, 470475. doi:10.1016/j.paid.2009.04.025

Joseph, D. L., \& Newman D. A. (2010). Emotional intelligence: an integrative meta-analysis and cascading model. Journal of Applied Psychology, 95, 54-78. doi:10.1037/a0017286

Juárez, F. (2011). El concepto de salud: Una explicación sobre su unicidad, multiplicidad y los modelos de salud. International Journal of Psychological Research, 4, 70-79.

Justo, J. (2002). Uma perspectiva psicológica sobre as doenças oncológicas: Etiologia, intervenção e articulações. In M. Dias \& E. Durá (Eds.), Territórios da psicologia oncológica (pp. 51-74). Lisboa: CLIMEPSI.

Kallay, E., \& Miclea, M. (2007). The role of meaning in life in adaptation to life threatening illness. Cognition, Brain, Behavior, 11, 159-170.

Kampfe, N., \& Mitte, K. (2010). Tell me who you are, and I will tell you how you feel? European Journal of Personality, 24, 291-308. doi:10.1002/per.743

Kaplowitz, M. J., Safran, J. D., \& Muran, C. J. (2011). Impact of therapist emotional intelligence on psychotherapy. Pubmed, 199, 74-84. doi:10.1097/NMD.0b013e3182083efb 
Keyes, C. L., Shmotkin, D., \& Ryff, C. D. (2002). Optimizing well-being: The empirical encounter of two traditions. Journal of Personality and Social Psychology, 82, 1007-1022. doi:10.1037/00223514.82.6.1007

Kieszkowska-Grudny, A., Grudny, J., Sierko, E., Janowicz-Zebrowska, A., Badurak, P., Galar, M., \& Wojyukiewicz, M. (2010). Role of psychological and emotional factors in cancer related fatigue (CRF) syndrome in advanced NSCLC patients undergoing palliative chemotherapy. Advances in Palliative Medicine, 9, 81-86.

Kleftaras, G. \& Psarra, E. (2012). Meaning in life, psychological well-being and depressive symptomatology: A comparative study. Psychology, 3, 337-345. doi:org/10.4236/psych.2012.34048

Klinger, E. (1998). The search for meaning in evolutionary perspective and its clinical implications. In P. Wong \& P. Fry (Eds.), Handbook of personal meaning: Theory, research, and application (pp. 27-50). Mahwah, NJ: Erlbaum.

Killgore, W. D., Weber, M., Schwab, Z. J., DelDonno, S. R., Kipman, M., Weiner, M. R., \& Rauch, S. L. (2012). Gray matter correlates of trait and ability models of emotional intelligence. Neuroreport, 23, 551-555. doi:10.1097/WNR.0b013e32835446f7

Kim, H., \& Agrusa, J. (2010, June). Emotional intelligence and coping styles among hospitality industry employees. International CHRIE Conference-Refereed Track, Event 8. University of Massachusetts, Amherst.

Kim, Y., Carver, C. S., Spillers, R. L., Love-Ghaffari, M., \& Kaw, C. K. (2012). Dyadic effects of fear of recurrence on the quality of life of cancer survivors and their caregivers. Quality of Life Research, 21, 517-525. doi:10.1007/s11136-011-9953-0

King, L. A., Hicks, J. A., Krull, J. L., \& Gaiso, A. K. (2006). Positive affect and the experience of meaning in life. Journal of personality and social psychology, 90, 179-196. doi:10.1037/00223514.90.1.179

Kissane, D. W. (2000). Psycho spiritual and existential distress: The challenge for palliative care. Australian Family Physician, 29, 1022-1025.

Kissane, D. W., Grabsch, B., Clarke, D. M., Christie, G., Clifton, D., Gold, S. ...Smith, G. C. (2004). Supportive-expressive group therapy: the transformation of existential ambivalence into creative 
living while enhancing adherence to anti-cancer therapies. Psycho-Oncology., 13, 755-768. doi:10.1002/pon.798

Kline, R. (2011). Beyond significance testing: Reforming data analysis methods in behavioral research. (3rd ed.) Washington, DC: American Psychological Association.

Koczwara, A., Tavabie, A., \& Patterson, F. (2011). Evaluation of GP appraiser development centres using emotional intelligence: can positive learning outcomes be transferred to practice. Education for Primary Care, 22, 399-408.

Koven, N. S., Roth, R. M., Garlinghouse, M. A., Flashman, L. A., \& Saykin, A. J. (2011). Regional gray matter correlates of perceived emotional intelligence.Social Cognitive and Afective Neuroscience, 6, 582-590. doi:10.1093/scan/nsq084

Koydemir, S., Simsek, O. F., Schutz, A., \& Tipandjan, A. (2013). Differences in how trait emotional intelligence predicts life satisfaction: The role of affect balance versus social support in India and Germany. Journal of Happiness Studies, 14, 51-66. doi:10.1007/s10902-011-9315-1

Krauss, T., Rodrigues, M., \& Dixe, M. (2009) Meaning of life, health and human development. Revista Cientıfica da Unidade de Investigacão em Ciencias da Saude: Domınio de Enfermagem, 10, 7788.

Krause, N. (2004). Stressors in highly valued roles, meaning in life, and the physical health status of older adults. Journal of Gerontology: Social Sciences, 59, 287-297. doi:10.1093/geronb/59.5.S287

Kravvariti, E., Maridaki-Kassotaki, K., \& Kravvaritis, E. (2010). Emotional intelligence and coronary heart disease: How close is the link?. Global Journal of Health Science, 1, 127-137.

Kulikowska, A., \& Pokorski, M. (2008). Self-injuries in adolescents: Social competence, emotional intelligence, and stigmatization. Journal of Physiology and Pharmacology, 59, 383-392.

Kun, B., \& Dometrovics, Z. (2010). Emotional intelligence and addictions: A systematic review. Substance Use $\quad \& \quad$ Misuse, $\quad 45, \quad 1131-1160$. doi:10.3109/10826080903567855doi:10.3109/10826080903567855

Kwako, L. E., Szanton, S. J., Saligan, L. N., \& Gill, J. M. (2011). Major depressive disorder in persons exposed to trauma: Relationship between emotional intelligence and social support. Journal of the American Psychiatric Nurses Association, 17, 237-245. doi:10.1177/1078390311402498 
Lahaye, M., Luminet, O., Van Broeck, N., Bodart, E., \& Mikolajczak, M. (2010). Psychometric properties of the emotion awareness questionnaire for children in a French-speaking population. Journal of Personality Assessment, 92, 317-326. doi :10.1080/00223891.2010.482003

LaMothe, R. W. (2010). Types of faith and emotional intelligence. Pastoral Psychology, 59, 331-344. doi:10.1007/s11089-009-0229-3

Landy, F. J. (2005). Some historical and scientific issues related to research on emotional intelligence. Journal of Organizational Behaviour, 26, 411-424. doi:10.1002/job.317

Langdridge, D. (2007). Phenomenological psychology: theory, research and method. Harlw, England: Pearson Prentice Hall.

Larsen, R. J., \& Diener, E. (1987). Emotional response intensity as an individual difference characteristic. Journal of research in personality, 21(1), 1-39. doi:10.1016/0092-6566(87)90023-7

Latha, K. S., Sahana, M., Mariella, D., Subbannayya, K., \& Asha, K. (2013). Factors related to life satisfaction, meaning of life, religiosity and death anxiety in health care staff and students: A cross sectional study from India. Online Journal of Health and Allied Sciences, 12(2), 1-7. Retrieved from http://www.ojhas.org/issue46/2013-2-7.html

Lazarus, R. S. (1991). Emotion and adaptation. New York: Oxforf University Press.

Lazarus, R. S. (1993). Coping theory and research: Past, present, and future. Psychosomatic Medicine, 55, 234-247.

Lazarus, R. S. (1999). Stress and emotion: A new synthesis. London: Springer Publishing.

Lazarus, R. S., \& Folkman, S. (1984). On the primacy of cognition. American Psychologist, 39, 124-129. doi:10.1037/0003-066X.39.2.124

Lazarus, R. S., \& Lazarus, B. (1994). Passion and reason. New York: Oxforf University Press.

Lazzari, S. A. (2000). Emotional intelligence, meaning, and psychological well-being: A comparison between early and late adolescence. (Master's thesis). Retrevied from twu.ca/cpsy/theses.

Lee, V., Cohen, S. R., Edgar, L., Laizner, A. M., \& Gagnon, A. J. (2004). Clarifying "meaning" in the context of cancer research: A systematic literature review. Palliative \& Supportive Care, 2, 291303. doi:org/10.1017/S1478951504040386

Lepore, S. J., Fernandez-Berrocal, P., Ragan, J., \& Ramos, N. (2004). It's not that bad: Social challenges to emotional disclosure enhance adjustment to stress. Anxiety, Stress and Coping: An International Journal, 17, 341-361. doi:10.1080/10615800412331318625 
Lepore, S. J., \& Smyth, J. (2002). The writing cure: How expressive writing promotes health and emotional well-being. Washington, DC, US: American Psychological Association.

Levenson, R. (1988). Emotion and the autonomic nervous system: A prospectus for research on autonomic specificity. In H. Wagner (Ed.), Social psychophysiology and emotion: Theory and clinical applications (pp. 17-42). Chichester, U K: Wiley.

Leventhal, H., \& Patrick-Miller, L. (2000). Emotions and physical illness: Causes and indicators of vulnerability. In J. Haviland \& M. Lewis (Eds.), Handbook of emotions (2nd ed., pp. 523-570). New York: Guilford Press.

Leydy, N., Revicki, D., \& Genesté, B. (1999). Recommendations for evaluating the validity of quality of life claims for labeling and promotion. Value in Health, 2, 113-127.

Lightsey, O. R. (2006). Resilience, meaning, and well-being. The Counselling Psychologist, 34, 96-107. doi:10.1177/0011000005282369

Lightsey Jr, O. R., \& Boyraz, G. (2011). Do positive thinking and meaning mediate the positive affectlife satisfaction relationship? Canadian Journal of Behavioural Science, 43, 203-213. doi: $10.1037 / \mathrm{a} 0023150$

Lima-Santos, N., \& Faria, L. (2005). Inteligência emocional: adaptação do "emotional skills and competence questionnaire" (ESCQ) ao contexto Português. Revista da Faculdade de Ciências Humanas e Sociais da UFO, 2, 275-289.

Limonero, J. T., Tomás-Sábado, J., Fernández-Castro, J., \& Gómez-Benito, J. (2004). Influencia de la inteligencia emocional percibida en el estrés laboral de enfermería. Ansiedad y Estrés, 10, 29-41.

Limonero, J. T., Tomás-Sábado, J., \& Fernández-Castro, J. (2006). Relación entre inteligencia emocional percibida y ansiedad ante la muerte en estudiantes universitario. Ansiedad y estrés, 12, 267-278.

Linley, P. A., Felus, A., Gillett, R., \& Joseph, S. (2012). Emotional expression and growth following adversity: Emotional expression mediates subjective distress and is moderated by emotional intelligence. Journal of Loss and Trauma: International Perspectives on Stress \& Coping, 16, 387401.

Lipowski, Z. J. (1969). Psychosocial aspects of disease. Annuals of Internal Medicine, 71, 1197-1206. doi:10.7326/0003-4819-71-6-1197 
Liu, C. C. (2010). The relationship between personal religious orientation and emotional intelligence. Social Behavior and Personality, 38, 461-468. doi:org/10.2224/sbp.2010.38.4.461

Livneh, H. (2000). Psychosocial adaptation to cancer: The role of coping strategies. Journal of Rehabilitation, 66, 40-49.

Lizeretti, N., \& Extremera-Pacheco, N. (2011). Emotional intelligence and clinical symptoms in outpatients with generalized anxiety disorder (GAD). Psychiatry Quarterly, 82, 253-260.

Lizeretti, N., \& Rodríguez, A. (2011). La inteligencia emocional en salud mental: Una revisión. Ansiedad y Estrés, 17, 233-253.

Llorca-Ramón, G., Díez-Sánchez, M., et al. (1999). Intervención en pacientes oncológicos. In E. GarcíaCamba (Ed.), Manual de psicooncología (pp.231-258). Madrid: Aula Médica.

Loehlin, J. (2004). Latent variable models: an introduction to factor, path, and structural equation analysis (4th ed.). N.J.: L. Erlbaum Associates.

López-Curbelo, M., Acosta-Pérez, I., García-García, L., \& Fumero, A. (2006). Inteligencia emocional en policías locales. Ansiedad y estrés, 12, 463-477.

Lopez-Zafra, E., Pulido-Martos, M., Martos, M. P. B., \& Augusto-Landa, J. M. (2012). Psychometric properties of the Spanish version of the work group emotional intelligence profile-short version. Psicothema, 24, 495-502.

Low, G., \& Molzahn, A. E. (2007). Predictors in quality of life in old age: A cross-validation study. Research in Nursing and Health, 30, 141-150. doi:10.1002/nur.20178

Lyons, J. B., \& Schneider, T. R. (2005). The influence of emotional intelligence on performance. Personality and Individual Differences, 39, 693-703. doi:10.1016/j.paid.2005.02.018

Lyusin, D. B. (2006). Emotional intelligence as a mixed construct: Its relation to personality and gender. Journal of Russian and East European Psychology, 44, 54-68. doi:10.2753/RPO1061-0405440604

Macedo, A., Andrade, S., Moital, I., Moreira, A., Pimentel, F., Barroso, S. ... Bonfill, X. (2008). Perfil da doença oncológica em Portugal: racional, objectivos e metodologia - estudo perfil. Acta Médica Portuguesa, 21, 329-334.

Mahmoud, J. S. R., Staten, R. T., Hall, L. A., \& Lennie, T. A. (2012). The relationship among young adult college students' depression, anxiety, stress, demographics, life satisfaction, and coping styles. Issues in Mental Health Nursing, 33, 149 - 156. doi:10.3109/01612840.2011.632708 
Malouff, J. M., Schutte, N. S., \& Thorsteinsson, E. B. (2014). Trait emotional intelligence and romantic relationship satisfaction: A meta-analysis. American Journal of Family Therapy, 42, 53-66. doi:10.1080/01926187.2012.748549

Martins, A., Ramalho, N., \& Morin, E. (2010). A comprehensive meta-analysis of the relationship between emotional intelligence and health. Personality and Individual Differences, 49, 554 - 564. doi:10.1016/j.paid.2010.05.029

Martínez-Pons, M. (1997). The relation of emotional intelligence with selected areas of personal functioning. Imagination, Cognition and Personality, 17, 3-13. doi:10.2190/68VD-DFXB-K5AWPQAY

Martínez, A. E. (2009). Autoconcepto, motivación académica y estrategias de aprendizage en estudiantes prosociales de educación secundaria obligatoria. (Doctoral thesis). Retrieved from reme.uji.es.

Mascaro, N., \& Rosen, D. H. (2008). Assessment of existential meaning and its longitudinal relations with depressive symptoms. Journal of social and clinical psychology, 27, 567-599. doi:10.1521/jscp.2008.27.6.576

Massie, M., \& Holland, J. (1989). Overview of normal reactions and prevalence of psychiatric disorders. In J. Holland \& J. Rowland (Eds.), Handbook of psychooncology: Psychological care of the patient with cancer (pp.273-282). New York: Oxford University Press.

Matthews, A. B., Baker, F., Hann, D. M., Denniston, M., \& Smith, T. G. (2002). Health status and life satisfaction among breast cancer survivor peer support volunteers. Psychooncology, 11, 199-211. doi: 10.1002/pon.550

Matthews, G., \& Zeidner, M. (2000). Emotional intelligence, adaptation to stressful encounters and health outcomes. In R. Bar-On \& J. Parker (Eds.), Handbook of emotional intelligence (pp.459-489). San Francisco: Jossey-Bass.

Mavroveli, S., \& Sánchez-Ruiz, M. J. (2011). Trait emotional intelligence influences on academic achievement and school behavior. British Journal of Educational Psychology, 81, 112-134. doi:10.1348/2044-8279.002009

Mayer, J. D. (2000). Emotion, intelligence, and emotional intelligence. In J. Forgas (Ed.), Handbook of affect and social cognition (pp.410-431). Mahwoh, NJ: Erl baum. 
Mayer, J. D. (2006). A new field guide to emotional intelligence. In J. Ciarrochi, J. Forgas, \& J. Mayer (Eds.), Emotional intelligence in everyday life (pp. 3-26). Philadelphia, PA: Psychol. Press.

Mayer, J. D., Caruso, D. R., \& Salovey, P. (2000). Selecting a measure of emotional intelligence: the case for ability scales. In R. Bar-On \& J. Parker (Eds.), The handbook of emotional intelligence: theory, development, assessment and application at home, school and in the workplace (pp. 320-342). San Francisco: Jossey-Bass.

Mayer, J. D., \& Cobb, C. D. (2000). Educational policy on emotional intelligence: does it make sense? Educational psychology review, 12, 163-183. doi:10.1023/A:1009093231445

Mayer, J. D., DiPaolo, M., \& Salovey, P. (1990). Perceiving affective content in ambiguous visual stimuli: A component of emotional intelligence. Journal of personality assessment 54, 772-781. doi:10.1207/s15327752jpa5403\&4_29

Mayer, J. D., Roberts, R. D., \& Barsade, S. G. (2008). Human abilities: Emotional intelligence. Annual review psychology, 59, 507-536. doi:10.1146/annurev.psych.59.103006.093646

Mayer, J. D., \& Salovey, P. (1993). The intelligence of emotional intelligence. Intelligence, 17, 433-442. doi:10.1016/0160-2896(93)90010-3

Mayer, J. D., \& Salovey, P. (1995). Emotional intelligence and the construction and regulation of feelings. Applied and preventive psychology, 4, 197-208. doi:10.1016/S0962-1849(05)80058-7

Mayer, J. D., \& Salovey, P. (1997). What is emotional intelligence? In P. Salovey \& D. Sluyter (Eds.), Emotional development and emotional intelligence. New York: Basic Books.

Mayer, J. D., \& Salovey, P. (2007). Qué es inteligencia emocional?. In J. Navas, \& P. Berrocal (Eds.), Manual de inteligencia emocional. (pp.25-45). Madrid: Ediciones Pirámide.

Mayer, J. D., Salovey, P., \& Caruso, D. R. (2000). Models of emotional intelligence. In R. Stenberg (Ed.), Handbook of intelligence (pp.396-420). Cambridge, England: Cambridge University Press.

Mayer, J. D., Salovey P., \& Caruso D. R. (2002). Mayer-Salovey-Caruso Emotional Intelligence Test (MSCEIT) user's manual. Toronto, ON: MHS.

Mayer, J. D., Salovey, P., Caruso, D. R., \& Sitarenios, G. (2001). Emotional intelligence as a standard intelligence. Emotion, 1, 232-242. doi:10.1037/1528-3542.1.3.232

Mayer, J. D., Salovey, P., Caruso, D. R., \& Sitarenios, G. (2003). Measuring emotional intelligence whit the MSCEIT V 2.0. Emotion, 3, 97-105. doi:10.1037/1528-3542.3.1.97 
Mehnert, A., \& Koch, U. (2008). Psychometric evaluation of the German version of the Life Attitude Profile--Revised (LAP-R) in prostate cancer patients. Palliative and Supportive Care, 6, 119-24.

Meraviglia, M. (2006). Effects of spirituality in breast cancer survivors. Oncology Nursing Forum, 33(1), 1-7. doi:10.1188/06

McQueen, A. C. H. (2004). Emotional intelligence in nursing work. Journal of advanced nursing, 47, 101-108. doi:10.1111/j.1365-2648.2004.03069.x

Melton, A. M. A., \& Schulenberg, S. E. (2008). On the measurement of meaning: Logotherapy's empirical contributions to humanistic psychology. The Humanistic Psychologist, 36, 1-14. doi:10.1080/08873260701828870

Mestre, J., Comunian, A., \& Comunian, M. (2007). Inteligencia emocional: una revisión a sus primeros quince años y un acercamiento conceptual desde los procesos psicológicos. In J. Navas \& P. Berrocal (Eds.), Manual de inteligencia emocional. (pp.47-68). Madrid: Ediciones Pirámide.

Meyerowitz, B., Heinrich, R., \& Schag, C. (1983). A competency-based approach to cancer. In T. Burish \& L. Bradley (Eds.), Coping with chronic disease (pp. 137-158). New York: Academic.

Mikolajczak, M. (2009). Going beyond the ability-trait debate: A three level model of emotional intelligence. E-Journal of Applied Psychology, 5, 25-31. doi: 10.7790/ejap.v5i2.175

Mikolajczak, M., Luminet, O., \& Menil, C. (2006). Predicting resistance to stress: Incremental validity of trait emotional intelligence over alexithymia and optimism. Psicothema, 18, $79-88$.

Mikolajczak, M., Nelis, D., Hansenne, M., \& Quoidbach, J. (2008). If you can regulate sadness, you can probably regulate shame: Associations between trait emotional intelligence, emotion regulation and coping efficiency across discrete emotions. Personality and Individual Differences, 44, 13561368. doi:10.1016/j.paid.2007.12.004

Mikolajczak, M., Petrides, K. V., \& Hurry, J. (2009). Adolescents choosing self-harm as an emotion regulation strategy: The protective role of trait emotional intelligence. British Journal of Clinical Psychology, 48, 181-193. doi:10.1348/014466508X386027

Mikulincer, M., \& Florian, V. (1996). Emotional reactions to loss over the life span: An attachment perspective. In S. McFadden \& C. Magai (Eds.), Handbook of emotions, adult development, and aging (pp. 269-285). New York: Academic Press.

Millon, T. (1999). Personality-guided therapy. Hoboken, NJ, US: John Wiley \& Sons Inc. 
Millon, T., \& Davis, R. (1998). Ten subtypes of psychopathy. In T. Millon, E. Simonsen, M. BirketSmith, \& R. Davis (Eds.), Psychopathy: Antisocial, criminal, and violent behavior (pp. 161-170). New York: Guilford Press.

Millon, T., \& Davis, R. (2001). Trastornos de la personalidad en la vida moderna. Barcelona: Masson.

Moadel, A., Morgan, C., Fatone, A., Grennan, J., Carter, J., Laruffa, G. ... Dutcher, J. (1999). Seeking meaning and hope: self-reported spiritual and existential needs among an ethnically diverse cancer patient population. Psycho-Oncology, $\quad 8, \quad 378-385 . \quad$ doi:10.1002/(SICI)10991611(199909/10)8:5<378::AID-PON406>3.0.CO;2-A

Mols, F., Vingerhoets, A. J. J. M., Coebergh, J. W. W., \& Poll-Franse, L. V. (2009). Wellbeing, posttraumatic growth and benefit finding in long-term breast cancer survivors. Psychology and Health, 24, 583-595. doi:10.1080/08870440701671362

Montes-Berges, B., \& Augusto-Landa, J. (2007). Exploring the relationship between perceived emotional intelligence, coping, social support an mental health in nursing students. Journal of Psychiatric and Mental Health Nursing 14, 163-171.

Moos R., \& Schaefer, J. (1984). The crisis of physical illness: an overview and conceptual approach. In R. Moos (Ed.), Coping with physical illness, 2: New perspectives (pp. 3-25). New York: Plenum Medical Book Co.

Moreno-Jiménez, B., Garrosa, E., Losada, M., Morante, M., \& Rodríguez, R. (2004). Competencia emocional y salud. Encuentros en Psicología Social, 2, 271-279.

Morris, T., \& Greer, S. (1980). A type C for cancer? Low trait anxiety in the pathogenesis of breast cancer. Cancer Detection and Prevention, 3, Abstract 102.

Mozaz, M., Mestre, J., \& Vázquez, I. (2007). Inteligencia emocional e cerebro. In J. Navas \& P. Berrocal (Eds.), Manual de inteligencia emocional (pp.123-151). Madrid: Ediciones Pirámide.

Muniz, M., Primi, R., \& Miguel, F. K. (2007). Investigação da inteligência emocional como fator de controle do stress em guardas municipais. Psicologia: Teoria e prática, 9, 27-41.

Naves, J. F. (2013). Avaliação de qualidade de vida e bem-estar subjetivo em oncologia: Um estudo com sobreviventes de câncer ósseo. (Master thesis). Retrieved from repositorio.unb.br.

Neimeyer, R. A. (2001). Reauthoring life narratives: Grief therapy as meaning reconstruction. Israeli Journal of Psychiatry, 38, 171-183. 
Neto, F. (1993). Satisfaction with life among Portuguese adolescents. Journal of Youth and Adolescence, 22, 125-134. doi:10.1007/BF01536648

Nevitt, J., \& Hancock, G.R. (2001). Performance of Bootstrapping approaches to model test statistics and parameter standard error estimation in structural equation modeling. Structural Equation Modeling 8, 353-377. doi:10.1207/S15328007SEM0803_2

Noorbakhsh, S. N., Besharat, M. A., \& Zarei, J. (2010). Emotional intelligence and coping styles with stress. Procedia - Social and Behavioral Sciences, 5, 818-822. doi:10.1016/j.sbspro.2010.07.191

Nordin, K., \& Glimelius, B. (1998). Reactions to gastroentestinal cancer: Variation in mental adjustment and emotional well-being over time in patients with different prognoses. Psycho-oncology, 7, 413423. doi:10.1002/(SICI)1099-1611(1998090)7:5<413::AID-PON318>3.0.CO;2-Q

Nunnaly, J., \& Bernstein, I. (1994). Psychometric theory. New York: McGraw-Hill.

O'Brien, C. W., \& Moorey, S. (2010). Outlook and adaptation in advanced cancer: A systematic review. Psycho-Oncology, 19, 1239-1249. doi:10.1002/pon.1704

O'Donnell, C. J., \& Elosua, R. (2008). Cardiovascular risk factors: Insights from framingham heart study. Revista Spañola de Cardiología, 61, 299-310. doi:10.1016/S1885-5857(08)60118-8

Ogden, J. (1999). Psicologia da saúde. Lisboa: CLIMEPSI.

Ojedokun, O. (2010). Effort-reward imbalance and attitude towards unethical work behavior of police personnel: Emotional intelligence as a moderator. IfePsychologia, 18, 168-189.

Ong, A. D., Bergeman, C. S., Bisconti, T. L., \& Wallace, K. A. (2006). Psychology resilience, positive emotions, and successful adaptation to stress in later life. Journal of personality and social psychology, 91, 730-749. doi:10.1037/0022-3514.91.4.730

Pais-Ribeiro, J. L. (1997, February). A promoção da saúde e da qualidade de vida em pessoas com doenças crónicas. Congresso Nacional de Psicologia da Saúde, 2, Universidade do Minho, Portugal.

Pais-Ribeiro, J. L. (1998). Psicologia e Saúde. Lisboa: ISPA.

Pais-Ribeiro, J. L. (2001). Mental health inventory: Um estudo de adaptação à população portuguesa. Psicologia, Saúde \& Doenças, 2, 77-99.

Pais -Ribeiro, J. L. (2002). Qualidade de vida e doença oncológica. In M. Dias \& E. Durá (Eds.), Territórios da psicologia oncológica (pp. 75-98). Lisboa: CLIMEPSI. 
Pais-Ribeiro, J. L. (2004). Quality of life is a primary end-point in clinical setting. Clinical Nutrition, 23, 121-130. doi:10.1016/S0261-5614(03)00109-2

Pais-Ribeiro, J. L. (2006). Relação entre a psicologia positiva e as suas variáveis protectoras e a qualidade de vida e bem-estar como variáveis de resultado. In I. Leal (Ed.), Perspectivas em psicologia da saúde (pp.231-244). Quarteto: Coimbra.

Pais-Ribeiro, J. L. (2010). Psicologia e saúde (2 ed.). Lisboa: Placebo.

Pais-Ribeiro, J. L. (2012). Validação transcultural da Escala de Felicidade Subjectiva de Lyubomirsky e Lepper. Psicologia, Saúde \& Doenças, 13, 157-168.

Pais-Ribeiro, J. L., Ramos, D., \& Samico, S. (2003). Contribuição para uma validação conservadora da escala reduzida de ajustamento mental ao cancro (Mini-MAC). Psicologia, Saúde e Doenças, 4, 231-247.

Pais-Ribeiro, J. L., \& Rodrigues, A. (2004). Questões acerca do coping: a propósito do estudo de adaptação do brief cope. Psicologia, Saúde e Doenças, 5, 3-15.

Palmer, B., Donaldson, C., \& Stough, C. (2002). Emotional intelligence and life satisfaction. Personality and Individual Differences, 33, 1091-1100. doi:10.1016/S0191-8869(01)00215-X

Palmero, F., \& Mestre, J. (2004). Emoción. In J. Mestre \& F. Palmero (Eds.), Procesos psicológicos básicos (pp. 215-247). Madrid: McGraw-Hill.

Pan, J. (2011). A resilience-based and meaning-oriented model of acculturation: A sample of mainland Chinese postgraduate students in Hong Kong. International Journal of Intercultural Relations, 35, 592-603. doi:10.1016/j.ijintrel.2011.02.009

Pan, J., Wong, D. F. K., Joubert, L., \& Chan, C. L. W. (2008). The protective function of meaning of life on life satisfaction among Chinese students in Australia and Hong Kong: A cross-cultural comparative study. Journal of American College Health, 57, 221-231. doi:10.3200/JACH.57.2.221-232

Panagiotakos, D. B., Pitsavos, C., Chrysohoou, C., Stefanadis, C., \& Toutouzas, P. (2002). Risk stratification of coronary heart disease in Greece: Final results from the CARDIO2000 Epidemiological Study. Preventive Medicine, 35, 548-556. doi:10.1006/pmed.2002.1108

Pandey, R., \& Choubey, A. K. (2010). Emotion and health: An overview. SIS Journal of Projective Psychology and Mental Health, 17, 135-152. 
Park, C.L. (2005). Religion as a meaning-making framework in coping with life stress. Journal of social issues, 61, 707-729. doi:10.1111/j.1540-4560.2005.00428.x

Park, C. L. (2008). Testing the meaning making model of coping with loss. Journal of social and clinical psychology, 27, 970-994. doi:10.1521/jscp.2008.27.9.970

Park, C. L., \& Blank, T. O. (2012). Associations of positive and negative life changes with well-being in young- and middle-aged adult cancer survivors. Psychology \& Health, 27, 412-429. doi:10.1080/08870446.2011.586033

Park, C. L., \& Folkman, S. (1997). Meaning in the context of stress and coping. Review of General Psychology, 1, 115-144. doi:10.1037/1089-2680.1.2.115

Park, N., Park, M., \& Peterson, C. (2010). When is the search for meaning related to life satisfaction? Applied Psychology: Health and Well-Being, 2(1), 1-13. doi:10.1111/j.1758-0854.2009.01024.x

Parker, M. (2002). Aesthetic ways in day to day nursering. In D. Freshwater (Ed.), Therapeutic Nursering (pp. 100-120). London: Sage, London.

Parker, J. D., Keefer, K. V., \& Wood, L. M. (2011). Toward a brief multidimensional assessment of emotional intelligence: Psychometric properties of the Emotional Quotient Inventory Short Form. Psychological Assessment, 23, 762-777. doi:10.1037/a0023289

Patrick, D. (2008). A qualidade de vida pode ser medida? Como? In M. Fleck (Ed.), A avaliação da qualidade de vida: Guia para profissionais de saúde (pp. 29-39). Porto Alegre: Artmed.

Pau, A. K. H., Croucher, R., Sohanpal, R. Muirhead, V., \& Seymour, K. (2004). Emotional intelligence and stress coping in dental undergraduates: A qualitative study. British Dental Journal, 197, 205209. doi:10.1038/sj.bdj.4811573

Pearlin, L. I., \& Schooler, C. (1978). The structure of coping. Journal of Health and Social Behavior, 19(1), 2-21. doi:org/10.2307/2136319

Pelletteri, J. (2002). The relationship between emotional intelligence and ego defense mechanism. Journal of Psychology, 136, 182-194. doi:10.1080/00223980209604149

Pence, P. (2010). Emotional intelligence, motivation, and retention among undergraduate students attending associate-degree nursing programs in Illinois. (Doctoral dissertation). Retrevied from media.proquest.com.

Pennebaker, J. W., \& Lee, C. H. (2002). The power of words in social, clinical, and personality psychology. Korean Journal of Thinking Problem Solving 12, 35-43. 
Peralta, E., \& Silva, M. (2003). Teste dos objectivos de vida (PIL_R). In M. Gonçalves, M. Simões, L. Almeida, \& C. Machado (Eds.), Avaliação psicológica: Instrumentos validados para a população portuguesa (Vol.1, pp. 61-73). Coimbra: Quarteto.

Pereira-Teques, A., Llorca-Ramón, G., Bueno-Carrera, G., Pais-Ribeiro, J., \& Teques, P. (in press). Desenvolvimento e avaliação das caracteristicas psicométricas do Questionário de Auto-Percepção de Inteligência Emocional (QIE-AP). Revista Psicologia: Reflexão e Crítica.

Pérez-González, J., Petrides, K. V., \& Furnham, A. (2007). La medida de la inteligencia emocional rasgo. In J. Navas \& P. Berrocal (Eds.), Manual de inteligencia emocional (pp. 81-93). Madrid: Ediciones Pirámide.

Pérez, J. C., Petrides, K.V., \& Furnham, A. (2005). Measuring trait emotional intelligence. In R. Schulze \& R. D. Roberts (Eds.). International Handbook of Emotional Intelligence. Cambridge, MA: Hogrefe and Huber.

Perlini, H., \& Halverson, R. T. (2006). Emotional intelligence in the national hockey league. Canadian Journal of Behavioural Science, 38, 109-119. doi:10.1037/cjbs2006001.

Peter, M., Schuurmans, H., Vingerhoets, A. J., Smeets, G., Verkoeijen, P., \& Arntz, A. (2013). Borderline personality disorder and emotional intelligence. The Journal of Nervous and Mental diseases, 201, 99-104. doi:10.1097/NMD.0b013e31827f64b0

Petrides, K. V., \& Furnham, A. (2000). On the dimensional structure of emotional intelligence. Personality and individual differences, 29, 313-320. doi:10.1016/S0191-8869(99)00195-6

Petrides, K. V., \& Furnham, A. (2001). Trait emotional intelligence: Psychometric investigation with reference to established trait taxonomies. European journal of personality, 15, 425-448. doi:10.1002/per.416

Petrides, K. V., \& Furnham, A. (2003). Trait emotional intelligence: Behavioural validation in two studies of emotion recognition and reactivity to mood induction. European Journal of Personality, 17, 39-75. doi:10.1002/per.466

Petrides, K. V., Pita, R., \& Kokkinaki, F. (2007). The location of trait emotional intelligence in personality factor space. British Journal of Psychology, 98, $273 \quad-\quad 289$. doi:10.1348/000712606X120618 
Peterson, C., Park, N., \& Seligman, M. E. (2005). Orientations to happiness and life satisfaction: The full life versus the empty life. Journal of Happiness Studies, 6, 25- 41. doi:10.1007/s10902-004-1278Z.

Philip, E. J., Merluzzi, T. V., Peterman, A., \& Cronk, L. B. (2009). Measurement accuracy in assessing patient's quality of life: To weight or not to weight domains of quality of life. Quality of Life Research, 18, 775-782. doi:10.1007/s11136-009-9492-0

Pimentel, F. (2006). Qualidade de vida e oncologia. Coimbra: Almedina.

Pinquart, M. (2002). Creating and maintaining purpose in life in old age: A meta-analysis. Ageing International, 27, 90-114. doi:10.1007/s12126-002-1004-2

Preacher, K. J., \& Hayes, A. F. (2004). SPSS and SAS procedures for estimating indirect effects in simple mediation models. Behavior Research Methods, Instruments, and Computers, 36, 717-731. doi:10.3758/BF03206553

Preacher, K. J., \& Hayes, A. F. (2008). Asymptotic and resampling strategies for assessing and comparing indirect effects in multiple mediator models. Behavior Research Methods, 40, 879-891. doi:10.3758/BRM.40.3.879

Puglia, M. L., Stough, C., Cárter, J. D., \& Joseph, M. (2005). The emotional intelligence of adult sex offenders: ability based in assessment. Journal of sexual aggression, 11, 249-258. doi:10.1080/13552600500271384

Queirós, M., Fernández-Berrocal, P., Extremera-Pacheco, N., Carral, J., \& Queirós, P. (2005).Validação e fiabilidade da versão portuguesa modificada da Trait Meta-Mood Scale. Revista de Psicologia, Educação e cultura, 9, 199-216.

Reardon, K. K., \& Buck, R. (1989). Emotion, reason, and communication in coping with cancer. Health Communication, 1, 41-54. doi:10.1207/s15327027hc0101_6

Registo Oncológico do IPO - Porto (2012). Registo oncológico 2010. Porto: Instituto Português de Oncologia do Porto - Francisco Gentil, E.P.E.

Regner, E. (2008). Validez convergente y discriminante del inventario de cociente emocional (EQ-I). Interdisciplinaria, 25, 29-51.

Rego, A., \& Fernandes, C. (2005). Inteligência emocional: contributos adicionais para a validação de um instrumento de medida. Manuscrito no publicado. Universidade de Aveiro, Portugal. 
Reker, G. T. (2000). Theoretical perspective, dimensions, and measurement of existential meaning. In G. Reker \& K. Chamberlain (Eds.), Exploring existential meaning: Optimizing human development across the life span (pp. 39-58). Thousand Oaks, CA: Sage Publications.

Reker, G. T., \& Wong, P. T. P. (1988). Aging as an individual process: Toward a theory of personal meaning. In J. Birren \& V. Bengston (Eds.), Emergent theories of aging (pp. 214-246). New York: Springer.

Reker, G. T., \& Wong, P. T. P. (2012). Personal meaning in life and psychosocial adaptation in the later years. . In P. T. P. Wong (Ed.), The human quest for meaning: Theories, research, and applications (2nd ed., pp. 433-456). New York, NY: Routledge.

Resende, M. C., Silva, R. M., Marques, T. P., \& Abreu, M. V. (2008). Coping e satisfação com a vida em adultos com AIDS. Psicologia, 39, 232-239.

Rey, L., Extremera-Pacheco, N., \& Pena, M. (2011). Perceived emotional intelligence, self-esteem and life satisfaction in adolescents. Psychosocial Intervention, 20, 227-234.

Rey, L., Extremera-Pacheco, N., Durán, A., \& Ortiz-Tallo, M. (2013). Subjective quality of life of people with intellectual disabilities: The role of emotional competence on their subjective well-being. Journal of Applied Research in Intellectual Disabilities, 26, 146-156.

Rey, L., Extremera-Pacheco, N., \& Trillo, L. (2013). Exploring the relationship between emotional intelligence and health-related quality of life in patients with cancer. Journal of Psychosocial Oncology, 31, 51-64.

Ricoeur, P. (1996). Teoria da interpretação. Lisboa: Edições 70. (Original work published 1976)

Rieck, T., \& Callahan, J. L. (2013). Emotional intelligence and psychotherapy outcomes in the training clinic.Training and Education in Professional Psychology, 7, 42-52. doi:10.1037/a0031659

Roberts, R. D., MacCann, C., Matthews, G., \& Zeidner, M. (2010). Emotional intelligence: Toward a consensus of models and measures. Social and Personality Psychology Compass, 4, 821-840. doi:10.1111/j.1751-9004.2010.00277.x

Roberts, R. D., Zeidner, M., \& Matthews, G. (2001). Does emotional intelligence meet traditional standards for an intelligence? Some new data and conclusions. Emotions, 1, 196-231. doi:10.1037/1528-3542.1.3.196

Rodríguez, P. (1999) Estrategias de afrontamiento de la enfermedad (coping) y cancér. In E. GarcíaCamba (Ed.), Manual de psicooncología (pp. 127-142). Madrid: Aula Médica. 
Rodríguez, P. F. S. M. (2004). Cancer, inteligencia emocional y ansiedad en essalud-cusco: Una aproximación a la psiconcologia. Situa, 13, 37-41.

Rodrigues, N., Rebelo, T., \& Coelho, J. V. (2011). Adaptação da Escala de Inteligência Emocional de Wong e Law (WLEIS) e análise da sua estrutura factorial e fiabilidade numa amostra portuguesa. Psychologica, 55, 189-207.

Rogers, P., Qualter, P., Phelps, G., \& Gardner, K. (2006). Belief in the paranormal, coping and emotional intelligence. Personality and Individual Differences, 41, 1089-105. doi:10.1016/j.paid.2006.04.014

Rowland, J. (1989). Intrapersonal resources: Coping. In J. Holland \& J. Rowland (Eds.), Handbook of psychooncology: Psychological care of the patient with cancer (pp.44-57). New York: Oxford University Press.

Ruini, C., \& Vescolli, F. (2013). The role of gratitude in breast cancer: Its relationships with posttraumatic growth, psychological well-being and distress. Journal of Happiness Studies, 14, 263 274. doi: 10.1007/s10902-012-9330-X

Ruíz-Aranda, D., Fernández-Berrocal, P., Extremera-Pacheco, N., \& Salguero, J. (2005, November). Inteligencia emocional ante situaciones de estrés agudo. Congreso universitario de psicología y logopedia, Málaga.

Ruiz-Aranda, D., Fernández-Berrocal, P., González-Ordi, H., Miguel-Tobal, J., \& Salguero Noguera, J. (2007). Emotional intelligence and acute stress. Inteligencia Humana.Congreso, Universidad Complutense de Madrid, Spain.

Rutkowska, K., \& Gierczuk, D. (2012). Emotional intelligence and the sense of efficiency of coaching and instructing in wrestling. Polish Journal of Sport and Tourism, 19, 46-51. doi: 10.2478/v10197012-0006-1

Ryff, C. D. (1989). Happiness is everything, or is it? Explorations on the meaning of psychological wellbeing. Journal of Personality and Social Psychology, 57, 1069-81.

Ryff, C., \& Keyes, C. L. (1995). The structure of psychological well-being revisited. Journal of Personality and Social Psychology, 69, 719-27.

Saklofske, D. H., Austin, E. J., Galloway, J., \& Davidson, K. (2007). Individual difference correlates of health-related behaviours: Preliminary evidence for links between emotional intelligence and coping. Personality and Individual Differences, 42, 491-502. doi:10.1016/j.paid.2006.08.006 
Saklofske, D. H., Austin, E. J., \& Minski, P. S. (2003). Factor structure and validity of a trait emotional intelligence measure. Personality and Individual Differences, 34, 707- 721. doi:10.1016/S01918869(02)00056-9

Salami, S. O. (2010). Emotional intelligence, self-efficacy, psychological well-being and students attitudes: Implications for quality education. European Journal of Education Studies, 2, 247-257.

Salovey, P. (2001) Applied emotional intelligence: Regulating emotions to become healthy, wealthy, and wise: Emotional intelligence and intimate relationships. In J. Ciarrochi, J. Forgas, \& J. D. Mayer (Eds.), Emotional intelligence and everyday life (pp. 168-184). New York: Psychology Press.

Salovey, P., Detweiler-Bedell, B., Detweiler-Bedell, J., \& Mayer, J. D. (1999). Coping intelligently: Emotional intelligence and the coping process. In C. Snyder (Ed.), Coping: the psychology of what works (pp. 141-164). New York: Oxford University Press.

Salovey, P., Detweiler-Bedell, B., Detweiller-Bedell, J., \& Mayer, J. D. (2000). Current directions in emotional intelligence research. In M. Lewis \& J. Haviland-Jones (Eds.), Handbook of emotions (pp. 504-520). New York: Guildford Press.

Salovey, P., Detweiler-Bedell, B., Detweiler-Bedell, J., \& Mayer, J. D. (2008). Emotional intelligence. In M. Lewis, J.M. Haviland-Jones, \& Feldman Barrett, L. (Eds.), Handbook of emotions (3rd ed., pp. 533-547). New York: Guilford Press.

Salovey, P., Hsee, C., \& Mayer, J. D. (1993). Emotional intelligence and the self-regulation of affect. In D. Wegner \& J. Pennebaker (Eds.), Handbook of mental control (pp. 258-277). Englewwod cliffs, NJ: Prentice Hall.

Salovey, P., \& Mayer, J. D. (1990). Emotional intelligence. Imagination, cognition, and personality, 9, 185-211. doi:10.2190/DUGG-P24E-52WK-6CDG

Salovey, P., Mayer, J. D., \& Caruso, D. R. (2002). The positive psychology of emotional intelligence. In C. Synder \& S. López (Eds.): Handbook of positive psychology (pp. 159-171). New York: Oxford.

Salovey, P., Mayer, J., Goldman, S. L., Turvey, C., \& Palfai, T. P. (1995). Emotional attention, clarity and repair: Exploring emotional intelligence using the Trait Meta-Mood Scale. In J. Pennebaker (Ed.), Emotion, disclosure, and health (pp.125-154). Washinton, DC: American Psychology Association.

Salovey, P., Rothman, A. J., Detweiler-Bedell, J. B., \& Steward, W. T. (2000). Emotional states and physical health. American Psychologist, 55, 110-121. doi:10A037//0003-O66X.55.1.110. 
Salovey, P., Stroud, L. R., Woolery, A., \& Epel, E. S. (2002). Perceived emotional intelligence, stress reactivity, and symptom reports: Further explorations using the trait meta-mood scale. Psychology and health, 17, 611-627. doi:10.1080/08870440290025812

Samar, A. (2001). The relationship between emotional intelligence, self-management and glycemic control in individuals with type 1 diabetes. Dissertation Abstracts International, 62, 4B.

Santos, C. S. (2003). Representação cognitiva e emocional, estratégias de coping e qualidade de vida no doente oncológico e família. (Doctoral dissertation). Retrevied repositorio-aberto.up.pt.

Santos, A., Moura, J., Santos, C., Figueiroa, J., \& Souza, A. (2012). Avaliação da qualidade de vida relacionada à saúde em pacientes com câncer do colo do útero em tratamento radioterápico. Revista Brasileira de Cancerologia, 58, 507-515.

Saxena, P., Pandey, T., Dubey, A., Pratap, S., \& Pandey, R. (2012). Differential affective profile of patients with diabetes and coronary artery disease. SIS Journal of Projective Psychology \& Mental Health, 19, 137-149.

Schaefer, J., \& Moos, R. (1992). Life crises and personal growth. In B. Carpenter (Ed.), Personal coping: Theory, research, and application (pp. 149-170). Westport, CT: Praeger.

Schachter, S., \& Singer, J. (1962). Cognitive, social and physiological determinants of emotional state. Psychological Review, 69, 379-399. doi:10.1037/h0046234.

Schlegel, R. J., Manning, M. A., \& Bettencourt, B. A. (2013). Expectancy violations and the search for meaning among breast cancer survivors. Journal of Positive Psychology, 8, 387-394. doi.org/10.1080/17439760.2013.807354

Schmidt, J. E., \& Andrykowski, M. A. (2004). The role of social and dispositional variables associated with emotional processing in adjustment to breast cancer: an internet-based study. Health Psychology, 23, 259-266. doi:10.1037/0278-6133.23.3.259

Schnoll, A. R., Harlow, L. L., Stolbach, L., \& Brandt, U. (1998). A structural model of the relationships among stage of disease, age, coping, and psychological adjustment in women with breast cancer. Psychooncology, $\quad 7, \quad$ 69-77. doi:10.1002/(SICI)1099-1611(199803/04)7:2<69::AIDPON286>3.0.CO;2-8

Schnoll, A. R., Mackinnon, J. R., Stolbach, L., \& Lorman, C. (1995). The relationship between emotional adjustment and two factor structure of the Mental Adjustment to Cancer (MAC) scale. Psychooncology, 4, 265-272. doi:10.1002/pon.2960040403 
Schroevers, M., Kraaij, V., \& Garnefski, N. (2008). How do cancer patients manage unattainable personal goals and regulate their emotions? An examination of the relations between goal adjustment, cognitive emotion-regulation strategies, and positive and negative affect. British Journal of Health Psychology, 13, 551-62. doi:10.1348/135910707X241497

Schroevers, M. J., Kraaij, V., \& Garnefski, N. (2011). Cancer patients' experience of positive and negative changes due to the illness: Relationships with psychological well-being, coping, and goal reengagement. Psycho-Oncology, 20, 165-172. doi:10.1002/pon.1718

Schulenberg, S. E., Schnetzer, L. W., \& Buchanan, E. M. (2011). The Purpose In Life Test-short form: Development and psychometric support. Journal of Happiness Studies, 12, 861-876. doi:10.1007/s10902-010-9231-9

Schutte, N. S., Malouff, J. M., \& Bhullar, N. (2007). The assessing emotions scale. In C. Stough, D. Saklofske, \& J. Parker (Eds.), The assessment of emotional intelligence. Springer Publishing.

Schutte, N. S., Malouff, J. M., Hall, L. E. Haggerty, D. J., Cooper, J. T., Golden, C. J., \& Dornheim, L. (1998). Development and validation of a measure of emotional intelligence. Personality and individual differences, 25, 167-177. doi:10.1016/S0191-8869(98)00001-4

Schutte, N. S., Malouff, J. M., Simunek, M., McKenley, J., \& Hollander, S. (2002). Characteristic emotional intelligence and emotional well-being. Cognition and emotion, 16, 769-785. doi:10.1080/02699930143000482

Schutte, N. S., Thorsteinsson, E. B., Hine, D. W., Foster, R., Cauchi, A., \& Binns, C. (2010). Experiential and rational processing styles, emotional intelligence and well-being. Australian Journal of Psychology, 62, 14-19. doi:10.1080/00049530903312865

Seitz, D. C. M., Hagmann, D., Besier, T., Dieluweit, U., Debatin, K. M., Grabow, D., ...Goldbeck, L. (2010). Life satisfaction in adult survivors of cancer during adolescence: What contributes to the latter satisfaction with life? Quality of Life Research, 20, 225-236. doi:10.1007/s11136-010-97399

Seligman, M. E. P., Steen, T. A., Park, N., \& Peterson, C. (2005). Positive psychology practice: Empirical validation of interventions. American Psychologist, 60, 410-421. doi:10.1037/0003066X.60.5.410

Shah, M., \& Thingujam, N. S. (2008). Perceived emotional intelligence and ways of coping among students. Journal of the Indian Academy of Applied Psychology, 34, 83-91. 
Sherman, N. E., Michel, R., Rybak, C., Randall, G. K., \& Davidson, J. (2011). Meaning in life and volunteerism in older adults. Adultspan Journal, 10, 78-90. doi:10.1002/j.21610029.2011.tb00127

Sherman, A. C., Simonton, S., Latif, U., \& Bracy, L. (2010). Effects of global meaning and illnessspecific meaning on health outcomes among breast cancer patients. Journal of Behavioral Medicine, 33, 364-377. doi:10.1007/s10865-010-9267-7

Silva, C. H. D., \& Derchain, S. F. M. (2006). Qualidade de vida em mulheres com câncer ginecológico: Uma revisão de literatura. Revista Brasileira de Cancerologia, 52, 33-47.

Simonelli, L. E., Fowler, J., Maxwell, G. L., \& Andersen, B. L. (2008). Physical sequelae and depressive symptoms in gynecologic cancer survivors: meaning in life as a mediator. Annuals of Behavioral Medicine, 35, 275-84. doi: 10.1007/s12160-008-9029-8

Sirgy, M. (2002). The psychology of quality of life. Dordecht, The Netherlands: Kluwer Academic Publishers.

Skrabski, A., Kopp, M., Rozsa, S., Rethelyi, J., \& Rahe, R. H. (2005). Life meaning: An important correlate of health in the Hungarian population. International Journal of Behavioral Medicine, 12, 78-85. doi:10.1207/s15327558ijbm1202_5

Slaski, M., \& Cartwright, S. (2002). Health, performance, and emotional intelligence: An exploratory study of retail managers. Stress and Health, 18, 63-68. doi:10.1002/smi.926

Slaski, M., \& Cartwright, S. (2003). Emotional intelligence training and its implications for stress, health and performance. Stress Health, 19, 233-239. doi:10.1002/smi.979

Smith, C. A., \& Lazarus, R. S. (1990). Emotion and adaptation. In L. Pervin (Ed.), Handbook of Personality: theory \& research (pp. 609-637). NY: Guilford Press.

Smith, C. A., \& Lazarus, R. S. (1993). Appraisal components, core relational themes, and the emotions. Cognition and Emotion, 7, 233-269. doi:10.1080/02699939308409189

Smith, J. A., Lumley, M. A., \& Longo, D. J. (2002). Contrasting emotional approach coping with passive coping for chronic myofascial pain. Annuals of Behavioral Medicine, 24, 326-335. doi:10.1207/S15324796ABM2404_09

Smith, S. G., Petrides, K. V., Green, J. S., \& Sevdalis, N. (2012). The role of trait emotional intelligence in the diagnostic cancer pathway. Support Care Cancer, 20, 2933-2939. doi:10.1007/s00520-0121423-X 
Snyder, C., \& Lopez, S. (2004). Handbook of positive psychology. New York: Oxford University Press.

Speck, P. (2011). Spiritual religious issues in care of the dying. In J. Ellershaw \& S. Wilkinson (Eds.), Care of Dying: A pathway to excellence (2 nd ed., pp. 106-126). New York: Oxford University Press Inc.

Speck, P., Higginson, I., \& Addington-Hall, J. (2004). Spiritual needs in health care. British Medical Journal, 329, 123-124. doi:org/10.1136/bmj.329.7458.123

Stanton, A., \& Franz, R. (1999). Focusing on emotion: An adaptive coping strategy? In C. Snyder (Ed.), Coping: The psychology of what works (pp. 90-118). New York: Oxford University Press.

Steger, M. (2009). Meaning in life. In S. Lopez (Ed.), Oxford handbook of positive psychology (2nd ed., pp. 679-687). Oxford, UK: Oxford University Press.

Steger, M. F., \& Frazier, P. (2005). Meaning in life: One link in the chain from religion to well-being. Journal of Counseling Psychology, 52, 574-582. doi:10.1037/0022-26 0167.52.4.574

Steger, M. F., Frazier, P., Oishi, S., \& Kaler, M. (2006). The meaning life questionnaire: Assessing the presence of and search for meaning in life. Journal of counselling psychology, 53, 80-93. doi:10.1037/0022-0167.53.1.80

Steger, M. F., \& Kashdan, T. B. (2007). Stability and specificity of meaning in life and life satisfaction over one year. Journal of Happiness Studies, 8, 161-179. doi:10.1007/s10902-006-9011-8

Steger, M. F., Kashdan, T. B., Sullivan, B. A., \& Lorentz, D. (2008). Understanding the search for meaning in life: Personality, cognitive style, and the dynamic between seeking and experiencing meaning. Journal of personality, 76, 199-228. doi:10.1111/j.1467-6494.2007.00484.x

Steger, M. F., Kawabata, Y., Shimai, S., \& Otake, K. (2008). The meaningful life in Japan and the United States: Levels and correlates of meaning in life. Journal of Research in Personality, 42, 660-678. doi:10.1016/j.jrp.2007.09.003

Sternberg, R. J. (1988). Mental self-government: A theory of intellectual styles and their development. Human Development, 31, 197-224. doi:10.1159/000275810

Strine, T. W., Chapman, D. P., Balluz, L. S., Moriarty, D. G., \& Mokdad, A. H. (2008). The associations between life satisfaction and health-related quality of life, chronic illness, and health behaviours among U.S. communitydwelling adults. Journal of Community Health 33, 40-50. doi:10.1007/s10900-007-9066-4 
Suárez -Löcher, T., \& Cynthia-Pérez, G. (2011). Influencia de la expresión emocional escrita sobre el afrontamiento del dolor en la enfermedad del cáncer. Ajayu Órgano de Difusión Científica del Departamento de Psicología UCBSP, 9, 284-307.

Swatton, S., \& O’Callaghan, J. (1999). The experience of healing stories in the life narrative: A grounded theory. Counselling psychology quarterly, 12, 413-429. doi:10.1080/09515079908254109

Tabachnick, B., \& Fidell, L. (2007). Using multivariate statistics (5th ed.). Boston: Allyn \& Bacon.

Takeuchi, H., Taki, Y., Sassa, Y., Hashizume, H., Sekiguchi, A., Fukushima, A., \& Kawashima, R. (2011). Regional gray matter density associated with emotional intelligence: Evidence from voxelbased morphometry. Human Brain Mapping, 32, 1497-1510. doi:10.1002/hbm.21122

Takeuchi, H., Taki, Y., Nouchi, R., Sekiguchi, A., Hashizume, H., Sassa, Y. .. Kawashima, R. (2013). Resting state functional connectivity associated with trait emotional intelligence. Neuroimage, 83, 318-328. doi:10.1016/j.neuroimage.2013.06.044

Taksic, V., Takalcic, M., \& Brajkovic, S. (2001, June). Emotional intelligence: An empirical validation of the construct. European Congress of Psychology, London.

Tamaren, K. (2010). Factors of emotional intelligence associated with marital satisfaction. (Doctoral dissertation). Retrevied from search.proquest.com.

Tavabie, A., Koczwara, A., \& Patterson, F. (2010). Using emotional intelligence to facilitate strengthened appraiser development. Education for Primary Care, 21, 9-19.

Taylor, S. E. (1983). Adjustment to threatening events: A theory of cognitive adaptation. American Psychologist, 38, 1161-1173. doi:10.1037/0003-066X.38.11.1161

Taylor, S. (1993). The structure of fundamental fears. Journal of Behavior Therapy and Experimental Psychiatry, 24, 289-299. doi:10.1016/0005-7916(93)90053-Y

Taylor, C., Farver, C., \& Stoller, J. K. (2011). Can emotional intelligence training serve as an alternative approach to teaching professionalism to residents? Academic Medicine, 86, 1551-1554. doi:10.1097/ACM.0b013e318235aa76

Tedeschi, R., Park, C., \& Calhoun, L. (1998). Posttraumatic growth: Conceptual issues. In R. Tedeschi, C. Park, \& L. Calhoun (Eds.), Posttraumatic growth: Positive changes in the aftermath of crisis (pp. 1-17). Mahwah, NJ: Erlbaum.

Temoshok, L. (1987). Personality, coping style, emotion, and cancer: Towards an integrative model. Journal of Cancer Survivorship, 6, 545-567. 
Teques, A. (2009). Inteligencia emocional y acontecimientos de vida negativos. (Unpublished Tesina). Universidad de Salamanca, Spain.

Thombre, A., Sherman, A. C., \& Simonton, S. (2010). Posttraumatic growth among cancer patients in India. Journal of Behavioral Medicine, 33, 15-23. doi:10.1007/s10865-009 9229-0

Thompson, R. A. (1991). Emotional rgulation and emotional development. Educational Psychology Review, 3, 269-307. doi:10.1007/BF01319934

Thompson, B. L., Waltz, J., Croyle, K., \& Pepper, A. C. (2007). Trait meta-mood and affect as predictors of somatic symptoms and life satisfaction. Personality and Individual Differences, 43, 1786-1795. doi:10.1016/j.paid.2007.05.017

Toyota, H. (2011). Individual differences in emotional intelligence and incidental memory of words. Japanese Psychological Research, 53, 213-220. doi:10.1111/j.1468-5884.2011.00467.x

Toyota, H. (2013). The self-choice effects on memory and individual differences in emotional intelligence. Japanese Psychological Research, 55, 45-57. doi:10.1111/j.1468-5884.2012.00530.x

Triplett, K. N., Tedeschi, R. G., Cann, A., Calhoun, L. G., \& Reeve, C. L. (2012). Posttraumatic growth, meaning in life, and life satisfaction in response to trauma. Psychological Trauma: Theory, Research, Practice, and Policy, 4, 400-410. doi:10.1037/a0024204

Tross, S., \& Holland, J. (1989). Psychological sequelae in cancer survivors. In J. Holland \& J. Rowland (Eds.), Handbook of psychooncology: Psychological care of the patient with cancer (pp.101-116). New York: Oxford University Press.

Tugade, M. M., \& Fredrickson, B. L. (2004). Resilient individuals use positive emotions to bounce back from negative emotional experiences. Journal of personality and social psychology, 86, 320-333. doi:10.1037/0022-3514.86.2.320

Ulmer, A., Range, L. M., \& Smith, P. C. (1991). Purpose in life: A moderator of recovery from bereavement. Omega, 23, 279-289. doi:10.2190/33VU-BANW-C54V-W7VF

Vallath, N. (2006). Perspectives on psycho-neuro-immunology in oncology. Indian Journal of Palliative Care, 12, 29-33. doi:10.4103/0973-1075.25916

Van der Zee, K., Thijs, M., \& Schakel, L. (2002). The relationship of emotional intelligence with academic intelligence and the big five. European journal of personality, 16, 103-125. doi:10.1002/per.434 
Veenhoven, R. (1997). Progrès dans la compréhension du bonheur. Revue Québécoise de Psychologie, $18,29-47$.

Veenhoven, R. (2000). The four qualities of life: Ordering concepts and measures of the good life. Journal of Happiness Studies, 1(1), 1-39. doi:10.1023/A:1010072010360

Velasco, C., Fernández, I., Páez, D., \& Campos, M. (2006). Perceived emotional intelligence, alexithymia, coping and emotional regulation. Psicothema, 18, 89-94.

Veríssimo, R. (2003). Inteligência emocional: Da alexitimia ao controlo emocional. Acta Médica Portuguesa, 16, 407-411.

Veríssimo, R. (2005). Inteligência emocional, apoio social e regulação afectiva. Acta Médica Portuguesa, $18,345-352$.

Vickberg, S. M. J., Bovbjerg, D. H., DuHamel, K. N., Currie, V., \& Redd, W. H. (2000). Intrusive thoughts and psychological distress among breast cancer survivors: Global meaning as a possible protective factor. Behavioral Medicine, 25, 152-160. doi:10.1080/08964280009595744

Vickberg, S. M. J., DuHamel, K. N., Smith, M. Y., Manne, S. L., Winkel, G., Papadopoulos, E. B., \& Redd, W. H. (2001). Global meaning and psychological adjustment among survivors of bone marrow transplant. Psycho-Oncology, $10, \quad 29-39 . \quad$ doi:10.1002/10991611(200101/02)10:1<29::AID-PON482>3.0.CO;2-Y

Wallace, K., \& Lahti, E. (2004). Spirituality as a mediator of the relation between perceived stress and life satisfaction. The Gerontologist, 44, 567-571.

Watson, M., Greer, S., Rowden, L., Gorman, C., Robertson, B., Bliss, J. M., \& Tunmore, R. (1991). Relationships between emotional control, adjustment to cancer and depression and anxiety in breast cancer patients. Psychological Medicine, 21, 51-57. doi: org/10.1017/S0033291700014641

Watson, M., Greer, S., Young, J., Inayat, Q., Burgess, C., \& Robertson, B. (1988). Development of a questionnaire measure of adjustment to cancer: the MAC scale. Psychological Medicine, 18, $203-$ 209. doi:org/10.1017/S0033291700002026

Watson, M., Law, M. G., Santos, M. D., Greer, S., Baruch, J., \& Bliss, J. (1994). The Mini- Mac: Further development of The Mental Adjustment to Cancer Scale. Journal of Psychosocial Oncology, 12, 33-45. Doi:10.1300/J077V12N03_03.

Welty, M. (2010). The relationship between emotional intelligence and adult male perpetrators of intimate partner violence. (Doctoral dissertation). Retrevied from search.proquest.com. 
White, C. A. (2004). Meaning and its measurement in psychosocial oncology. Psycho-Oncology, 13, 468481. doi:10.1002/pon.815

Willard, S. (2006). Relationship of emotional intelligence and adherence to combination antiretroviral medications by individuals living with HIV disease. Journal of the Association of Nurses in AIDS Care, 17, 16-26. doi:10.1016/j.jana.2006.01.001

Winters, J., Clift, R. J., \& Dutton, D. G. (2004). An exploratory study of emotional intelligence and domestic abuse. Journal of Family Violence, 19, 255-267. doi:10.1023/B:JOFV.0000042076.21723.f3

Wnuk, M. (2010). An empirical test of the mediating role of variables between religiosity and psychological wellbeing among Alcoholics Anonymous. Alcoholism and Drug Addiction, 23.

Wnuk, M., \& Marcinkowski, J. T. (2014). Do existencial variables mediate between religious-spiritual facets of functionality and psychological wellbeing. Journal of Religion and Health, 53, 56-67. doi:10.1007/s10943-012-9597-6

Wojtalik, J. A., Eack, S. M., \& Keshavan, M. S. (2013). Structural neurobiological correlates of MayerSalovery-Caruso Emotional Intelligence Test performance in early course schizophrenia. Progress in Neuro-Psychopharmacology \& Biological Psychiatry, 40, 207-212. doi:10.1016/j.pnpbp.2012.09.013

Wong, P. (1998). Meaning-centered counseling. In P. Wong \& P. Fry (Eds.), The human quest for meaning (pp. 395-435). Mahwah, NJ: Erlbaum.

Woolery, A., \& Salovey, P. (2004). Emotional intelligence and physical health. In I. Nyklicek, L. Temoshok, \& A. Vingerhoets (Eds.), Emotional expression and health: biobehavioral perspectives on health and disease prevention (Vol. 6, pp. 154-168). New York: Harwood Academic Publishers.

Worthington, R. L., \& Whittaker T. A. (2006). Scale development research: A content analysis and recommendations for best practices. The Counseling Psychologist, 34, 806-838. doi:10.1177/0011000006288127

Wrosch, C., Scheier, M. F., Miller, G. E., Schulz, R., \& Carver, C. S. (2003). Adaptive self-regulation of unattainable goals: Goal disengagement, goal re-engagement, and subjective well being. Personality and Social Psychology Bulletin, 29, 1494-1508. doi:10.1177/0146167203256921 
Woyciekoski, C., \& Hutz, C. S. (2009). Inteligência emocional: Teoria, pesquisa,medida, aplicações e controvérsias. Psicologia: Reflexão e Crítica, 22(1), 1-11.

Yalcin, B. M., Karahan, T. F., Ozcelik, M., \& Igde, F. A. (2008). The effects of an emotional intelligence program on the quality of life and well-being of patients with type 2 diabetes mellitus. The Diabetes Educator, 34, 1013- 1024. doi:10.1177/0145721708327303

Yalom, I. (1980). Existential psychotherapy. New York: Basic Books.

Zaccagnini, J. (2004). Qué es? La inteligencia emocional: La relación ente pensamientos y sentimientos en la vida cotidiana. Madrid: Editorial Biblioteca Nueva.

Zautra, A., Smith, B., Affleck, G., \& Tennen, H. (2001). Examinations of chronic pain and affect relationships: Application of a dynamic model of affect. Journal of Consulting and Clinical Psychology, 69, 786-795. doi:10.1037/0022-006X.69.5.786

Zeidner, M., Kloda, I., \& Matthews, G. (2013). Does dyadic coping mediate the relationship between emotional intelligence (EI) and marital quality?. Journal of Family Psychology, 27, 795-805. doi:10.1037/a0034009

Zeidner, M., Matthews, G., \& Roberts, R. D. (2004). Emotional intelligence in the workplace: A critical review. Applied Psychology: An International Review, 53, 371-399. doi:10.1111/j.14640597.2004.00176.x

Zeidner, M., Matthews, G., \& Roberts, R. D. (2006). Emotional intelligence, adaptation, and coping. In J. Ciarrochi, J. Forgas, \& J. D. Mayer (Eds.), Emotional intelligence in everyday life: A scientific inquiry (2nd ed., pp. 100-125). Philadelphia, PA: Psychology Press.

Zeidner, M., Matthews, G., \& Roberts, R. D. (2012). The Emotional intelligence, health, and well-being nexus: What have we learned and what have we missed?. Applied Psychology: Health and WellBeing, 4(1), 1-30. doi:10.1111/j.1758-0854.2011.01062.x

Zidner, M. (2007). Coping with test situations: Resources, strategies and adaptation outcomes. Anxiety, Stress, and Coping, 17, 23-28.

Zysberg, L. (2012). Loneliness and emotional intelligence. The Journal of Psychology: Interdisciplinary and Applied, 146, 37-46. doi:10.1080/00223980.2011.574746

Zysberg, L., \& Rubanov, A. (2010). Emotional intelligence and emotional eating patterns: A new insight into the antecedents of eating disorders? Journal of Nutrition Education and Behavior, 42, 345348. doi:10.1016/j.jneb.2009.08.009 
Anexos 


\section{Anexo I Instrumentos}




\section{Anexo II}

Autorización de los autores para la utilización de los instrumentos 
Anexo III

Autorización del Hospital para la recogida de la muestra 